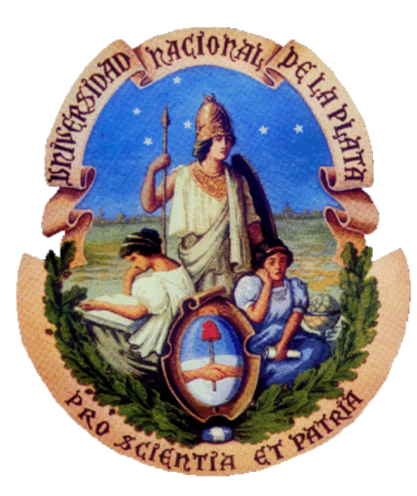

Universidad Nacional de La Plata

Facultad de Ciencias Exactas

Departamento de Física

Trabajo de Tesis Doctoral

\title{
ESTADÍSTICA DE LA PROPAGACIÓN DE LUZ EN ATMÓSFERAS TURBULENTAS
}

\author{
M. DAMIÁN GULICH
}

Director

LUCIANO JOSÉ ZUNINO

Codirector (CONICET)

DARÍO GABRIEL PÉREZ 

CLARA: Who's that?

THE DOCTOR: Never mind, let's get back.

ClARA: But who is he?

THE DOCTOR: He's me. There's only me here, that's the point. Now let's get back.

CLARA: But I never saw that one. I saw all of you. Eleven faces all of them you. You're the Eleventh Doctor.

THE DOCTOR: I said he was me, I never said he was the Doctor.

CLARA: I don't understand.

THE Doctor: My name, my real name. That is not the point. The name I chose is the Doctor. The name you choose it's like, it's like a promise you make. He's the one who broke the promise!

- Doctor Who, 'The name of The Doctor' 


\section{Prefacio}

La presente Tesis Doctoral es presentada a la Facultad de Ciencias Exactas, Universidad Nacional de La Plata, Argentina, como requisito parcial para finalizar el Doctorado de la Facultad de Ciencias Exactas, Área Física.

Este trabajo corresponde al período 2011-2016, realizado en el Centro de Investigaciones Ópticas de La Plata (CIOp), bajo la dirección del Dr. Luciano Zunino y la codirección (por CONICET) del Dr. Darío Pérez. Durante este período el autor contó con el financiamiento del Consejo Nacional de Investigaciones Científicas y Técnicas (CONICET) por medio de las becas de postgrado Tipo I y tipo II.

Además, parte de los resultados de esta Tesis fueron desarrollados durante estancias de investigación que el autor realizó en los siguientes centros:

- Instituto de Física de la Pontificia Universidad Católica de Valparaíso (PUCV), Chile.

- Facultad de Ingeniería y Ciencias Aplicadas, Universidad de Los Andes, Chile.

Las visitas fueron financiadas por el convenio MINCYT- CONICYT de los Programas de Cooperación Bilateral del Ministerio De Ciencia, Tecnología e Innovación Productiva de la Nación (Dirección Nacional de Relaciones Internacionales).

La mayor parte de los resultados originales que están expuestos en esta Tesis dieron lugar a las siguientes publicaciones en revistas científicas internacionales con referato (al final de cada referencia se indica el capítulo de la Tesis con que se corresponde):

1. Gulich, D.; Funes, G.; Pérez, D. \& Zunino, L. (2015), 'Estimation of $C_{n}^{2}$ based on scintillation of fixed targets imaged through atmospheric turbulence', Optics Letters 40(23), 5642.

(Capítulo6.

2. Zunino, L.; Gulich, D.; Funes, G. \& Pérez, D. G. (2015), 'Turbulence-induced persistence in laser beam wandering', Optics Letters 40(13), 3145.

(Capítulo5. 
3. Zunino, L.; Gulich, D.; Funes, G. \& Ziad, A. (2014), 'Experimental confirmation of long-memory correlations in star-wander data', Optics Letters 39(13), 3718.

(Capítulo 4.

4. Gulich, D. \& Zunino, L. (2014), 'A criterion for the determination of optimal scaling ranges in DFA and MF-DFA', Physica A: Statistical Mechanics and its Applications 397, 17-30.

(Capítulo 2).

5. Gulich, D. \& Zunino, L. (2012), 'The effects of observational correlated noises on multifractal detrended fluctuation analysis', Physica A: Statistical Mechanics and its Applications 391, 4100-4110.

(Capítulo2).

Además de los artículos publicados, el siguiente trabajo se encuentra bajo referato:

1. Gulich, D., 'Temporal correlations imaging fixed targets through turbulence', Optics Letters. Manuscript ID259578 (2016).

(Capítulo6.

Las presentaciones en congresos nacionales e internacionales que también apor$\tan$ a este trabajo fueron las siguientes:

1. Gulich, D.; Zunino, L.; Pérez, D. \& Garavaglia, M. (2013), 'Multifractality and the effect of turbulence on the chaotic dynamics of a HeNe laser', Laser Communication and Propagation through the Atmosphere and Oceans II. $\mathrm{El}$ autor expuso oralmente el trabajo por invitación al evento de SPIE en San Diego, Estados Unidos. (Capítulo7).

2. Funes, G.; Figueroa, E.; Gulich, D.; Zunino, L. \& Pérez, D. G. (2013), 'Characterizing inertial and convective optical turbulence by detrended fluctuation analysis', Remote Sensing of Clouds and the Atmosphere XVIII; and Optics in Atmospheric Propagation and Adaptive Systems XVI.

3. Gulich, D.; Funes, G.; Zunino, L. \& Garavaglia, M. (2013), La multifractalidad y el efecto de la turbulencia en la dinámica caótica de un láser de $\mathrm{HeNe}$, in Marcos D. Actis; Gabriela Caorsi \& Liliana Mabel Gassa, ed., 'Segundas Jornadas de Investigación y Transferencia', Facultad de Ingeniería, Universidad Nacional de La Plata , pp. 305-309.

(Capítulo7).

Asimismo el autor ha organizado los siguientes eventos vinculados estrechamente a la temática tratada en la Tesis:

1. Encuentro de Estudiantes de Óptica y Fotofisica (EEOF) 2012 "Óptica y Fotónica en Sistemas Aeroespaciales" (2012), CCT CONICET La Plata, La Plata. También colaboró en en VII Taller De Óptica Y Fotofísica "TOPFOT 2012", de la misma temática, a continuación del EEOF2012. 
2. Primera Jornada de Óptica Atmosférica (2013), CIOp (Centro de Investigaciones Ópticas), La Plata. 


\section{Resumen}

En este trabajo realizamos estudios experimentales sobre la la propagación de luz por atmósfera turbulenta empleando como herramienta principal de análisis el estudio de la fractalidad y multifractalidad de las series temporales registradas.

En la primera parte desarrollamos principalmente herramientas para estimar la fractalidad y el grado de multifractalidad de series temporales (Capítulo 2. En concreto, hacemos una implementación propia del algoritmo de multifractal detrended fluctuation analysis (MF-DFA), del cual el detrended fluctuation analysis (DFA, usualmente empleado para estimar el exponente de Hurst $H$ ) resulta ser un caso particular. Un estudio crítico de este método permitió sugerir un criterio propio para determinar el rango óptimo de ajuste en esta técnica. Asimismo, mediante un detallado análisis numérico, se lograron identificar los efectos que los ruidos coloreados tienen sobre el espectro multifractal. Vale la pena remarcar que todo registro experimental es, en mayor o en menor medida, inevitablemente contaminado por este tipo de ruidos.

En la segunda parte nos abocamos de lleno a la Óptica Atmosférica. Primero hacemos una rápida introducción al tema que desemboca en un método para la simulación de propagación de luz en atmósferas turbulentas (Capítulo 3. Luego aplicamos las técnicas desarrolladas en la primera parte a cuatro casos experimentales concretos, siendo cada uno de ellos fruto de la investigación desarrollada durante el Doctorado.

En el primer caso (Capítulo 44 estudiamos la presencia de correlaciones de largo alcance en las fluctuaciones de ángulo de arribo para luz proveniente de fuentes estelares y confirmamos un comportamiento no-Kolmogorov fundamentado por la estimación del exponente de Hurst.

Las demás experiencias tratan sobre propagación de luz a través de una turbulencia atmosférica controlada en laboratorio empleando un generador de turbulencias isotrópicas (turbulador). En este aparato es bien conocida y configurable la constante de estructura para el índice de refracción $\left(C_{n}^{2}\right)$, la cual es una medida de la intensidad de la turbulencia que sirve entonces como parámetro para los experimentos.

En el segundo caso (Capítulo 5) se estudia el exponente de Hurst del bailoteo (wandering) de un haz láser en diversas condiciones de turbulencia controlada. En esta experiencia también confirmamos desviaciones respecto del valor de $H$ esperado para el modelo de Kolmogorov. 
En el tercer caso (Capítulo 6 se aborda la formación de secuencias de imágenes (video) a través de turbulencia atmosférica de diversas intensidades aprovechando situaciones en las que el objetivo presenta regiones de alto contraste. Hacemos una nueva definición del índice de centelleo para un estudio píxel por píxel y, después de seleccionar sólo las regiones de mayor contraste, encontramos que la cantidad de píxeles con centelleo por arriba del ruido presenta una muy buena correlación con $C_{n}^{2}$, haciendo de éste un método útil para estimar la constante de estructura con un arreglo experimental muy sencillo. A esto se le suma un estudio de correlaciones temporales estimando el $H$ de cada píxel de la secuencia en todas las condiciones de turbulencia.

Finalmente, estudiamos el efecto de la turbulencia atmosférica cuando por ésta se propaga un haz láser gaseoso en condiciones de caos (Capítulo7). Estudiamos en este caso el exponente de Hurst y el rango multifractal versus la intensidad de la turbulencia.

Dejamos para los apéndices los siguientes aspectos: los detalles de las rutinas implementadas para el análisis de multifractalidad (Apéndices $\mathrm{A}$ y B, un breve repaso de técnicas básicas para caracterizar la caoticidad de una serie temporal (Apéndice C) con las rutinas desarrolladas a tal efecto (Apéndice D), y finalmente la caracterización del turbulador (Apéndice E. 


\section{Otras (más) palabras del Autor}

[Música de violines, sale EL AUTOR de atrás del telón]

EL AUTOR: Damas y caballeros, lamentablemente no existe un consenso respecto a los verdadera metodología contemporánea de la Óptica Atmosférica aplicada en concreto a la propagación de luz por la atmósfera turbulenta. En lecturas apresuradas, Andrews y Phillips [1 2] parecen sostener que se trata del empleo de la serie hipergeométrica para ajustar datos experimentales que otros anónimos de su equipo les pasan. Schmidt [3], por otro lado, indica que es la búsqueda del mejor filtro de fase que ajuste espacialmente con lo que sus amigos astrónomos observan por un telescopio. Sasiela [4 nos sugiere que se trata de no mucho más que hacer ingeniosas transformaciones en el plano complejo. En esta aventura filológica usted rara vez encontrará en esta temática gente que se mueva con soltura en el laboratorio y el campo (aún con recursos materialmente acotadísimos), que pueda analizar e interpretar los datos registrados, y que pueda convertir eso en una publicación. Gustavo Funes y Damián Gulich tal vez seamos dos excepciones.

Mario Bunge sostendrá que, en todo caso, la experimentación es algo con sus patas en la técnica, que excepcionalmente puede extenderse hasta la obra arte (recordemos a Faraday y Michelson, como casos particularmente destacados). Sin embargo, su monumental plan filosófico aún no ha llegado a estudiar la estética de las ciencias. Para más detalle: a lo largo de los cinco años de trabajo en esta tesis he tenido la oportunidad de visitar y contactarme con diversos grupos de trabajo afines en el mundo y he encontrado una suerte de ley de conservación de los problemas experimentales: quienes son verdaderamente competentes en un laboratorio se ven forzados a trabajar con poco material (de descarte, principalmente), mientras que hay laboratorios desbordantes del más moderno equipamiento en manos de incompetentes que no saben ni montar una lente. Los primeros no publican ni tanto ni tan bien como desearían, mientras que los segundos (a pesar de su impericia operativa) publican en gran volumen y primera línea, para mayor tormento de los primeros. Tengo el agrado de reportar que el Dr. Funes en la Universidad de Los Andes (Chile) es el 
primer caso de violación a esta ley que acabo de enunciar: es una persona totalmente competente a cargo de un laboratorio muy bien equipado, y por ello le auguro un gran futuro.

En terminar este texto noto que lo expuesto por Andrew Loomis [5], que leí en mi juventud para prepararme en el igualmente difícil mundo del dibuj ${ }^{1}$ bien vale para la Física:

Si queréis dibujar, si queréis arriesgar todo en una apuesta que valga la pena, tenéis una excelente oportunidad de triunfar. Si chapuceáis, ciertamente perderéis la apuesta, pues los demás jugadores están decididos a sacar el mayor provecho de sus cartas. He encontrado estudiantes que me han dicho que les gustaría estudiar dibujo como una «ayuda extra». En esto no hay «ayudas extra». Estáis enteramente en el juego, o fuera de él. «Bueno, entonces, ¿cómo puedo saber si voy a ser lo suficientemente bueno para consagrarme en ello?» Posiblemente nadie puede estar seguro de que va a ser suficientemente bueno en cualquier cosa a que se consagre. Fe en nosotros mismos y laboriosidad es lo único que tenemos para empezar.

Quiero agradecer al Dr. Luciano Zunino y al Dr. Darío Pérez el esfuerzo y la dedicación puestos de manifiesto en la dirección de esta Tesis.

Un agradecimiento destacadísimo merecen Flavia Gómez Albarracín y Mario Garavaglia por su apoyo y sus lecturas críticas de este manuscrito. Ellos han sabido mitigar mis inocultables falencias como escritor.

Ahora, una vez más: Allons-y!

Damián Gulich

La Plata, febrero de 2016

[EL AUTOR sale del escenario, se abre el telón.]

\footnotetext{
${ }^{1}$ El Autor es, por su Bachillerato, Maestro de Plástica, pero esa es una historia para otro libro.
} 


\section{Índice general}

$\begin{array}{ll}\text { 1. Introducción } & 17\end{array}$

1.1. Antecedentes . . . . . . . . . . . . . . . . 17

1.2. Objetivos . . . . . . . . . . . . . . . . . . . 18

1.3. Actividades y metodología. . . . . . . . . . . . . . . . 18

\begin{tabular}{|ll}
\hline Herramientas de análisis & 21
\end{tabular}

2. Multifractal Detrended Fluctuation Analysis 23

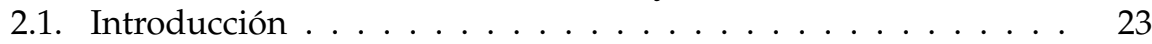

2.2. DFA y MF-DFA . . . . . . . . . . . . . . . . . . 23

2.3. El efecto de los ruidos correlacionados en MF-DFA . . . . . . 25

2.3 .1$. Datos numéricos . . . . . . . . . . . . . . 26

2.3.2. Resultados y discusión. . . . . . . . . . . . . . . . . 27

2.4. Criterio de determinación de rangos óptimos de estimación por calidad de ajuste lineal $\ldots \ldots \ldots \ldots \ldots \ldots$

2.4.1. Introducción . . . . . . . . . . . . . . . . . 38

2.4.2. Criterio basado en la calidad de ajuste lineal . . . . . . . 39

2.4.3. Ejemplos ilustrativos $\ldots \ldots \ldots \ldots \ldots$. . . . . . . . . 41

2.4.4. Applicación al estudio de las series temporales de man-

2.5. Conclusiones . . . . . . . . . . . . . . . . . . . . 49

II Óptica Atmosférica y Experiencias 55

3. Óptica atmosférica y simulación numérica de propagación de ondas \begin{tabular}{l|l} 
ópticas & 57
\end{tabular}

3.1. Propagación de luz a través de la atmósfera turbulenta . . . . . 57

3.1.1. Método de propagacion del haz dividido . . . . . . . . . 58

3.1.2. Propiedades refractivas de la atmósfera turbulenta . . . 59

3.1.3. Filtros de fase Monte-Carlo $\ldots \ldots \ldots \ldots$. . . . . . . 71

3.1.4. Restricciones para el muestreo . . . . . . . . . . . . . . 75

3.2. Aspectos temporales $\ldots \ldots \ldots \ldots \ldots \ldots$ 
\begin{tabular}{|ll|}
\hline 4. Memoria en frentes de onda estelares & 79
\end{tabular}

4.1. Introducción . . . . . . . . . . . . . . . . . . 79

4.2. Datos experimentales . . . . . . . . . . . . . . . . . . . . 80

4.3. Análisis y discusión . . . . . . . . . . . . . . . . . . . . . 81

4.4. Conclusiones . . . . . . . . . . . . . . . . . . . . . . . 84

5. Persistencia en el wandering láser inducida por la turbulencia 87

5.1. Introducción $\ldots \ldots \ldots \ldots \ldots$. $8 \ldots \ldots \ldots$

5.2. Arreglo experimental . . . . . . . . . . . . . . . . . . . 88

5.3. Análisis y discusión. . . . . . . . . . . . . . . . . . . . . . . . . . 89

5.4. Conclusiones . . . . . . . . . . . . . . . . . . . . . . 90

6. Centelleo de imágenes y correlaciones temporales 95

6.1. Análisis de centelleo de propagación de luz incoherente. . . . . 95

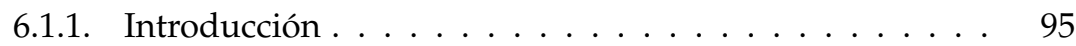

6.1.2. Arreglo experimental. . . . . . . . . . . . . . . . . 97 97

6.1.3. Análisis y resultados . . . . . . . . . . . . . . . . 9 97

6.2. Estudio de la dinámica temporal por píxel, cálculo del expo-

nente de Hurst . . . . . . . . . . . . . . . . . . . . . . . . 99

6.2.1. Cuantificación de las correlaciones temporales por DFA 103

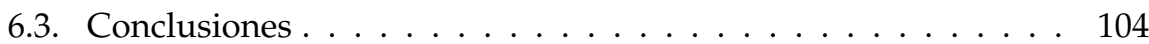

7. La multifractalidad y el efecto de la turbulencia en la dinámica caótica \begin{tabular}{l|l} 
de un láser de HeNe & 109
\end{tabular}

7.1. Introducción con un repaso histórico . . . . . . . . . . . . . 109

7.2. Arreglo experimental . . . . . . . . . . . . . . . . . . . . . . . 111

7.3. Análisis y discusión. . . . . . . . . . . . . . . . . . . . . . 111

7.4. Conclusiones . . . . . . . . . . . . . . . . . . . . 116

8. Conclusiones 121

8.1. Técnicas de análisis . . . . . . . . . . . . . . . . . . . . . . 121

8.2. Experiencias . . . . . . . . . . . . . . . . . . 122

8.2.1. Memoria en frentes de onda estelares . . . . . . . . . . 122

8.2.2. Persistencia en el wandering láser inducida por la turbu-

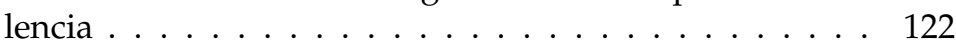

8.2.3. Centelleo de imágenes y correlaciones temporales . . . . 123

8.2.4. La multifractalidad y el efecto de la turbulencia en la dinámica caótica de un láser de HeNe $\ldots \ldots \ldots$. . . . . . 124

8.3. Temas de frontera . . . . . . . . . . . . . . . . . . . . . 124

8.3.1. Centelleo de imágenes y correlaciones temporales . . . . 124

8.3.2. Comunicaciones ópticas por un canal caótico . . . . . . . 124

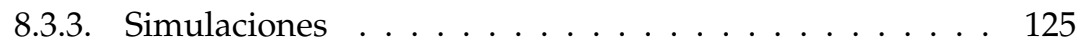




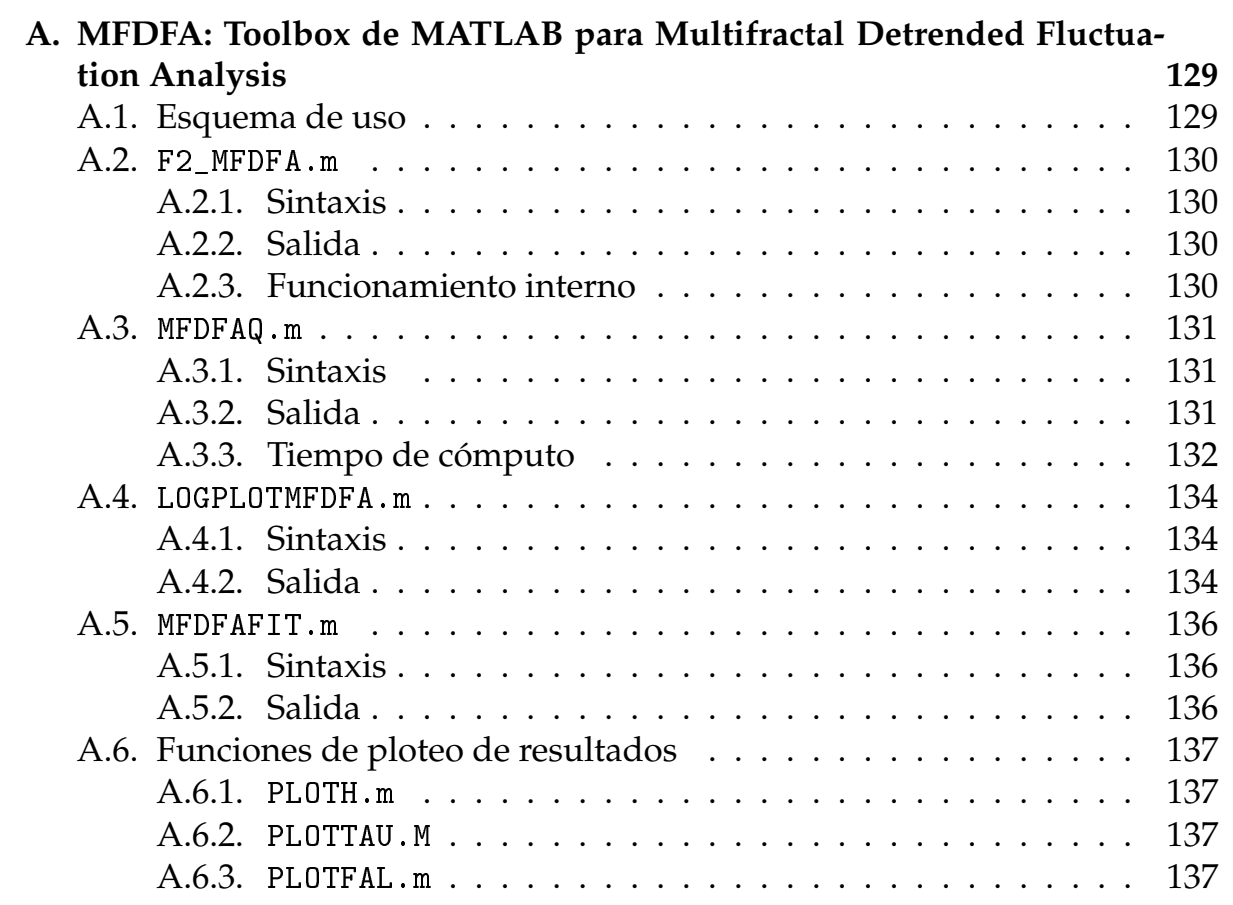

B. Performance del criterio basado en la calidad de ajuste lineal 139

C. Estimación del máximo exponente de Lyapunov $\left(\lambda_{M}\right)$ de una serie temporal $\quad 141$

C.1. Introducción ..................... 141

C.1.1. Reconstrucción desfasada (delay reconstruction) . . . . . 141

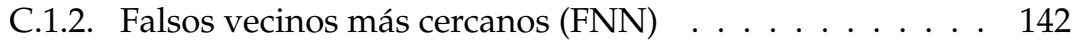

C.1.3. Máximo exponente de Lyapunov $\left(\lambda_{M}\right)$. . . . . . . . . . . 143

D. Rutinas para la estimación del máximo exponente de Lyapunov $\quad 145$

D.0.1. Funciones principales . . . . . . . . . . 145

D.0.2. Funciones auxiliares . . . . . . . . . . . . . . . . . . 145

D.1. Ejemplos de uso . . . . . . . . . . . . . . . . . . . . . . . . . . . . . . . . . . . . 146

D.1.1. Atractor de Lorenz . . . . . . . . . . . . . . . . . . . 146

D.1.2. Mapa de Hénon . . . . . . . . . . . . . . . . . . 148

E. Caracterización del turbulador $\quad 155$

E.1. Introducción . . . . . . . . . . . . . . . . . . . 155

E.2. Caracterización de tiempos operativos de estabilización de tem-

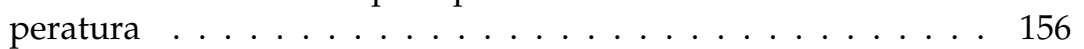

E.2.1. Modelo teórico . . . . . . . . . . . . . . . . 156

E.2.2. Desarrollo experimental . . . . . . . . . . . . . . . . . 157

E.2.3. Resultados y análisis . . . . . . . . . . . . . . . . . . . . . 157

E.2.4. Cálculo práctico . . . . . . . . . . . . . . . . . . . . . . . . 157 
E.3. Determinación de $l_{0}, L_{0}$ y $C_{n}^{2}, \ldots \ldots \ldots \ldots \ldots$. . . . . . 160

E.3.1. Método del ángulo de arribo . . . . . . . . . . . . . . 161

E.4. Procedimiento experimental $\ldots \ldots \ldots \ldots$. . . . . . . . . . . . . . 162

E.5. Método de ajuste numérico de los datos . . . . . . . . . . . 163

\begin{tabular}{ll}
\hline Bibliografía & 171
\end{tabular} 


\section{Capítulo 1}

\section{Introducción}

\subsection{Antecedentes}

A medida que la luz se propaga a través de la atmósfera turbulenta terrestre, experimenta fluctuaciones aleatorias en el índice de refracción del aire [1. Estas variaciones espaciales y temporales degradan el frente de onda que llega a cualquier sistema óptico: telescopios astronómicos, sistemas de proyección láser, identificación y seguimiento de objetivos, imágenes activas, y vínculos de comunicación óptica por espacio libre; las mismas están limitadas por la presencia de turbulencia. A través de los años muchas técnicas han sido aplicadas para reducir sus efectos, por nombrar algunas de las más populares, se pueden mencionar la óptica adaptativa, interferometría, y el postprocesamiento de imágenes. Durante mucho tiempo, estas correcciones se han modelado en base a una teoría debida a Obukhov para el índice de refracción turbulento originada en la muy bien conocida teoría K41 de turbulencia atmosférica desarrollada por Kolmogorov en la década de 1940 [6] (teoría OK); las extensiones que dan cuenta del tamaño finito del recinto (escala externa) y los efectos de disipación (escala interna), fueron posteriormente incluidas en la teoría [1].

Recientemente, los nuevos desarrollos de la teoría de campos escalares pasivos difundidos en un medio turbulento, tales como las fluctuaciones del índice de refracción, han demostrado que la teoría OK constituye sólo una primera aproximación de un comportamiento más general. Se entiende que un campo escalar es pasivo cuando éste no afecta la dinámica de la turbulencia. Por lo tanto, este modelo resulta a veces incompleto para describir en detalle una atmósfera turbulenta. Las desviaciones de este comportamiento se conocen habitualmente con el nombre de turbulencia no-Kolmogorov.

Se ha hallado evidencia experimental de apartamientos de los modelos basados en la teoría de Kolmogorov-Obukhov al estudiar la dinámica temporal de un campo propagado a través de un medio turbulento [78]. También se ha estudiado esta fenomenología con diversos análisis numéricos [3, 9 .

Desde hace más de 15 años la propagación de luz por medios turbulen- 
tos es una línea de investigación consolidada en el Centro de Investigaciones Ópticas [10. y referencias citadas en el artículo]. Durante este tiempo se han logrado establecer teórica y experimentalmente resultados importantes como el carácter browniano fraccionario del índice de refracción en situaciones turbulentas [11. Asimismo, se han implementado novedosas técnicas de análisis de datos experimentales: técnicas fractales (exponente de Hurst, DFA), multifractales (MF-DFA), teoría wavelet, herramientas derivadas de la Teoría de la Información (permutation entropy and statistical complexity) [12 13, 14, y análisis de imágenes por características de textura [15].

\subsection{Objetivos}

Estudiar y desarrollar modelos del índice de refracción turbulento, utilizando como principal herramienta el análisis estadístico de datos experimentales. Se analizará la turbulencia en las capas más bajas de la atmósfera terrestre, donde los modelos de tipo no-Kolmogorov son predominantes. Los efectos derivados de la presencia de las escalas externa e interna de la turbulencia serán también considerados. Por otro lado, se profundizará en el poco estudiado carácter de dinámica temporal de cantidades difundidas en un medio turbulento (índice de refracción).

Las comunicaciones ópticas a través de la atmósfera 16, 17 constituyen un tema de gran interés reciente debido a la movilidad de los equipos y el gran ancho de banda disponible. Se justifica entonces la necesidad de un estudio detallado de los modelos más adecuados para describir los fenómenos involucrados. El famoso modelo (gaussiano) de Kolmogorov es ampliamente usado aunque existen numerosos estudios experimentales que demuestran desviaciones de dicho modelo [18. Asimismo son escasos los estudios que justifican estas desviaciones. Se espera que el presente trabajo pueda contribuir al desarrollo de herramientas más eficientes para la comprensión de estos fenómenos.

\subsection{Actividades y metodología}

Este trabajo se fundamenta en dos pilares para estudiar la propagación de luz en medios turbulentos: la experimentación y el análisis de datos.

Para la experimentación física, se desarrollarán y se participará en experiencias de propagación de luz en condiciones de turbulencia atmosférica. Con respecto al análisis y comparación con los modelos estocásticos, se explorarán técnicas asociadas a la al análisis de datos. Un simple experimento de unos 60 segundos de duración, implica desde no menos de 60.000 datos numéricos y hasta cerca del millón al ser hecha con alta resolución temporal. Se implementarán herramientas para el manejo y análisis de estos grandes conjuntos de datos (que también pueden ser imágenes secuenciales, agregándose a lo anterior su procesamiento). En principio, se emplearán las metodologías discutidas por Zunino et al. 19, 20, 21] para medir la multifractalidad, el comportamien- 
to autosimilar, y la dependencia a largo plazo de los procesos subyacentes. Asimismo se investigará la propagación de imágenes con luz incoherente en estas condiciones y se vincularán los parámetros atmosféricos con las dinámicas encontradas. Esto permitirá aportar información de dinámica temporal a modelos de simulación como el planteado por Schmidt [3]. Finalmente se investigará sobre la multifractalidad y su relación con la propagación de láser en situaciones de caos cuando la luz de un láser gaseoso se propaga a través de una atmósfera turbulenta. 


\section{Parte I}

\section{Herramientas de análisis}





\section{Capítulo 2}

\section{Multifractal Detrended Fluctuation Analysis}

CLARA: Doctor, what are you going to do? THE DOCTOR: I don't know. Talk very fast, hope something good happens.

Take the credit. That's generally how it works.

- Doctor Who, 'The time of the Doctor'

\subsection{Introducción}

Desde el trabajo pionero en Detrended Fluctuation Analysis (DFA) por Peng et al. 22] y su generalización multifractal Multifractal Detrended Fluctuation Analysis (MF-DFA) por Kantelhardt et al. [23] estas técnicas han sido ampliamente empleadas en el análisis de series temporales. Ambas han sido empleadas en campos tan diversos como la econofísica [21] 24], sismología [25, biología [22], medicina [26 27], cosmología [28], materia condensada [29], y música 30, 31, 32, 33, 34 entre otros.

\subsection{DFA y MF-DFA}

El MF-DFA puede resumirse brevemente como sigue [23]:

1. Sea $x_{1}, x_{2}, \ldots, x_{N}$ una serie de $N$ datos. Dado su promedio $\langle x\rangle$ determinamos una nueva serie $Y(1), \ldots, Y(N)$ de valores dados por

$$
Y(i)=\sum_{k=1}^{i}\left(x_{k}-\langle x\rangle\right)
$$

2. Dividimos la serie de $Y(1), \ldots, Y(N)$ en $N_{s}$ ventanas no superpuestas de $s$ puntos donde $N_{s}=\lfloor N / s\rfloor$. Si $N$ no es divisible por $s$, quedarán algunos 
valores $r\left(r=N-N_{s} s\right)$ al final de la serie. Para resolver esto, tomamos otros $N_{S}$ segmentos pero comenzando en $Y(r+1)$. Así obtenemos $2 N_{S}$ ventanas de $s$ valores.

3. Sea $v$ el índice de las $2 N_{s}$ ventanas $\left(v=1,2, \ldots, 2 N_{s}\right)$. Para cada una de las ventanas tomamos el polinomio $y_{v}(i)$ de grado $m$ que mejor ajusta a los datos de la ventana de índice $i$. Calculamos luego las $N_{S}$ varianzas locales para $v=1, \ldots, N_{s}$ :

$$
F^{2}(v, s)=\frac{1}{s} \sum_{i=1}^{s}\left\{Y[(v-1) s+i]-y_{v}(i)\right\}^{2}
$$

$m$ es el mismo para cada paso de esta técnica y determina la variante del análisis; así MF-DFA1 significa $m=1$, etc. Si $N$ no es divisible por $s$, entonces también debemos calcular las varianzas de las otras ventanas $\left(v=\left(N_{s}+1\right), \ldots, 2 N_{s}\right)$ según

$$
F^{2}(v, s)=\frac{1}{s} \sum_{i=1}^{s}\left\{Y\left[N-\left(v-N_{s}\right) s+i\right]-y_{v}(i)\right\}^{2}
$$

4. Calculamos las funciones de fluctuación según

$$
F_{q}(s)=\left\{\begin{array}{cl}
\left\{\frac{1}{2 N_{s}} \sum_{v=1}^{2 N_{s}}\left[F^{2}(v, s)\right]^{q / 2}\right\}^{1 / q} & , q \neq 0 \\
\exp \left\{\frac{1}{4 N_{s}} \sum_{v=1}^{2 N_{s}} \ln \left[F^{2}(v, s)\right]\right\}, & q=0
\end{array}\right.
$$

Nótese que $q=2$ devuelve los resultados de la técnica tradicional de DFA.

5. Repetimos los pasos 2-4 para distintos valores de $s$, usualmente en el intervalo [10, $\lfloor N / 4\rfloor]$ elegidos de manera de obtener un conjunto de valores equidistantes en escala logarítmica (esto es necesario para el siguiente paso).

6. Finalmente determinamos el comportamiento de escala de las funciones de fluctuación analizando la representación en escala log-log de todas las $F_{q}(s)$ versus $s$. Si los valores originales de $x_{i}$ tienen correlaciones de largo alcance, entonces para grandes valores de $s: F_{q}(s) \sim s^{h(q)}$ donde $h(q)$ es el exponente de Hurst generalizado; el mismo puede ser estimado como la pendiente en el gráfico log-log de $F_{q}(s)$. Si la serie es estacionaria, entonces $h(2) \equiv H$ es el exponente de Hurst. 


\subsection{El efecto de los ruidos correlacionados en MF- DFA}

Las propiedades multifractales de series temporales registradas de cantidades observables asociadas a un sistema han sido extensamente estudiadas por la abundancia de los multifractales en la naturaleza. Para hacer una completa y apropiada descripción de la compleja dinámica asociada a un sistema multifractal se requieren múltiples exponentes de escala en el mismo rango temporal o espacial. La precisa estimación de estos exponentes de escala es fundamental para desarrollar modelos de simulación apropiados para la finalidad de hacer predicciones [35. El análisis de la multifractalidad de datos experimentales es una tarea crítica debido principalmente al tamaño finito y la discretización del registro de datos [36, 37]. Vale la pena destacar que recientemente se ha demostrado que una multifractalidad residual puede aparecer debido a la longitud finita de las señales y/o por las correlaciones de largo alcance presentes en una serie temporal. 38. Es sabido que la metodología de MF-DFA permite una cuantificación confiable del escaleo multifractal de series temporales no estacionarias [39]. Otros métodos, como wavelet transform modulus maxima (WTMM) 40], high-order autocorrelation function [41] y wavelet leaders [42], se han propuesto con la misma finalidad. Sin embargo, el MF-DFA es ampliamente aceptado por su fácil implementación y precisión. Aún más, es recomendado para la mayoría de las situaciones en que el carácter fractal de los datos es desconocido a priori [43]. La metodología de MF-DFA asimismo ha sido generalizada para más dimensiones [44]. Recientemente se ha desarrollado el multifractal detrended cross-correlation analysis (45]) para poder develar los comportamientos multifractales en las correlaciones de leyes de potencia entre dos series temporales o cantidades de mayor dimensión registradas simultáneamente, generalizando así el detrended cross-correlation analysis previamente introducido por Podobnik y Stanley [46, 47.

Es evidente que los datos experimentales se ven afectados por el fenómeno de ruido; el componente aleatorio puede ser inherente al proceso de suministro de información sobre la dinámica intrínseca (ruido informativo) o puede ser debido a la limitada precisión del equipo de medición (ruido de medición) [48]. En consecuencia, el análisis de la influencia que este entorno ruidoso tiene sobre las propiedades multifractales de una serie temporal es esencial. Se ha estudiado recientemente el rendimiento de MF-DFA en presencia de ruido aditivo blanco, el efecto de memoria a corto plazo y de periodicidades [49]. Se encontró que en el caso de cantidad moderada de ruido completamente no correlacionado los exponentes generalizados de Hurst para momentos negativos se subestiman considerablemente. Sin embargo, el comportamiento para grandes momentos positivos permanece prácticamente sin afectar. El considerar al ruido de medición como ruido blanco, suponiendo un espectro de potencia chato y sin correlaciones, es, de alguna manera, arbitrario puesto que el filtrado preliminar en el equipo de medición por lo general conduce al ruido coloreado que se caracteriza por un espectro de potencia finito [48]. El objetivo de la pre- 
sente sección es evaluar cómo los ruidos aditivos correlacionados corrompen la estimación de la multifractalitdad empleando MF-DFA. Para ello, se analizaron los exponentes de Hurst generalizados de multifractales binomiales simulados contaminados con diferentes cantidades de ruidos coloreados. Como se verá más adelante, nos encontramos con que los momentos positivos también se ven afectados en el caso con correlaciones. Además, el efecto es más pronunciado cuando la correlación del ruido aumenta. Argumentamos que estos hallazgos son relevantes para una comprensión más adecuada de la naturaleza multifractal escondida en series temporales experimentales y naturales.

\subsubsection{Datos numéricos}

El proceso multiplicativo binomial es un modelo paradigmático para datos multifractales [50, cap. 6]. Se ha demostrado que este proceso se adapta extraordinariamente bien el espectro multifractal observado del campo de disipación de la turbulencia completamente desarrollada [51]. En el modelo, un registro de longitud $N=2^{n_{\max }}$ está construido de forma recursiva en $n_{\max }+1$ pasos. En la generación, se construye una serie constante de tiempo, es decir, $x_{t}=1$ para todo $t=1, \ldots, N$. En el primer paso de la cascada, la primera mitad de la serie se multiplica por un factor $a$ y la segunda mitad de la serie se multiplica por un factor de $b=1-a$, con el parámetro del modelo $a \in \mathbb{R}$ restringido $0,5<a<1$. Este procedimiento se repite en los siguientes pasos. Cada serie de la etapa anterior se divide en dos subseries de igual longitud, y la mitad izquierda se multiplica por $a$ y la mitad derecha por $b$ hasta que las mitades constan de un solo elemento y no sea posible dividirlas más. A efectos prácticos de este trabajo consideramos la versión estocástica del proceso multiplicativo binomial. El carácter estocástico se incorpora multiplicando al azar en cada iteración la las mitades derecha e izquierda o por el parámetro de modelo $a$ [52]. Téngase en cuenta que de esta manera el determinismo poco realista es eliminado mientras que la jerarquía multiescalar subyacente se conserva. Este procedimiento no es equivalente a realizar una permutación aleatoria del modelo determinista porque todas las correlaciones temporales se eliminan con un barajado aleatorio.

Tanto para los modelos estocásticos y determinísticos es posible hallar teóricamente los exponentes generalizados de Hurst. Se ha demostrado 39 52 que:

$$
h(q)= \begin{cases}\frac{1}{q}\left(1-\log _{2}\left(a^{q}+(1-a)^{q}\right)\right) & , q \neq 0 \\ -\frac{1}{2}\left(\log _{2} a+\log _{2}(1-a)\right) & , q=0\end{cases}
$$

La Figura 2.1 muestra realizaciones completamente deterministas y estocásticas del multifractal binomial multiplicativo para diferentes valores del parámetro de modelo $a$ junto a los valores teóricos de sus exponentes de Hurst generalizados. Como se puede ver fácilmente mediante la comparación de los exponentes de Hurst generalizados (Figura $2.1 \mathrm{~g}, \mathrm{i})$ ), el rango multifractal o in- 
tensidad de la multifractalitad 1

$$
\Delta h=h(-\infty)-h(+\infty)
$$

aumenta y la dependencia a largo plazo (es decir, $h(2)$ ) disminuye para valores más altos del parámetro del modelo. Para $a \rightarrow 0,5$ la multifractalidad se debe principalmente a las correlaciones temporales. Con valores mayores del parámetro $(a \rightarrow 1)$ el valor mínimo de la serie temporal, $(1-a)^{n_{\max }}$, es muy pequeño en comparación con el máximo, $a^{n_{\max }}$, y la amplia distribución de probabilidad también contribuye a la multifractalidad [43]. Vale la pena comentar que este modelo multifractal tiene un solo parámetro. Por lo tanto, la correlación a largo plazo y la multifractalidad no pueden ser fijadas independientemente una de la otra. Para superar este inconveniente, se ha propuesto una versión generalizada del proceso multiplicativo binomial [35,52].

\subsubsection{Resultados y discusión}

Con el fin de comprender la influencia que los ruidos correlacionados aditivos tienen sobre las propiedades multifractales, se simularon multifractales binomiales estocásticos con distintos porcentajes de ruido coloreado y se analizaron mediante MF-DFA. Hemos utilizado el método de filtrado de Fourier (FFM) para generar los ruidos coloreados. En este algoritmo numérico los coeficientes de la transformada de Fourier de números aleatorios no correlacionados con una distribución gaussiana se multiplican por $f^{-\beta / 2}$. La transformada inversa de Fourier de estos coeficientes modificados produce una nueva serie temporal con el espectro de potencia $f^{-\beta}$ [53, 49]. Se generaron ruidos correlacionados con valores de $\beta$ entre 0 (ruido blanco) y 1 (ruido de parpadeo) con paso 0,2 . Cabe señalar que el exponente de escala $\beta$ y el exponente de Hurst $H$ se relacionan a través de la fórmula $\beta=2 H-1$. Por otra parte, las señales correlacionadas a largo alcance se caracterizan por un decaimiento de ley de potencias en la función de correlación $C(\tau) \equiv\left\langle x_{t} x_{t+\tau}\right\rangle=\tau^{-\gamma}$ con $\gamma=1-\beta=2-2 H$. En consecuencia, el grado de correlación aumenta para mayores valores de $\beta$ en el espectro de potencia. Diferentes niveles de ruido (NL), definidos por la desviación estándar del ruido dividida por la desviación estándar de la señal original, se añadieron numéricamente a las señales multifractales originales. Se analizaron cien realizaciones independientes de longitud $N=2^{15}$ y se promediaron luego sus exponentes de Hurst generalizados $h(q)$ para $q$ en el rango entre -20 y 20 con paso igual a 0,5 . En esta sección se empleó MF-DFA lineal $(m=1)$ para escalas de tiempo $s \in[10, N / 4]$ y los comportamientos de escala se estimaron en el rango de ajuste $s \in[100,5000]$.

En las Figs.2.2. 2.10 se estimaron con MF-DFA los exponentes de Hurst generalizados de multifractales binomiales estocásticos simulados y contaminados con diferentes niveles de ruidos coloreados. En cada figura, el parámetro $a$ y el nivel de ruido están fijos, mientras que el grado de persistencia asociado al

\footnotetext{
${ }^{1}$ También llamada multifractalidad, a secas. A efectos prácticos el rango multifractal se estima con $\Delta h_{q}=h(-q)-h(+q)$ para grandes valores del orden $q$.
} 

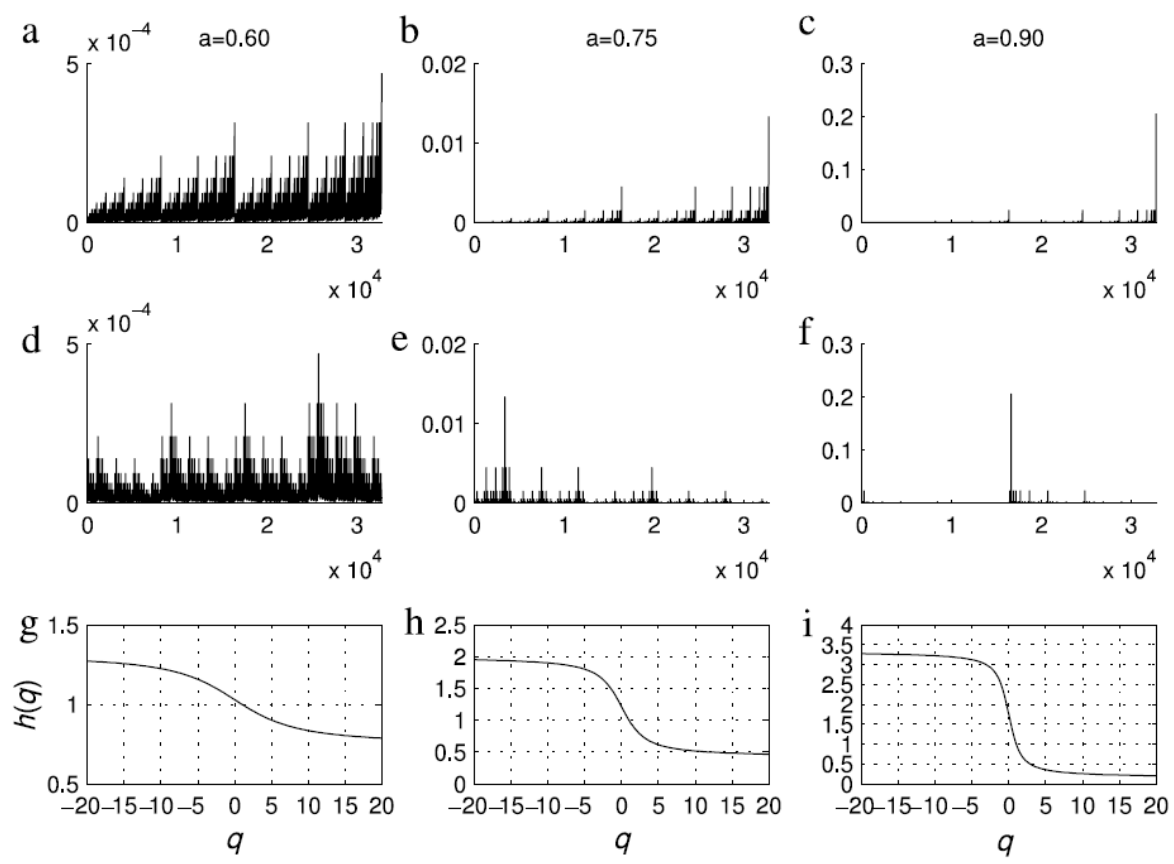

Figura 2.1: Simulaciones numéricas para el modelo multiplicativo binomial con longitud $N=2^{15}$ para diferentes valores del parámetro de modelo $a$. Los casos (a-c) son completamente deterministas y los casos (d-f) son estocásticos. Los exponentes de Hurst generalizados están calculados analíticamente según la Ecuación 2.5 y se muestran en (g-i). La dependencia de largo alcance del grado de multifractalidad para diferentes parámetros del modelo son: $h(2)_{a=0,60} \approx 0,972, h(2)_{a=0,75} \approx 0,839, h(2)_{a=0,90} \approx 0,643$, $\Delta h_{a=0,60} \approx 0,585, \Delta h_{a=0,75} \approx 1,585$ y $\Delta h_{a=0,90} \approx 3,170$. 

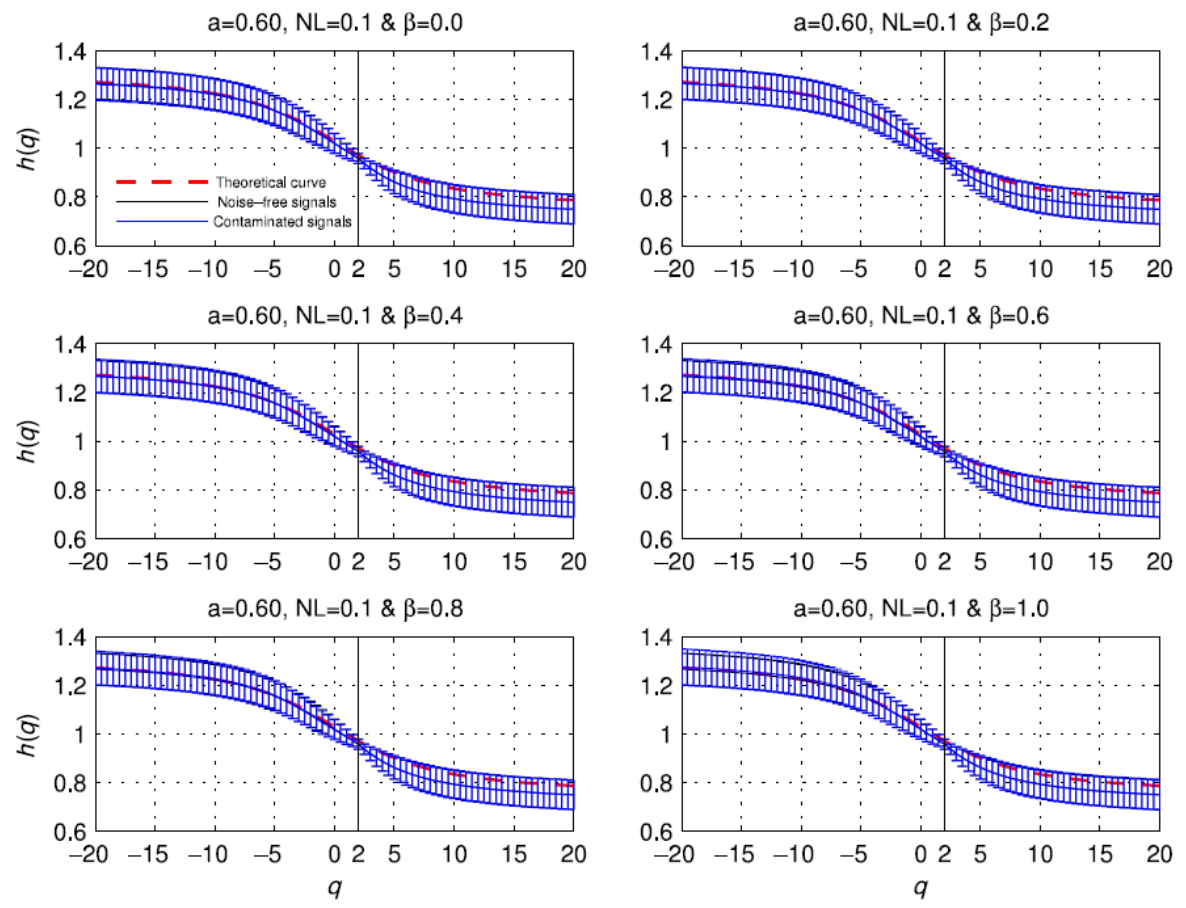

Figura 2.2: Exponentes generalizados de Hurst de multifractales binomiales estocásticos con el parámetro del modelo $a=0,6$ contaminados con ruidos correlacionados de largo alcance con espectro de potencia $f^{-\beta}$. El nivel de ruido se fijó igual a 0,1 . Se muestran la media y desviación estándar estimada de cien realizaciones independientes (curvas azules). Los resultados obtenidos para las simulaciones libres de ruido se incluyen a efectos comparativos (curvas negras). La curva teórica (Ecuación 2.5) también se representa (rojo). Las líneas negras verticales se utilizan para identificar el caso $q=2$.

ruido aumenta de arriba hacia abajo $(\beta=0,0,0,2, \ldots, 1,0)$. En las Figs. 2.2.2.4. 2.52 .7 y 2.8 2.10 se muestran los parámetros $a=0,60,0,75$ and 0,90, respectivamente. Se consideraron tres niveles de ruido diferentes: $\mathrm{NL}=0,1$ (Figs. 2.2. 2.5 y 2.8, $\mathrm{NL}=0,5$ (Figs. 2.3, 2.6 y 2.9 y NL $=1,0$ (Figs. 2.4 2.7 y 2.10).

Se observa claramente que los exponentes de Hurst generalizados para $q<2$ se subestiman significativamente, incluso en presencia de pequeñas adiciones de ruido (correlacionado o no correlacionado). El efecto es más notable para valores mayores del parámetro del modelo $(a=0,75$ y $a=0,90)$, es decir, para grandes multifractalidades y menor dependencia de largo alcance. La mayor robustez ante ruido aditivo observado para $a=0,60$ se puede atribuir al hecho de que la jerarquía multifractal para este parámetro de modelo se origina a partir de correlaciones temporales. El multiescaleo para $a=0,75$ y $a=0,90$ también se relaciona con las anchas distribuciones de probabilidad de los datos, y esta fuente de multifractalidad parece ser mucho más sensible 

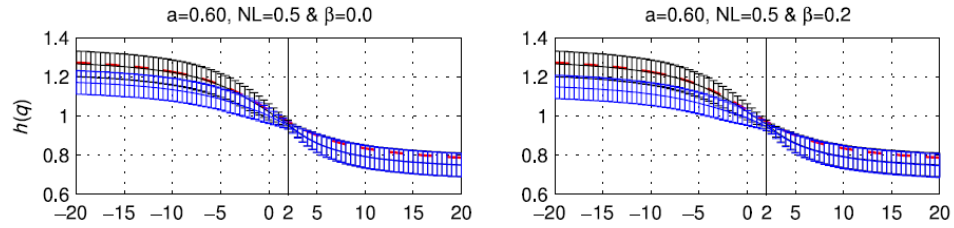

$a=0.60, N L=0.5 \& \beta=0.4$
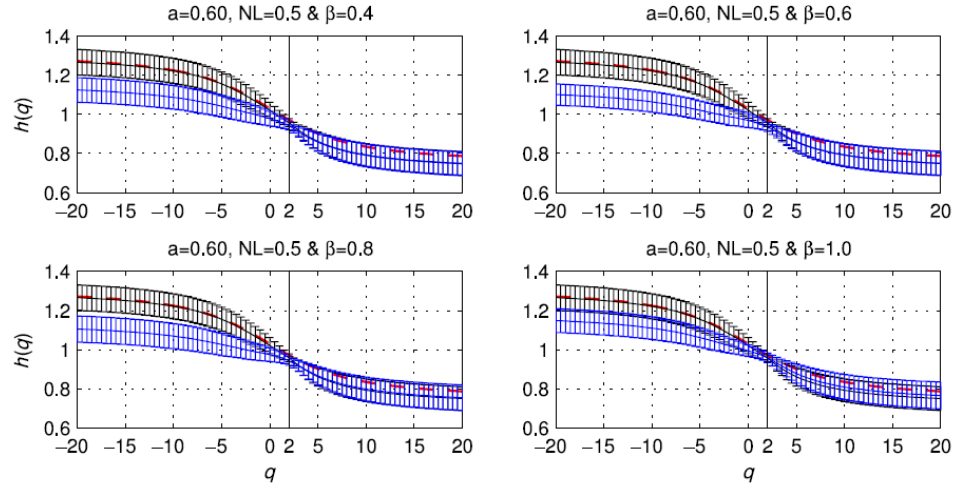

Figura 2.3: Idem Figura 2.2 pero con NL $=0,5$.
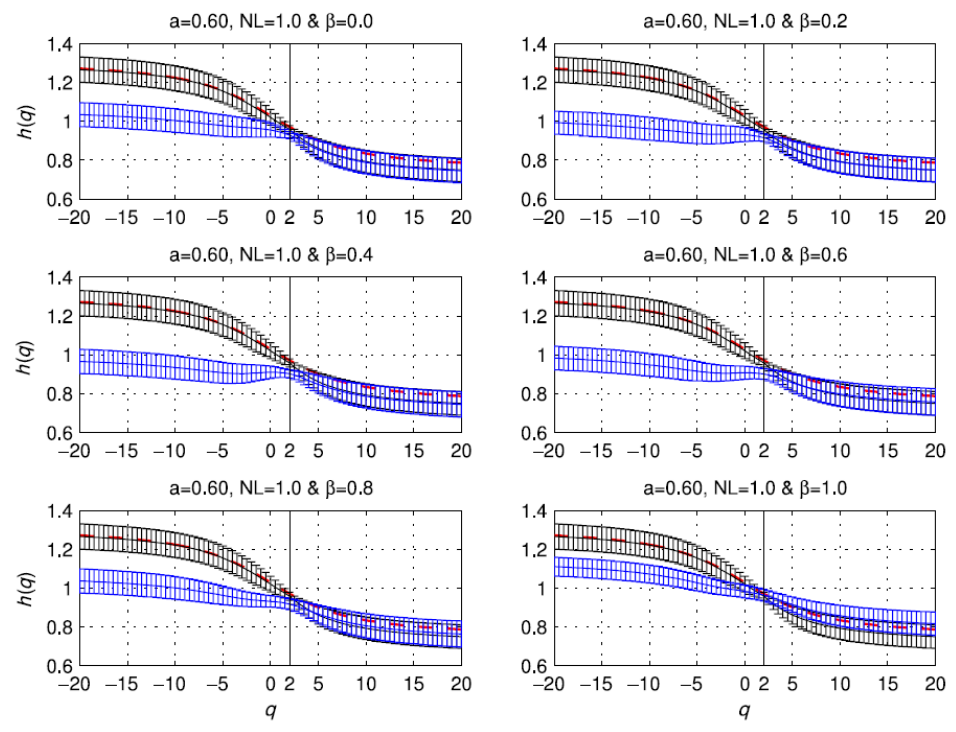

Figura 2.4: Idem Figura 2.2 $\mathrm{NL}=1,0$. 

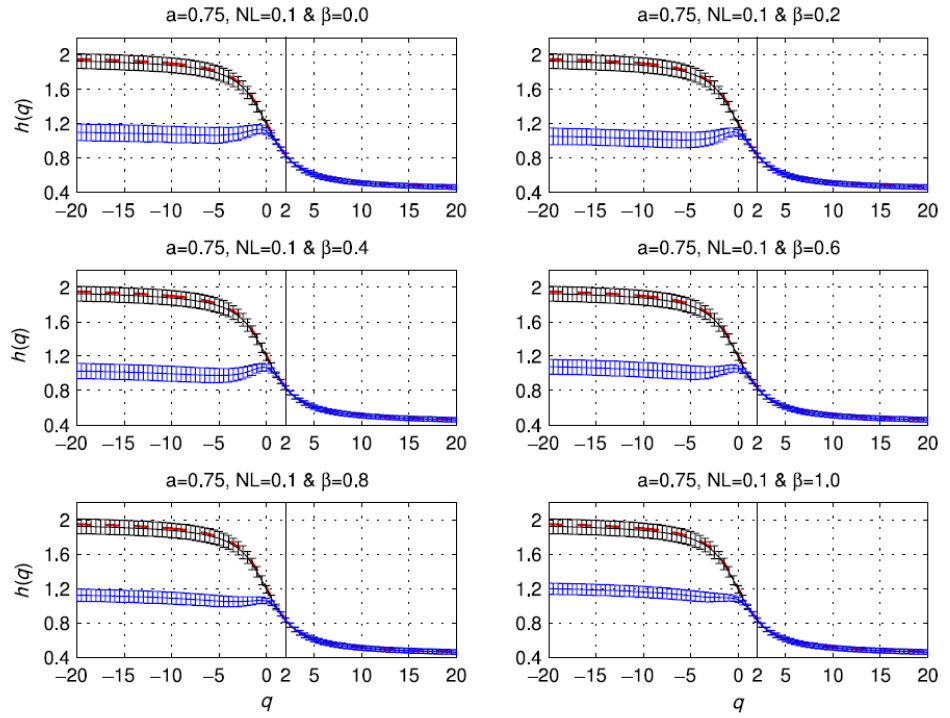

Figura 2.5: Idem Figura 2.2 $a=0,75$ y NL $=0,1$.
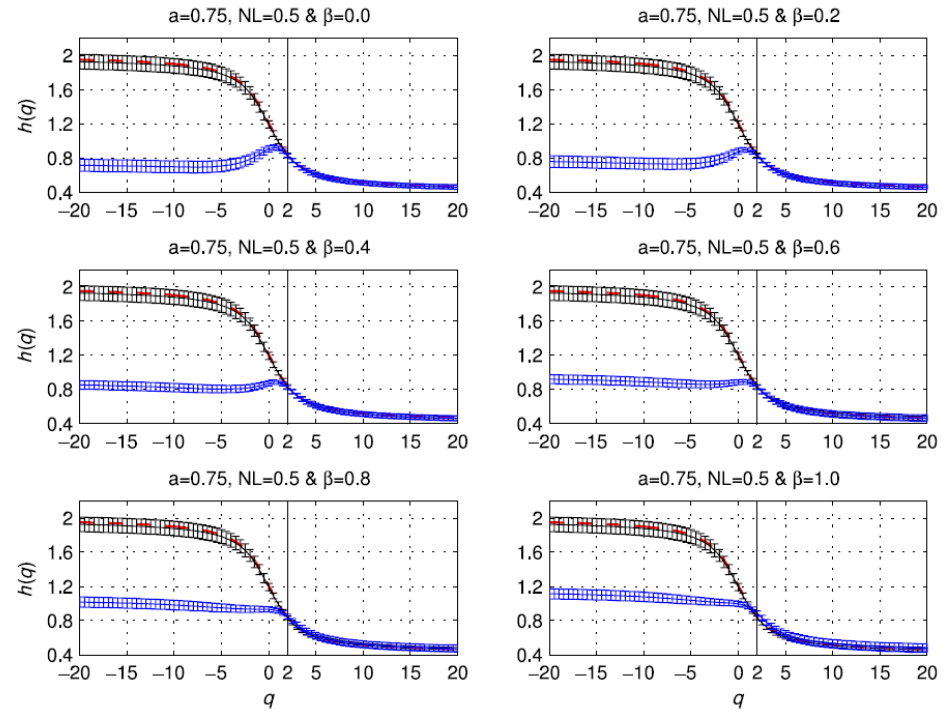

Figura 2.6: Idem Figura 2.2 $a=0,75$ y NL $=0,5$. 

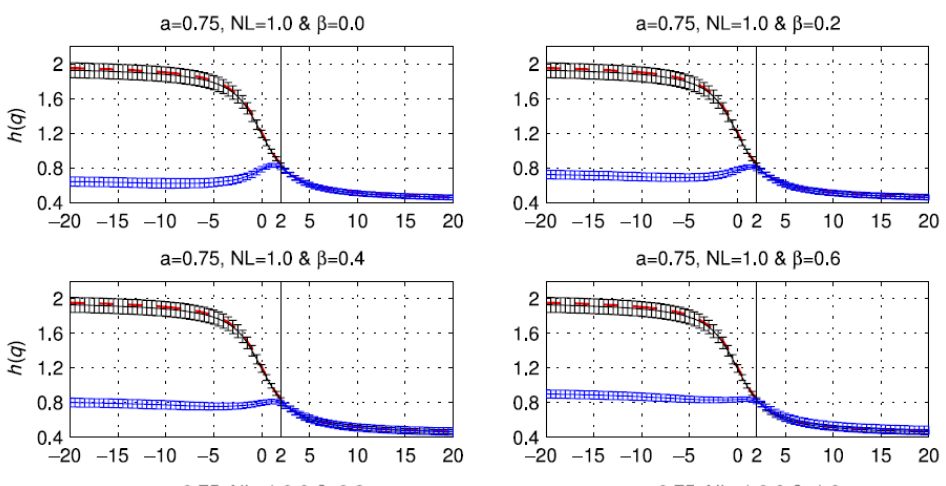

$a=0.75, N L=1.0 \& \beta=0.6$
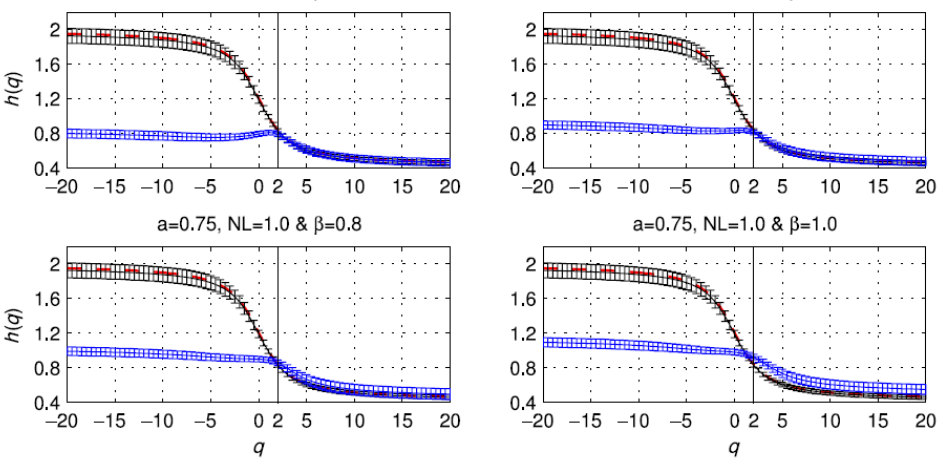

Figura 2.7: Idem Figura 2.3 $a=0,75$ y NL $=1,0$.
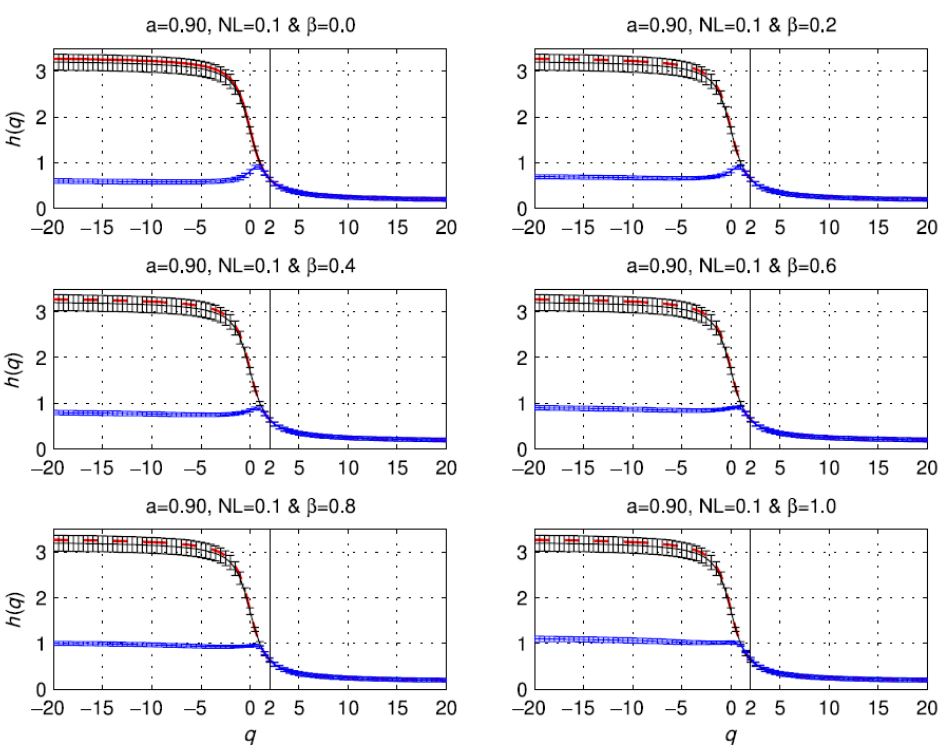

Figure 2.8: Idem Figura 2.2, $a=0,90$ y NL $=0,1$. 

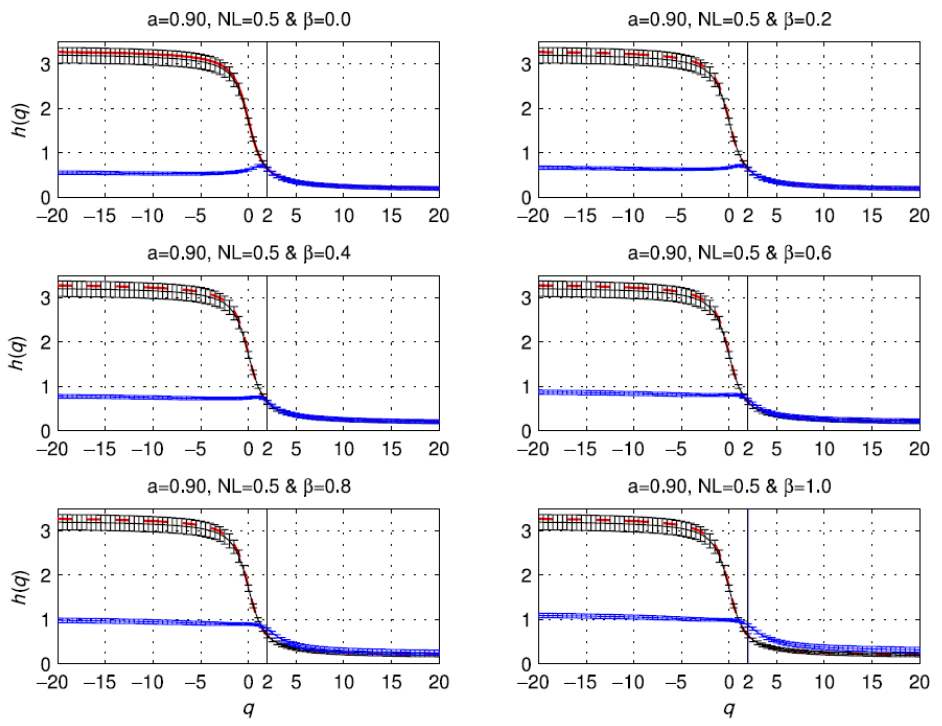

Figure 2.9: Idem Figura 2.3 $a=0,90$ y NL $=0,5$.
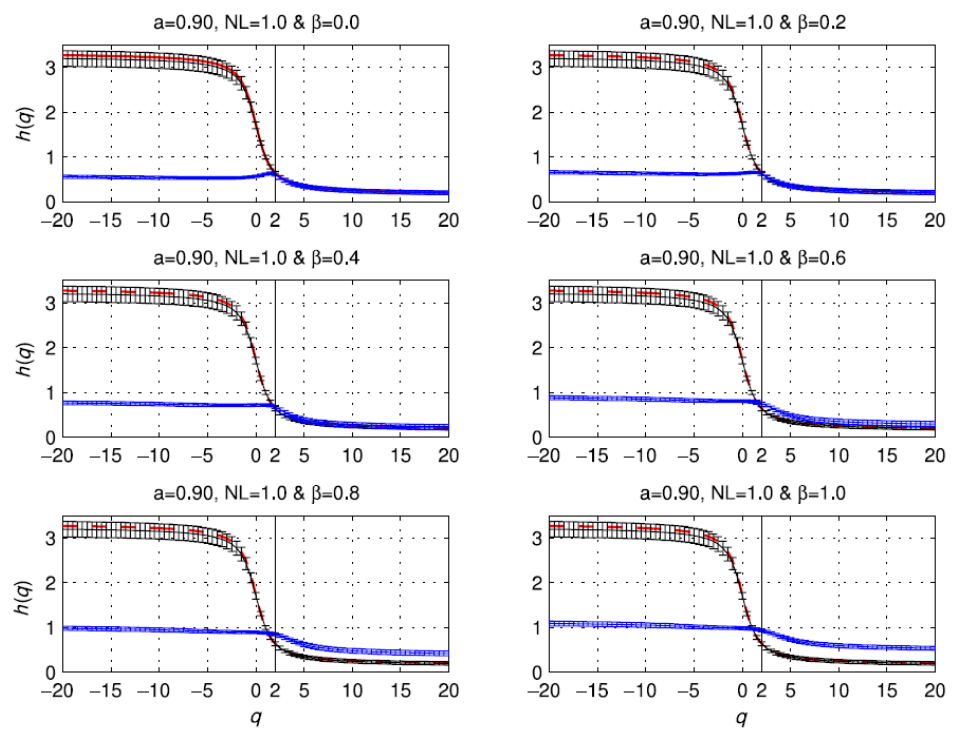

Figura 2.10: Idem Figura2.2 $a=0,90$ y NL $=1,0$. 
al ruido aditivd ${ }^{2}$ Para una mejor visualización de estos resultados, en la Figura 2.11 se muestra el cambio relativo $\delta_{q=-20}=\left[h(-20)-h_{c}(-20)\right] / h(-20)$ entre los bordes de los exponentes de Hurst generalizados estimados para la señal de multifractal original, $h(-20)$, y su contraparte contaminada, $h_{\mathcal{c}}(-20)$, como una función del exponente de escala $\beta$ del ruido añadido. Los resultados obtenidos para los parámetros del modelo y los diferentes niveles de ruido diferente se incluyen en la mismo gráfico. Se obtiene una relación lineal clara para $a=0,90$ independientemente de la intensidad del ruido. Este resultado se justifica teniendo en cuenta que, para $a=0,90$ y $q<0, h(q) \approx h_{\text {noise, }}$ donde $h_{\text {noise }}$ es el exponente de Hurst de los ruidos de largo alcance correlacionados añadidos (ver Figs. 2.8 2.10). Para este parámetro del modelo multifractal, los escaleos obtenidos para momentos negativos dan información sobre las correlaciones espurias que corrompen las señales multifractales originales. Para $a=0,60$ se obtiene una desviación máxima para un exponente de escala intermedio $\beta$ en el caso de ruidos aditivios moderados y fuertes. Una posible razón detrás de este efecto podría ser una especie de mezcla entre las correlaciones de largo alcance de la señal y las del ruido coloreado; pero aún se sigue estudiando con el fin de confirmar esta hipótesis. Por último, para $a=0,75$ se observa un resultado intermedio, con respuestas lineales para ruidos aditivos entre moderados y fuertes, y una clara desviación máxima clara para $\beta=0,4$ cuando $\mathrm{NL}=0,1$.

También hemos encontrado que una cantidad moderada de ruido coloreado $(\mathrm{NL}=0,5$ y NL $=1,0)$ impide una estimación fiable de los exponentes de escala para momentos positivos. Esto es debido al hecho de que las escaleos relacionados con grandes fluctuaciones se ven afectados por las correlaciones de largo alcance presentes en los ruidos coloreados. Obviamente, el sesgo es más pronunciado cuando aumenta el ruido aditivo de la memoria a la largo plazo, y una desviación máxima desde el comportamiento esperado se encuentra para el caso superpersistente $(\beta=1,0)$. Este resultado es fácil de ver en la Figura 2.12 donde el cambio relativo $\delta_{q=2}=\left[h(2)-h_{c}(2)\right] / h(2)$ se representa como una función del exponente de escala $\beta$ del ruido añadido para el parámetro de modelo $a=0,90$. En consecuencia, los exponentes de Hurst generalizados para $q>0$ son sobreestimados cuando la serie original se corrompe por ruido aditivo coloreado.

Tratando de arrojar más luz sobre las razones detrás de este efecto espurio, en la Figura 2.13 se muestran las funciones de fluctuación $F_{q}(s)$ como funciones de $s$ para $a=0,90, \mathrm{NL}=1,0$ y los diferentes ruidos coloreados considerados para una realización elegida al azar. Una escala de crossover $s^{*}$ se observa claramente para los órdenes de $q$ positivos cuando la serie de tiempo multifractal subyacente está afectada por ruidos con grandes correlaciones $(\beta=0,6, \beta=0,8$ y $\beta=1,0)$. Esta escala particular se identifica con una línea discontinua negra vertical en la Figura 2.13 d) -f). Los exponentes de Hurst generalizados con $q>0$ están sobreestimados debido a este cambio en la tendencia. El uso de un

\footnotetext{
${ }^{2}$ La identificación de las fuentes de la multifractalidad es un tema complejo; S. Drożdż et al. 37 han encontrado que una genuina jerarquía multifractal sólo puede originarse de correlaciones temporales.
} 


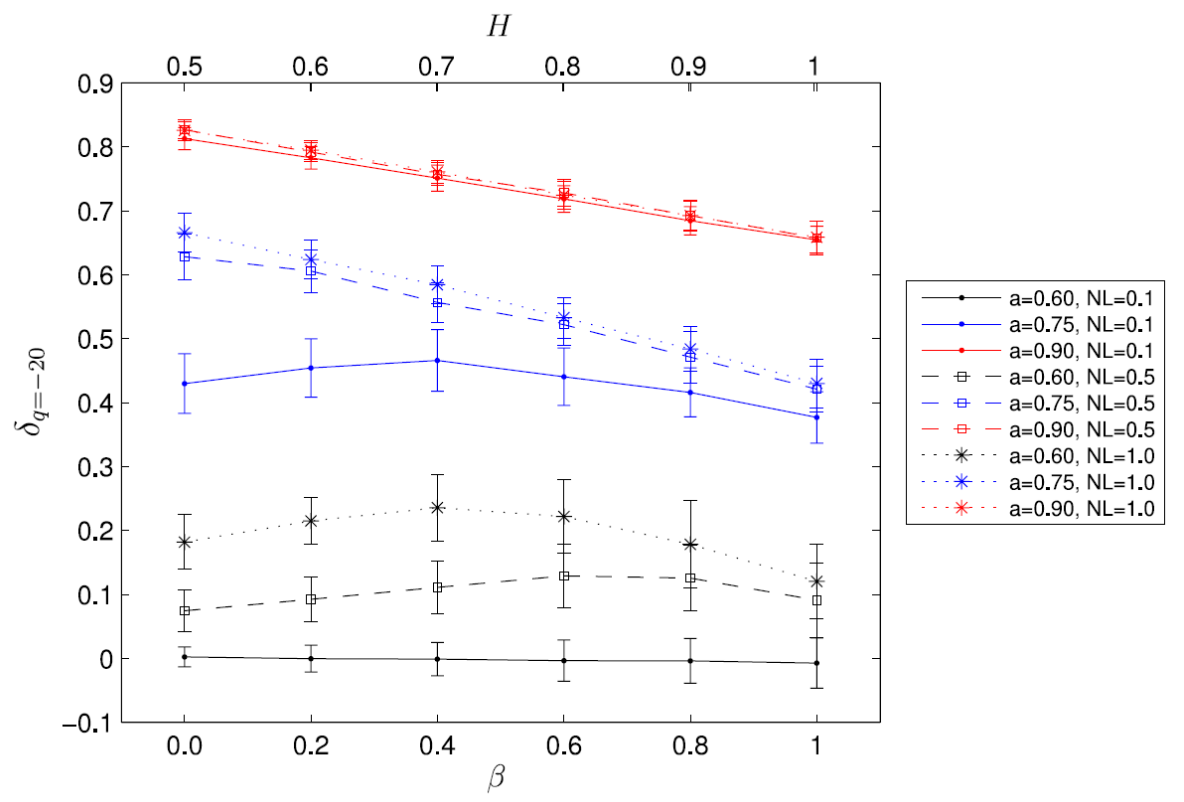

Figura 2.11: Cambio relativo $\delta_{q=-20}=\left[h(-20)-h_{c}(-20)\right] / h(-20)$ entre los bordes de los exponentes de Hurst generalizados estimados para la señal de multifractal original, $h(-20)$, y su contraparte contaminada, $h_{\mathcal{c}}(-20)$, como función del exponente de escala $\beta$ del ruido añadido para diferentes parámetros del modelo y niveles de ruido. Se representa la media y desviación estándar de cien realizaciones independientes. 


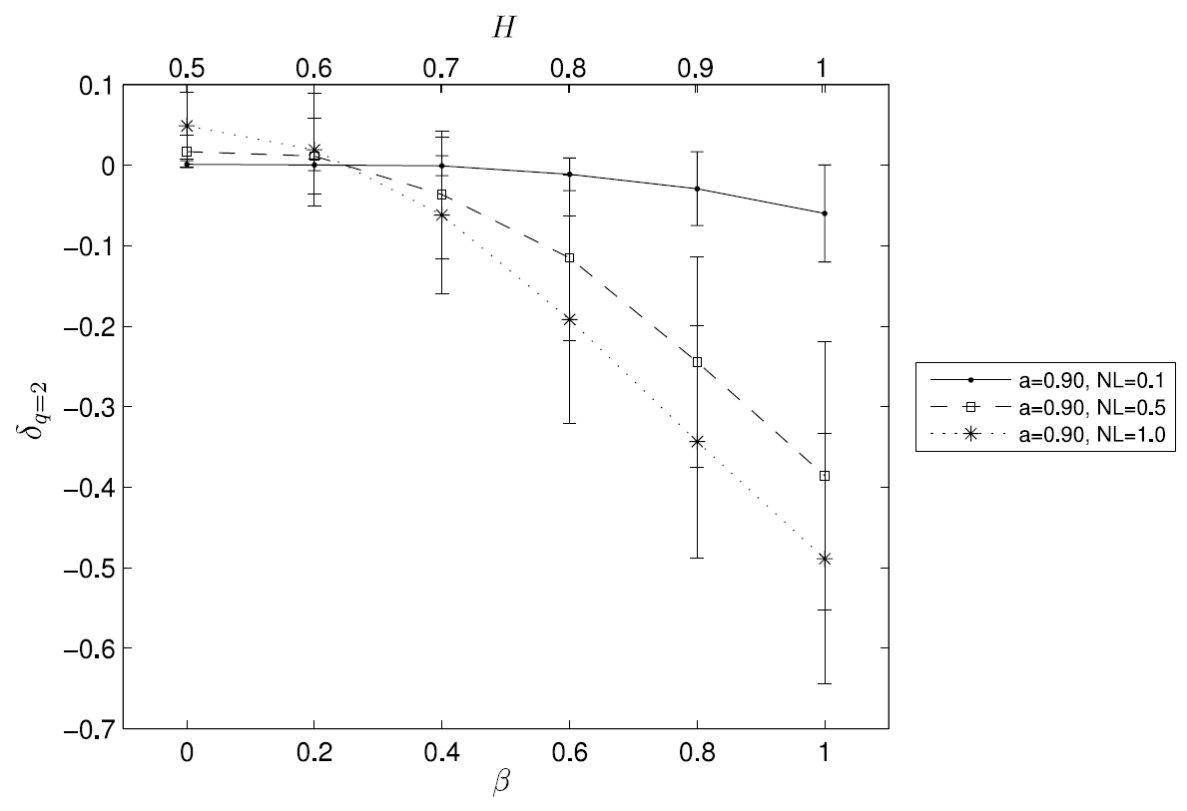

Figura 2.12: Cambio relativo $\delta_{q=2}=\left[h(2)-h_{c}(2)\right] / h(2)$ entre las estimaciones del exponente de Hurst para la señal multifractal original $h(2)$ y su contraparte contaminada $h_{c}(2)$, como función del exponente de escala $\beta$ del ruido sumado para el parámetro de modelo $a=0,90$. Media y desviación estándar de cien realizaciones independientes. 
a
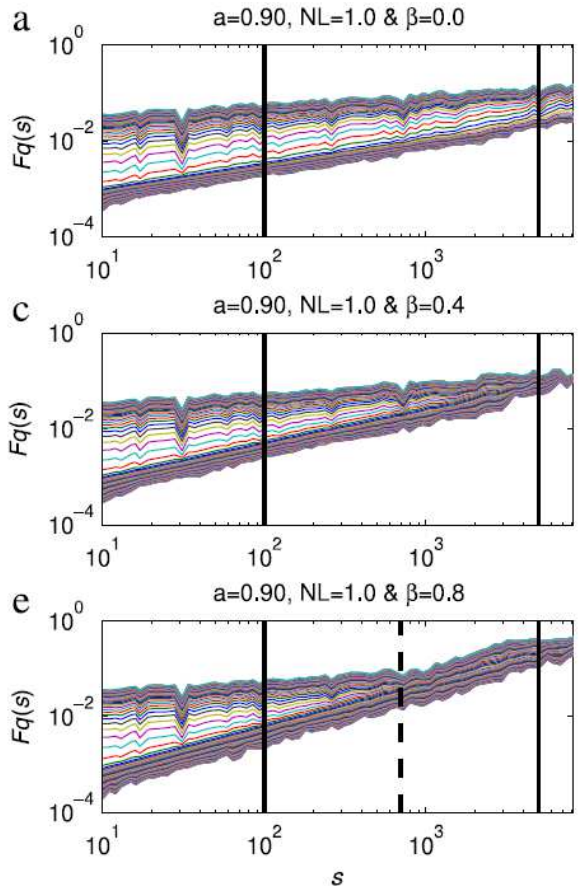

b

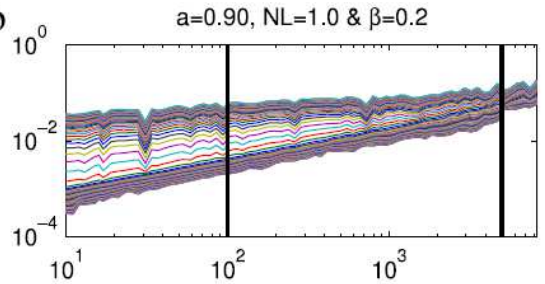

d

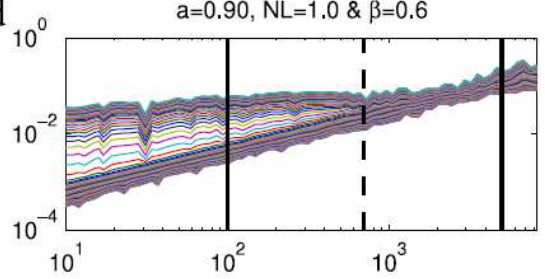

$a=0.90, N L=1.0 \& \beta=1.0$

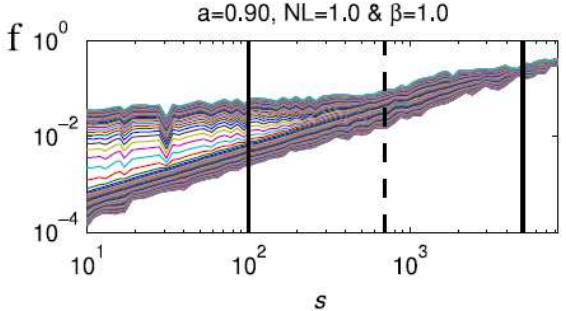

Figura 2.13: $F_{q}(s)$ versus $s$ para $a=0,90$ y $\mathrm{NL}=1,0$ para una sola realización. El comportamiento observado aquí es representativo de todo el conjunto. El orden $q$ $(q=-20,-19,5, \ldots, 19,5,20)$ aumenta de abajo hacia arriba. Se pueden visualizar los efectos de los diferentes ruidos coloreados con espectro de potencia $f^{-\beta}$. Las líneas verticales sólidas indican el rango de ajuste. Las líneas verticales punteadas marcan la escala de crossover $s^{*}$ observada para $q$ positivos cuando la señal multifractal original es contaminada con ruidos con correlaciones largas.

rango uniforme de escalas para el ajuste lineal es totalmente cuestionable en estos casos. Para ser más precisos, dos regiones distintas de escalamiento, $s<s^{*} \mathrm{y}$ $s>s^{*}$, deben ser consideradas. Por otra parte, las pendientes para las regiones de pequeñas escalas y grandes escalas parecen ser dependientes e independientes, respectivamente, del orden $q$. Esto sugiere que el comportamiento en escalas de tiempo grandes $\left(s>s^{*}\right)$ podría ser muy útil para dar a conocer la naturaleza del ruido contaminante. También detallamos esta discusión en [54]. 


\subsection{Criterio de determinación de rangos óptimos de estimación por calidad de ajuste lineal}

\subsubsection{Introducción}

Tanto DFA como MF-DFA requieren la identificación de comportamientos de ley de potencia en un rango de escalas con el fin de estimar los exponentes de escaleo asociados. Sin embargo, las regiones de ajuste son a veces muy difíciles de determinar sin un modelo teórico para los comportamientos de escala; incluso con tal modelo la determinación de estas regiones es subjetivo y por tanto los resultados derivados de diferentes análisis de la misma serie son difíciles de comparar. Según observan Shao et al. [55]: «no hay consenso sobre la determinación objetiva del rango de escaleo, que desempeña un papel crucial en la estimación de los exponentes de escala». Esta es también una cuestión sutil cuando se trata de series que tienen más de un comportamiento de escala. Los comportamientos multi-escala se encuentran a menudo en los sistemas naturales y artificiales [56].

Es, por lo tanto, necesario desarrollar un criterio independiente del usuario para estimar las regiones de ajuste óptimas de las funciones de fluctuación. Una posibilidad es estudiar los exponentes locales por medio del registro gráfico de la derivada $\left(d\left(\log \left(F_{q}(s)\right)\right) / d(\log (s))\right.$ versus $\left.\log (s)\right)$, según lo sugerido por Govindan et al. [57, Bashan et al. [58] y Lopez et al. [59], en busca de regiones de valor constante. Sin embargo, las series experimentales muy generalmente tienen discontinuidades en su derivada logarítmica para pequeños $q$ cuando se trata de MF-DFA, por lo que este método es muy difícil de aplicar en estos casos. Michalski [60] ha identificado los tamaños de escala mínimo y máximo óptimos para los procesos persistentes (movimiento browniano fraccionario y ruido gaussiano fraccionario) a través de una serie de extensas simulaciones de Monte Carlo. Grech et al. 61 han estudiado la región de escala para DFA de series artificiales correlacionadas y descorrelacionadas como función de su longitud teniendo en cuenta su la calidad de ajuste lineal $\left(R^{2}\right)$ prefijando los niveles de confianza. El mismo estudio se ha ampliado recientemente con éxito a otras técnicas de análisis de fluctuación [62]. Siguiendo un enfoque relacionado, nos porponemos utilizar $R^{2}$ como una manera de localizar regiones de escalas óptimas para el ajuste. Este criterio basado en la calidad de ajuste lineal puede extenderse naturalmente a otras técnicas que requieren ajustes lineales. De hecho, los métodos de detrending modificados, como el Detrended Moving Average (DMA) 63], Centering Moving Average (CMA) 64, Modified Detrended Fluctuation Analysis (MDFA) 65], continuous DFA (CDFA) [66], Detrended Cross-Correlation Analysis (DCCA) [46], Multifractal Detrended Cross-Correlation Analysis (MF-DCCA) 67, multifractal detrending moving average (MF-DMA) 68, Multifractal Detrending Moving-Average CrossCorrelation Analysis (MFXDMA) 69], el método DFA basado en variar el orden polinómico [70], y MF-DFA basado en EMD [71 podrían ser beneficiados con su aplicación. Como se discutirá en detalle a continuación, los fenómenos 
de crossover, es decir, la presencia de escalas que separan dos regímenes con diferentes exponentes de escala, también puede ser estudiados de manera eficiente mediante la aplicación de esta metodología. La identificación de estas escalas características es relevante para una comprensión completa de las dinámicas multi-escala subyacentes [56].

\subsubsection{Criterio basado en la calidad de ajuste lineal}

\section{Caso DFA}

Supongamos que $x_{t}$ es una serie temporal y que tenemos $M$ escalas dada ${ }^{3}$ $s: s \equiv\left\{s_{1}, s_{2}, \ldots, s_{M}\right\}$ para las cuales ya hemos calculado la función de fluctuación $F(s) \equiv\left\{F\left(s_{k}\right)\right\}(1 \leq k \leq M)$. En este trabajo elegimos $M=100$. El siguiente algoritmo determina los rangos de escala óptimos para hacer el ajuste lineal de la función de fluctuación asociada a la serie:

1. Definir una cantidad mínima de datos $\delta$. En la práctica, este parámetro no debe ser menos de 10 para que el ajuste lineal tenga sentido estadístico; hemos encontrado que valores de $\delta$ entre $\lfloor M / 4\rfloor$ y $\lfloor M / 3\rfloor$ discriminarán regiones de al menos esa cantidad de puntos, lo cual es una partición razonable del dominio de puntos.

2. Calcular la serie logarítmice ${ }^{4} L_{s}=\left\{\log \left(s_{k}\right)\right\}$ y $L_{F}=\left\{\log \left(F\left(s_{k}\right)\right)\right\}(1 \leq$ $k \leq M)$.

3. Definir la matriz $r_{M \times M}$ con valores todos cero por defecto.

4. Calcular todos los elementos no nulos de $r$ según

$$
r_{i j}=R^{2}\left(s_{i}, s_{j}\right)
$$

donde $R^{2}\left(s_{i}, s_{j}\right)$ es el coeficiente de determinación $\left(R^{2}\right)$ del ajuste lineal de $L_{F}$ versus $L_{s}$ entre (e incluyendo) $\log \left(s_{i}\right)$ y $\log \left(s_{j}\right)$. También $1 \leq i \leq$ $(M-\delta+1)$ y $(i+\delta-1) \leq j \leq M$. Por definición, todo $r_{i j} \leq 1$ y los valores no nulos están en la diagonal superior de la matriz.

5. Ordenar todos los valores no nulos de $r_{i j}$ en orden decreciente, manteniendo el registro de sus índices originales.

6. Si hay valores repetidos en $r$, se requiere un criterio extra de ordenamiento: basándose en la cantidad de puntos del intervalo elegir primero el más grande.

El primer elemento de esta lista dará el intervalo de mejor ajuste lineal ('Dominant') y el resto lo seguirán en calidad decreciente. Puesto que la pendiente del ajuste lineal en ese rango estima el exponente de escala $h\left(F \sim s^{h}\right)$, hemos hallado el mejor rango de estimación para este parámetro.

\footnotetext{
${ }^{3}$ Equidistantes en logaritmo.

${ }^{4} \log \equiv \log _{10}$
} 
Este algoritmo es de fuerza bruta y calcula todos los ajustes posibles de al menos $\delta$ puntos entre $s_{1}$ y $s_{M}$; esto no es computacionalmente prohibitivo puesto que estamos lidiando con relativamente pocos puntos.

\section{Generalización a MF-DFA}

En MF-DFA [23] las funciones de fluctuación dependen del exponente $q=$ $\left\{q_{1}, \ldots, q_{Q}\right\}: F_{q}(s)$ (por lo tanto hay $Q$ funciones de fluctuación). El algoritmo descrito más arriba puede generalizarse como sigue:

1. Definir un mínimo de puntos $\delta$ como en el paso 1 del caso DFA . Éste $\delta$ permanecerá constante para los próximos pasos.

2. Repetir los pasos 2 25 de la anterior subsección para cada $F_{q}(s)$ obteniendo la versión generalizada de la Ecuación 2.7):

$$
r_{i j}^{(n)} \equiv R_{q_{n}}^{2}\left(s_{i}, s_{j}\right)
$$

con $1 \leq n \leq Q$.

3. Con la Ecuación. 2.8 calcular la matriz $\langle r\rangle$ :

$$
\langle r\rangle \equiv\langle r\rangle_{i j}=\frac{1}{Q} \sum_{n=1}^{Q} r_{i j}^{(n)}
$$

4. Aplicar el criterio de ordenamiento descrito en el paso5de la subsección anterior $\langle r\rangle$.

5. Si hay valores repetidos en $\langle r\rangle$, el ordenamiento requiere un criterio extra: ordenar primero los más anchos (en cantidad de puntos en el intervalo).

Nótese que esta generalización producirá los mismos resultados para DFA. Otra posibilidad es calcular la función de fluctuación para muchos valores $\left\{q_{1}, \ldots, q_{Q}\right\}$ y luego aplicar esta técnica solo para un subconjunto $\left\{q_{1}^{\prime}, \ldots, q_{Z}^{\prime}\right\} \subseteq$ $\left\{q_{1}, \ldots, q_{Q}\right\},(Z \leq Q)$

\section{Diferentes comportamientos en diferentes escalas}

En varias situaciones las correlaciones de los datos no siguen la misma ley de escala para todas las escalas consideradas $s$, y se observan diferentes regímenes con una o más escalas de crossover [72]. Por ejemplo, se ha demostrado la presencia de correlaciones de largo alcance en las pequeñas escalas $\left(s<s_{x}\right.$, siendo $s_{x}$ la escala de crossover) y un comportamiento prácticamente no correlacionado a escalas mayores $\left(s>s_{x}\right)$ (véase la Figura 11 en la Ref. [73]). Por otra parte, se ha observado una transición de multifractal a monofractal en una escala de crossover bien definida en fluctuaciones de velocidad de tránsito [74]. Sin lugar a dudas, la identificación de estas escalas de crossover puede 
proporcionar información muy útil sobre la dinámica subyacente. De hecho, las diferencias en el escaleo para ventanas temporales cortas y largas pueden emplearse como potenciales indicadores para distinguir lo normal de lo patológico en series temporales de origen fisiológico [26]. Cabe notar aquí que Ge y Leung [56] han introducido recientemente un enfoque estadístico riguroso, llamado scaling-identification regression model, que es capaz de identificar las escalas de crossover con intervalos de confianza.

Es interesante notar que la determinación de intervalos de calidad no superpuestos implica diferentes comportamientos de escala: $F \sim s^{h_{1}}, s^{h_{2}}, \ldots$ para el caso de DFA y $F_{q}(s) \sim s^{h_{1}(q)}, s^{h_{2}(q)}, \ldots$ para el caso de MF-DFA. La metodología propuesta aquí primero dará el mejor rango de ajuste tanto para DFA como para MF-DFA, mientras que regímenes distintos pueden hallarse encontrando los intervalos más cercanos en la lista que (incluyendo los elementos del borde)

- terminen antes del comienzo del intervalo óptimo

- comiencen después del final del intervalo óptimo

El proceso puede ser iterado para cubrir todas las escala involucradas, pudiendo así discriminar regiones con un comportamiento de ley de potencias bien definido. El primer intervalo a la derecha (izquierda, respectivamente) se llamará 'Next' ('Previous'). Otras regiones pueden existir a la derecha (izquierda) de las regiones 'Next' ('Previous') siempre y cuando satisfagan la condición sobre $\delta(\lfloor M / 4\rfloor \leq \delta \leq\lfloor M / 3\rfloor)$.

\subsubsection{Ejemplos ilustrativos}

\section{DFA de funciones de fluctuación artificiales simples}

Generamos 99 puntos equidistantes $u_{k}$ en el intervalo $[1,4]$ y agregamos el valor 3 para tener 100 puntos en total. Luego calculamos

$$
v_{k}=\left\{\begin{array}{cc}
0,95 \cdot u_{k} & u_{k} \leq 3 \\
1,35+0,5 \cdot u_{k} & u_{k}>3
\end{array}\right.
$$

También generamos una serie de 100 números aleatorios uniformes $e_{k}$ en el intervalo $[-0,035,0,035]$ para ser usados como ruido aditivo, generando así la serie $\widetilde{v}_{k}=v_{k}+e_{k}(1 \leq k \leq 100)$. Luego obtenemos funciones de fluctuación artificiales $F(s)$ cuyas series respectivamente son $y_{k}$ e $\widetilde{y}_{k}$ con escalas $s$ según:

$$
\begin{aligned}
& s_{k}=10^{u_{k}} \\
& y_{k}=10^{v_{k}} \\
& \widetilde{y}_{k}=10^{\widetilde{v}_{k}}
\end{aligned}
$$

$(1 \leq k \leq 100)$. Un gráfico log-log de $\left(s_{k}, y_{k}\right)$ muestra una línea recta de pendiente 0,95 para escalas $\leq 10^{3}$ y otra de pendiente 0,5 para escalas mayores que 


\begin{tabular}{|c|c|c|c|}
\hline Parámetro & Teórico (sin ruido) & Sin ruido (algoritmo) & Con ruido (algoritmo) \\
\hline \hline Región 'Dominant' & {$\left[10,10^{3}\right]$} & {$\left[10,10^{3}\right]$} & {$[10,1124,658]$} \\
\hline$R^{2}\left({ }^{\prime}\right.$ Dominant') & - & 1 & 0,999 \\
\hline$h\left({ }^{\prime}\right.$ Dominant') & 0,95 & $0,950 \ldots \pm 4,24 \cdot 10^{-17}$ & $0,947 \pm 0,004$ \\
\hline Cant. puntos ('Dominant') & 67 & 67 & 69 \\
\hline Región 'Next' & {$\left[10^{3}, 10^{4}\right]$} & {$\left[10^{3}, 10^{4}\right]$} & {$[1124,658,9319,396]$} \\
\hline$R^{2}\left({ }^{\prime} \mathrm{Next}^{\prime}\right)$ & - & 1 & 0,980 \\
\hline$h\left({ }^{\prime} \mathrm{Next}^{\prime}\right)$ & 0,5 & $0,50 \ldots \pm 2,20 \cdot 10^{-16}$ & $0,511 \pm 0,014$ \\
\hline Cant. puntos('Next') & 34 & 34 & 31 \\
\hline
\end{tabular}

Tabla 2.1: Sumario de los resultados de la Figura 2.14

$10^{3}$ respectivamente (Figura 2.14 a), mientras que ambos regímenes no son tan claros para $\left(s_{k}, \widetilde{y}_{k}\right)$ (Figura 2.15 a). Las figuras 2.14 y 2.15 muestran los resultados del algoritmo aplicado a ambas series $(\delta=25)$. Los resultados obtenidos se comparan en la Tabla 2.1

Es interesante notar que en ambos casos las regiones determinadas permanecen sin cambios para valores de $\delta$ mayores que 25 y menores que el ancho de la región 'Next' en cantidad de puntos. Cuando el ancho de la región 'Next' (34 puntos sin ruido y 31 con ruido) se hace más pequeño que $\delta$ el criterio reestima la región. En ests casos, las regiones 'Dominant' siguen sin cambios hasta $\delta=67$ (without noise) and $\delta=69$ (con ruido). Ambas regiones 'Dominant' y 'Next' permanecen aproximadamente sin cambios en el rango de $\delta$ entre $\lfloor N / 4\rfloor$ $\mathrm{y}\lfloor N / 3\rfloor$.

\section{Análisis sistemático de ruidos gaussianos fraccionarios}

Hemos realizado un análisis sistemático de ruidos gaussianos fraccionarios (fGns) con el criterio introducido en esta sección. Es bien conocido que las correlaciones de largo alcance asociadas a estos procesos estocásticos estacionarios gaussianos monofractales están completamente caracterizadas por el exponente de Hurst $H$. Para este fin hemos generado 100 realizaciones numéricas independientes de fGns con $H \in\{0,3,0,5,0,7\}$ de longitud $N=10^{4}$ puntos mediante el uso de la función wfbm de MATLAB ${ }^{5}$ Los resultados obtenidos de este estudio automatizado mediante la aplicación de DFA con un orden de polinomio de detrending $m=1, M=100$ y $\delta=25$ se muestran en la Figura 2.16 La calidad de ajuste $\left(R^{2}\right)$ aumenta con $H$ mientras que disminuye su dispersión (Figura 2.16 b).

\footnotetext{
${ }^{5}$ Esta función simula el movimiento browniano fraccionario (fBms) siguiendo el algoritmo propuesto por Abry y Sellan 75. Los fGns se obtuvieron a través de diferencias sucesivas de los fBms generados.
} 

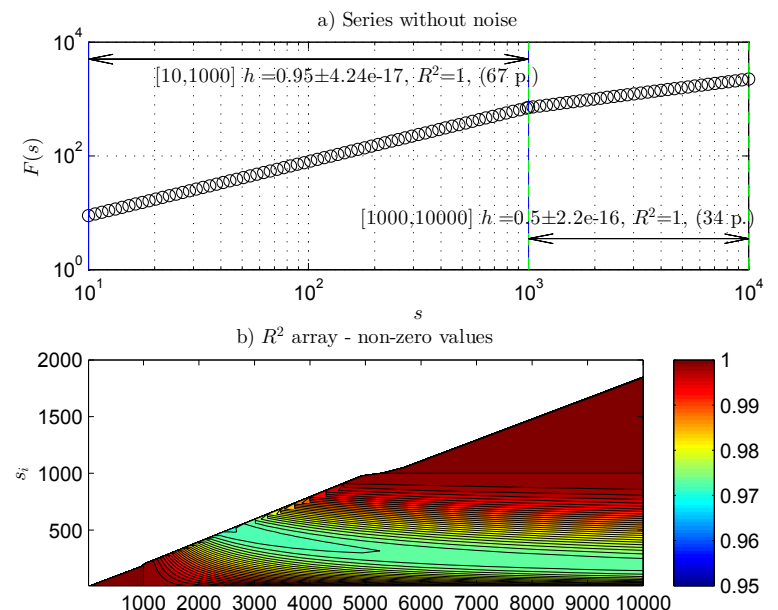

10002000300040005000600070008000900010000

$s_{f}$

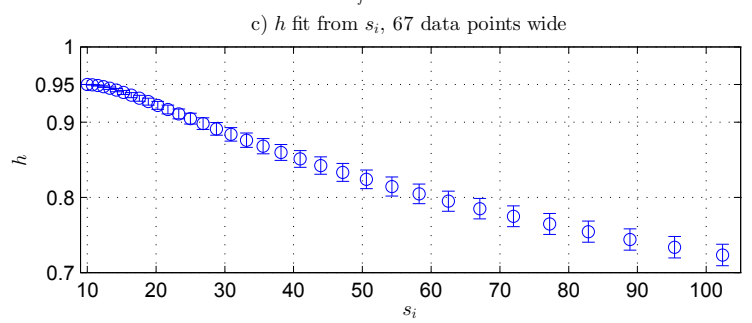

d) $R^{2}$ fit from $s_{i}, 67$ data points wide

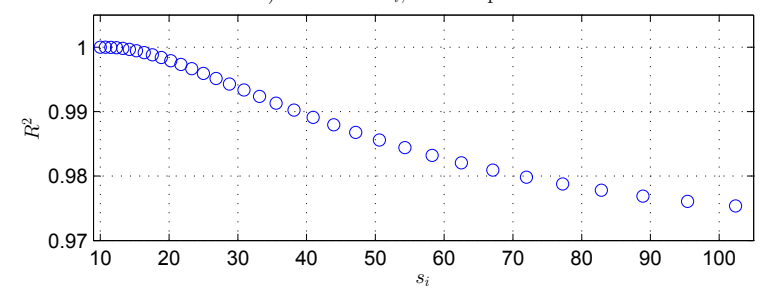

Figure 2.14: Funciones de fluctuación simuladas estudiadas con el algoritmo (DFA), $\delta=\lfloor 100 / 4\rfloor=25$.

a) Función de fluctuación simulada sin ruido.

b) Contour plot de la matriz $\langle r\rangle$. La región 'Dominant' determinada es $\left[10,10^{3}\right], R^{2}=1$ (67 puntos de ancho); la región 'Next' es $\left[10^{3}, 10^{4}\right], R^{2}=1$ (34 puntos de ancho).

c) El $h$ estimado ajustando 67 puntos consecutivos desde $s_{i}$; las barras de error aumentan a medida que el intervalo de ajuste tiene más puntos de la región 'Next'.

d) $R^{2}$ de los ajustes de c); la calidad del ajuste disminuye. El mejor ajuste es en la región 'Dominant' y allí se estima $h=0,950 \ldots \pm 4,238 \cdot 10^{-17}$ (el valor esperado es $h=0,95$ ); y para la región 'Next' $h=0,50 \ldots \pm 2,20 \cdot 10^{-16}$ (el valor esperado es $h=0,5$ ). 

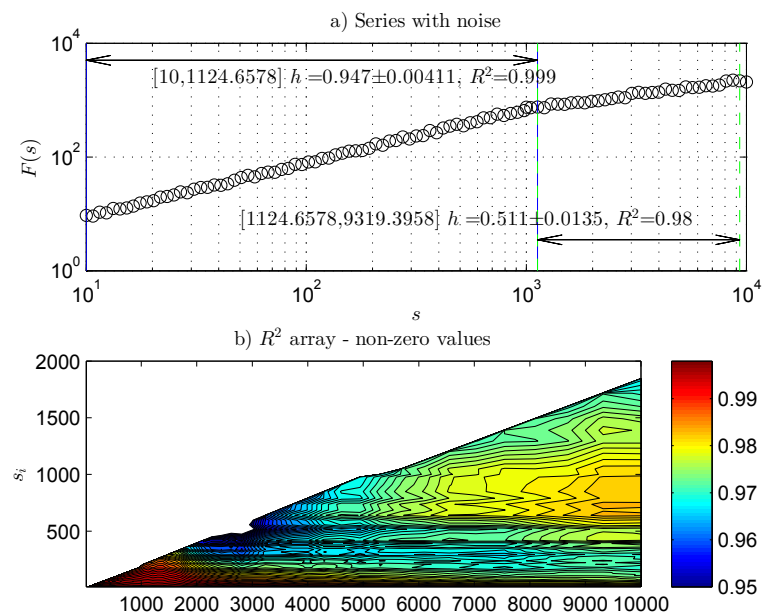

10002000300040005000600070008000900010000

$s_{f}$

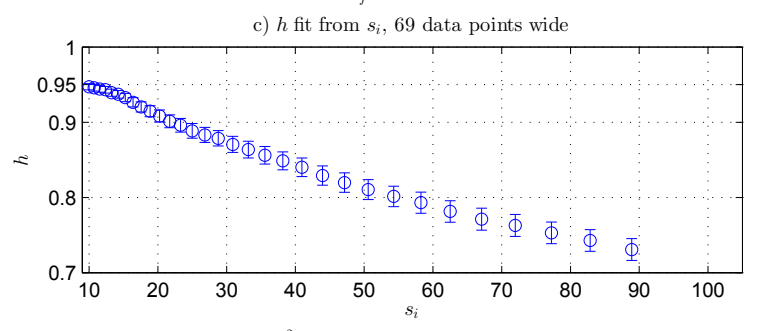

d) $R^{2}$ fit from $s_{i}, 69$ data points wide

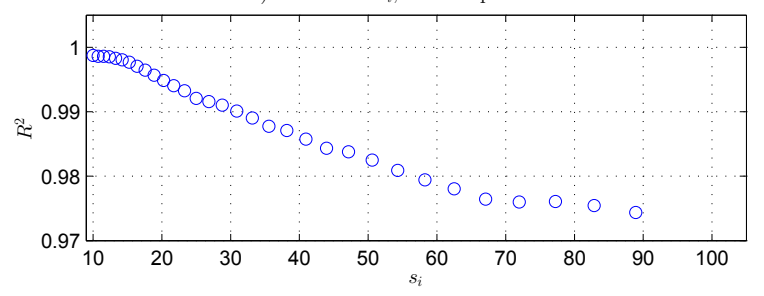

Figure 2.15: Funciones de fluctuación simuladas estudiadas con el algoritmo (DFA), $\delta=\lfloor 100 / 4\rfloor=25$.

a) Función de fluctuación simulada con ruido aditivo.

b) Contour plot de la matriz $\langle r\rangle$. La región 'Dominant' determinada es $[10,1124,658]$, $R^{2}=0,999$ (69 puntos de ancho); la región 'Next' es $[1124,658,9319,396], R^{2}=0,980(31$ puntos de ancho).

c) El $h$ estimado ajustando 69 puntos consecutivos desde $s_{i} ;$ las barras de error aumentan a medida que el intervalo de ajuste tiene más puntos de la región 'Next'.

d) $R^{2}$ de los ajustes de c); la calidad del ajuste disminuye. El mejor ajuste es en la región 'Dominant' y allí se estima $h=0,947 \pm 0,004$ (el valor esperado es $h=0,95$ ); y para la región 'Next, $h=0,511 \pm 0,014$ (el valor esperado es $h=0,5$ ). 

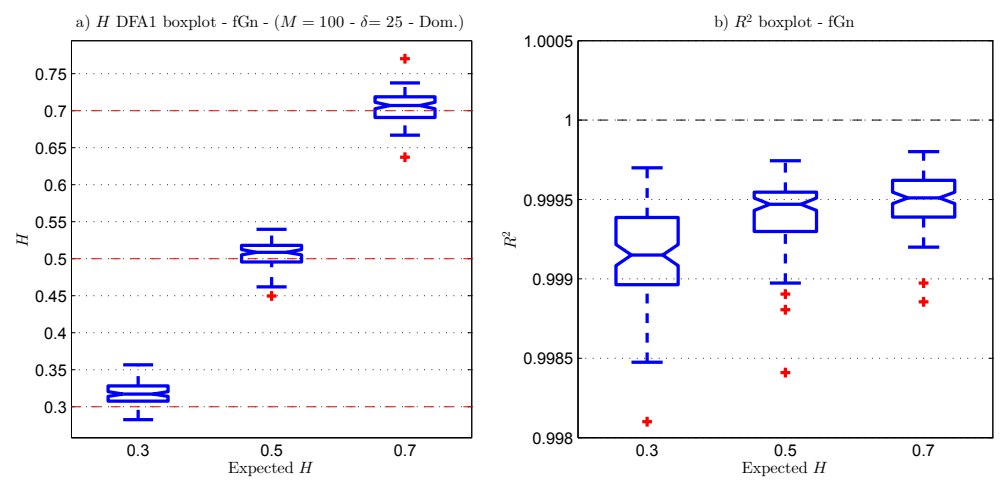

Figura 2.16: Estudio automático de fGns. a) Boxplot de los valores estimados de $H$ calculados en las regiones 'Dominant' versus el $H$ esperado. b) Boxplot de $R^{2}$ para los valores esperados de $H$ : la calidad del ajuste aumenta con $H$.

\section{Identificación de escalas temporales de crossover}

Ahora debemos estudiar la performance del criterio propuesto para la estimación de crossovers. Con este objetivo en mente generamos series artificiales con dos escalas de crossover $s_{1}$ y $s_{2}$ bien localizadas. Estas series de prueba pueden ser fácilmente simuladas siguiendo la receta descrita por de Schumann y Kantelhardt en Ref. [52]. Se hace una segmentación de la serie de tiempo original en bloques no superpuestos de longitud $s_{u}$ y una permutación aleatoria posterior de estos bloques permite destruir las correlaciones de largo alcance en las escalas por encima de la escala $s_{u}$ [58. De esta manera, la serie generada es monofractal y no correlacionada $(h(q)=1 / 2)$ para $s>s_{u}$. Análogamente, las correlaciones en escalas pequeñas $s<s_{v}$ pueden ser eliminadas después de permutar al azar los datos dentro de los bloques de tamaño $s_{v}$, mientras que el orden de los bloques se mantiene sin cambios. En consecuencia, $h(q)=1 / 2$ para $s<s_{v}$.

Generamos 20 realizaciones numéricas independientes de fGns con $H=0,6$ y $N=10^{5}$ usando el mismo algoritmo descrito en la subsección 2.4.3 Por un lado, la correlación subyacente es eliminada para la escalas más pequeñas $(s<$ $s_{1}=10^{2}$ ) haciendo una permutación de los datos originales dentro de bloques es ese tamaño. Por otro lado, se simula un comportamiento descorrelacionado para las escalas más grandes $\left(s>s_{2}=10^{3}\right)$ permutando bloques enteros de este tamaño. Así, las correlaciones originales sólo están preservadas para una escala intermedia, es decir, $s_{1}<s<s_{2}$.

Las escalas de crossover se estimaron a partir de las intersecciones de los ajustes lineales en las distintas regiones. Véase la Figura 2.17 donde se muestran los resultados obtenidos para los crossovers estimados mediante la aplicación de DFA con un orden de polinomio de detrending $m=1$ y $\delta=25$. Se identifican los tres regímenes de escala diferentes. El primer crossover ('Dominant'- 


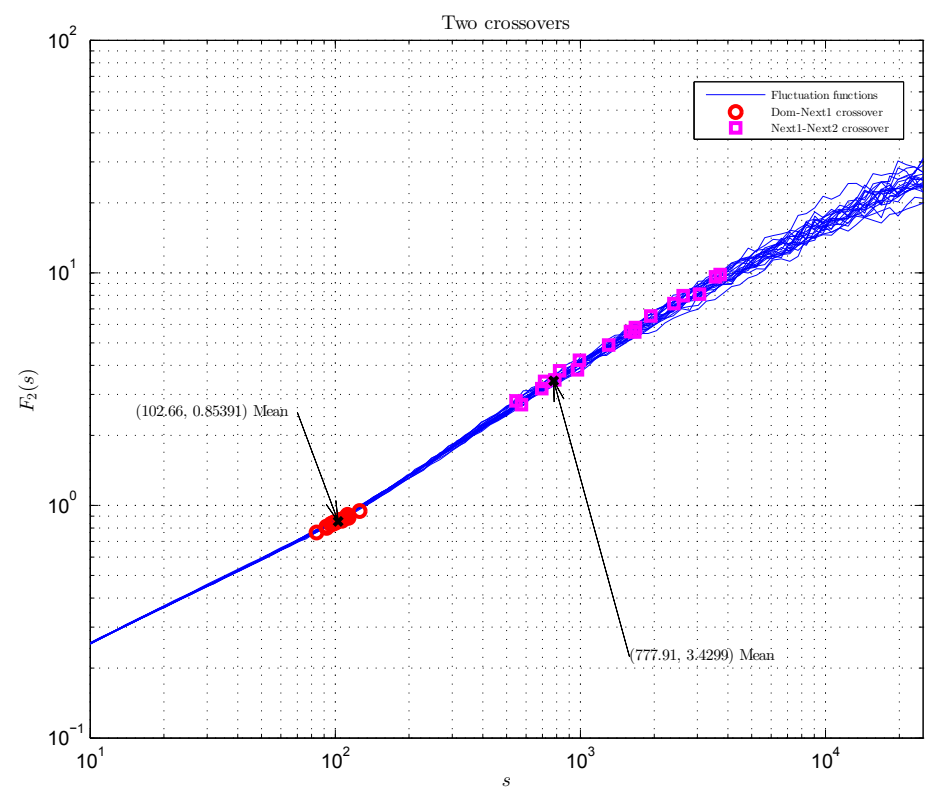

Figura 2.17: Resultados del criterio aplicado a 20 series con escalas de crossover teóricas en $s_{1}=10^{2}$ y $s_{2}=10^{3}$. Todos los puntos de crossover observados son del tipo ‘Dominant-Next1' y 'Next1-Next2'.

'Next1') tiene una dispersión más baja que el segundo ('Next1' - 'Next2'); esto puede explicarse considerando que hay un menor número de ventanas para escalas mayores (esto tiene un efecto similar al ruido en las funciones de fluctuación para grandes $s$ ).

\section{Serie binomial multifractal}

De acuerdo a lo explicado en la Ref. 23] generamos una serie de of $2^{16}$ valores según

$$
x_{k}=a^{n(k-1)}(1-a)^{n_{\max }-n(k-1)}
$$

donde $1 \leq k \leq 2^{16}$ y $n(k)$ es el número de dígitos iguales a 1 en la representación binaria de $k$. Esta serie tiene un espectro multifractal teórico dado por

$$
h(q)=\frac{1}{q}-\frac{\ln \left[a^{q}+(1-a)^{q}\right]}{q \ln (2)} .
$$

La Figura 2.18 muestra los resultados del algoritmo aplicado a la serie con $a=0,75$ (empleando MF-DFA3). La región 'Dominant' $\left[10,2^{14}\right]$ tiene un mejor acuerdo con los valores teóricos que otras regiones (Figura 2.18d1). También confirmamos un buen acuerdo con los valores teóricos para $a=0,6$ y $a=0,9$. 

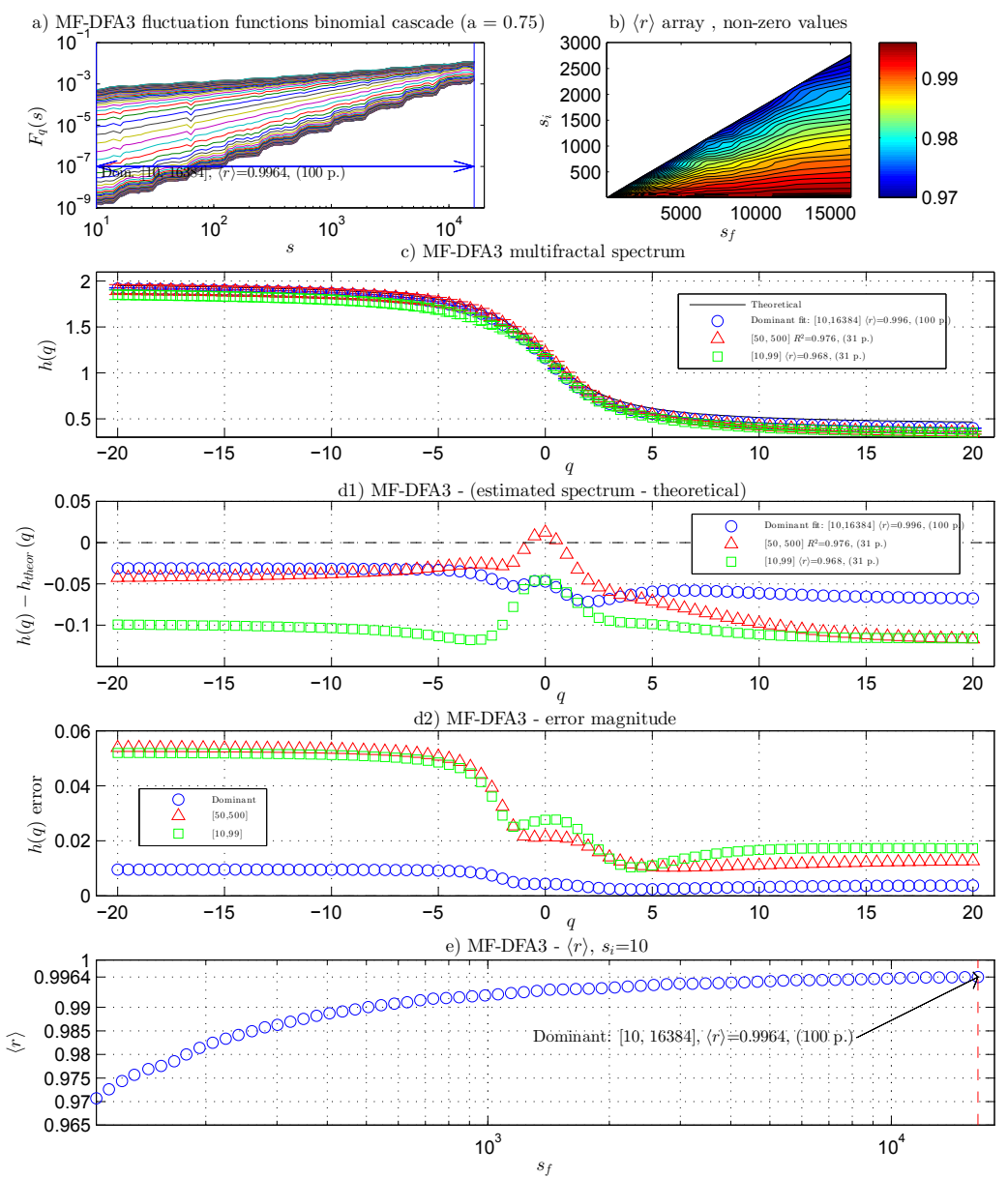

Figura 2.18: MF-DFA3 para el binomial multifractal $(a=0,75)$.

a) Funciones de fluctuación, $q=-20,-19,5, \ldots, 20$.

b) Contour plot de la matriz $\langle r\rangle$ de la serie (valores no nulos, $\delta=25$ ).

c) Espectro multifractal teórico y espectro estimado: región 'Dominant' $\left(\left[10,2^{14}\right]\right)$ - ajuste de 100 puntos $(\langle r\rangle \simeq 0,996)$; un ejemplo de rango medio $[50,500]-31$ puntos ajustados $(\langle r\rangle \simeq 0,976), \mathrm{y}[10,99]-31$ puntos ajustados $(\langle r\rangle \simeq 0,968)$.

d1) Calidad de los tres espectros de c) mostrada como la diferencia entre la estimación y el valor teórico $h(q)$. d2) Magnitud estimada para el error de los tres espectros.

e) Una sección del contour plot de la matriz $\langle r\rangle$ (subfigura b): valores del la estimación del espectro multifractal ajustado entre $s_{i}=10 \mathrm{y}$ terminando en $s_{f}$ (variable); el valor final es un máximo absolutode $\langle r\rangle \simeq 0,996$ e indica la región 'Dominant' (líneas verticales punteadas) también indicada en a): $\left[10,2^{14}\right]$. 


\subsubsection{Applicación al estudio de las series temporales de man- chas solares}

El análisis de series temporales naturales representa un reto más duro que los ejemplos anteriores porque son intrínsecamente mucho más complejas. En esta sección aplicamos el criterio propuesto para la caracterización de la estructura fractal y multifractal asociada a las fluctuaciones de número de manchas solares.

Aunque las manchas solares se han observado durante milenios [76 77], sólo la observación telescópica desde 1610 permitió el estudio sistemático de este fenómeno [76. El número de estos puntos de temperatura relativamente más baja en la superficie del sol durante un período determinado de tiempo es un buen indicador de su actividad [78]. El vínculo entre la actividad solar y el clima dinámico de la Tierra ha sido ampliamente investigado [78, 79, 80, 81, 82] haciendo de ésta un área de investigación muy activa. Se han identificado ciclos generales [78, 83], mientras que los esfuerzos más recientes se han centrado en la caracterización del 'ruido' en la series temporales montadas sobre dichos ciclos generales 8485 .

Hemos analizado la serie mensual International Sunspot Number a disposición pública desde la página web SIDCs http://sidc.oma.be/sunspot-data/. Este conjunto de datos se inicia en enero de 1749 y se actualiza regularmente. Se ha estudiado con DFA (y MF-DFA) en el pasado: hasta el año 2006 por Movahed et al. [86, por Hu et al. [84] (hasta 2008), y más recientemente por Zhou et al. 85] (hasta 2009). El conjunto de datos mensual utilizado en este trabajo abarca el período de enero 1749 a noviembre 2012 (3167 meses).

Es bien sabido que las tendencias afectan particularmente a la estimación de las correlaciones temporales relacionadas con las fluctuaciones intrínsecas 87]. En consecuencia, para una detección fiable del comportamiento de escala en una serie de datos, es esencial separar las tendencias (por lo general debidas a efectos externos y no a priori conocidas) de las fluctuaciones intrínsecas. El DFA y MF-DFA permiten una eliminación sistemática de tendencias polinómicas de orden diferente [58. Por otro lado, las tendencias oscilatorias, por ejemplo los ciclos estacionales de tiempo y las series de clima [88, pueden perturbar considerablemente el análisis de correlación y merecen un tratamiento especial [89 49]. Más precisamente, las periodicidades extrínsecas inducen la presencia de crossovers espurios en las funciones de fluctuación asociadas; lo cual impide una estimación fiable del comportamiento de escala intrínseco.

\section{Empirical Mode Decomposition (EMD)}

Teniendo en cuenta la presencia del conocido período de 11 años en la dinámica solar, hemos filtrado el registro mensual de manchas solares mediante la implementación de empirical mode decomposition (EMD) [90]. Esta técnica ha demostrado ser eficaz para lidiar con tendencias periódicas [85]. Dada una señal $x(t)$, el algoritmo EMD descompone la serie original en un conjunto de componentes básicos denominados intrinsic mode functions $\left(\mathrm{IMF}_{k}\right.$ ) (una descripción 
detallada se puede encontrar en las Refs. 90, 91]). La serie se filtró utilizando el toolbox de MATLAB para empirical mode decomposition desarrollado por Rilling y Flandrin del Laboratoire de Physique CNRS y ENS Lyon (Francia) 92], descargado desde http://perso.ens-lyon.fr/patrick.flandrin/emd. html y se siguió el análisis realizado por Zhou et al. [85] (incluyendo el criterio de parada para la iteración). La descomposición EMD de la serie de tiempo mensual original de las manchas solares se representa en la Figura 2.19 Las sumas parciales de la reconstrucción son $S(i, j)$ de acuerdo con

$$
S(i, j)=\sum_{k=i}^{j} \mathrm{IMF}_{k}
$$

En la Figura 2.20 a) trazamos las funciones de fluctuación de DFA para $S(1, j)(1 \leq j \leq 9)$. Se puede observar fácilmente una transición abrupta entre el escalado obtenido para $S(1,4)$ y $S(1,5)$. Estos resultados son comparables con los reportados por Zhou et al. [85. Los exponentes de escala y escalas de crossover se estimaron a partir de $S(1,4)$ (Figura 2.20 b)), ya que todos los ciclos de más de 11 años se filtran en esta reconstrucción. La región 'Dominant' hallada es $[10,56]$ con $h=0,702 \pm 0,007\left(R^{2}=0,996,34\right.$ puntos); mientras que la región 'Next' es [56,581] con $h=0,306 \pm 0,008\left(R^{2}=0,969,54\right.$ puntos). La escala de crossover estimada es entonces $s_{c}=57,441$ meses, en completa concordancia con el punto de crossover $\left(s_{c}=57,544\right.$ meses) reportado por la Ref. 85].

Los resultados de MF-DFA para $S(1,4)$ (MF-DFA1 a MF-DFA4) se muestran en la Figura 2.21 En la parte superior trazamos las funciones de fluctuación y mostramos el intervalo 'Dominant' determinado por la generalización MF-DFA del criterio; a continuación trazamos el espectro multifractal de cada región 'Dominant'. Los resultados confirman un comportamiento multifractal de la serie para los $q$ negativos y un comportamiento monofractal para valores positivos de $q$; este comportamiento general no cambia mucho de MF-DFA2 en lo sucesivo. Vale la pena comentar que este resultado está en línea con el espectro multifractal obtenido por Hu et al. (compárese con la Figura 12 de la Ref. 84]).

\subsection{Conclusiones}

Hemos encontrado que el efecto espurio de ruidos aditivos correlacionados debería tenerse debidamente en cuenta al analizar el carácter multifractal de datos experimentales (Sección 2.3. Los espectros multifractales estimados mediante la técnica MF-DFA pueden estar sesgados debido a la presencia de tales artefactos. Por un lado los $h(q)$ con $q<2$ son notablemente subestimados para una pequeña cantidad de ruido aditivo correlacionado y no correlacionado. Por otro lado, las adiciones moderadas de ruidos coloreados también afectan $h(q)$ con $q \geq 2$. Más precisamente, los exponentes de Hurst generalizados en este rango de $q$ están sobreestimados y el sesgo es más significativo cuando la 

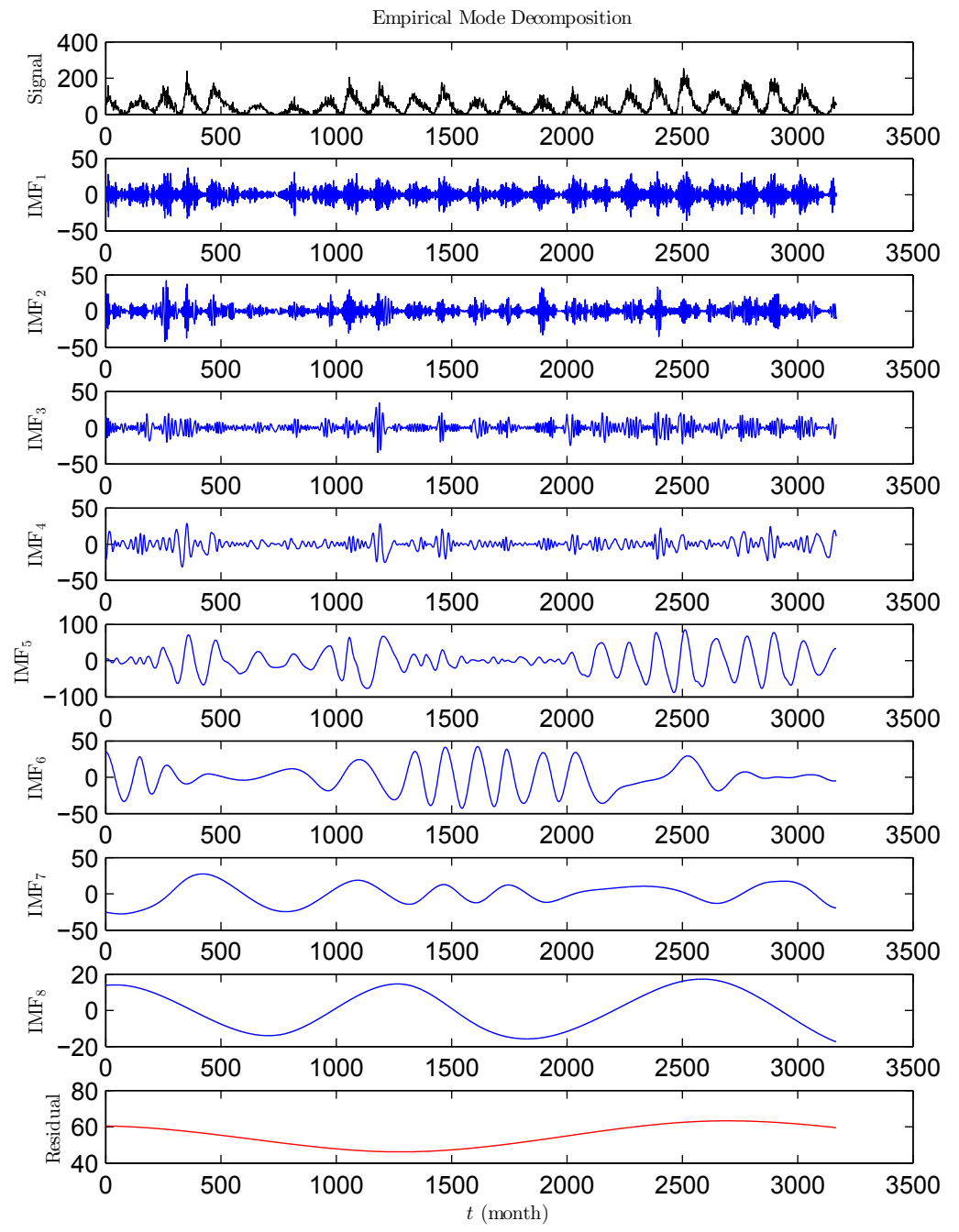

Figure 2.19: Descomposición EMD de la serie mensual de manchas solares. De arriba hacia abajo $\mathrm{IMF}_{1}$ a IMF ; el residuo es considerado como $\mathrm{IMF}_{9}$. 
a ) DFA1 versus level of reconstruction

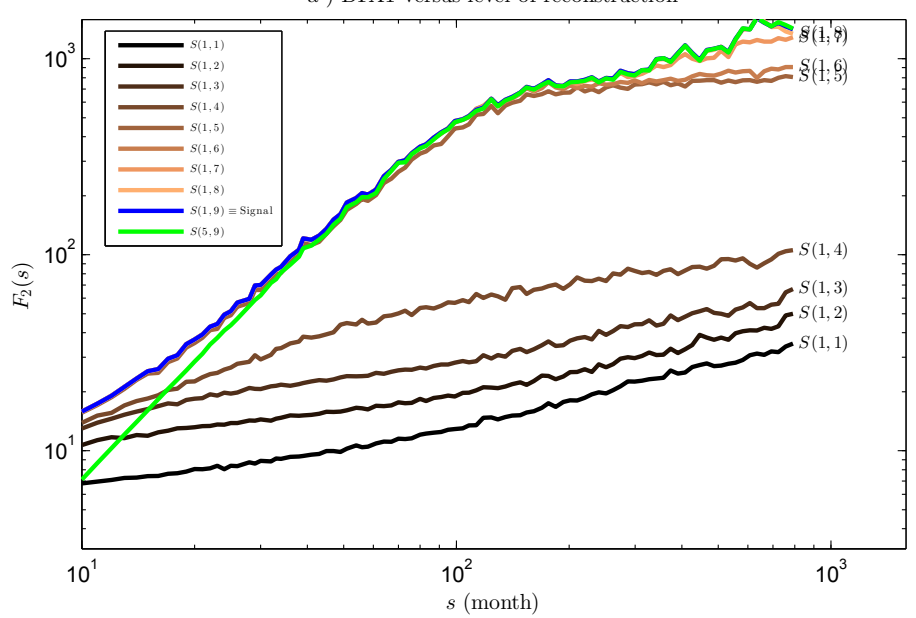

b) $S(1,4)-\mathrm{DFA} 1$

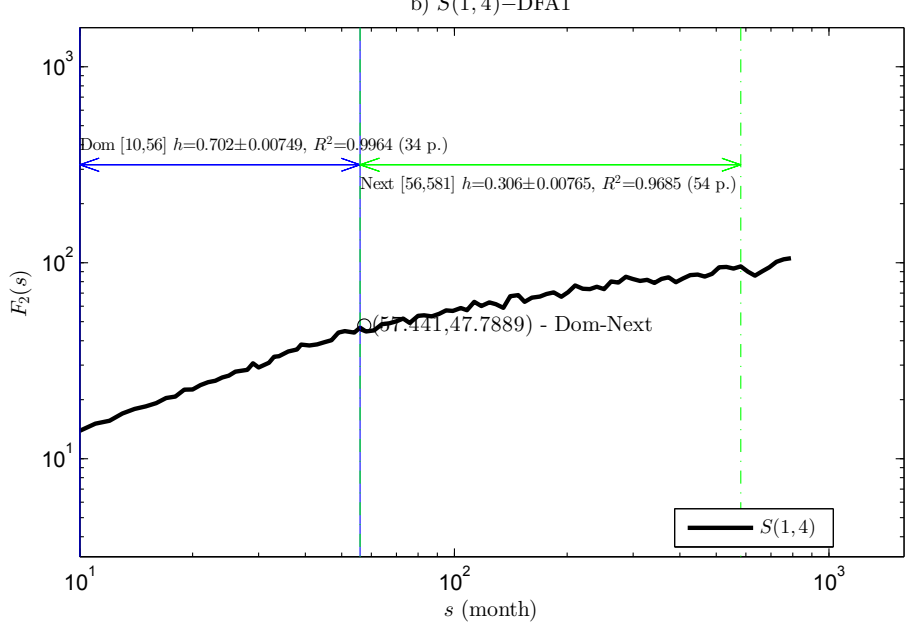

Figura 2.20: a) Funciones de fluctuación de DFA para $S(1, j)(1 \leq j \leq 9)$. Nótese la transición entre los escaleos obtenidos en $S(1,4)$ y $S(1,5)$.

b) Función de fluctuación por DFA para $S(1,4)$. La región 'Dominant' es $[10,56]$ con $h=0,702 \pm 0,007\left(R^{2}=0,996,34\right.$ puntos); la región 'Next' es $[56,581]$ con $h=0,306 \pm 0,008\left(R^{2}=0,969,54\right.$ puntos $)$. La escala de crossover es $s_{c}=57,441$ meses. 

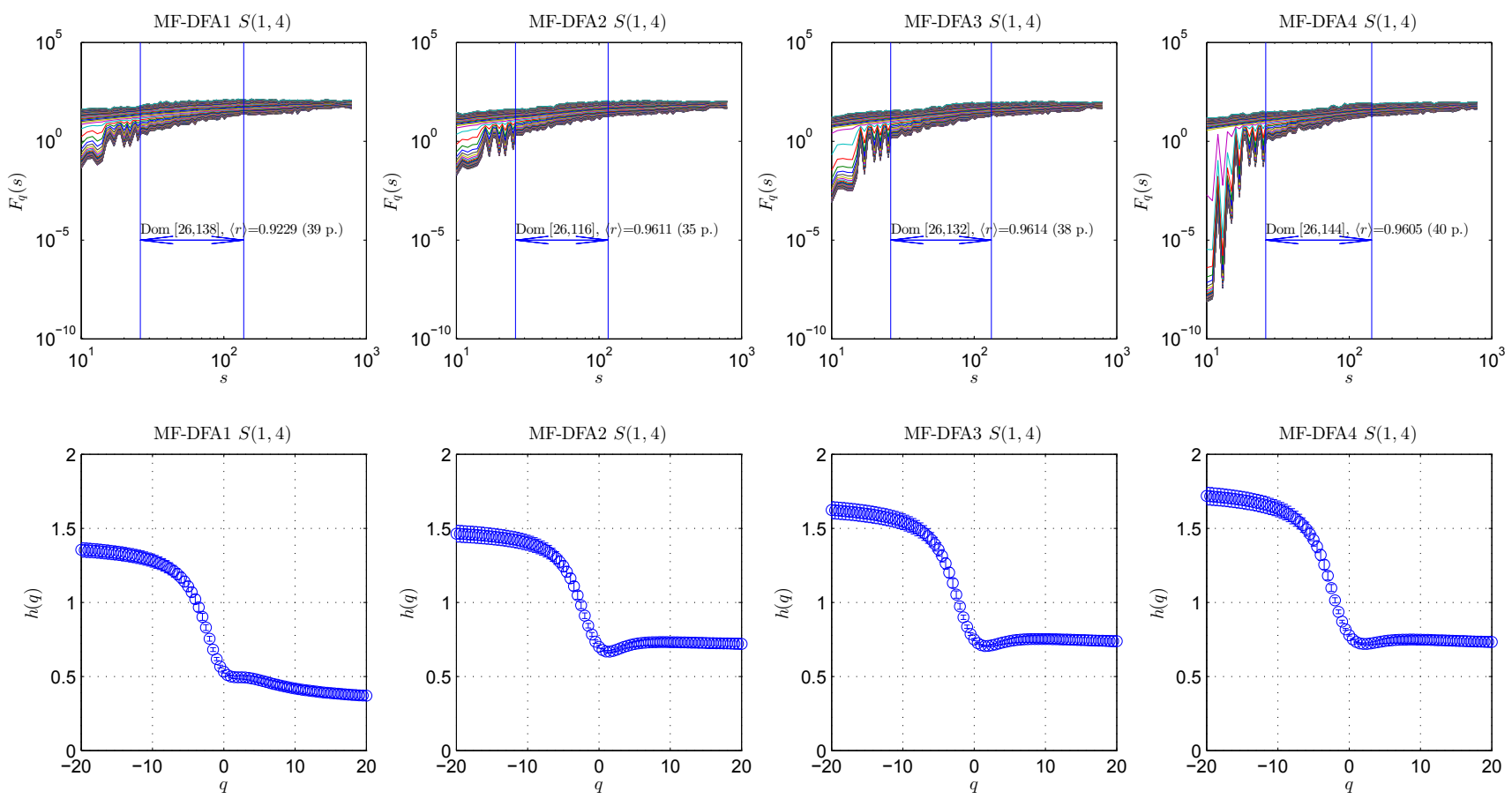

Figura 2.21: Arriba: funciones de fluctuación de los datos mensuales de manchas solares basadas en MF-DFA con orden polinómico creciente; se indican las regiones 'Dominant'. Abajo: espectros multifractales calculados en esos rangos. 
correlación del ruido aumenta. Está claro que las correlaciones de largo alcance presentes en los ruidos tienen una influencia en los comportamientos de escala asociados a grandes fluctuaciones y por lo tanto, los momentos positivos resultan afectados. Teniendo en cuenta que los ruidos correlacionados están inherentemente presentes en los datos experimentales, los resultados obtenidos pueden ser útiles para revelar características multifractales en situaciones prácticas.

Hemos propuesto y empleado un criterio conceptualmente simple para determinar sistemáticamente las regiones óptimas de ajuste para las funciones de fluctuación en DFA; y lo hemos generalizado para MF-DFA. Este método proporciona una clasificación para estas regiones de escalamiento óptimo ('Previous', 'Dominant', 'Next') sobre la base de la calidad del ajuste lineal de las funciones de fluctuación en un gráfico log-log. Cuando se utiliza en DFA, esta técnica ayuda a identificar las escalas de crossover entre los diferentes regímenes de ley de potencia. Cuando se utiliza en MF-DFA, estima el rango de ajuste del espectro multifractal que tiene las barras de error más pequeñas.

Las regiones de ajuste son un punto crítico en DFA y MF-DFA y su identificación óptima es una tarea fundamental para una verdadera determinación del fenómeno de escala subyacente. Tanto el caso mono como el multifractal a menudo son dependientes del tamaño de escala; el criterio propuesto en este trabajo ayuda a identificar comportamientos de escala y de multi-escala de una manera más precisa, confiable y objetiva. Por otra parte, las escalas de crossover que separan dos o más regímenes pueden estimarse fácilmente.

Este criterio puede ser automatizado para el análisis de grandes conjuntos de series temporales, ya que no requiere ningún conocimiento previo sobre los datos en bruto. Por otra parte, las variantes en tiempo real de DFA introducidas para el seguimiento y previsión de las señales que cambian dinámicamente (médicas, meteorológicas, de mercado, acciones, etc.) 93] así como los análisis locales de DFA MF-DFA ideados para seguir la evolución en el tiempo de propiedades fractales y multifractales en los datos 94 pueden beneficiarse especialmente de su implementación. A pesar de tratarse de un algoritmo de fuerza bruta, la cantidad de cálculos implicados hace que sea computacionalmente práctico. Este criterio propuesto también se encuentra detallado en 95. 


\section{Parte II}

\section{Óptica Atmosférica y Experiencias}





\section{Capítulo 3}

\section{Óptica atmosférica y simulación numérica de propagación de ondas ópticas}

\subsection{Propagación de luz a través de la atmósfera tur- bulenta}

La atmósfera de la Tierra es un medio cuyo índice de refracción es aproximadamente 1. Esto permite hacer una ligera modificación a las técnicas de propagación en el vacío para simular la propagación a través de la atmósfera. Desafortunadamente, el índice de refracción de la atmósfera evoluciona aleatoriamente sobre el espacio y el tiempo. Este efecto causa que la luz se deforme aleatoriamente a medida que se propaga. Como resultado los sistemas ópticos que dependen de la propagación de la luz a través de la atmósfera deben superar un gran desafío. Por ejemplo, los astrónomos han observado por siglos que turbulencia atmosférica limita la resolución de sus telescopios. Es por esta razón que los observatorios en tierra se construyen en cimas de las montañas; la localización minimiza la longitud de trayectoria turbulenta por la cual la luz debe propagarse.

Para simular la propagación atmosférica en primer lugar desarrollamos el algoritmo de propagación y luego discutiremos la turbulencia atmosférica y cómo modelar sus propiedades refractivas. Finalmente, discutiremos cómo plantear una simulación numérica, como muestrearla apropiadamente con la debida consideración de los efectos atmosféricos y verificando que el resultado es consistente con la teoría analítica. 


\subsubsection{Método de propagacion del haz dividido}

La simulación de la propagación a través de un medio vacío se logra a través del método de propagación del haz dividido [3. Este método es útil para simular la propagación a través de diversos tipos de materiales inhomogéneos, anisotrópicos y no lineales. En esta sección la discusión está restringida a la atmósfera, la cual es un medio lineal, isotrópico con un índice de refracción no homogéneo $(n \equiv n(x, y, z))$. Cuando $\delta n=n-1$ es pequeño, puede demostrarse que el campo del plano $i+1$ es

$$
U\left(\mathbf{r}_{i+1}\right) \simeq \mathcal{R}\left[\frac{\Delta z_{i}}{2}, \mathbf{r}_{i}, \tilde{\mathbf{r}}_{i+1}\right] \mathcal{T}\left[z_{i}, z_{i+1}\right] \mathcal{R}\left[\frac{\Delta z_{i}}{2}, \mathbf{r}_{i}, \tilde{\mathbf{r}}_{i+1}\right]\left\{U\left(\mathbf{r}_{i}\right)\right\}
$$

donde $\mathcal{T}\left[z_{i}, z_{i+1}\right]$ es un operador que representa la acumulación de la fase y $\tilde{\mathbf{r}}_{i+1}$ es la coordenada en un plano a medio camino entre el plano $i$-ésimo y el plano $(i+1)$-ésimo. Su forma viene dada por

$$
\mathcal{T}\left[z_{i}, z_{i+1}\right]=\exp \left[-i \phi\left(\mathbf{r}_{i+1}\right)\right]
$$

donde la fase acumulada es

$$
\phi\left(\mathbf{r}_{i}\right)=k \int_{z_{i}}^{z_{i+1}} \delta n\left(\mathbf{r}_{i}\right) d z
$$

La Ecuación 3.1 indica que podemos separar la propagación a través de un medio en dos efectos: difracción y refracción. La difraccion en el espacio libre está representada con el operador $\mathcal{R}$, mientras que la refraccion está representada por el operador $\mathcal{T}$. Este método es comúnmente utilizado para simular la propagación a través de la atmósfera turbulenta. De hecho, se lo utiliza para emular la propagación a través de la turbulencia en ópticas de laboratorio también [96 97. . El método consiste en alternar pasos de propagación parcial en el vacío con interacción entre la luz y el material [98, 99, 100].

Para escribir este algoritmo, se debe hacer una pequeña modificación al algoritmo de propagación en el vacío, dado por

$$
\begin{aligned}
U\left(\mathbf{r}_{n}\right)= & \mathcal{Q}\left[\frac{m_{n-1}-1}{m_{n-1} \Delta z_{n-1}}, \mathbf{r}_{n}\right] \times \ldots \\
& \prod_{i=1}^{n-1}\left\{\mathcal{T}\left[z_{i}, z_{i+1}\right] \mathcal{F}^{-1}\left[\mathbf{f}_{i}, \frac{\mathbf{r}_{i+1}}{m_{i}}\right] \mathcal{Q}_{2}\left[-\frac{\Delta z_{i}}{m_{i}}, \mathbf{f}_{i}\right] \mathcal{F}\left[\mathbf{r}_{i}, \mathbf{f}_{i}\right] \frac{1}{m_{i}}\right\} \\
& \times\left\{\mathcal{Q}\left[\frac{1-m_{1}}{\Delta z_{1}}, \mathbf{r}_{1}\right] \mathcal{T}\left[z_{1}, z_{2}\right] U\left(\mathbf{r}_{1}\right)\right\}
\end{aligned}
$$

Nótese que hay $n-1$ propagaciones y $n$ planos con interacción en cada plano. El caso de propagación en el vacío está contemplado tomando el caso $\mathcal{T}=1$ en cada paso. 


\subsubsection{Propiedades refractivas de la atmósfera turbulenta}

En esta sección presentamos la teoría básica de atmósfera turbulenta. Comienza con el análisis original del flujo turbulento hecho por Kolmogorov, el cual eventualmente llevó a modelos estadísticos de la variación del índice de refracción. Luego se utiliza teoría de perturbaciones con el modelo para resolver las ecuaciones de Maxwell y así obtener propiedades estadísticas útiles del campo óptico en el plano de observación. Las varianzas, correlaciones, y densidades espectrales de propiedades como la amplitud logarítmica, la fase, y la irradiancia se usan para dos propósitos en conjunción con las simulaciones. El primer uso es producir bajas aleatorias en el factor de interacción para el método de propagación del haz dividido. Luego, después de simular la propagación a través de un medio turbulento, los campos en el plano de observación se pueden procesan para determinar sus propiedades estadísticas y compararlos contra la teoría.

\section{Teoría de Kolmogorov sobre la turbulencia}

La turbulencia en la atmósfera de la Tierra es causada por variaciones aleatorias en la temperatura y el movimiento convectivo del aire, que alteran el índice de refracción, tanto espacial como temporalmente. A medida que las ondas ópticas se propagan a través de la atmósfera, las ondas se deforman por estas fluctuaciones en el índice de refracción. Esta dispersión de la luz ha frustrado a los astrónomos por siglos porque degrada las imágenes de los objetos celestes. Para superar esta distorsión, se fue necesario de un modelo físico adecuado para la turbulencia y sus efectos en la propagación de ondas ópticas. La turbulencia afecta a todos los sistemas ópticos que dependen de la propagación de luz a través de caminos atmosféricos, como por ejemplo los sistemas de comunicación láser.

Durante los últimos cien años el modelado de los efectos de la turbulencia en la propagación óptica ha recibido mucha atención. Mucho se ha escrito sobre varias teorías y sus posteriores verificaciones experimentales. El foco del modelado estadístico ha producido varias teorías útiles. En estas teorías es necesario emplear análisis estadísticos, porque es imposible describir exactamente el índice de refracción en todas las posiciones espaciales al mismo tiempo. Hay demasiadas variables y comportamientos aleatorios como para dar cuenta de todos al mismo tiempo en una solución de forma cerrada. La teoría más ampliamente aceptada del flujo turbulento, por su consistencia con las observaciones, fue publicada primeramente por A. N. Kolmogorov [. Luego Obukhov 101 e independientemente Corrsin [102 adaptaron el modelo de Kolmogorov para fluctuaciones de temperatura. Posteriormente la teoría de las fluctuaciones de temperatura se pudo relacionar directamente con las fluctuaciones del índice de refracción. Este modelo es la base para todas las teorías contemporáneas sobre turbulencia [103].

Existen variaciones de gran escala de la temperatura del aire debidas a las diferencias entre el calentamiento y enfriamiento de la superficie terrestre por 
la luz solar y los ciclos diurnos. Este proceso consecuentemente crea los vientos. A medida que el aire se mueve, hace la transición de un flujo laminar a un flujo turbulento. En el flujo laminar, la velocidad y otras características son uniformes o al menos cambian de manera regular. En un flujo turbulento, el aire de diferentes temperaturas se mezcla, por lo que el campo de velocidades ya no es uniforme y se forman burbujas de aire aleatoriamente distribuidas, llamados torbellinos turbulentos (eddies). Estos torbellinos varían en sus tamaños y temperaturas características. Como la densidad del aire, y por lo tanto su índice de refracción, depende de la temperatura, la atmósfera terrestre tiene un perfil de índice de refracción aleatorio.

El flujo turbulento es un proceso no lineal gobernado por las ecuaciones de Navier-Stokes. Debido a las dificultades para resolver las ecuaciones de Navier-Stokes en una turbulencia completamente desarrollada, Kolmogorov desarrolló una teoría estadística. Sugirió que en un flujo turbulento la energía cinética de los eddies más grandes se transfiere a eddies más pequeños. El tamaño promedio de los eddies más grandes, $L_{0}$, se llama escala externa. Cerca del suelo, $L_{0}$ está en el orden de la altura a la que se observa, mientras que muy por arriba del suelo puede ser de decenas a centenares de metros [104. El tamaño promedio de los torbellinos turbulentos más pequeños, $l_{0}$, se denomina escala interna. A muy pequeña escala, menor que la escala interna, la disipación de energía causada por la fricción evita que la turbulencia se sostenga a sí misma. La escala interna $l_{0}$ puede ser de unos pocos milímetros cerca del suelo a unos pocos centímetros más arriba [104. El rango de tamaños de eddies entre la escala interna y externa se llama rango inercial.

En el análisis de Kolmogorov se asume que los vecinos con un rango inercial son estadísticamente homogéneos e isotrópicos dentro de regiones pequeñas del espacio; es decir, que propiedades como la velocidad y el índice de refracción tienen incrementos estacionarios. Esta es la razón por la que se utilizó la función de estructura en vez de la covarianza. Esto le permitió hacer un análisis dimensional para determinar que la velocidad promedio de los torbellinos turbulentos $v$ debe estar relacionada con la escala de los torbellinos según [ ]

$$
v \propto r^{1 / 3}
$$

Luego, como la función de estructura de la velocidad es el cuadrado de las velocidades, la función de estructura $D_{v}(r)$ debe tener la forma

$$
D_{v}(r)=C_{v}^{2} r^{2 / 3}
$$

donde $C_{v}$ es el parámetro de estructura para la velocidad. En el caso de un flujo laminar, que ocurre a escalas muy pequeñas, la dependencia física es ligeramente diferente, de manera que la función de estructura tiene la forma

$$
D_{v}(r)=C_{v}^{2} l_{0}^{-4 / 3} r^{2}
$$

Para las escalas más grandes de la turbulencia el flujo es altamente anisotrópico. Si el campo de velocidad fuese homogéneo e isotrópico, la función de estructura se acercaría asintóticamente al doble de la varianza de velocidad. 
Este desarrollo basado en la velocidad llevó a un análisis similar de la temperatura potencial $\theta$ (la temperatura potencial está linealmente relacionada con la temperatura ordinaria $T$ ). Los resultados son que $\theta \propto r^{1 / 3}$ de manera que la temperatura potencial tiene una función estructura $D_{\theta}(r)$ que sigue la misma dependencia que la función de estructura de la velocidad según [101,102

$$
D_{\theta}(r)=\left\{\begin{array}{cc}
C_{\theta}^{2} l_{0}^{-4 / 3} r^{2}, & 0 \leq r \ll l_{0} \\
C_{\theta}^{2} r^{2 / 3}, & l_{0} \ll r \ll L_{0}
\end{array}\right.
$$

donde $C_{\theta}^{2}$ es la constante de estructura para $\theta$.

El índice de refracción del aire en un punto $\mathbf{r}$ puede modelarse según

$$
n(\mathbf{r})=\mu(\mathbf{r})+n_{1}(\mathbf{r})
$$

donde $\mu(\mathbf{r}) \simeq 1$ es el valor medio del índice de refracción que varía muy lentamente y $n_{1}(\mathbf{r})$ es la desviación. Escrito de esta forma, $n_{1}(\mathbf{r})$ describe un proceso aleatorio con media cero, que es más sencillo de emplear en un análisis estadístico. En longitudes de onda ópticas, el índice de refracción del aire puede aproximarse como

$$
\begin{aligned}
n(\mathbf{r}) & =1+77,6 \cdot 10^{-6}\left(1+7,52 \cdot 10^{-3} \lambda^{2}\right) \frac{P(\mathbf{r})}{T(\mathbf{r})} \\
& \cong 1+7,99 \cdot 10^{-5} \frac{P(\mathbf{r})}{T(\mathbf{r})} \quad(\lambda=0,5 \mu \mathrm{m})
\end{aligned}
$$

donde $\lambda$ está en $\mu \mathrm{m}, P$ en milibars y $T$ en Kelvin. La variación del índice de refracción 3.10 está dada por

$$
d n=7,99 \cdot 10^{-5}\left(d P-\frac{-d T}{T^{2}}\right)
$$

En este modelo, se considera que cada eddy tiene una presión relativamente uniforme. Teniendo en cuenta la relación lineal entre $\theta$ y $T$ tenemos que

$$
d n=7,99 \cdot 10^{-5} \frac{d \theta}{T^{2}}
$$

Debido a que la variación en el índice de refracción es directamente proporcional a la variación de la temperatura potencial, la función de estructura $D_{n}(r)$ sigue la misma ley de potencias que $D_{\theta}(r)$ :

$$
D_{n}(r)=\left\{\begin{aligned}
C_{n}^{2} l_{0}^{-4 / 3} r^{2}, & 0 \leq r \ll l_{0} \\
C_{n}^{2} r^{2 / 3}, & l_{0} \ll r \ll L_{0}
\end{aligned}\right.
$$

donde $C_{n}^{2}$ es la constante de estructura para el índice de refracción, medida en $\mathrm{m}^{-2 / 3}$. La relación que tiene con la constante de estructura para la temperatura es

$$
C_{n}^{2}=\left[77,6 \cdot 10^{-6}\left(1+7,52 \cdot 10^{-3} \lambda^{2}\right) \frac{P}{T^{2}}\right]^{2} C_{T}^{2}
$$


Los valores atmosféricos típicos para $C_{n}^{2}$ están entre $10^{-17}-10^{-13} \mathrm{~m}^{-2 / 3}$, donde los valores mayores se encuentran cerca de la superficie terrestre y los menores a gran altura.

Con la Ecuación 3.13 es sencillo hacer una descripción de espectro de potencias $\Phi_{n}(\kappa)$ de las fluctuaciones del índice de refracción. Por ejemplo, el espectro de potencias de Kolmogorov (válido sólo para campos aleatorios que son localmente homogéneos e isotrópicos) se calcula como

$$
\begin{aligned}
\Phi_{n}^{K}(\kappa) & =\frac{1}{4 \pi \kappa^{2}} \int_{0}^{\infty} \frac{\sin (\kappa r)}{\kappa r} \frac{d}{d r}\left[r^{2} \frac{d}{d r} D_{n}(r)\right] d r \\
& =0,033 C_{n}^{2} \kappa^{-11 / 3}, \quad \frac{1}{L_{0}} \ll \kappa \ll \frac{1}{l_{0}}
\end{aligned}
$$

donde $\kappa=2 \pi\left(f_{x} \hat{\mathbf{i}}+f_{y} \hat{\mathbf{j}}\right)$ es la frecuencia angular espacial ( $\left.\mathrm{rad} / \mathrm{m}\right)$.

Existen otros modelos más refinados para el espectro de potencias, como los de Tatarskii, von Kármán, el modificado de von Kármán y el de Hill [1]. Estos modelos incluyen factores para tomar en cuenta las escalas interna y externa para ajustarse a las medidas experimentales. Por ejemplo, el de von Kármán está dado por

$$
\Phi_{n}^{v K}(\kappa)=\frac{0,033 C_{n}^{2}}{\left(\kappa^{2}+\kappa_{0}^{2}\right)^{11 / 6}}, \quad 0 \leq \kappa \ll \frac{1}{l_{0}}
$$

mientras que el espectro modificado de von Kármán es

$$
\Phi_{n}^{m v K}(\kappa)=\Phi_{n}^{v K}(\kappa) e^{-\left(\kappa / \kappa_{m}\right)^{2}}=\frac{0,033 C_{n}^{2}}{\left(\kappa^{2}+\kappa_{0}^{2}\right)^{11 / 6}} e^{-\left(\kappa / \kappa_{m}\right)^{2}}, \quad 0 \leq \kappa<\infty
$$

donde $\kappa_{m}=5,92 l_{0}$ y $\kappa_{0}=2 \pi / L_{0}$. El espectro modificado de von Kármán es el modelo más simple que incluye efectos de las escalas interna y externa. Nótese que tomando $l_{0}=0$ y $L_{0}=\infty$ la Ecuación 3.18 se convierte en la Ecuación 3.16. En la Figura 3.1 se muestran algunos modelos de espectro de potencias.

Cuando se trata con la propagación de ondas electromagnéticas por la atmósfera, el índice de refracción se puede considerar independiente del tiempo cuando este tiempo tiene una escala corta $(100 \mu \mathrm{s})$. Debido al valor de la velocidad de la luz, el tiempo que le toma a ésta atravesar inclusive un torbellino muy grande es muchísimo más corto que el tiempo que se tarda en que las propiedades del torbellino cambien. Consecuentemente, las propiedades temporales se ponen en los modelos de turbulencia a través de la hipótesis de la turbulencia congelada de Taylor. La hipótesis es que las variaciones temporales en las cantidades meteorológicas en un punto del espacio son causadas por la advección de estas cantidades por el promedio de velocidad del viento, no por cambios en las cantidades mismas [1]. Consecuentemente los torbellinos turbulentos se tratan como congelados en el espacio y desplazados a lo largo del eje óptico por medio de la velocidad del aire $\mathbf{v}$. Luego, con conocimiento del promedio de la velocidad del viento se convierten las estadísticas espaciales en 


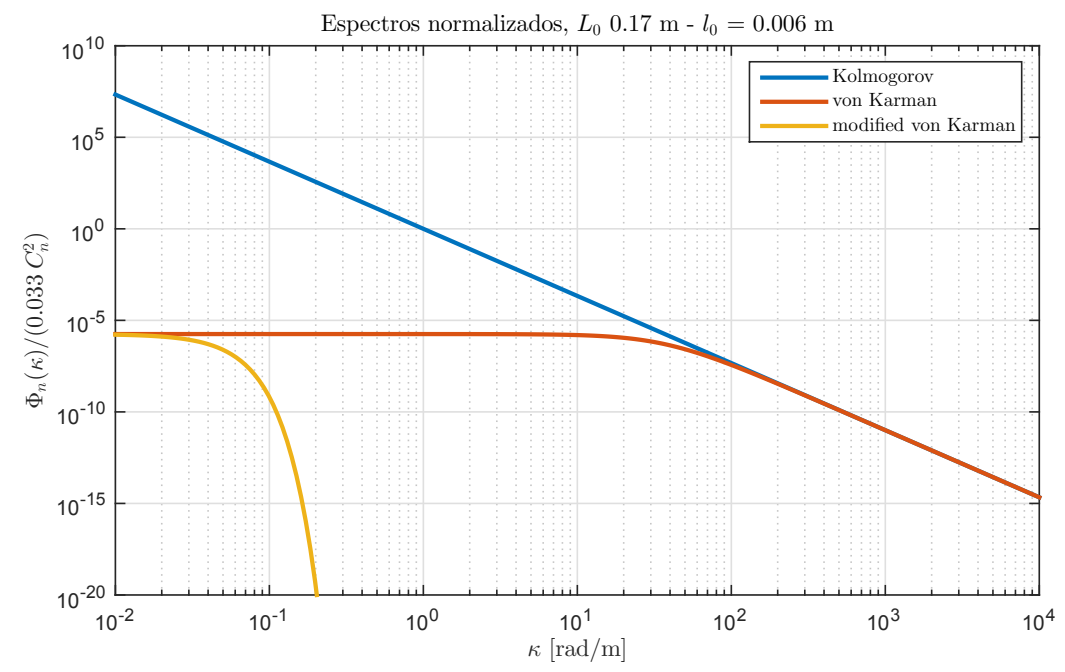

Figura 3.1: Modelos usuales para el espectro de potencias.

temporales. Por ejemplo, la dependencia temporal de la fase óptica $\phi(x, y)$ está dada por fórmula

$$
\phi(x, y, t)=\phi\left(x-v_{x} t, y-v_{y} t, 0\right)
$$

donde $v_{x} \mathrm{y} v_{y}$ son las componentes cartesianas del promedio de velocidad del aire, y $t$ es el tiempo.

\section{Propagación óptica a través de la turbulencia}

Los fenómenos electromagnéticos están gobernados por la ecuaciones de Maxwell tanto para el vacío como para la atmósfera turbulenta. La atmósfera puede ser considerada como un medio isotropico sin fuentes y no magnético. Para la propagación de ondas ópticas, buscamos soluciones de una onda viajera con una dependencia armónica del tiempo exp $(-i 2 \pi v t)$, donde $v=c / \lambda$ es la frecuencia de la luz. Luego, la ecuación de onda para el campo eléctrico puede escribirse como 15

$$
\nabla^{2} \mathbf{E}(\mathbf{r})+k^{2} n^{2}(\mathbf{r}) \mathbf{E}(\mathbf{r})+2 \nabla[\mathbf{E}(\mathbf{r}) \cdot \nabla \ln (n(\mathbf{r}))]=\mathbf{0}
$$

dónde $\mathbf{E}$ es el vector de campo eléctrico y $k$ es el número de onda óptica en el vacío. El último término de la Ecuación 3.20 se refiere al cambio en la polarización a medida que la onda se propaga. Se la puede despreciar para $\lambda<l_{0}$, y consecuentemente la fórmula simplifica a

$$
\left[\nabla^{2}+k^{2} n^{2}(\mathbf{r})\right] \mathbf{E}(\mathbf{r})=\mathbf{0}
$$


El campo de inducción magnética $\mathbf{B}$ también obedece esta ecuación así que podemos escribir solamente una ecuación para cualquiera de las seis componentes en total de los dos campos:

$$
\left[\nabla^{2}+k^{2} n^{2}(\mathbf{r})\right] U(\mathbf{r})=0
$$

En esta fórmula el índice de refracción explícitamente es dependiente de la posición. Al resolver esta ecuación asumimos que $\left|n_{1}(\mathbf{r})\right| \ll 1$. Esto es lo que se sume para fluctuaciones débiles a cuantificar más tarde. Con esta aproximación, el factor $n^{2}(\mathbf{r})$ en la Ecuación 3.22 puede ser aproximado como

$$
n^{2}(\mathbf{r}) \cong 1+2 n_{1}(\mathbf{r})
$$

Luego, la ecuación de onda se convierte en

$$
\left\{\nabla^{2}+k^{2}\left[1+2 n_{1}(\mathbf{r})\right]\right\} U(\mathbf{r})=0
$$

Cuando el medio tiene un índice de refracción constante, la Ecuación 3.22 puede resolverse con métodos de óptica de Fourier, que involucran el uso de funciones de Green. Sin embargo, cuando el medio es homogéneo pero de manera aleatoria, como lo es en el caso de la atmósfera, se utilizan métodos perturbativos con las funciones de Green para obtener soluciones. En el método de Rytov, el campo óptico se escribe como

$$
U(\mathbf{r})=U_{0}(\mathbf{r}) \exp [\psi(\mathbf{r})]
$$

Donde $U_{0}(\mathbf{r})$ es la solución en el vacío $\left(n_{1}=0\right)$ de la Ecuación 3.24 y $\psi(\mathbf{r})$ es la perturbación en la fase compleja. La forma

$$
\psi(\mathbf{r})=\psi_{1}(\mathbf{r})+\psi_{2}(\mathbf{r})+\ldots
$$

es empleada para tomar la sucesivas perturbaciones. Estas perturbaciones sucesivas son utilizadas para calcular diversos momentos estadísticos de $\psi$, los cuales a su vez proveen los momentos estadísticos del campo. Más aún, es útil aislar la amplitud y la fase escribiendo

$$
\psi=\chi+i \phi
$$

donde $\chi$ es la amplitud logarítmica de la perturbación y $\phi$ es la perturbación de la fase. El método de Rytov puede emplearse con un dado modelo de espectro de potencia para calcular analíticamente los momentos del campo para fuentes simples como haces gaussianos, ondas esféricas y ondas planas [1, 103, 105, 4]

\section{Parámetros ópticos de la atmósfera}

El método de Rytov permite calcular los siguientes momentos: 
- el valor medio del campo óptico:

$$
\langle U(\mathbf{r})\rangle=U_{0}(\mathbf{r})\langle\exp [\psi(\mathbf{r})]\rangle
$$

- la función de coherencia mutua

$$
\begin{aligned}
\Gamma\left(\mathbf{r}, \mathbf{r}^{\prime}, z\right) & =\left\langle U(\mathbf{r}) U^{*}\left(\mathbf{r}^{\prime}\right)\right\rangle \\
& =U_{0}(\mathbf{r}) U_{0}^{*}\left(\mathbf{r}^{\prime}\right)\left\langle\exp \left[\psi(\mathbf{r}) \psi^{*}\left(\mathbf{r}^{\prime}\right)\right]\right\rangle
\end{aligned}
$$

De la función de coherencia mutua, se pueden computar varias propiedades útiles, incluyendo:

- el módulo del factor de coherencia compleja

$$
\mu\left(\mathbf{r}, \mathbf{r}^{\prime}, z\right)=\frac{\left|\Gamma\left(\mathbf{r}, \mathbf{r}^{\prime}, z\right)\right|}{\left[\Gamma(\mathbf{r}, \mathbf{r}, z) \Gamma\left(\mathbf{r}^{\prime}, \mathbf{r}^{\prime}, z\right)\right]^{1 / 2}}
$$

- la función de estructura de la onda

$$
\begin{aligned}
D\left(\mathbf{r}, \mathbf{r}^{\prime}, z\right) & =-2 \ln \left[\mu\left(\mathbf{r}, \mathbf{r}^{\prime}, z\right)\right] \\
& =D_{\chi}\left(\mathbf{r}, \mathbf{r}^{\prime}, z\right)+D_{\phi}\left(\mathbf{r}, \mathbf{r}^{\prime}, z\right)
\end{aligned}
$$

donde $D_{\chi}$ es la función de estructura de la amplitud logarítmica y $D_{\phi}$ es la función de estructura de la fase.

- la densidad espectral de fase (análogamente a 3.15):

$$
\Phi_{n}(\kappa)=\frac{1}{4 \pi \kappa^{2}} \int_{0}^{\infty} \frac{\sin (\kappa r)}{\kappa r} \frac{d}{d r}\left[r^{2} \frac{d}{d r} D_{\phi}(r)\right] d r
$$

- la función de transferencia modulada para el camino turbulento

$$
\mathcal{H}(f)=\exp \left[-\frac{1}{2} D\left(\lambda f_{l} f\right)\right]
$$

donde $f_{l}$ es la distancia focal.

Discutiremos cada una de estas propiedades en breve. Algunas de estas propiedades teóricas se usan para validar simulaciones de óptica turbulenta.

La constante de estructura $C_{n}^{2}$ es una medida de la intensidad del local de la turbulencia. Asimismo, $C_{n}^{2}$ es una función de la distancia de propagación $\Delta z$, de manera que algunas veces las magnitudes caracterizadas con un solo número puede ser más útiles para describir los efectos ópticos. Consecuentemente, $C_{n}^{2}(z)$ se utiliza comúnmente para computar parámetros como el diámetro de coherencia $r_{0}$ y el ángulo y isoplanático $\theta_{0}$. De hecho, ambas magnitudes son integrales de $C_{n}^{2}(z)$.

En el caso de un campo óptico isótropo y homogéneo, el módulo del factor de coherencia puede calcularse como

$$
\mu\left(\mathbf{r}, \mathbf{r}^{\prime}, z\right)=\mu(\mathbf{r}, \mathbf{r}+\Delta \mathbf{r}, z)=\mu(\Delta \mathbf{r}, z)=\mu(|\Delta \mathbf{r}|, z)
$$

La forma exacta del factor de coherencia depende tanto del tipo de fuente óptica así cómo de la distribución de espectro de potencias para el índice de refracción. 
Ejemplo: onda plana utilizando espectro de Kolmogorov Como ejemplo sencillo, cuando la fuente es una onda plana,

$$
\mu(|\Delta \mathbf{r}|, z)=\exp \left\{-4 \pi^{2} k^{2} \int_{0}^{\Delta z} \int_{0}^{\infty} \Phi_{n}(\kappa, z)\left[1-J_{0}(\kappa|\Delta \mathbf{r}|)\right] \kappa d \kappa d z\right\}
$$

y la única dependencia con el camino de propagación es $C_{n}^{2}(z)$. Cuando se utiliza el espectro de Kolmogorov, el resultado del factor de coherencia es

$$
\mu^{K}(|\Delta \mathbf{r}|, z)=\exp \left\{-1,46 k^{2}|\Delta \mathbf{r}|^{5 / 3} \int_{0}^{\Delta z} C_{n}^{2}(z) d z\right\}
$$

El radio de coherencia espacial $\rho_{0}$ de una onda óptica está definido como el punto $e^{-1}$ de $\mu(|\Delta \mathbf{r}|, z)$. Con esto en mente, y por 3.31 podemos escribir

$$
D\left(\rho_{0}, z\right)=2 \operatorname{rad}^{2}
$$

como una definición equivalente para $\rho_{0}$. Con cualquiera de las dos, el radio de coherencia para una onda plana en una turbulencia Kolmogorov es

$$
\rho_{0}=\left[1,46 k^{2} \int_{0}^{\Delta z} C_{n}^{2}(z) d z\right]^{-3 / 5}
$$

por lo que

$$
D\left(r_{0}, z\right)=6,88 \operatorname{rad}^{2}
$$

mientras que el diámetro de coherencia mutua $r_{0}$ (el parámetro o radio de Fried [4106]) para este caso (onda plana) es 11

$$
r_{0}=2,1 \rho_{0}
$$

Para una fuente de onda plana, el diámetro de coherencia , $r_{0, p w}$ se computa como 4]

$$
r_{0, p w}=\left[0,423 k^{2} \int_{0}^{\Delta z} C_{n}^{2}(z) d z\right]^{-3 / 5}
$$

donde $z=0$ es el origen y el punto de observación es $z=\Delta z$. Cuando se trata de una onda esférica, el resultado es

$$
r_{0, s w}=\left[0,423 k^{2} \int_{0}^{\Delta z} C_{n}^{2}(z)\left(\frac{z}{\Delta z}\right)^{5 / 3} d z\right]^{-3 / 5}
$$

\footnotetext{
${ }^{1}$ Este parámetro fue introducido por Fried de manera distinta a $\rho_{0}$. Analizó la resolución de un telescopio como el volumen debajo de una función de transferencia modulada. Cuando se lo escribe como una función del diámetro de un telescopio, es el corte en la curva el que se identifica como $r_{0}$.
} 
Los valores típicos de $r_{0}$ están entre los 5-10 $\mathrm{cm}$ para longitudes de onde ópticas y tomando una visión vertical.

Con estas definiiones y tomando $r=|\Delta \mathbf{r}|$, la función de estructura para un frente de onda plano con una turbulencia Kolmogorov $\left(l_{0}=0\right.$ y $\left.L_{0}=\infty\right)$ puede escribirse como [1]

$$
D^{K}(r)=6,88\left(\frac{r}{r_{0}}\right)^{5 / 3}
$$

En el caso del espectro de von Kármán $\left(l_{0}=0\right.$ y $\left.L_{0}<\infty\right)$ el resultado es

$$
D^{v K}(r)=6,16 r_{0}^{-5 / 3}\left[\frac{3}{5} \kappa_{0}^{-5 / 3}-\frac{\left(2 r / \kappa_{0}\right)^{5 / 6}}{\Gamma(11 / 6)} K_{5 / 6}\left(\kappa_{0} r\right)\right]
$$

donde $K_{\alpha}(r)$ es una función de Bessel modificada.

Cuando ambas escalas son relevantes, el resultado para el espcetro de von Kármán modificado es

$$
\begin{aligned}
D^{m v K}(r)= & 3,08 r_{0}^{-5 / 3}\left\{\Gamma\left(-\frac{5}{6}\right) \kappa_{m}^{-5 / 3} \times\right. \\
& {\left.\left[1-{ }_{1} F_{1}\left(-\frac{5}{6} ; 1 ;-\frac{\kappa_{m}^{2} r^{2}}{4}\right)\right]-\frac{9}{5} \kappa_{0}^{1 / 3} r^{2}\right\} }
\end{aligned}
$$

donde ${ }_{1} F_{1}(a: c: z)$ es una función hipergeométrica confluentes de la primera especie. Andrews en 107 presentó una aproximación para la función hipergeométrica que permite aproximar con un $2 \%$ de error la Ecuación 3.45:

$$
D^{m v K}(r) \simeq 7,75 r_{0}^{-5 / 3} l_{0}^{-1 / 3} r^{2}\left[\frac{1}{\left(1+2,03\left(\frac{r}{l_{0}}\right)^{2}\right)^{1 / 6}}-0,72\left(\kappa_{0} l_{0}\right)^{1 / 3}\right]
$$

Con las distintas formas de la función de estructura de onda, la Ecuación 3.33 nos permite calcular las distribuciones de espectro de potencias. En términos prácticos, hay otra relación más sencilla que noas permite calcular una distribución de espectro de potencias. Para una onda plana en turbulencia débil, la distribución de espectro de potencias para la fase es

$$
\Phi_{\phi}(\kappa)=2 \pi^{2} k^{2} \Delta z \Phi_{n}(\kappa)
$$

En las otras distribuciones los resultados son

$$
\begin{gathered}
\Phi_{\phi}^{K}(\kappa)=0,49 r_{0}^{-5 / 3} \mathcal{K}^{-11 / 3} \\
\Phi_{\phi}^{v K}(\kappa)=\frac{0,49 r_{0}^{-5 / 3}}{\left(\kappa^{2}+\kappa_{0}^{2}\right)^{11 / 6}}
\end{gathered}
$$




$$
\Phi_{\phi}^{m v K}(\kappa)=\Phi_{\phi}^{v K}(\kappa) \exp \left\{-\left(\kappa / \kappa_{m}\right)^{2}\right\}=\frac{0,49 r_{0}^{-5 / 3}}{\left(\kappa^{2}+\kappa_{0}^{2}\right)^{11 / 6}} \exp \left\{-\left(\kappa / \kappa_{m}\right)^{2}\right\}
$$

Utilizaremos luego estas distribuciones de espectro de potencias para generar realizaciones aleatorias de filtros de fase turbulentos. El método emplea las transformadas de Fourier con la frecuencia en términos de ciclos/m en vez de la más tradicional frecuencia angular en $\mathrm{rad} / \mathrm{m}$. A tales fines, también es útil escribir la distribución de espectro de potencias en términos de $f$ :

$$
\Phi_{\phi}^{K}(f)=0,023 r_{0}^{-5 / 3} f^{-11 / 3}
$$

Cuando Fried introdujo $r_{0}$, lo hizo para calcular la función de transferencia de modulación de imágenes tomadas a través de la atmósfera [106. Los resultados se pueden resumir como

$$
\begin{aligned}
\mathcal{H}(f) & =\exp \left\{-3,44\left(\frac{\lambda f_{l} f}{r_{0}}\right)^{5 / 3}\left[1-\alpha\left(\frac{\lambda f_{l} f}{D}\right)^{1 / 3}\right]\right\} \\
& =\exp \left\{-3,44\left(\frac{f}{2 f_{0}} \frac{D}{r_{0}}\right)^{5 / 3}\left[1-\alpha\left(\frac{f}{2 f_{0}}\right)^{1 / 3}\right]\right\}
\end{aligned}
$$

donde $f_{0}$ es la frecuencia de corte limitada por difracción y

$$
\alpha= \begin{cases}0 & \text { imágenes de larga exposición } \\ 1 / 2 & \text { imágenes de corta exposición con centelleo } \\ 1 & \text { imágenes de corta duración sin centelleo }\end{cases}
$$

La distinción principal entre exposiciones cortas y exposiciones largas está en la corrección del tilt atmosférico. Se asume que en las imágenes de larga exposición el tiempo de captura es lo suficientemente largo como para qué el centro bailotee aleatoriamente muchas veces en el plano de la imagen. Cuando se hace un promedio de muchas imágenes de corta exposición las imágenes primero deben centrarse, removiendo así el efecto del tilt. Debe notarse que la atmósfera tiene una función de transferencia dada por la Ecuación 3.53 mientras que el sistema de imagen tiene su propia función de transferencia óptica. La función de transferencia óptica de un sistema compuesto es el producto de las dos funciones de transferencia óptica. Como ejemplo, en la Figura 3.2 se muestra la función de transferencia de modulación óptica para una abertura circular con una relación $D / r_{0}=4$.

La función de transferencia de modulacion en promedio puede ser usada para determinar el radio de Strehl de un sistema. El trabajo de Fried proporciona una manera de incluir los efectos de la turbulencia al calcular el radio de Strehl. Usando 3.53, el radio de Strehl para una abertura circular en turbulen- 


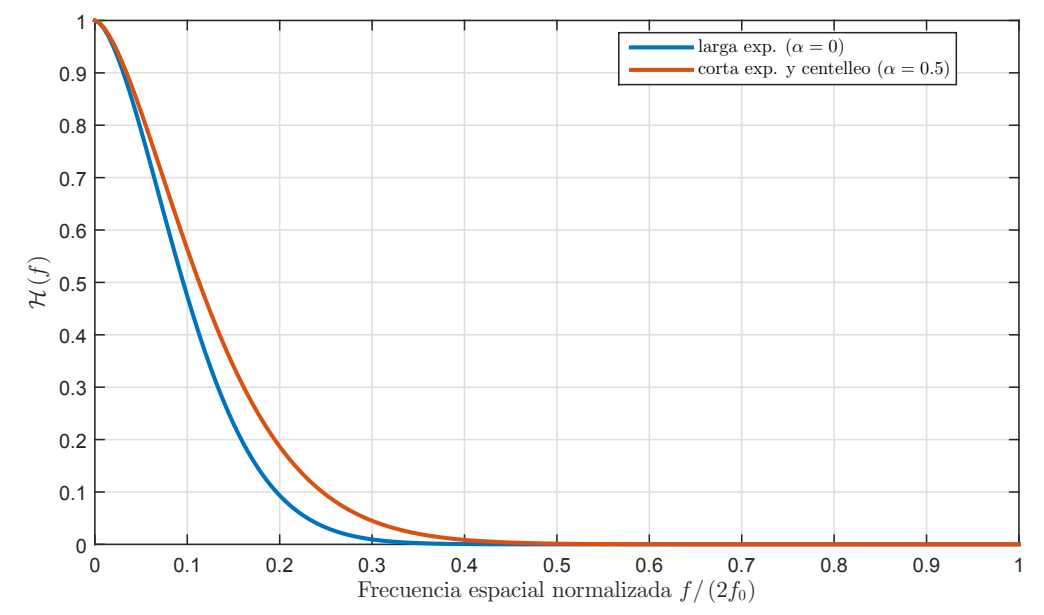

Figura 3.2: Funciones de transferencia de modulación para $D / r_{0}=4$.

cia es

$$
\begin{aligned}
\mathcal{S}= & \frac{16}{\pi} \int_{0}^{1} f^{\prime}\left(\cos ^{-1} f^{\prime}-f^{\prime} \sqrt{1-f^{\prime 2}}\right) \\
& \times \exp \left\{-3,44\left(f^{\prime} \frac{D}{r_{0}}\right)^{5 / 3}\left[1-\alpha\left(f^{\prime}\right)^{1 / 3}\right]\right\}
\end{aligned}
$$

donde $f^{\prime}=f /\left(2 f_{0}\right)$ es la frecuencia espacial normalizada.

Si las características ópticas de un sistema (función de transferencia óptica y point-spread function) son invariantes de translación, el sistema tiene una propiedad llamada anisoplanatismo. Esto es válido para cualquier sistema óptico, incluida la atmósfera como es este caso. Para medir la severidad del anisoplanatismo angular, podemos determinar la función de estructura angular de la fase $D_{\phi}(\theta)$ definida por

$$
D_{\phi}(\theta)=\left\langle|\phi(\theta)-\phi(\theta+\Delta \theta)|^{2}\right\rangle
$$

donde $\theta$ es la coordenada angular en el plano objeto y $\Delta \theta$ es la deparación angular entre dos puntos en el plano objeto. El ángulo anisoplanático $\theta_{0}$ está definido tal que es el ángulo en el cual

$$
D_{\phi}\left(\theta_{0}\right)=1 \operatorname{rad}^{2}
$$

De manera similar a como se llegó a 3.42, encontramos que

$$
\theta_{0}=\left[2,91 k^{2} \Delta z^{2 / 3} \int_{0}^{\Delta z} C_{n}^{2}(z)\left(1-\frac{z}{\Delta z}\right) d z\right]^{-3 / 5}
$$


Esto puede interpretarse como el mayor ángulo en el plano sobre el cual el camino óptico a través de la turbulencia no difiere significativamente del camino por el eje óptico a través de la turbulencia. Los valores de $\theta_{0}$ usualmente son de 5-10 $\mu \mathrm{rad}$ en longitudes de onda ópticas y en dirección vertical.

\section{Modelo de capas atmosféricas}

Es posible derivar los efectos de la turbulencia atmosférica en la propagación óptica si asumimos un modelo estadístico simple. Sin embargo, cuando se desea considerar situaciones más complejas como por ejemplo utilizar sistemas de óptica adaptativa, generalmente sucede que las estadísticas de los campos ópticos corregidos ya no pueden ser calculadas de forma cerrada. Para simplificar el problema matemático, una técnica común es tratar a la turbulencia como compuesta por un número finito de capas discretas. Este enfoque es común para cálculos analíticos, simulaciones de computadora, y la emulación de la turbulencia en un laboratorio [1, 96, 97. Un modelo por capas es útil si el espectro del índice de refracción y las propiedades en centelleo encajan con las del medio extendido correspondiente 108,109.

Cada capa que es un filtro de fase de grosor unitario representa un volumen turbulento de mucha mayor extensión. Un filtro de fase se considera fino si su grosor es mucho menor que la distancia de propagación a través del filtro [1]. Un filtro de fase es una realización de una perturbación de fase atmosférica y se la usa en la Ecuación (3.2) para calcular la realización del operador de refracción $\mathcal{T}\left[z_{i}, z_{i+1}\right]$. Así es como los filtros de fase son incorporados en el método de propagación por haz dividido para simular la propagación atmosférica.

\section{Teoría}

Para representar teóricamente los filtros de fase atmosféricos, simplemente describimos el perfil de la turbulencia en términos de la constante de estructura efectiva $C_{n_{i}}^{2}$, localizado en coordenada de propagación $z_{i}$, y con un espesor $\Delta z_{i}$ para el $i$-ésimo filtro de fase extendido para la turbulencia. Los valores de $C_{n}^{2}$ se eligen de manera tal que que los menores momentos del model contínuo se ajusten con el modelo de capas 110, 109:

$$
\int_{0}^{\Delta z} C_{n}^{2}\left(z^{\prime}\right)\left(z^{\prime}\right)^{m} d z^{\prime}=\sum_{i=1}^{n} C_{n_{i}}^{2} z_{i}^{m} \Delta z_{i}
$$

donde $n$ es el número de filtros de fase usados, y $0 \leq m \leq 7$. De esta forma, parámetros como $r_{0}, \theta_{0}$, etc. del modelo por capas se ajustan a los de la referencia que se está modelando. Los parámetros atmosféricos para el modelo de turbulencia por capas se encuentran con las versiones de sumas discretas de 3.41, 3.42:

$$
r_{0, p w}=\left[0,423 k^{2} \sum_{i} C_{n_{i}}^{2} \Delta z_{i}\right]^{-3 / 5}
$$




$$
r_{0, s w}=\left[0,423 k^{2} \sum_{i} C_{n_{i}}^{2}\left(\frac{z_{i}}{\Delta z}\right)^{5 / 3} \Delta z_{i}\right]^{-3 / 5}
$$

Agrupando términos en 3.60 , la i-ésima capa tiene un diámetro de coherencia efectivo $r_{0_{i}}$ dado por 109:

$$
r_{0_{i}}=\left[0,423 k^{2} C_{n_{i}}^{2} \Delta z_{i}\right]^{-3 / 5}
$$

Nótese que esto es el $r_{0}$ de una onda plana, y es válido sólo cuando la capa es muy fina. Los valores de $r_{0}$ usualmente se usan para caracterizar la intensidad de la turbulencia en una capa.

\subsubsection{Filtros de fase Monte-Carlo}

La variación en el índice de refracción de la atmósfera es un proceso aleatorio así como no es el camino óptico a través de ella. Consecuentemente los modelos de turbulencia proveen promedios estadísticos, como la función de estructura y el espectro de potencias de las variaciones del índice de refraccion. El problema al crear filtros de fase atmosféricos consiste en generar realizaciones individuales de un proceso aleatorio. Esto significa que sea crean filtros de fase transformando números aleatorios generados por computadora dispuestos en arreglos bidimensionales de valores de fase sobre una red de puntos muestrales que tienen la misma estadística que las variaciones de fase inducidas por la turbulencia.

Generalmente, la fase es escrita como una combinación lineal de funciones de base. Los conjuntos de base generalmente utilizados para este propósito han sido los polinomios de Zernike y las series de Fourier. Ambos conjuntos tienen sus ventajas y desventajas. El método más utilizado para la generación de filtros de fase está basado en transformadas de Fourier y fue desarrollado por McGlamery [111].

Asumiendo que la fase inducida por la turbulencia $\phi(x, y)$ es una función con transformada de Fourier, podemos entonces escribir su representación integral de Fourier como:

$$
\phi(x, y)=\int_{-\infty}^{\infty} \int_{-\infty}^{\infty} \Psi\left(f_{x}, f_{y}\right) e^{i 2 \pi\left(f_{x} x+f_{y} y\right)} d f_{x} d f_{y}
$$

donde $\Psi\left(f_{x}, f_{y}\right)$ es la representación de la fase en el dominio de frecuencias. Por supuesto, $\phi(x, y)$ es una realización de un proceso aleatorio con una densidad espectral dada por $\Phi_{\phi}(f)$ (o equivalentemente $\Phi_{\phi}(\kappa)$ ) como se discutió en la subsección 3.1.2 en la página $64 \mathrm{Al}$ tratar a la fase como una señal en dos dimensiones, la potencia total $P_{t o t}$ en la fase se puede escribir de dos maneras usando la definición de densidad de potencia espectral y el teorema de Parseval:

$$
P_{\text {tot }}=\int_{-\infty}^{\infty} \int_{-\infty}^{\infty}|\phi(x, y)|^{2} d x d y=\int_{-\infty}^{\infty} \int_{-\infty}^{\infty} \Phi_{\phi}\left(f_{x}, f_{y}\right) d f_{x} d f_{y}
$$


Para generar filtros de fase en una red finita, escribimos la fase óptica $\phi(x, y)$ como serie de Fourier [9]:

$$
\phi(x, y)=\sum_{n=-\infty}^{\infty} \sum_{m=-\infty}^{\infty} c_{n, m} \exp \left\{i 2 \pi\left(f_{x_{n}} x+f_{y_{m}} y\right)\right\}
$$

donde $f_{x_{n}}$ y $f_{y_{m}}$ son las frecuencias espaciales discretas en cada dirección, y los $c_{n, m}$ son los coeficientes de la serie de Fourier. Debido a que las variaciones de fase a través de la atmósfera son debidas a muchas inhomogeneidades aleatorias a lo largo del camino óptico, usamos el teorema central del límite para determinar que los coeficientes $c_{n, m}$ tienen una distribución gaussiana. Nótese que, en general, $\operatorname{los} c_{n, m}$ son valores complejos; las partes real e imaginaria tienen media cero e iguales varianzas, mientras que sus covarianzas cruzadas son cero. Consecuentemente siguen una estadística gaussiana circular compleja con media cero y varianza dada por 98, 9]:

$$
\left\langle\left|c_{n, m}\right|^{2}\right\rangle=\Phi_{\phi}\left(f_{x_{n}}, f_{y_{m}}\right) \Delta f_{x_{n}} \Delta f_{y_{m}}
$$

Al usar una transformada rápida de Fourier, las frecuencias deben estar linealmente espaciadas en una red cartesiana. Si los tamaños de red para cada eje son $L_{x}$ y $L_{y}$, los rangos de frecuencias espaciales son $\Delta f_{x_{n}}=1 / L_{x}$ y $\Delta f_{y_{m}}=$ $1 / L_{y}$ de manera que 3.66 queda como

$$
\left\langle\left|c_{n, m}\right|^{2}\right\rangle=\frac{1}{L_{x} L_{y}} \Phi_{\phi}\left(f_{x_{n}}, f_{y_{m}}\right)
$$

¿Cómo se producen las realizaciones de coeficientes de Fourier? En general los generadores de números aleatorios producen números pseudoaleatorios con media cero y varianza unitaria y deben ser transformados para nuestros fines. Si $x$ es una variable aleatoria con distribución gaussiana con media $\mu \mathrm{y}$ varianza $\sigma^{2}$, entonces si definimos $z=(x-\mu) / \sigma$ tenemos una variable aleatoria con media cero y varianza unitaria.

Lamentablemente, el método de la transformada de Fourier no produce filtros de fase apropiados. Para entender esto, nótese que en la figura 3.1 en la página 63 dada por la Ecuación 3.50 gran parte de la potencia se encuentra en las frecuencias espaciales más bajas. De hecho, se ha documentado extensamente que en general no es posible hacer un muestreo espacial del reticulado de frecuencias espaciales lo suficientemente bajo como para representar adecuadamente los modos más bajos como el tilt. La diferencia es evidente en la Figura 3.4 donde generamos filtros de fase para un ejemplo de simulación de propagación atmosférica. Para esta figura, se generaron 40 filtros de fase turbulenta utilizando el método de transformada de Fourier en el modelo de Kolmogorov $\left(l_{0}=0, L_{0}=\infty\right.$, un filtro de fase cuadrado de $2 \mathrm{~m}$ de lado, $r_{0}=0,1 \mathrm{~m}$ y 256 puntos por lado de muestreo). Luego, la función de estructura para cada filtro fue calculada y los resultados promediados. Representamos la función de estructura promedio para $|\Delta \mathbf{r}| / r_{0}$ r entre 0 y 10. 

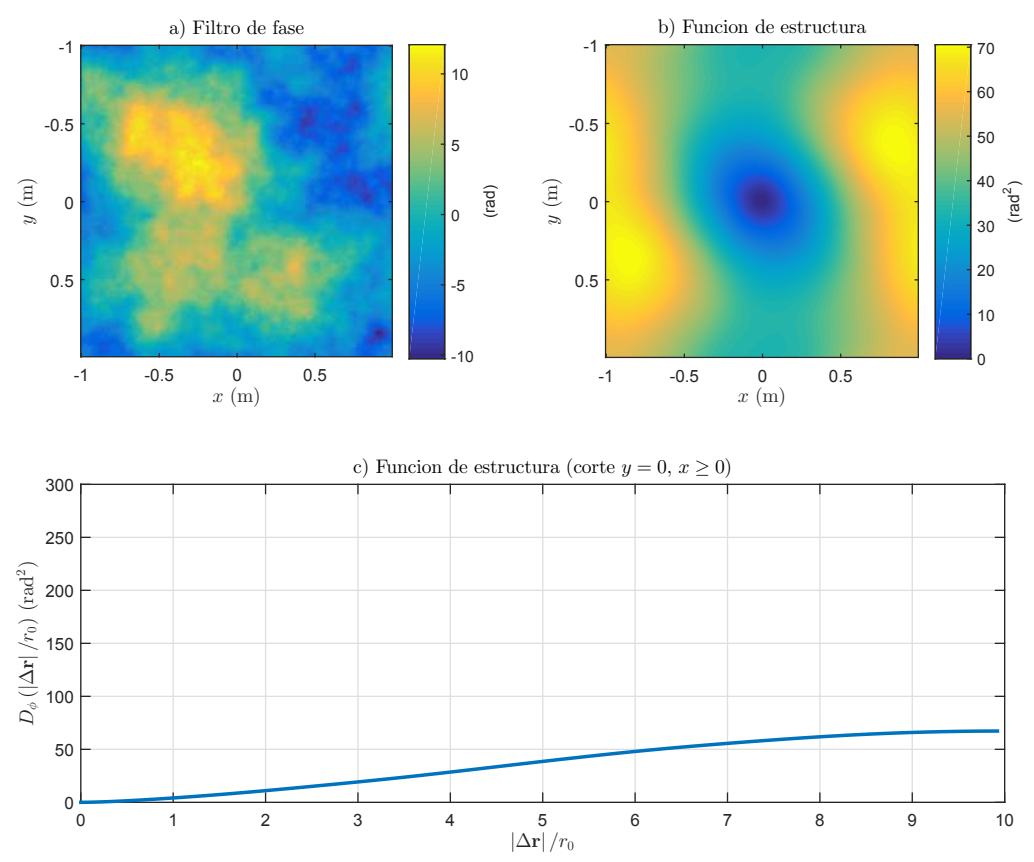

Figura 3.3: Método basado en transformada de Fourier para generación de filtros de fase para el modelo de Kolmogorov $\left(l_{0}=0, L_{0}=\infty\right.$, un filtro de fase cuadrado de $2 \mathrm{~m}$ de lado, $r_{0}=0,1 \mathrm{~m}$ y 256 puntos por lado de muestreo). a) Filtro de fase, b) función de estructura, c) corte de la función de estructura en $y=0, x \geq 0$. 


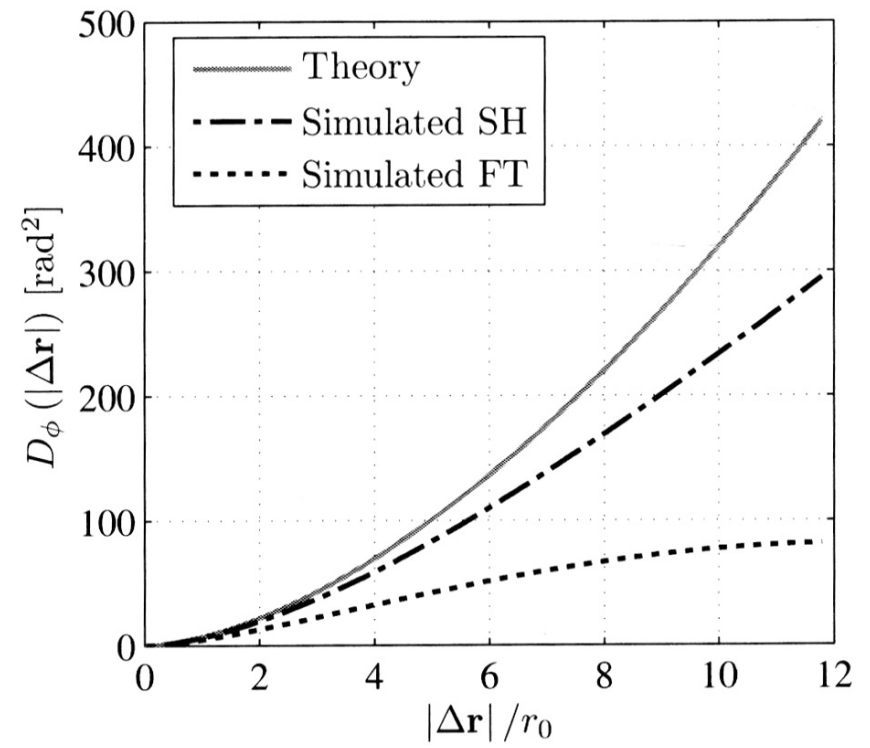

Figura 3.4: Función de estructura promedio de filtros de fase para el modelo de Kolmogorov $\left(l_{0}=0, L_{0}=\infty\right.$, un filtro de fase cuadrado de $2 \mathrm{~m}$ de lado, $r_{0}=0,1 \mathrm{~m}$ y 256 puntos por lado de muestreo). Valores teóricos comparados con los calculados por el método de transformada de Fourier y por el método subarmónico (Figura de [3). 
Como solución a esto describimos el método empleado por Lane [112, del que Frehlich mostró que produce buenos resultados como simulación de filtros de fase para turbulencia [113]. La técnica comienza generando un filtro de fase por transformada de Fourier como ya se ha explicado antes. Luego se genera un filtro de fase de baja frecuencia. Este filtro $\phi_{L F}(x, y)$ es la suma de $N_{p}$ filtros diferentes según

$$
\phi_{L F}(x, y)=\sum_{p=1}^{N_{p}} \sum_{n=-1}^{1} \sum_{m=-1}^{1} c_{n, m} \exp \left\{i 2 \pi\left(f_{x_{n}} x+f_{y_{m}} y\right)\right\}
$$

dpnde las sumas en $n$ y $m$ son sobre frecuencias discretas y cada valor del índice $p$ corresponde a una grilla distinta y se suman $N_{p}$ grillas distintas. En la implementación utilizada, sólo una red de $3 \times 3$ frecuencias se usa para cada valor de $p, \mathrm{y} N_{p}=3$. El espaciado de la grilla para cada valor de $p$ es $\Delta f_{p}=$ $1 /\left(3^{p} L\right)$. De esta forma, las redes en frecuencia tienen un espaciado que es un subarmónico del espaciado del filtro por transformada de Fourier. En la figura 3.5 en la página siguiente mostramos el resultado de este tipo de método.

\subsubsection{Restricciones para el muestreo}

A medida que la luz se propaga por la atmósfera turbulenta de dispersa por dos efectos principales: el tilt y las aberraciones de mayor orden. Las aberraciones de mayor orden hacen que el haz se expanda más allá de la dispersión debida puramente a la difracción. El tild hace que el haz bailotee alrededor del eje óptico de una manera aleatoria. A lo largo del tiempo ( $\gtrsim 1 \mathrm{~ms})$, este bailoteo aleatorio causa que energía del frente se desparrame sobre todo el plano de observación. La dispersión debida a las aberraciones de mayor grado puede ser vista en una exposición muy corta, mientras que la debida al tilt sólo puede verse en exposiciones largas.

\subsection{Aspectos temporales}

La técnica original de simulaciones de propagación atmosférica con filtros de fase propuesta por McGlamery en 1967 [111 ha incorporado con el tiempo diversas modificaciones para dar cuenta de más detalles de las características atmosféricas [3]. Ya en [111] se reconocía el carácter fractal de los filtros de fase generados. Sin embargo, no existe un consenso generalizado para incorporar la variable temporal.

El método más elemental para generar dinámicas temporales es generar un conjunto de filtros de fase al azar (respetando los parámetros de la turbulencia), uno por cada fotograma a simular [114. Otro método consiste en incorporar una dinámica temporal al filtro de fase. Jakobson [115] genera un filtro de fase más grande que la apertura de interés y lo mueve para simular el viento que genera la turbulencia frente a la pupila. La desventaja de este método es que el filtro de fase debe ser muy grande y sólo puede moverse en múltiplos enteros 

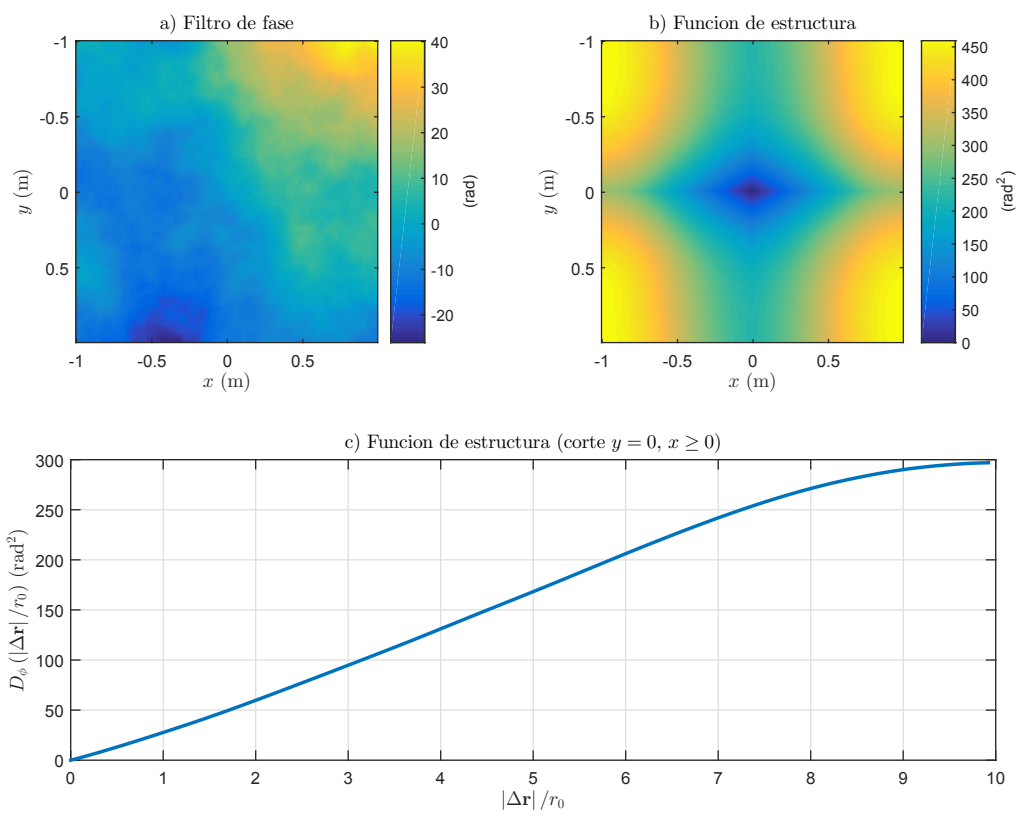

Figura 3.5: Método subarmónico para generación de filtros de fase para el modelo de Kolmogorov $\left(l_{0}=0, L_{0}=\infty\right.$, un filtro de fase cuadrado de $2 \mathrm{~m}$ de lado, $r_{0}=0,1 \mathrm{~m}$ y 256 puntos por lado de muestreo). a) Filtro de fase, $\mathrm{b}$ ) función de estructura, c) corte de la función de estructura en $y=0, x \geq 0$. 
del cuadriculado. Otra técnica consiste en calcular la matriz de correlación de filtros de fase temporal y angularmente separadas para luego usar la raíz cuadrada de la matriz de correlación [108, 116]. Sin embargo, la dificultad de este último método es la gran carga computacional [9. Roggeman y Welsh [109, 9 desarrollaron un método general para incorporar correlaciones temporales y espaciales en la generación de filtros de fase. Lamentablemente, los grupos experimentales no han ahondado en la caracterización empírica de las dinámicas temporales al capturar secuencias de imágenes afectadas por la turbulencia atmosférica; siendo ésta entonces la motivación del estudio que se detalla en el Capítulo6 


\section{Capítulo 4}

\section{Memoria en frentes de onda estelares}

VINCENT VAN GOGH: [Explaining how he sees the world] Look at the sky. It's not dark and black and without character. The black is, in fact deep blue. And over there: lighter blue and blowing through the blues and blackness the winds swirling through the air and then shining, burning, bursting through: the stars! [the sky gradually transforms into van Gogh's painting Starry Night] And you see how they roar their light. Everywhere we look, the complex magic of nature blazes before our eyes.

- Doctor Who, 'Vincent and the Doctor'

\subsection{Introducción}

Es bien sabido que las ondas ópticas se ven fuertemente afectadas por las fluctuaciones del índice de refracción a lo largo de su trayectoria. Debido a este fenómeno, la resolución espacial de los telescopios en la superficie de la Tierra está limitada principalmente por la turbulencia atmosférica en lugar de por el diseño y calidad óptica [108]. Esta es la razón primordial por la cual los mejores sitios en tierra, con un ambiente estable, son cuidadosamente seleccionados antes de realizar cualquier gran telescopio. Los métodos de imagen por speckle y técnicas de óptica adaptativa se introdujeron para mitigar las fluctuaciones de fase inducida por la turbulencia. Además, los telescopios espaciales también se han desarrollado como una solución eficiente pero demasiado cara para superar este inconveniente no deseado.

El rendimiento de la astronomía óptica terrestre está directamente relacionado con las condiciones atmosféricas. En consecuencia, el modelado preciso de los efectos de la turbulencia atmosférica es crucial para la mejora de las observaciones astronómicas. Por ejemplo, en sistemas de óptica adaptativa, las predicciones de frente de onda atmosféricamente distorsionados podrían ayu- 
dar a disminuir los errores de reconstrucción del frente de onda [117]. Puesto que el tilt del frente de onda es la aberración atmosférica dominante a través de la pupila del telescopio, su caracterización estadística resulta ser de suma importancia. Las imágenes distorsionadas por la atmósfera tradicionalmente se han modelado como un proceso estocástico totalmente aleatorio [118. Schwartz et al. [119] mejoraron esta idea mediante la identificación de los frentes de onda degradados por la turbulencia como superficies fractales. Más precisamente, la fase del frente de onda se modela en el rango inercial como una superficie de movimiento browniano fraccional con un exponente de Hurst $H=5 / 6$. Este modelo fractal puede ser también asociado con el comportamiento temporal asumiendo la validez de la hipótesis de flujo congelado [119. El movimiento browniano fraccionario ( $\mathrm{fBm}$ ) es una familia de procesos estocásticos autosimilares gaussianos con incrementos estacionarios (ruido gaussiano fraccionario, fGn) ampliamente utilizado para modelar fenómenos fractales que tienen espectros empíricos del tipo ley de potencia, $1 / f^{\alpha}$ y $\alpha=2 H+1$, con $1<\alpha<3$ [120]. El exponente de Hurst $H \in(0,1)$ cuantifica sus correlaciones intrínsecas de largo alcance: cuando $H>1 / 2$ los incrementos consecutivos tienden a tener el mismo signo de manera tal que estos procesos son persistentes [121, Chap. 9]. Para $H<1 / 2$, por otra parte, incrementos consecutivos son más propensos a tener signos opuestos, y se dice que los procesos son anti-persistentes [121] Chap. 9]. El sistema sin memoria estándar de movimiento browniano (random walk) se recupera para $H=1 / 2$. Siguiendo una hipótesis diferente, Jorgenson et al. [122] sugieren que los efectos inducidos atmosféricamente en las imágenes estelares pueden ser mejor modeladas por un proceso determinista caótico que por un proceso aleatorio. Sin embargo, unos años más tarde, los mismos autores concluyeron a favor de un dinámica estocástica correlacionada [123] en acuerdo con el modelo fBm propuesto en [119.

Estudiaremos entonces la multifractalidad presente en datos de wander (bailoteo) de estrellas. La identificación precisa de estos exponentes de escala es fundamental para el desarrollo de modelos adecuados para fines de simulación y predicción. Haremos un estudio de la naturaleza fractal y multifractal de registros experimentales de fluctuaciones de ángulo de arribo (AA) de las imágenes estelares empleando MF-DFA [23].

\subsection{Datos experimentales}

Las mediciones experimentales de fluctuación de AA fueron tomadas por el instrumento de Generalized Seeing Monitor (GSM) [124, 125] siguiendo a una estrella en el Observatorio Paranal (Antofagasta, Chile - ver Figura 4.1. Analizamos con detenimiento diecinueve conjuntos independientes de datos que fueron registrados el 16 de diciembre de 2007. Las fluctuaciones de AA se miden con un muestreo regular de $5 \mathrm{~ms}$ durante un tiempo de aproximadamente 1 min de adquisición (longitud de series $N=11984$ datos). La adquisición de datos se repite normalmente cada 4 minutos. En la Fig. 4.2 se presenta una muestra representativa de las fluctuaciones de AA (arriba) junto con la densi- 


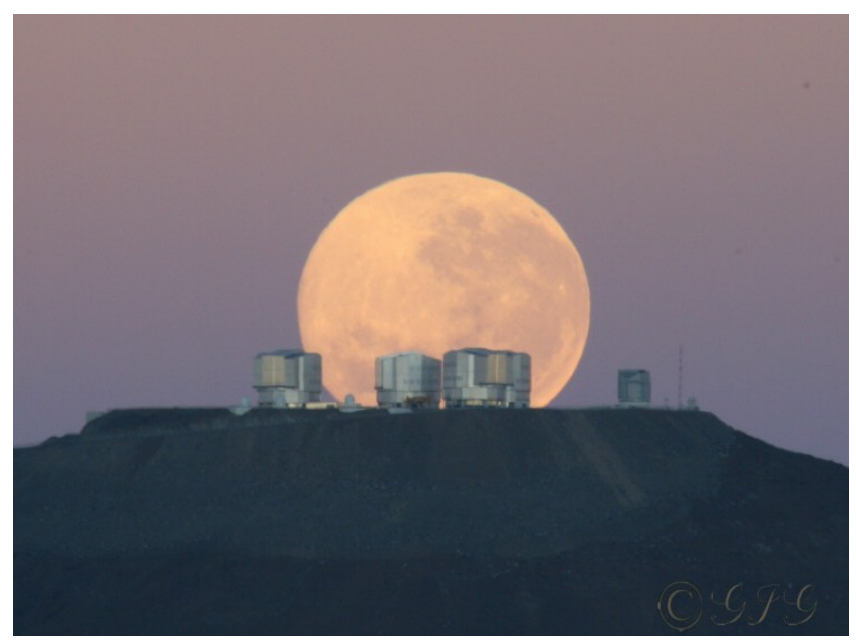

Figura 4.1: Observatorio de Cerro Paranal, Chile (2635 metros sobre el nivel del mar).

dad temporal espectral de potencia promedio (PSD) de las 19 muestras (abajo). En la misma figura se indica la ley de potencia esperada $(-2 / 3)$ en la región de baja frecuencia (línea roja discontinua). La línea negra vertical discontinua indica la frecuencia de corte que aparece debido al promedio espacial sobre la abertura del telescopio [126].

\subsection{Análisis y discusión}

Hemos analizado el comportamiento fractal y multifractal de las fluctuaciones de AA de imágenes estelares mediante la aplicación de la técnica de MF-DFA con un detrending de segundo orden $(m=2)$. Se obtuvieron resultados similares con otros órdenes de los polinomios de detrending $(m=1,3 \mathrm{y}$ 4). Se seleccionaron un centenar de escalas de tiempo $s \in[10, N / 4]$ igualmente distribuidas en escala logarítmica para la estimación de las funciones de fluctuación. Restringimos el momento $q$ al rango $[-20,20]$ con paso igual a 0,25 $(q=-20,-19,75, \ldots, 20)$. Como ejemplo ilustrativo en la Fig. 4.3 mostramos las funciones de fluctuación $F_{q}(s)$ para las fluctuaciones de AA de la Fig. 4.2 Para una mejor visualización, sólo mostramos en la figura las $F_{q}(s)$ con momentos en número entero, es decir, $q=-20,-19, \ldots, 20$. De esta figura se puede concluir que la pendiente de las funciones de fluctuación en el gráfico log-log, $h(q)$, disminuye ligeramente con el momento $q$.

Para entender mejor la naturaleza fractal de las series, la Fig. 4.4 muestra la función de fluctuación para el segundo momento $F_{2}(s)$ como una función de la escala $s$ para los diecinueve registros independientes de las fluctuaciones de AA. Cabe destacar la excelente linealidad observada para todas las escalas de 

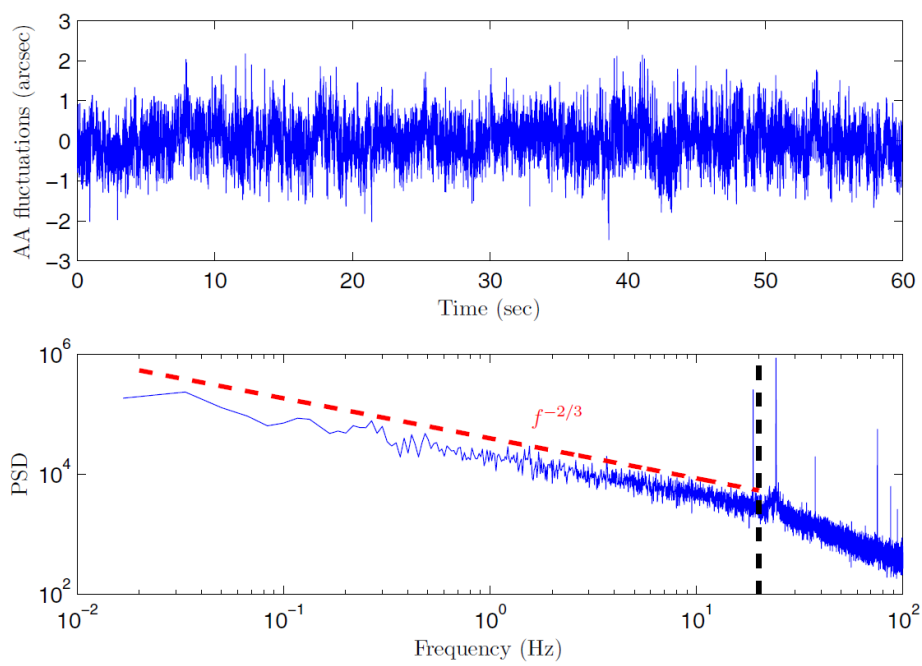

Figura 4.2: Muestra representativa de las fluctuaciones de AA (arriba) y la PSD promedio de los diecinueve registros (abajo). La ley de potencias esperada teóricamente $(-2 / 3)$ en la región de las bajas frecuencias se indica con una línea vertical roja discontinua. La frecuencia de corte se indica con una línea negra vertical discontinua. Los picos observados para frecuencias altas son debidos a las vibraciones del arreglo experimental.

tiempo. Este hallazgo permite confirmar la existencia de un comportamiento de ley de potencias bien definido, $F_{2}(s) \sim s^{h(2)}=s^{H}$ y, en consecuencia, una dinámica fractal en el rango completo analizado.

Los exponentes generalizados de Hurst estimados en el rango de la escala de tiempo completo, es decir, rango de ajuste $s \in[10, N / 4]$ para los diecinueve registros independientes de fluctuaciones de AA se representan en la Fig. 4.5 Los exponentes principales de Hurst relacionados $(H=h(2))$ se indican con una línea negra vertical. Los valores estimados para este parámetro $(H)$, junto con los obtenidos para la multifractalidad $(\Delta h \equiv h(-q)-h(q)$ para grandes valores de $q$ ) se detallan en la figura. 4.6 La media y la desviación estándar de los estimadores de ambas cantidades, a saber, el exponente de Hurst $H$ y la multifractalidad $\Delta h$, sobre todo el conjunto de datos son $0,79 \pm 0,03$ y $0,21 \pm$ 0,06 , respectivamente.

Por un lado, un comportamiento estocástico persistente se concluye del análisis DFA. Por otro lado, los resultados obtenidos para los exponentes de Hurst generalizados sugieren un pequeño grado de multifractalidad. Esta pequeña dispersión de los valores $h(q)$ se puede atribuir directamente a efectos de tamaño finito. Más precisamente, un aparente pero falso grado de multifractalidad $\Delta h \approx 0,2$ se encuentra comúnmente en señales puramente monofractales correlacionadas de largo alcance [52]. Como han demostrado Grech and Pa- 


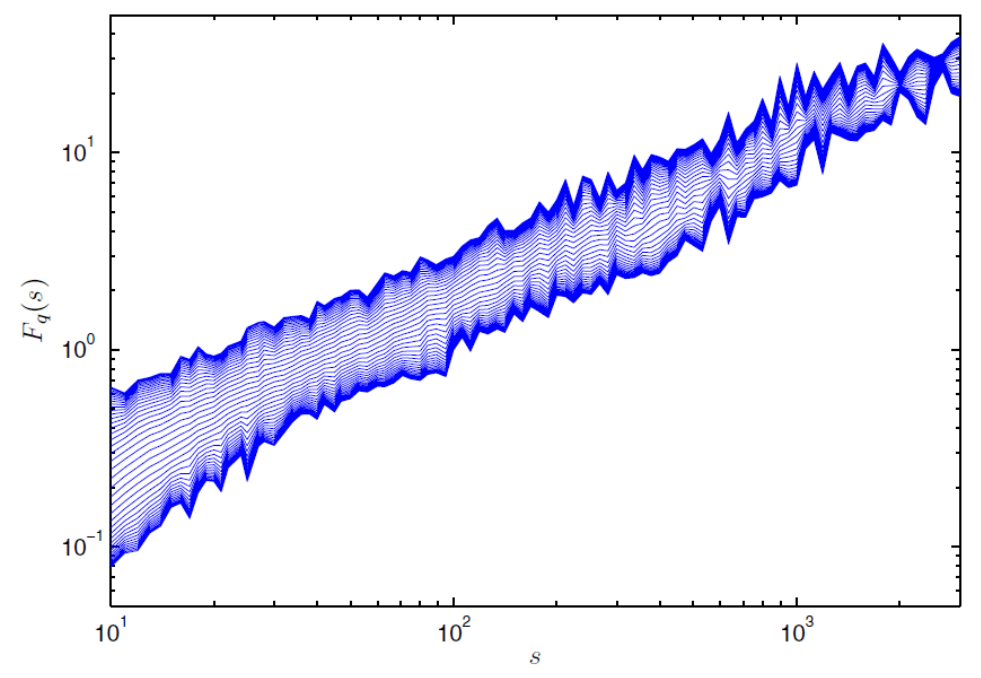

Figura 4.3: Funciones de fluctuación $F_{q}(s)$ como una función de la escala s para las fluctuaciones de AA representados en la Fig. 4.2. Se empleó MF-DFA con un polinomio de detrending de orden $m=2$ y 100 diferentes escalas $s \in[10, N / 4]$ equidistantes en la escala logarítmica. El orden $q(q=-20,-19, \ldots, 20)$ aumenta de abajo hacia arriba. El comportamiento observado es representativo de todo el conjunto.

muła [61, este efecto espurio aparece como resultado de la longitud finita de datos analizados y se amplifica adicionalmente por la presencia de la memoria a largo plazo. Para aclarar mejor esta cuestión, hemos estimado los exponentes generalizadas Hurst de un centenar de realizaciones independientes de fGn con exponente de Hurst $H=0,8$. Estas simulaciones numéricas, con la misma longitud $N$ de la serie temporal de fluctuación de $\mathrm{AA}$, se generaron a través de la función $w \mathrm{fbm}$ de MATLAB. Este algoritmo simula fBm siguiendo el método propuesto por Abry y Sellan [75]. Las realizaciones numéricas de fGn se obtienen a través de las diferencias sucesivas de las simulaciones fBm. Se hizo un estudio de MF-DFA con los mismos parámetros utilizados con los registros de fluctuación AA para este estudio numérico. La media y la desviación estándar de los valores estimados para $H$ y $\Delta h$ son $0,80 \pm 0,02$ y $0,16 \pm 0,03$, respectivamente. Estos resultados confirman la existencia de una multifractalidad en series temporales monofractales con correlaciones de largo alcance en la serie temporal debida a los efectos de tamaño finito. Por consiguiente, las fluctuaciones de AA de imágenes estelares pueden ser modeladas, al menos en una primera aproximación, como un proceso estocástico correlacionado monofractal con memoria de largo alcance.

Nuestros resultados experimentales apoyan el modelo fBm para las degradaciones de frente de onda atmosféricamente inducidas propuestas por Sch- 
wartz et al. [119]. El exponente Hurst estimado, sin embargo, es siempre inferior al valor de 5/ 6 esperado para una teoría de Kolmogorov convencional. Este exponente de Hurst más pequeño puede ser atribuido a un comportamiento no-Kolmogorov de la turbulencia atmosférica puesto que existen evidencias de desviaciones del modelo de Kolmogorov en la atmósfera superior [127 128]. De hecho, Du et al. [129] han encontrado teóricamente que la ley de potencia para los espectros de potencia temporal de las fluctuaciones de AA se modifica en la región de las frecuencias bajas cuando se considera un modelo de espectro de potencia generalizado para las fluctuaciones del índice de refracción (es decir, turbulencia no-Kolmogorov). Este cambio en la ley de escala para el régimen de baja frecuencia se puede asociar directamente con las desviaciones del exponente de Hurst esperado para el caso Kolmogorov que hemos observado experimentalmente.

\subsection{Conclusiones}

Hemos confirmado la presencia de correlaciones de largo alcance en las fluctuaciones de AA de frentes de onda estelares que se propagan a través de la turbulencia atmosférica. El exponente de Hurst estimado siempre está cerca, pero por debajo del valor $5 / 6$ esperado teóricamente para una turbulencia de Kolmogorov. De hecho, este exponente Hurst estimado por debajo de lo esperado originalmente se puede entender en términos de un modelo de turbulencia no-Kolmogorov. Vale la pena destacar que estos resultados permiten sugerir que la fase del frente de onda degradado por la turbulencia puede ser modelado como un $\mathrm{fBm}$ con $H \approx 0,8$. La predictibilidad inherente asociada con este proceso estocástico persistente podría ser útil para mejorar el rendimiento de técnicas de alta resolución angular. Una discusión detallada de este estudio se encuentra también en [130. 


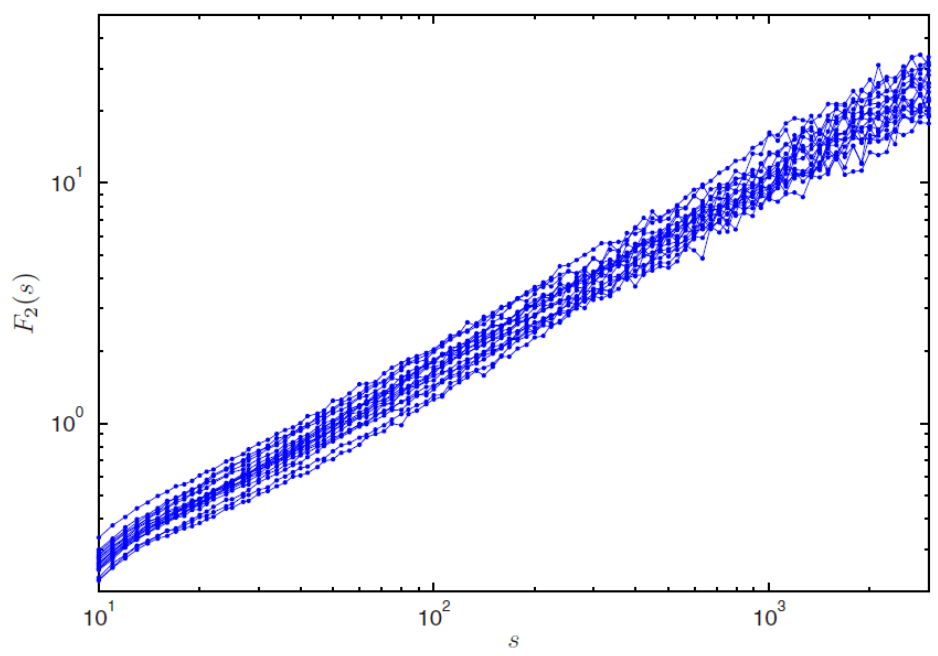

Figura 4.4: Funciones de fluctuación para el segundo momento $F_{2}(s)$ como una función de la escala $s$ para los diecinueve registros independientes de las fluctuaciones de AA. La pendiente del mejor ajuste lineal de cada uno de estas funciones es el estimador del exponente de Hurst de los registros experimentales (DFA estándar [22]).

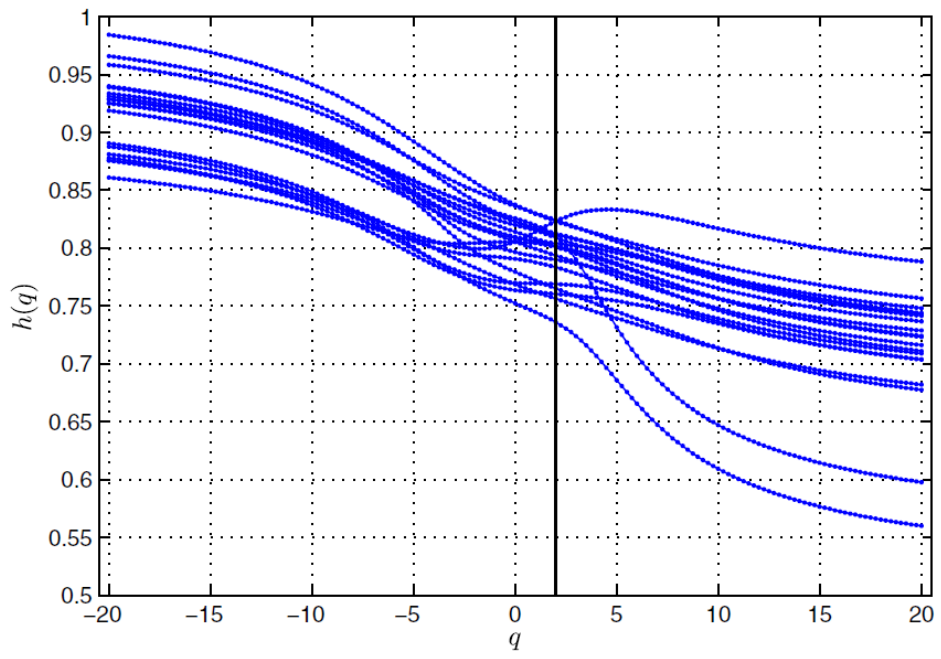

Figura 4.5: Exponentes de Hurst generalizados $h(q)$, estimados ajustando en todo el intervalo de escalas $s \in[10, N / 4]$ como funación del orden $q$ para los diecinueve registros independientes de fluctuaciones de AA. La línea negra vertical marca el valor del exponente principal de Hurst $(H=h(2))$. 


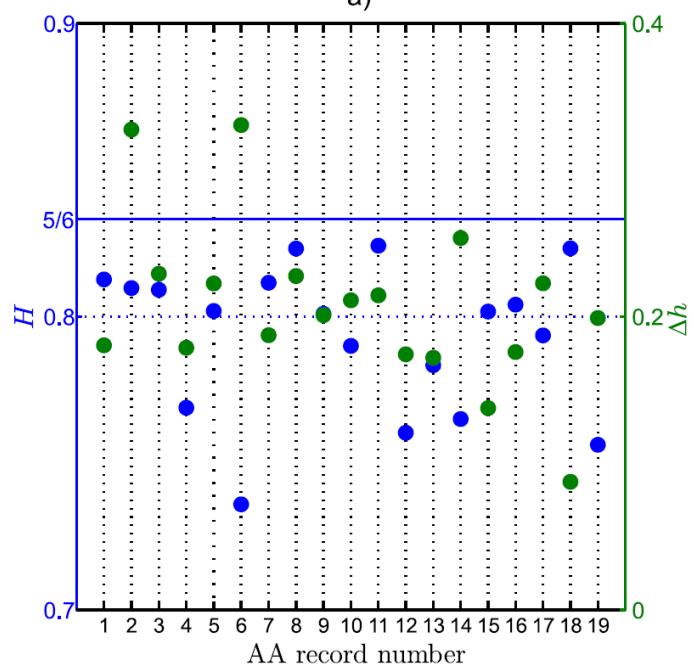

b)

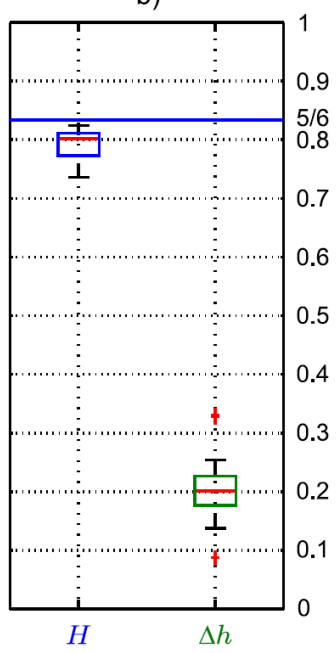

Figura 4.6: a) Valores estimados para el exponente de Hurst $H$ (puntos azules) y el grado de multifractalidad $\Delta h$ (puntos verdes) para los diecinueve registros independientes de fluctuaciones de AA. b) Boxplots para ambos cuantificadores. El valor esperado para el exponente de Hurst dentro del modelo de Kolmogorov $(H=5 / 6)$ está indicado conuna línea azul horizontal. 


\section{Capítulo 5}

\section{Persistencia en el wandering láser inducida por la turbulencia}

THE DOCTOR: Clara sometimes asks me if I dream. "Of course I dream", I tell her. "Everybody dreams". "But what do you dream about?", she'll ask. "The same thing everybody dreams about", I tell her. "I dream about where I'm going." She always laughs at that. "But you're not going anywhere, you're just wandering about." That's not true. Not anymore. I have a new destination. My journey is the same as yours, the same as anyone's. It's taken me so many years, so many lifetimes, but at last I know where I'm going. Where I've always been going. Home. The long way round.

- Doctor Who, 'The day of the doctor'

\subsection{Introducción}

El centroide de un haz láser experimenta múltiples desviaciones cuando se propaga a través de la atmósfera turbulenta de la Tierra debido a las fluctuaciones estocásticas del índice de refracción a lo largo del camino óptico. Como consecuencia de los cambios de fase, debido a remolinos turbulentos con dimensiones mayores que el diámetro del haz, el láser sufre desplazamientos perpendiculares a la dirección original de propagación. Este fenómeno se conoce como beam wandering o spot dancing. En una primera aproximación, el wandering del haz láser en la atmósfera turbulenta podría considerarse como totalmente aleatorio [131]. Esto significa que las fluctuaciones de coordenadas del centroide de láser en un dado instante son independientes de aquellas asociadas a los instantes anteriores. Sin embargo, existen algunas evidencias de que las correlaciones temporales de largo alcance están presentes en la dinámica temporal subyacente [117,123,132,133, 8, 7,134]. Está claro que una mejor 
comprensión del comportamiento temporal fluctuante es esencial para mejorar las aplicaciones prácticas de láser relacionadas con fines de seguimiento y comunicación. Particularmente, el wandering se considera como la principal causa de pérdida sustancial de señal en el plano receptor en sistemas de comunicación por láser en el espacio libre, degradando la calidad y fiabilidad en la transmisión de datos, y la limitando su rendimiento [135]. De hecho, recientemente se han propuesto sistemas de control de wandering para mitigar este inconveniente [136 137]. Tratando de arrojar algo de luz sobre la dinámica del wandering láser analizaremos cuidadosamente las correlaciones temporales en la posición registrada de un haz láser después de que se propaga a través de una cámara atmosférica en laboratorio. Conjeturamos que esta turbulencia de laboratorio es representativa de una turbulencia atmosférica completamente desarrollada. En consecuencia, es capaz de emular las principales propiedades de los flujos turbulentos que afectan el haz láser en un enlace de comunicación a nivel del suelo. De hecho, dispositivos similares se han utilizado para probar los efectos de la turbulencia atmosférica en varios contextos 135, 138, 139, 140, 141, 142, 143]. Las componentes horizontal y vertical de la posición del centroide del haz láser se miden como función del tiempo con un detector sensible a la posición situado en el extremo de la trayectoria de propagación. Con el objetivo de caracterizar estadísticamente las correlaciones temporales de estos flujos de datos hacemos un análisis con detrended fluctuation analysis (DFA). Los resultados obtenidos permiten concluir que los desplazamientos del centroide del láser son consistentes con procesos estocásticos correlacionados con memoria a largo plazo cuando la influencia de la turbulencia se hace claramente evidente.

\subsection{Arreglo experimental}

Realizamos una experiencia conceptualmente sencilla en condiciones controladas en las que un rayo láser se propaga a través de una turbulencia artificial - en la Figura 5.1 se detalla esquemáticamente el arreglo experimental. El wandering del haz láser (10 mW HeNe Melles Griot Modelo 05-LHP-991) es registrado por un detector sensible a la posición con una superficie de $1 \mathrm{~cm}^{2}$ (UDT SC-10 D). Este detector mide la posición del centroide del haz de láser incidente con una precisión de $2,5 \mu \mathrm{m}$. Las coordenadas horizontales y verticales se registraron a $500 \mathrm{~Hz}$ - hemos confirmado hallazgos similares para frecuencias de muestreo más altas.

Con el propósito de tener una turbulencia inercial completamente desarrollada en condiciones estables y repetibles estadísticamente, empleamos un generador de turbulencia de aire en laboratorio, comúnmente llamado turbulador, similar al propuesto originalmente por Fuchs et al. [144], y posteriormente mejorado por Keskin et al. [145] (ver el Apéndice E. Para simular la turbulencia atmosférica, dos flujos de aire a diferentes temperaturas se ven obligadas a

colisionar en la cámara de produciendo una mezcla isotrópica entre el aire caliente y frío. La fuente de calor es un calentador eléctrico en la que se controla 
la corriente que pasa a través de él. El haz láser delgado se propaga a través de casi $0,35 \mathrm{~m}$ de turbulencia en la cámara de mezcla. La velocidad del flujo de aire es fija debido a que ambos ventiladores funcionan a velocidades idénticas, por lo que las características de turbulencia son sólo por la diferencia de temperatura. $\mathrm{Al}$ aumentar la temperatura del foco caliente pueden producirse diferentes intensidades de turbulencia. La cámara en el laboratorio ofrece las ventajas de una caracterización completa del sistema y repetibilidad en una sola capa turbulenta. La intensidad de la turbulencia artificial cuantificada a través de la estructura constante $C_{n}^{2}$, y tanto la escala interna como la externa se estimaron previamente siguiendo el procedimiento sugerido por Masciadri y Vernin [138]. La caracterización completa del turbulador se detalla en el Apéndice $\mathrm{E}$ Realizamos la experiencia con doce diferencias de temperatura $\Delta T=T_{1}-T_{2}$ desde 5 hasta $180{ }^{\circ} \mathrm{C}$, y también se tomaron mediciones de referencia con los ventiladores apagados y encendidos (sin pasar corriente por el calentador). En particular, las mediciones con los ventiladores apagados pueden ser consideradas como una medición de fondo que cuantifica los efectos del ruido electrónico y la turbulencia en la habitación.

\subsection{Análisis y discusión}

En este arreglo experimental, 21 realizaciones independientes de 5.000 puntos de coordenadas se obtuvieron para cada condición de turbulencia. Posteriormente, se realizó el análisis DFA (de acuerdo a lo que se detalla en el Cap. 2 para las componentes horizontal y la vertical de la posición registrada. La Figura 5.2 muestra las funciones de fluctuación obtenidas mediante la aplicación de un análisis DFA con un polinomio de detrending de segundo orden $(m=2)$ para las diferentes intensidades de turbulencia. Se muestran resultados representativos para una realización particular para cada condición de turbulencia con $C_{n}^{2}$ aumentando de abajo hacia arriba. Se observa un comportamiento de ley de potencia bien definido con pendientes más altas para las mayores intensidades de turbulencia. En la Figura 5.3 se representa la media y la desviación estándar (en las 21 realizaciones independientes) de los exponentes de Hurst estimados para cada coordenada en el rango $s \in[30,1000]$ (líneas de trazos verticales en la Figura 5.2 como una función de $C_{n}^{2}$.

Con el fin de interpretar mejor los resultados obtenidos para el exponente de Hurst, en la Figura 5.4 se muestra la relación señal-ruido (SNR) para las diferentes condiciones de turbulencia. La SNR se estimó como la varianza de las señales en los estados turbulentos en relación con el valor asociado con las mediciones de referencia. De la Figura 5.4 se concluye que es necesario el

aumento de $C_{n}^{2}$ para resolver completamente los efectos de turbulencia en el turbulador con el sistema de detección implementado. 


\subsection{Conclusiones}

En las mediciones de referencia el detector no es capaz de resolver las diferencias de posición, y se mide un ruido electrónico totalmente sin correlación asociado con el detector. En consecuencia, el exponente de Hurst está cerca de 0,5 como intuitivamente se esperaba. A medida que la intensidad de la turbulencia aumenta la SNR es mayor que uno (véase la Figura 5.4 y el detector empieza a discernir la influencia de la turbulencia. Al mismo tiempo, el exponente de Hurst muestra un comportamiento creciente, tanto para las coordenadas horizontales y verticales, saturando a un valor cercano a 5/6 para los mayores valores de $C_{n}^{2}$ (véase la Figura 5.3. . Los resultados obtenidos permiten confirmar que la turbulencia introduce efectos de memoria en las series temporales de wandering, puesto que una dinámica altamente persistente se observa para las mayores intensidades de turbulencia. Además, la similitud entre los exponentes de Hurst estimados horizontales y verticales confirma la isotropía de la turbulencia dentro de la cámara de laboratorio. Vale la pena mencionar aquí que $H=5 / 6$ se ha propuesto originalmente como un resultado teórico dentro del modelo de Kolmogorov [119], y muy recientemente estudiado experimentalmente [130], por las fluctuaciones del ángulo de arribo de frentes de onda estelares propagándose a través de la turbulencia atmosférica.

Resumiendo, se concluye la existencia de un comportamiento fractal estocástico claramente persistente del análisis por DFA del wandering de un haz láser pasando por una turbulencia generada en laboratorio. Los exponentes de Hurst estimados para las dos coordenadas convergen a un valor cercano a 5/6 - el valor teórico asociado a la turbulencia de Kolmogorov - para las condiciones de turbulencia más intensa. Otra discusión detallada de esta experiencia se encuentra en [146]. 

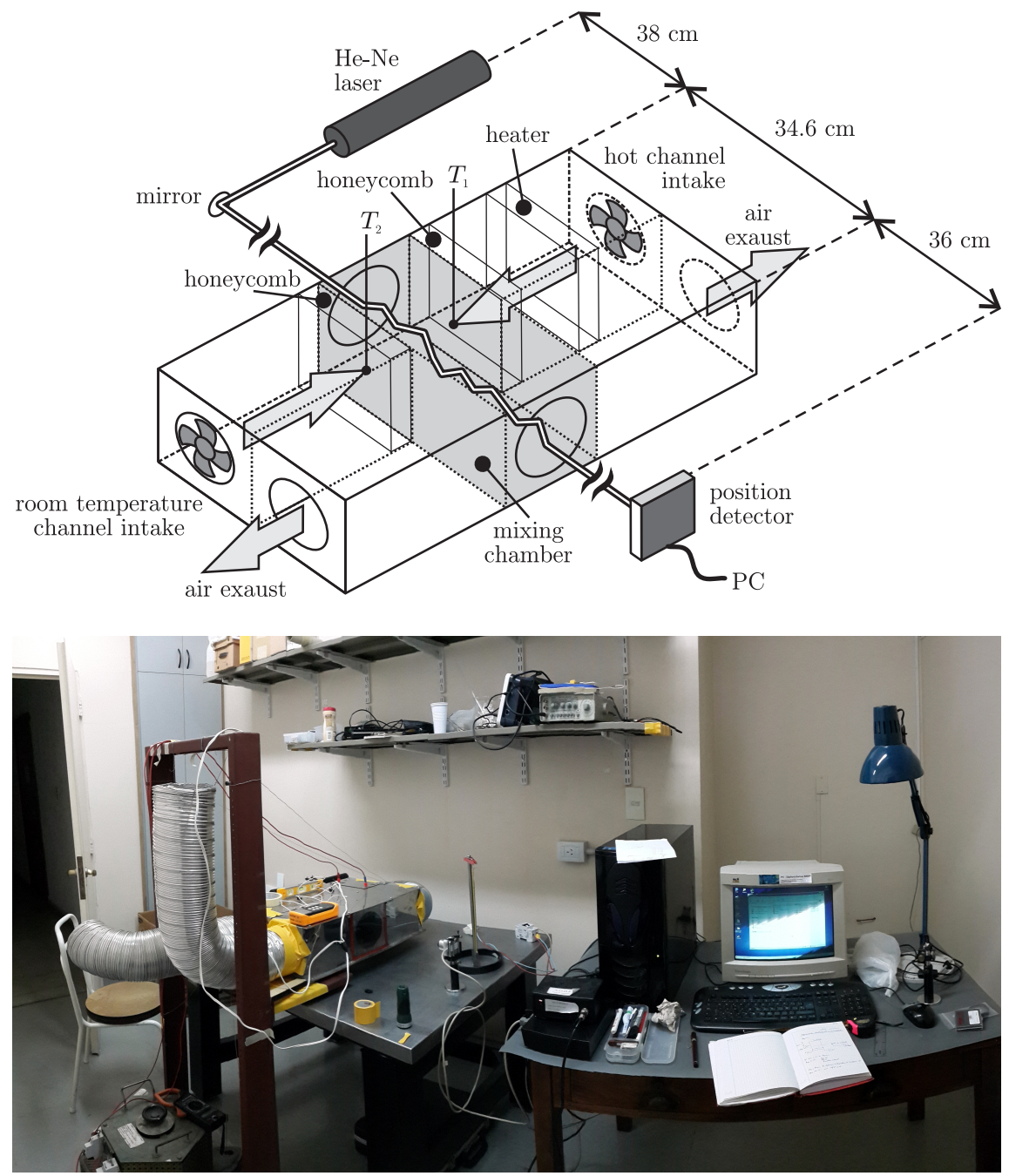

Figura 5.1: Esquema del arreglo experimental. 

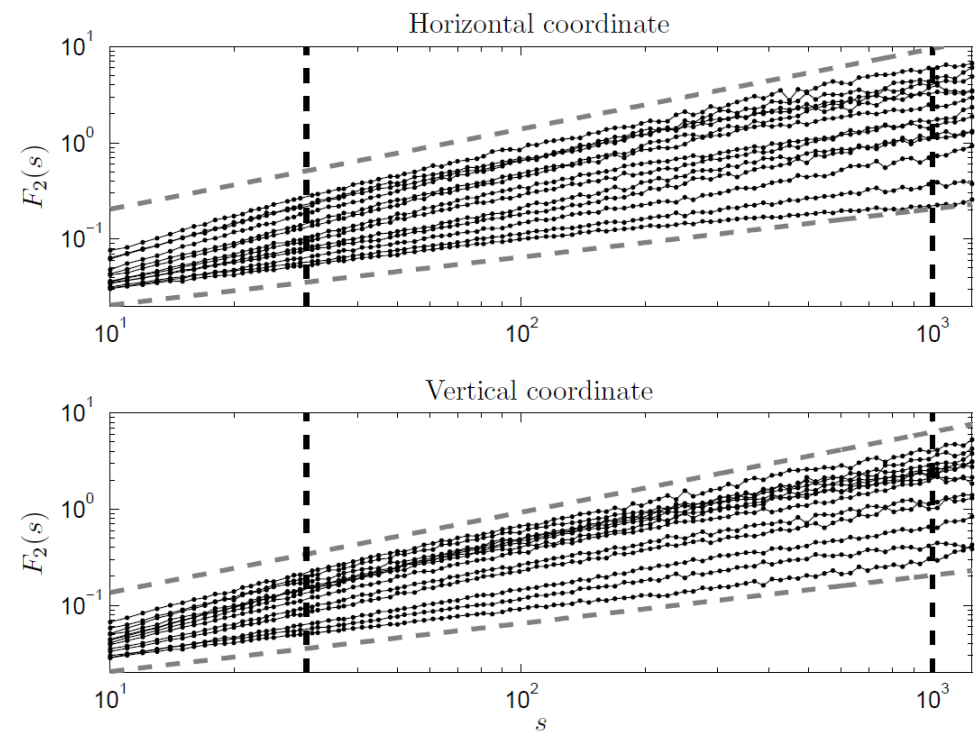

Figura 5.2: Funciones de fluctuación $F_{2}(s)$ en función de la escala de $s$ de la coordenada horizontal (gráfico superior) y vertical (gráfico inferior) para las diferentes condiciones de turbulencia. Se muestran los resultados obtenidos para una realización particular de los veintiún casos registrados. Se empleó DFA con un polinomio de detrending de orden $m=2$ y 96 diferentes escalas $s \in[10, N / 4]$ equidistantes en la escala logarítmica. $C_{n}^{2}$ aumenta de abajo a arriba. La pendiente del mejor ajuste lineal obtenido para cada una de estas funciones de fluctuación es la estimación del exponente de Hurst. Las líneas verticales discontinuas indican el intervalo en el que se realiza el ajuste lineal para estimar el exponente Hurst. La líneas (trazos grises punteados) con pendientes $1 / 2$ (línea inferior) y $5 / 6$ (línea superior) se muestran como referencia. El comportamiento observado es representativo de todo el conjunto de datos y se obtienen resultados similares para otros detrendings $(m=1$ y $m=3)$. 


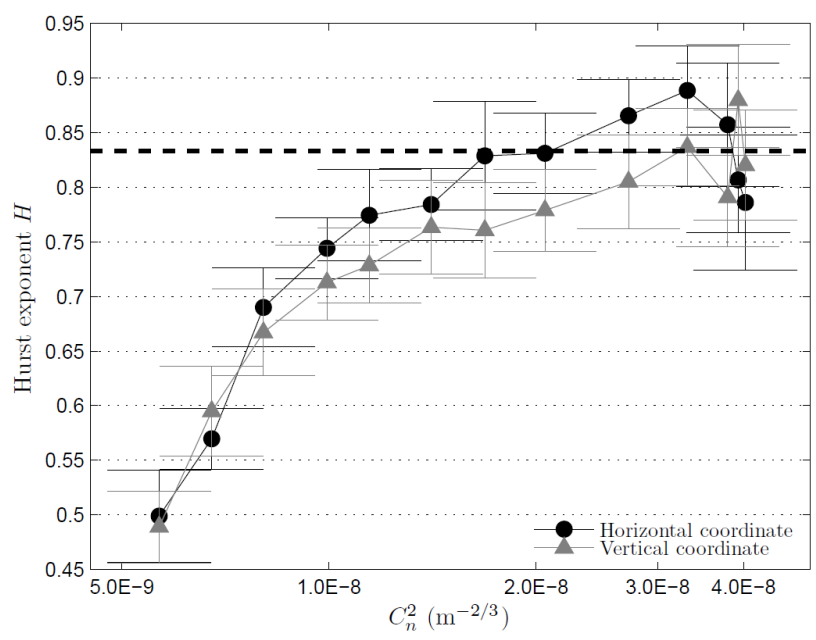

Figura 5.3: Valores estimados para el exponente de Hurst para las coordenadas horizontales y verticales del centroide haz de láser como una función de la intensidad de la turbulencia. Se representa la media y la desviación estándar de las 21 realizaciones para cada valor de $C_{n}^{2}$. Se muestra el valor teórico esperado para el exponente de Hurst en el modelo de Kolmogorov $(H=5 / 6)$ (línea negra horizontal discontinua). El ajuste de DFA-2 fue hecho en un rango $[30,1000]$. Se obtuvieron comportamientos muy similares para otros órdenes de detrending $(m=1$ y $m=3)$.

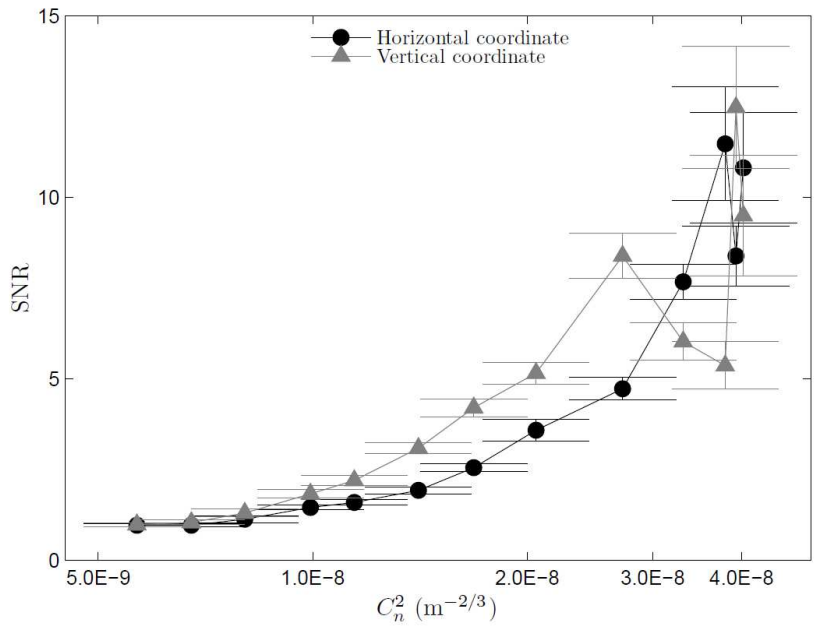

Figura 5.4: Relación señal-ruido para las componentes horizontal y vertical del registro de coordenadas de centroide láser como función de la intensidad de la turbulencia. Promedio y desviación estándar de las 21 realizaciones independientes para cada valor de $C_{n}^{2}$. 


\section{Capítulo 6}

\section{Centelleo de imágenes y correlaciones temporales}

THE DOCTOR: That which holds the image of an Angel becomes itself an

Angel.

— Doctor Who, 'The time of Angels'

\subsection{Análisis de centelleo de propagación de luz in- coherente}

\subsubsection{Introducción}

Alrededor de 1610 Galileo reportó brevemente el efecto de la turbulencia atmosférica en la observación astronómica 147. Este fenómeno es debido al hecho de que la atmósfera turbulenta produce un desenfoque dinámico que degrada los registros en imagen de objetivos fijos ('seeing'). Diversos parámetros de la turbulencia pueden ser extraídos de imágenes [148 149], mientras que a la inversa, su conocimiento permite simular sus efectos 150. La estimación de los parámetros de turbulencia atmosférica y la corrección simultánea del desenfoque (bluring) en imágenes dinámicas de un blanco de alto contraste ha sido estudiada recientemente por Gibson y Hammel [151. Proponemos aquí una técnica para una estimación simple de $C_{n}^{2}$ basada en la captura de imágenes de objetivos de alto contraste a través de un ambiente turbulento.

Luego de que un frente de onda se propague por un camino turbulento de longitud $L$, su índice de centelleo correspondiente está definido en un punto arbitrario de la pupila de entrada del receptor como $\sigma_{I}^{2}=\left\langle I^{2}\right\rangle /\langle I\rangle^{2}-1$ (donde I es la irradiancia). Este índice generalmente está determinado en experimentos en los que el frente de onda recibido es enfocado en un detector de luz de un sólo elemento. Ahora, consideramos al enfoque de imágenes de objetivos 
de alto contraste a través de turbulencia como la adquisición simultánea de muchas muestras de irradiancia definiendo el índice de centelleo por píxel:

$$
\left(\sigma_{I}^{2}\right)_{i, j}=\frac{\left\langle I_{i, j}^{2}\right\rangle}{\left\langle I_{i, j}\right\rangle^{2}}-1,
$$

donde $I_{i, j}(t)$ expresa la irradiancia a lo largo del tiempo para un píxel con coordenadas $(i, j)$ producto de una propagación de onda óptica a través de una turbulencia atmosférica y $\langle\cdot\rangle$ denota el promedio temporal. Esta definición en términos de imágenes plantea el problema de estimar la intensidad de la turbulencia con una matriz de índices de centelleo versus el método basado en un solo elemento. Encontramos que es posible extraer información de $C_{n}^{2}$ a partir de $\left(\sigma_{I}^{2}\right)_{i, j}$ luego de una cuidadosa selección y conteo de sus elementos como detallaremos a continuación.

Al capturar imágenes con luz incoherente que ha atravesado una atmósfera turbulenta, la intensidad de la imagen (en el plano del receptor) fluctuará más en los bordes de alto contraste [152] y apenas lo hará en las regiones uniformes; por lo tanto, la representación visual de $\left(\sigma_{I}^{2}\right)_{i, j}$ se verá como un filtro de borde aplicado a la imagen del objetivo. Para poder localizar y contar solamente los píxeles con un centelleo relativamente alto, se puede aplicar un valor umbral $\tau$ a la representación del índice de centelleo definiendo un conjunto

$$
\Omega_{i, j}=\left\{0 \mathrm{si}\left(\sigma_{I}^{2}\right)_{i, j}<\tau, \mathrm{y} 1 \mathrm{si} \tau \leq\left(\sigma_{I}^{2}\right)_{i, j}<1\right\}
$$

(los píxeles relacionados a los bordes de mayor contraste de la imagen-objetivo). Compararemos ahora este conjunto con la salida binaria $E_{i, j}$ de un filtro de borde 153 aplicado a la imagen promedio capturada en el punto de observación. Empleando análisis adimensional es posible deducir de [154] que cualquier haz que de propague por turbulencia tiene un índice de centelleo proporcional a $C_{n}^{2} k^{7 / 6} L^{11 / 6}$ para el modelo Obukhov-Kolmogorov en condiciones de turbulencia débil $\left(\sigma_{I}^{2}<1\right)$. La evidencia experimental presentada en este trabajo sugiere que el número de píxeles filtrados por el umbral es proporcional a este resultado según

$$
\gamma(\lambda, L) \cdot\left(\frac{\sum_{i, j} \Omega_{i, j}}{\sum_{i, j} E_{i, j}}\right)=C_{n}^{2}\left(\frac{2 \pi}{\lambda}\right)^{7 / 6} L^{11 / 6},
$$

donde $C_{n}^{2}$ es la constante de estructura para el índice de refracción del aire, $\lambda$ es la longitud de onda y $L$ es la distancia de propagación. Finalmente, $\gamma(\lambda, L)$ es un factor de proporcionalidad adimensional que proponemos caracterizar en condiciones de laboratorio analizando el cociente entre la cantidad de píxeles no nulos en $\Omega_{i, j}$ y la cantidad de píxeles no nulos en $E_{i, j}$. En este capítulo estudiamos sistemáticamente este factor y encontramos que su forma es

$$
\gamma(\lambda, L)=G_{0}\left(\frac{2 \pi}{\lambda}\right)^{7 / 6} L^{11 / 6}
$$


donde $G_{0}$ es el factor de estructura por centelleo de píxeles $\left(\mathrm{m}^{-2 / 3}\right)$ cuyo valor se determinará empíricamente. El conocimiento de este factor es clave para que a partir de las las Ecuaciones 6.3 y 6.4 se pueda estimar $C_{n}^{2}$ sencillamente como

$$
C_{n}^{2}=G_{0} \cdot\left(\frac{\sum_{i, j} \Omega_{i, j}}{\sum_{i, j} E_{i, j}}\right)
$$

Es interesante notar que al tomar imágenes de un objetivo fijo, el factor $\sum_{i, j} E_{i, j}$ dará aproximadamente el mismo resultado para un amplio rango de condiciones de turbulencia, mientras que $\sum_{i, j} \Omega_{i, j}$ puede ir de 0 a una fracción considerable de la totalidad de los píxeles de la imagen dependiendo de la intensidad de la turbulencia.

\subsubsection{Arreglo experimental}

\section{Imágenes en laboratorio}

Un experimento conceptualmente simple se realizó en condiciones controladas en que un patrón de damero se muestra en un monitor LCD (Fig. 6.2-a) seguido por el turbulador (Fig. 6.1. El damero fue enfocado en una cámara web comercial (Logitech Webcam Pro 9000, con una resolución de $640 \times 400$ píxeles, 30 frames/s).

En el turbulador se emplearon 13 diferencias de temperatura que fueron desde los 15.5 a los $152.7^{\circ} \mathrm{C}$ cada una con una $C_{n}^{2}$ caracterizada yendo desde $9,54 \cdot 10^{-9}$ a $3,99 \cdot 10^{-8} \mathrm{~m}^{-2 / 3}$, y una varianza de Rytov calculada $\sigma_{R}^{2}(632 \mathrm{~nm})$ desde 0,24 hasta 1,02 . Se tomaron además medidas con los ventiladores apagados y encendidos a modo de referencias.

\section{Experiencia independiente}

Para probar esta técnica en un caso independiente en el que $C_{n}^{2}$ era desconocida de antemano, empleamos una estufa eléctrica doméstica interpuesta entre un monitor LED mostrando un damero y la misma cámara web empleada en la caracterización grabando at 30 cuadros/s y con una resolución def $640 \times 400$ píxeles. La distancia al objetivo fue de $L \sim 0,6 \mathrm{~m}$ y seleccionamos una región de interés (ROI) de $200 \times 200$ píxeles debido a limitaciones espaciales del arreglo. La potencia de la estufa fue de $2000 \mathrm{~W}$.

\subsubsection{Análisis y resultados}

En el primer caso determinamos una ROI de $300 \times 300$ píxeles mientras que para el segundo caso fue de $200 \times 200$ (debido a restricciones del arreglo). En ambos casos analizamos la información proveniente del canal verde de la salida RGB de la cámara $(\lambda \sim 510 \mathrm{~nm})$ para realizar el análisis. Se tomaron promedios de 1100 cuadros consecutivos ( $\sim 36.7$ s) (ver la Fig. 6.2 -a). Para encontrar 

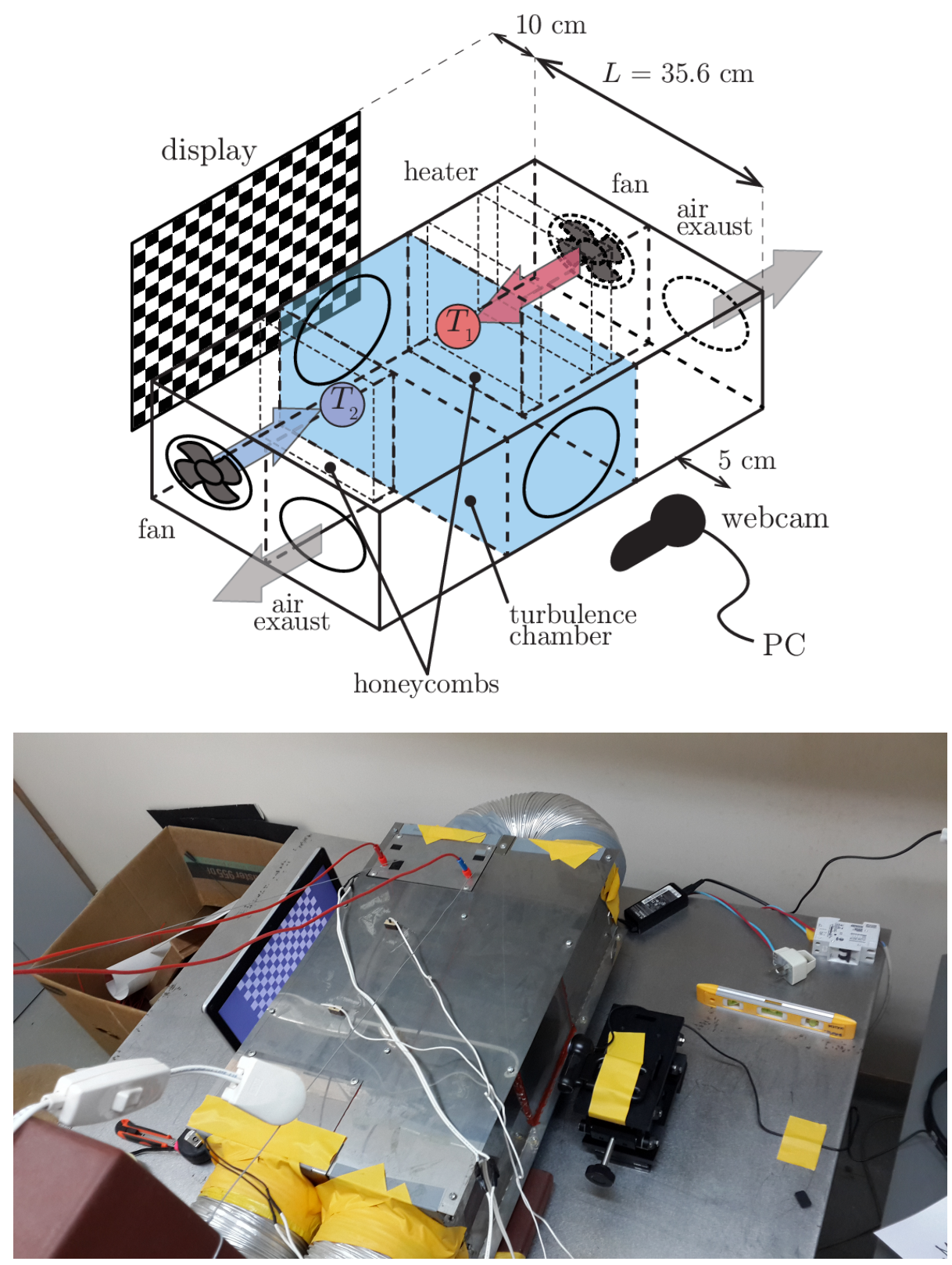

Figura 6.1: Arreglo experimental. El turbulador está suspendido de una estructura independiente para evitar cualquier vibración en los componentes ópticos. 
$E_{i, j}$ en todos los casos, empleamos el filtro de detección de bordes de Matlab con la configuración por defecto (con la opción «log»). Probamos con otros previamente y hallamos que éste en particular devuelve los resultados más adecuados en términos de detección de borde.

En el caso de laboratorio, para cada valor de $C_{n}^{2}$ calculamos la imagen del centelleo $\left(\sigma_{I}^{2}\right)_{i, j}$ (Fig. 6.2 b), de la cual puede visualizarse y estudiar su histograma (Fig. 6.2 f). Estudiamos cuidadosamente los histogramas de todos los casos y determinamos un valor de umbral $\tau=0,01$ para este caso de manera de obtener máscaras binarias $\Omega_{i, j}$ con suficientes elementos para este análisis (Fig. 6.2 d); y también aplicamos el filtro de borde simple a la imagen promedio (Fig. 6.2 e). Como era de esperar, encontramos que el número de píxeles con $\left(\sigma_{I}^{2}\right)_{i, j}<\tau$ decrece con $C_{n}^{2}$ (Fig. 6.3-a) mientras que aumenta con buena tendencia lineal para píxeles con $\tau \leq\left(\sigma_{I}^{2}\right)_{i, j}<1$ (Fig. 6.3-b). Por medio del ajuste lineal del cociente $\sum_{i, j} \Omega_{i, j} / \sum_{i, j} E_{i, j}$ versus $C_{n}^{2}$, encontramos el valor del factor de estructura por centelleo de píxeles (Ecuaciones 6.4 y 6.5):

$$
G_{0}=(2,39 \pm 0,08) \cdot 10^{-8} \mathrm{~m}^{-2 / 3}
$$

y por lo tanto en estas condiciones tenemos

$$
\gamma(\lambda, L)=(0,64 \pm 0,02)
$$

Para el caso independiente repetimos el mismo análisis detallado en el párrafo anterior (Fig. 6.4 a,b,c) y estimamos $C_{n}^{2}$ basados en la estimación empírica previa de $G_{0}$. Luego de examinar el histograma (Fig. 6.4 c) determinamos $\tau=0,033$ como un valor adecuado para este caso. Así, la estimación de la constante de estructura para el índice de refracción es

$$
C_{n}^{2}=(1,46 \pm 0,05) \cdot 10^{-8} \mathrm{~m}^{-2 / 3} .
$$

Este valor está de acuerdo con una estimación independiente basada en bailoteo de haz láser sobre la misma estufa (este método para estimar intensidades de turbulencia se describe en [155]).

\subsection{Estudio de la dinámica temporal por píxel, cálcu- lo del exponente de Hurst}

Desde el trabajo original de McGlamery [111] tratando el tema de la simulación de la propagación de luz a través de una atmósfera turbulenta, se han propuesto varios métodos para incorporar la dinámica temporal del proceso [115, 9 y demás referencias citadas] (ver la discusión al final del Capítulo 3 . Sin embargo, los esfuerzos experimentales usualmente se enfocan en la propagación de haces delgados [7 146] o en dinámicas de promedios espaciales del haz [8 2]. Ahora investigaremos la presencia de efectos de memoria a largo plazo en el mismo arreglo experimental descrito en la sección anterior. 
a) $\operatorname{Mean}(\mathrm{ROI})-C_{n}^{2}=3.9962 \mathrm{e}-08 \mathrm{~m}^{-2 / 3}$
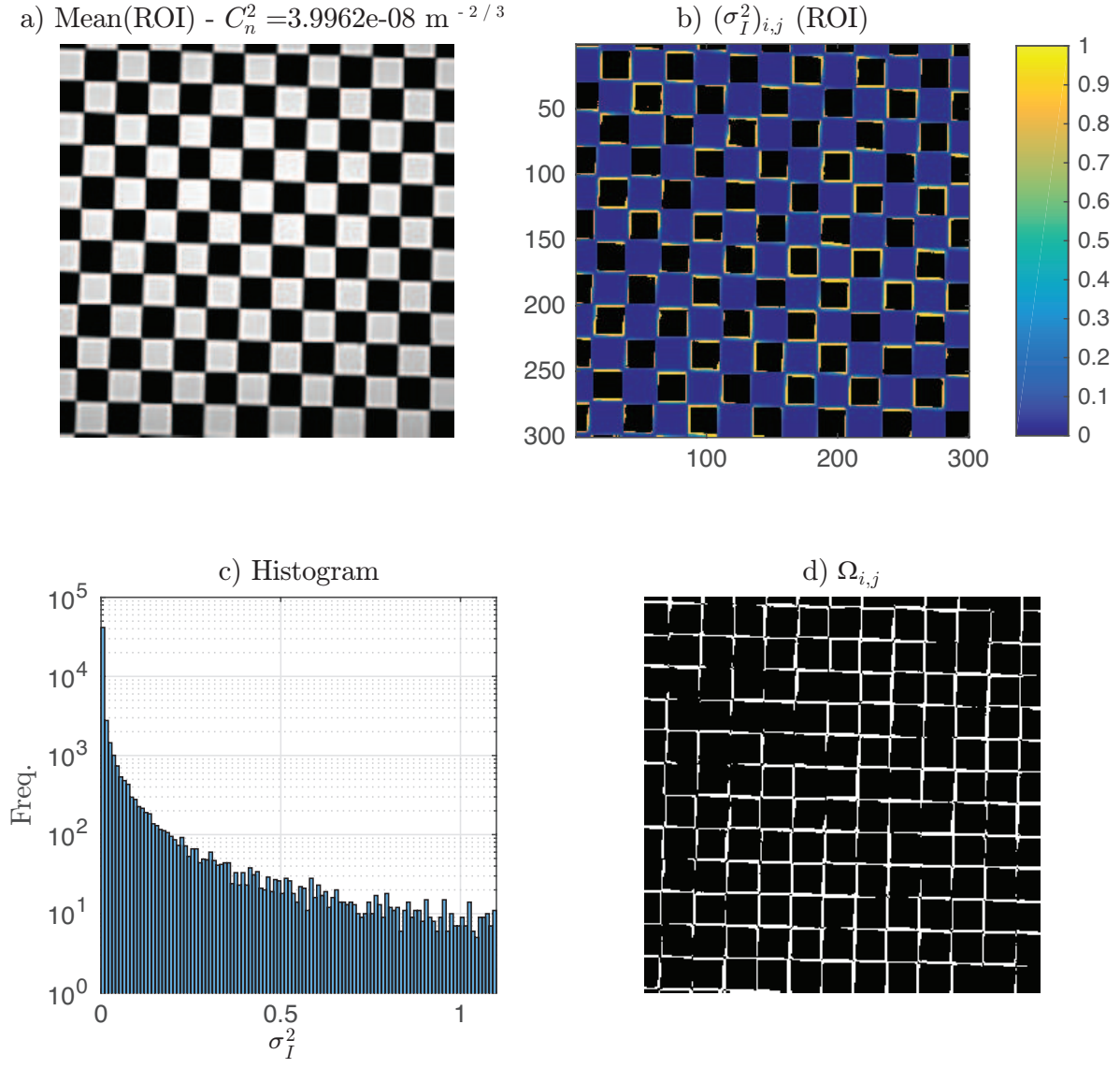

e) $E_{i, j}$

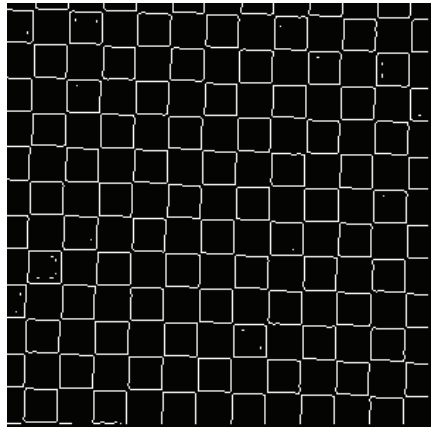

Figura 6.2: Caso representativo, condición de mayor turbulencia $\left(C_{n}^{2} \sim\right.$ $\left.4 \cdot 10^{-8} \mathrm{~m}^{-2 / 3}\right)$. a) Promedio del damero en la ROI $(300 \times 300$ píxeles, 300 píxeles $\equiv 15,027 \mathrm{~cm})$. b) Representación del índice de centelleo por píxel $\left(\sigma_{I}^{2}\right)_{i, j}$ $(\tau=0,01)$ (Nota: hay un número marginal de píxeles con un un valor $\left(\sigma_{I}^{2}\right)_{i, j}>$ 1 y se los representa como 1 por claridad en la escala). c) Histograma de los valores del índice de centelleo por píxel.d) Representación de la máscara binaria $\Omega_{i, j}$. e) Filtro de borde (binario) $E_{i, j}$ aplicado a la imagen promedio -a. 

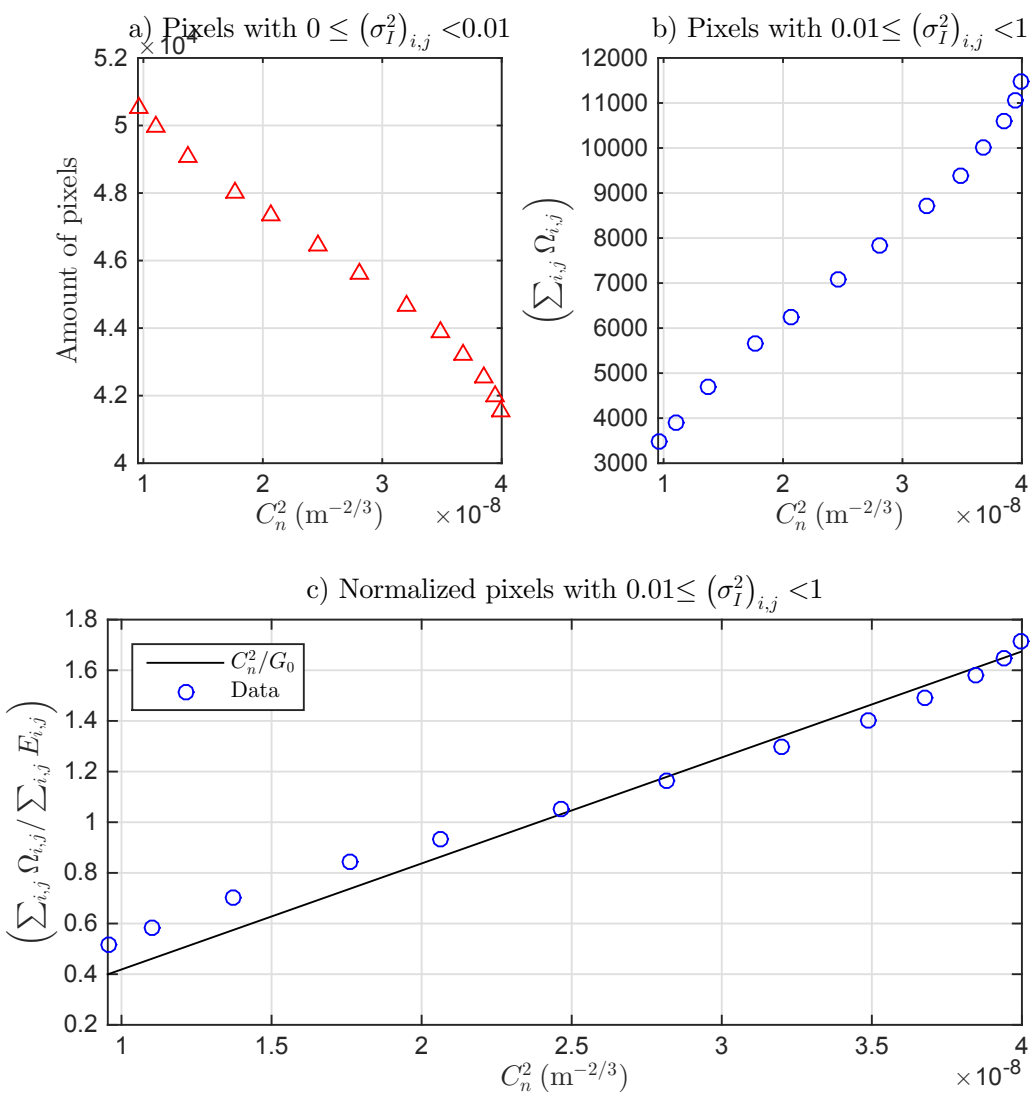

Figura 6.3: Cantidad de píxeles filtrados en la ROI. a) Valores de bajos de centelleo. b) Valores altos de centelleo. c) Cantidad de píxeles de alto centelleo normalizados por la cantidad de píxeles en el filtro de borde con su ajuste lineal. La constante de estructura de referencia estimada por el ajuste es $G_{0}=(2,39 \pm 0,08) \cdot 10^{-8} \mathrm{~m}^{-2 / 3}\left(R^{2}=0,9634\right)$. 
a) $\operatorname{Mean}(\mathrm{ROI})$

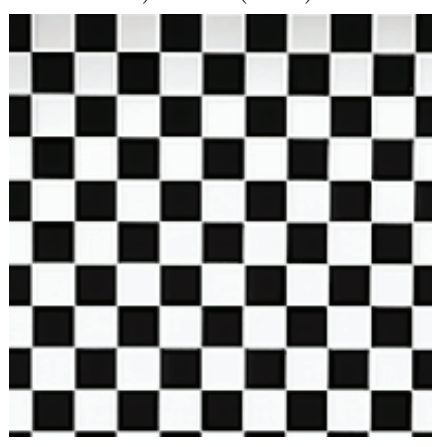

b) $\left(\sigma_{I}^{2}\right)_{i, j}(\mathrm{ROI})$

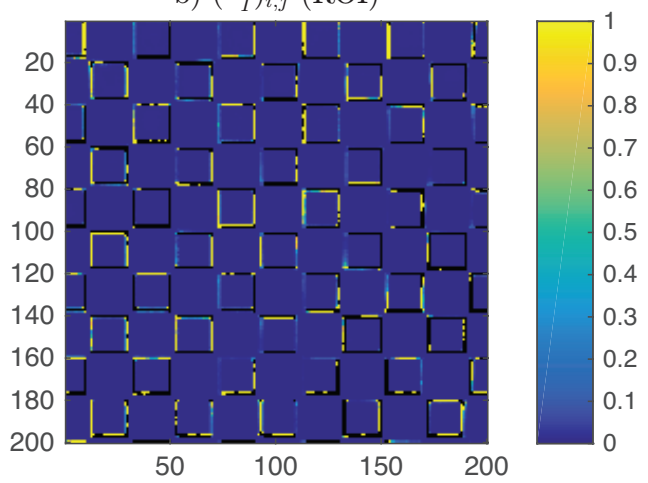

d) $\Omega_{i, j}$

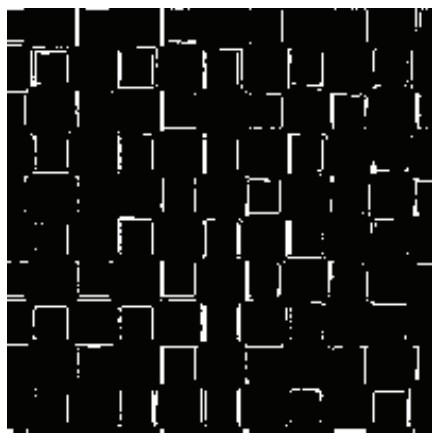

e) $E_{i, j}$

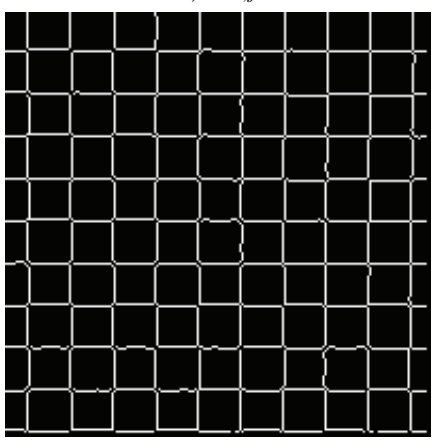

Figura 6.4: Caso independiente. a) Promedio del damero en la ROI $(200 \times 200$ píxeles, 200 píxeles $\equiv 19.993 \mathrm{~cm})$. b) Representación del índice de centelleo por píxel $\left(\sigma_{I}^{2}\right)_{i, j}(\tau=0,033)$ (Nota: hay un número marginal de píxeles con un un valor $\left(\sigma_{I}^{2}\right)_{i, j}>1$ y se los representa como 1 por claridad en la escala). c) Histograma de los valores del índice de centelleo por píxel. d) Representación de la máscara binaria $\Omega_{i, j}$. e) Filtro de borde (binario) $E_{i, j}$ aplicado a la imagen promedio -a. 
Con el propósito de estimar las correlaciones temporales presentes en esta situación, y para luego hallar su relación con la intensidad conocida de la turbulencia, emplearemos Detrended Fluctuation Analysis (DFA), tal y como se ha descrito en el Cap.2 En esta oportunidad emplearemos esta técnica para hacer una estimación píxel por píxel del exponente de Hurst $(H)$ : en efecto, como en nuestro arreglo experimental capturamos imágenes de un objetivo estático encontraremos un $H_{i, j}$ para la serie temporal de la intensidad de cada píxel $I_{i, j}(t)$. Otra forma de escribir la Ecuación (6.5) [156] de la sección anterior es:

$$
\sum_{i, j} \Omega_{i, j}=\left(\sum_{i, j} E_{i, j}\right) \frac{C_{n}^{2}}{G_{0}},
$$

con $G_{0}=(2,39 \pm 0,08) \cdot 10^{-8} \mathrm{~m}^{-2 / 3}$. Este resultado indica que:

a) el número de píxeles con alto centelleo aumenta con la intensidad de la turbulencia con respecto a la cantidad de píxeles hallados en los bordes de la imagen promedio

b) estos píxeles están localizados en las regiones de alto contraste de la imagen

c) la información sobre la intensidad de la turbulencia es preservada en $\sum_{i, j} \Omega_{i, j}$.

\subsubsection{Cuantificación de las correlaciones temporales por DFA}

Empleamos para nuestro estudio las mismas capturas y ROIs del caso de centelleo: $300 \times 300$ píxeles ( 300 pixels $\equiv 15.027 \mathrm{~cm}), \lambda \sim 510 \mathrm{~nm} ; 1100$ cuadros consecutivos ( $36.7 \mathrm{~s}$ ) (véase la Figura 6.5 a).

Para el análisis por DFA elegimos un polinomio de detrending de orden $m=3$ (hemos explorado otros órdenes con similares resultados). Calculamos las funciones de fluctuación para 100 escalas con $10 \leq s \leq 275$. En la Figura 6.5 mostramos un caso representativo. Elegimos todo el rango de escalas $s$ para ajustar las funciones de fluctuación. Esta elección es apoyada por la baja incertidumbre $(\sim 10 \%)$ en la estimación de las pendientes $(H)$ (Figura 6.5-e) y aplicando a varias funciones al azar el criterio de estimación de rangos óptimos de ajuste expuesto en [95] y detallado en el (Cap.2. Es interesante notar que para todas las intensidades de turbulencia exploradas, en la representación visual de $H_{i, j}$ (Fig. 6.5-d) los valores $H_{i, j} \sim 0(<1 / 2$, anti-persistentes) corresponden a píxeles de muy baja intensidad en el objetivo (áreas negras homogéneas), en las cuales inclusive el nivel de ruido es muy bajo en este arreglo de detección. Para píxeles del objetivo con valores muy altos (regiones blancas homogéneas), observamos predominantemente $H_{i, j} \sim 1 / 2$ (descorrelacionadas): las fluctuaciones en esas regiones están principalmente afectadas por ruido electrónico. Los valores de $H_{i, j}>1 / 2$ (persistentes) se observan en regiones de alto contraste de la imagen, las cuales se sabe que tienen un centelleo relativamente alto (Figura 6.5 b). Nos enfocaremos entonces en estudiar los valores del exponente de Hurst $H$ en $\Omega$ (dejamos por ahora los subíndices para mayor simplicidad en la notación). 
Estudiamos las distribuciones de los valores de $H$ en $\Omega$ para las referencias y todos los demás casos experimentales y encontramos que la media y la desviación estándard son representativas del conjunto. Los promedios de $H$ en $\Omega$ para ambas referencias son aproximadamente $1 / 2$ (series descorrelacionadas), y son predominantemente atribuíbles al ruido electrónico (el ruido mecánico es despreciable). Con estas consideraciones sobre los histogramas, ahora podemos estudiar el comportamiento del $H$ promedio en $\Omega\left(\bar{H}_{\Omega}\right)$ como función de $C_{n}^{2}$ (véase la Figura 6.6. Las correlaciones observadas aumentan generalmente con $C_{n}^{2}$ llegando a un máximo de promedio observado de $\bar{H}_{\Omega}=0,7 \pm 0,1$. Encontramos que en los rangos que hemos explorado experimentalmente, en primera aproximación $\bar{H}_{\Omega}$ crece como

$$
\bar{H}_{\Omega} \sim \frac{C_{n}^{2}}{C_{H}}+H_{0}
$$

donde $C_{H}=(3,6 \pm 1,4) \cdot 10^{-7} \mathrm{~m}^{-2 / 3}$ y $H_{0}=0,50 \pm 0,03$ (estos resultados se resumen en la Tabla 6.1. El valor de $H_{0}$ destaca el hecho de que los píxeles con un centelleo relativamente alto en condiciones de baja turbulencia (en esta experiencia) están principalmente afectados por ruido electrónico, como era de esperar.

Tabla 6.1: Resumen de resultados (DFA-3).

\begin{tabular}{cc}
\multicolumn{2}{c}{ Valor estimado } \\
\hline \hline$C_{H}$ & $(3,6 \pm 1,4) \cdot 10^{-7} \mathrm{~m}^{-2 / 3}$ \\
$H_{0}$ & $0,50 \pm 0,03$
\end{tabular}

\subsection{Conclusiones}

El modelo propuesto brinda la posibilidad de emplear un arreglo experimental sencillo para lograr una estimación razonable de $C_{n}^{2}$ tomando ventaja de la propagación de luz proveniente de una imagen de alto contraste. Propusimos un factor de estructura por centelleo de píxeles $\left(G_{0}\right)$ y estimamos su valor a partir de datos experimentales. El cociente $\sum_{i, j} \Omega_{i, j} / \sum_{i, j} E_{i, j}$ en la Ecuación 6.5 permite estimar constantes de estructura dentro de la relación lineal empírica (Figura 6.3 4 c). Una discusión detallada de este estudio se encuentra también en [156].

Hemos encontrado que, al capturar imágenes sucesivas de objetivos de alto contraste a través de turbulencia atmosférica, aumentan las correlaciones con la intensidad de la turbulencia para los píxeles con un índice de centelleo relativamente alto. Este comportamiento puede ser clave para refinar el aspecto temporal tanto en las técnicas de simulación como en los modelos teóricos. Las técnicas de simulación deben tener en cuenta las restricciones que las Ecuaciones 6.6 y 6.7 imponen sobre las series temporales de los píxeles individuales 
a) Mean(ROI) - $C_{n}^{2}=3.9962 \mathrm{e}-08 \mathrm{~m}^{-2 / 3}$

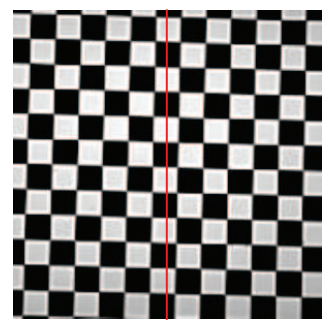

b) $\Omega_{i, j}(0.01 \leq \tau<1)$

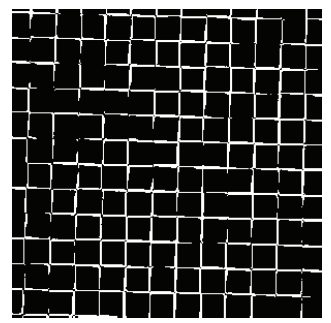

c) DFA-3 Fluctuation functions (central column)

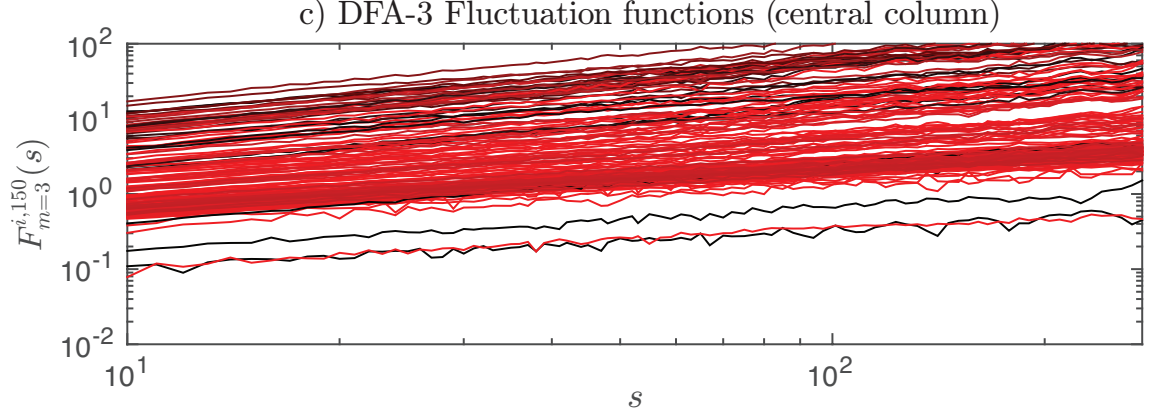

d) $H_{i, j}$

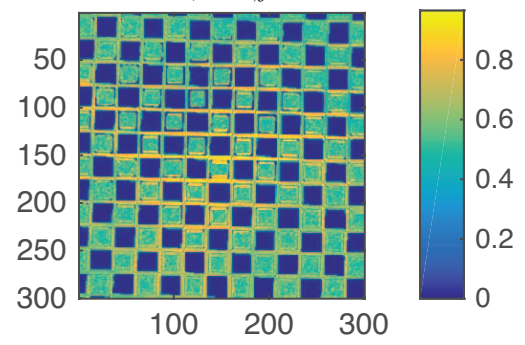

e) $\Delta H_{i, j}$

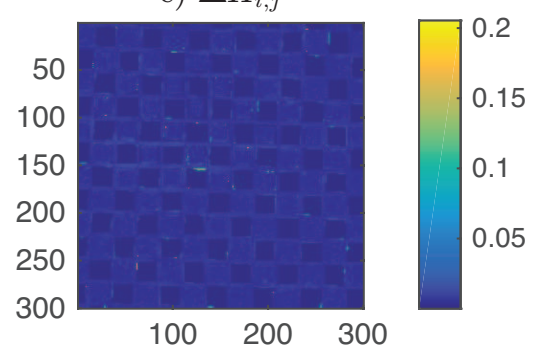

Figura 6.5: Caso representativo, mayor intensidad de turbulencia $\left(C_{n}^{2} \sim 4\right.$. $\left.10^{-8} \mathrm{~m}^{-2 / 3}\right)$. a) Imagen promedio del patrón en la ROI (300 $\times 300$ pixels; 300 pixels $\equiv 15.027 \mathrm{~cm}$ ); la línea roja vertical (columna central) está detallada en -c. b) Representación visual de $\Omega_{i, j}(\tau=0,01)$. c) Funciones de fluctuación para los píxeles de la columna central de -a (línea roja): las curvas van del negro al rojo basadas en el valor promedio del píxel al que corresponden (negro para los más oscuros, rojo para los más brillantes). d) Representación visual de $H_{i, j}$. e) Representación del error $\Delta H_{i, j}$ en la estimación de $H_{i, j}$ (nótese que todos los valores son un orden de magnitud más pequeños que $H_{i, j}$ ). 


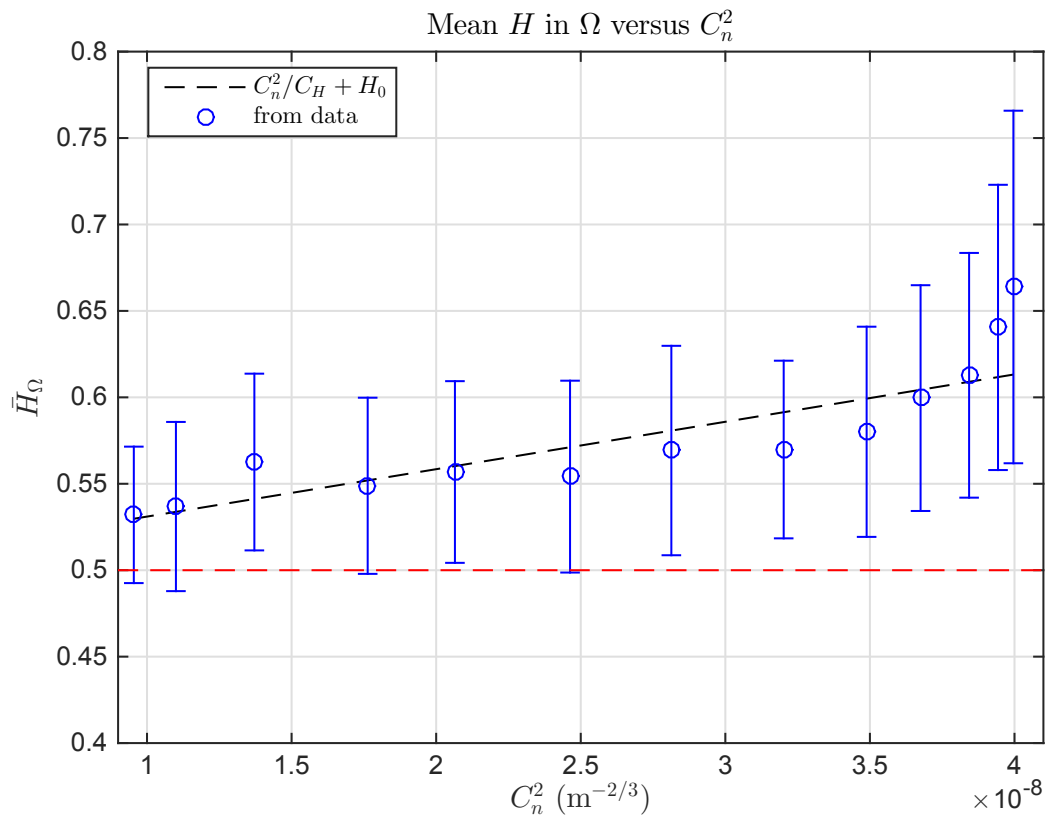

Figura 6.6: Promedio de $H$ en $\Omega$ como función de $C_{n}^{2}$ (las barras de error vienen de la std $(H)$ en ese conjunto); la aproximación lineal (línea negra punteada) tiene $R^{2}=0,7426$. La línea roja punteada indica $H=1 / 2$ (series descorrelacionadas). 
que producen. De hecho, en nuestro rango experimental hemos encontrado una relación lineal sencilla entre las variables descriptas por dichas ecuaciones y $C_{n}^{2}$.

El estudio general de $H_{i, j}$ que hemos hecho también puede ser de utilidad en el campo de reconstrucción de imágenes deformadas por condiciones de turbulencia: para los píxeles con $H_{i, j}<1 / 2$ (anti-persistentes) los incrementos sucesivos en la serie temporal tienen signos opuestos, de manera que tomar el promedio temporal se hace de alguna manera estadísticamente representativo del valor verdadero en el objetivo. Sin embargo, los píxeles que muestran valores mayores de $H_{i, j}$ deben ser necesariamente tratados con otras técnicas de reconstrucción. 


\section{Capítulo 7}

\section{La multifractalidad y el efecto de la turbulencia en la dinámica caótica de un láser de $\mathrm{HeNe}$}

THE Doctor: Amy Pond, there's something you better understand about me, cos it's important, and one day your life may depend on it:

[He smiles] I am definitely a madman with a box.

- Doctor Who, 'The Eleventh Hour'

\subsection{Introducción con un repaso histórico}

El caos en los sistemas de láser gaseoso se ha estudiado en el pasado por medio de un factor de retroalimentación que actúa como un parámetro de bifurcación en la dinámica generada [157 158]. Este fenómeno había sido utilizado anteriormente con fines de alineación [159. De hecho, el Doctor Mario Gallardo refiere la historia de este desarrollo en el Centro de Investigaciones Ópticas:

«Estamos hablando de 1968... 69. Pasaba esto porque cuando nosotros alineábamos los espejos de un láser en un tubo; si el láser pasaba por el tubo 'bien' el espejo hacía que volviera a la entrada del láser. Cuando el láser (que era viejo y estaba agotado) estaba alineado, se apagaba. Ésa fue la primera experiencia.

¿Por qué se apagaba el láser? Así dispuestas las cosas, el láser es perturbado por su propia luz. Según la teoría se produce un fenómeno de caos. Nos preguntamos qué pasaba ahí adentro. Dividi- 
mos el haz: mandábamos mediante un espejito un haz y lo enviábamos a un detector para ver qué pasaba. El haz medido fluctuaba, tenía spikes. Entonces lo usábamos para alinear: cuando mandábamos un haz que volvía y observábamos dividiendo se observaban estos spikes. Creo que [Aníbal "Polo"] Laquidara ahí dijo "che, ¿y si ponemos un parlante acá? a esto lo vamos a escuchar", por eso después se llamó "el ruidómetro". Efectivamente lo escuchábamos. Esa fluctuación del haz de ese sistema caótico que se formaba cuando volvía la luz y se escuchaba ese ruido loco. Empezamos a ver que eso servía para controlar cosas que se movían... que se podían hacer cosas a distancia: con un espejo que concentrara, podíamos hacer cosas a unos cien metros de distancia. [...]

Una experiencia importante que hicimos en los noventa con esto fue en la laminadora de Techint en Ensenada. Las chapas pasan por unos rodillos y las ponen a nivel de grosor de uso para automóviles y lavarropas. Un día se dieron cuenta de que la sección de ese laminado no era rectangular, que estaba deformada. Esto era porque el rodillo que traccionaba la chapa no estaba en su eje y las caras del laminado salían planas, pero no paralelas. Ellos midieron por sus medios y dijeron a la aseguradora que ya tenían estimado cuánto había que correr los rodillos, pero la aseguradora pidió la opinión de un tercero y nos llamaron a nosotros. [...] Entonces controlamos con esto el paralelismo de las superficies de los rodillos. Al final de la medida resultó que la punta estaba corrida un milímetro y monedas, cosa que ellos reconocieron como cierta porque lo habían estimado con unos teodolitos especiales que tenían y les había dado prácticamente igual. Hicimos la medida con Nélida Ruso, colaboró (sin crédito) mi hermano que era otro electrónico y fuimos seguidos por uno de los ingenieros de la planta que no conocía la técnica y quería aprenderla. La planta no paró. Usamos unos tubos de 50 metros para que la turbulencia atmosférica no altere el haz. Finalmente la aseguradora les dio el OK y pudieron mover todo.»

Aunque el caos en los sistemas de láser es una línea de investigación muy activa [160, 161] está enfocada principalmente en los láseres de tipo semiconductor, dejando a este fenómeno en los láseres gaseosos relativamente inexplorado.

Las comunicaciones ópticas a través de la atmósfera están inevitablemente afectadas por la turbulencia atmosférica [162]. Muy recientemente se ha llegado a la conclusión de que teóricamente, en las comunicaciones inalámbricas, el espectro de exponentes de Lyapunov de la serie de tiempo propagado no se degrada cuando pasa a través de la atmósfera, mientras que varias otras propiedades de las series sí se deterioran [163]. En consecuencia, se deduce que las comunicaciones en condiciones caóticas pueden ser capaces de permitir la transmisión de información de manera tanto eficiente como segura [164. Las comunicaciones caóticas a través de la atmósfera con láseres semiconductores se han estudiado por ejemplo por Rulkov et al. [165] y se ha demostrado que 
este tipo de sistemas permite establecer enlaces de comunicación de hasta $5 \mathrm{~km}$ de distancia.

Proponemos el uso de DFA y MF-DFA (Cap.2) para medir la influencia de la turbulencia atmosférica en las dinámica caótica de un láser de HeNe como alternativa al espectro Lyapunov [166]. El comportamiento caótico se genera por medio de un arreglo interferométrico sencillo con una retroalimentación retardada a la cavidad del láser gaseoso. Tales dinámicas se han estudiado en el pasado y modelado como una función del nivel de retroalimentación [157,158. Vamos a emplear nuestro propio criterio basado en la calidad del ajuste lineal para la determinación de los intervalos de ajuste de DFA y MF-DFA para discriminar el mejor rango de adaptación según lo detallado en la Secc. 2.4 Diferentes intensidades de turbulencia isotrópica se han generado con el turbulador 145] (véase el Apéndice E), lo que permite tener una constante de estructura para el índice de refracción del aire $\left(C_{n}^{2}\right)$ ajustable por medio de un parámetro de diferencia de temperatura $(\Delta T)$ en la unidad.

\subsection{Arreglo experimental}

El arreglo experimental se muestra en la Figura 7.1 Los elementos principales son:

- Melles Griot 05-LHP-991 Red Cylindrical Helium Neon Laser (633 nm).

- Turbulador [167, as designed by Keskin et al. 145. Se detalla en el Apéndice $\mathrm{E}$

- Edmund Optics Stepped Neutral Density (ND) Filter (usando una reflectividad de aproximadamente $70 \%$ ).

- Edmund Optics Mounted Linear Glass Polarizing Filter.

- Photodiode detector (0-20 kHz de ancho de banda).

- OWON Digital oscilloscope SDS7102, $100 \mathrm{MHz} 2 \mathrm{Ch}$.

Los ángulos $\alpha$ y $\beta$ (Figura 7.1 arriba) son pequeños, pero son de magnitud suficiente para asegurar que ni el turbulador ni el polarizador realimenten luz a la cavidad del láser.

El filtro ND fue alineado cuidadosamente para reflejar luz directamente dentro de la cavidad del láser y el polarizador fue ajustado y fijado de manera que el detector no saturase su señal de salida $V(t)$ (proporcional a la intensidad lumínica incidente). La frecuencia de muestreo fue de $10 \mathrm{kHz}$ y las series fueron registradas durante 1 segundo.

\subsection{Análisis y discusión}

Corrimos un análisis basado en EMD y MF-DFA con criterio de ajuste sobre los datos crudos de $V(t)$ y encontramos valores de $H$ en el rango [1,2]. 

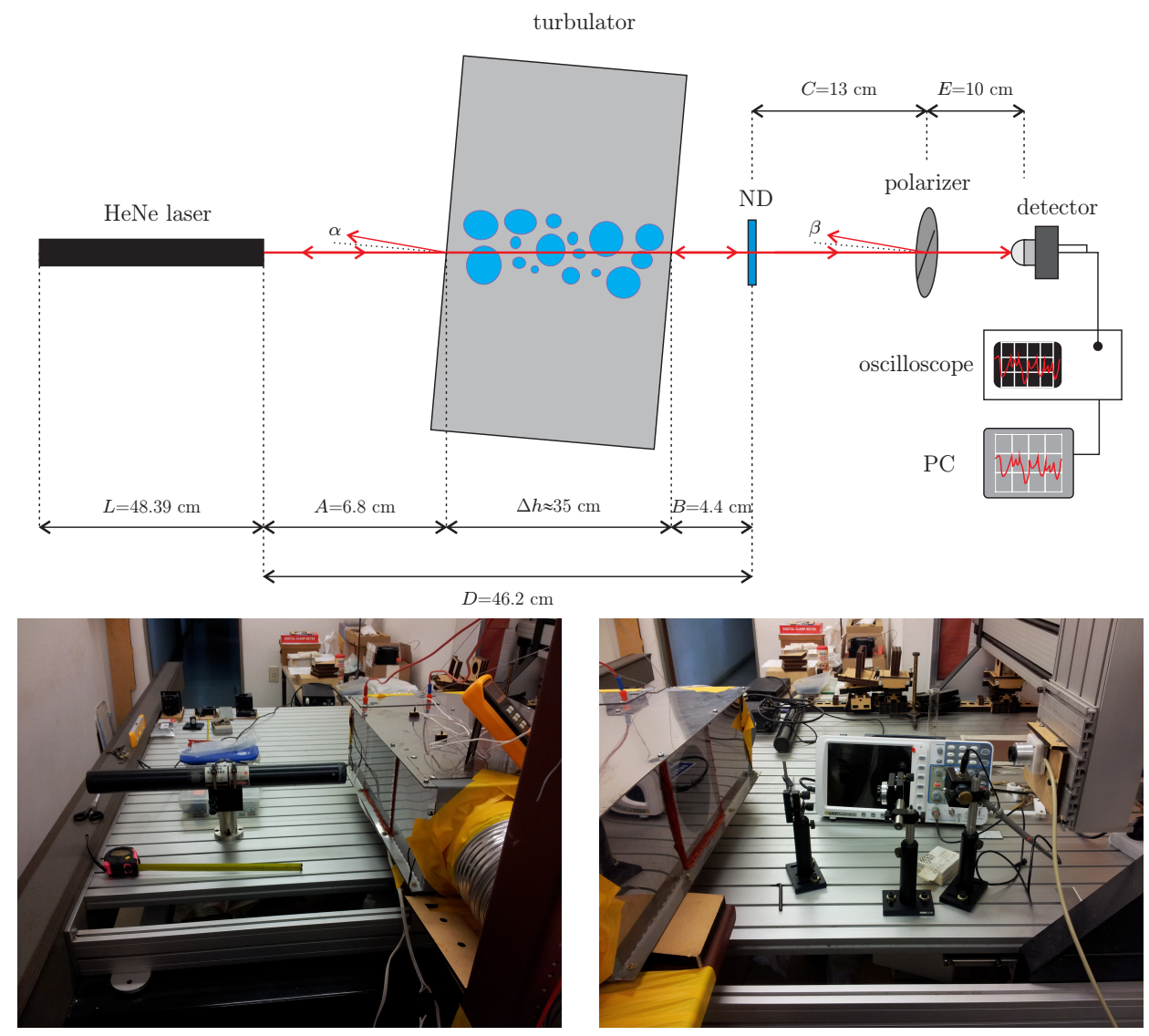

Figura 7.1: Arriba: Esquema del arreglo experimental. Abajo: Detalles del láser y el sistema de detección. 


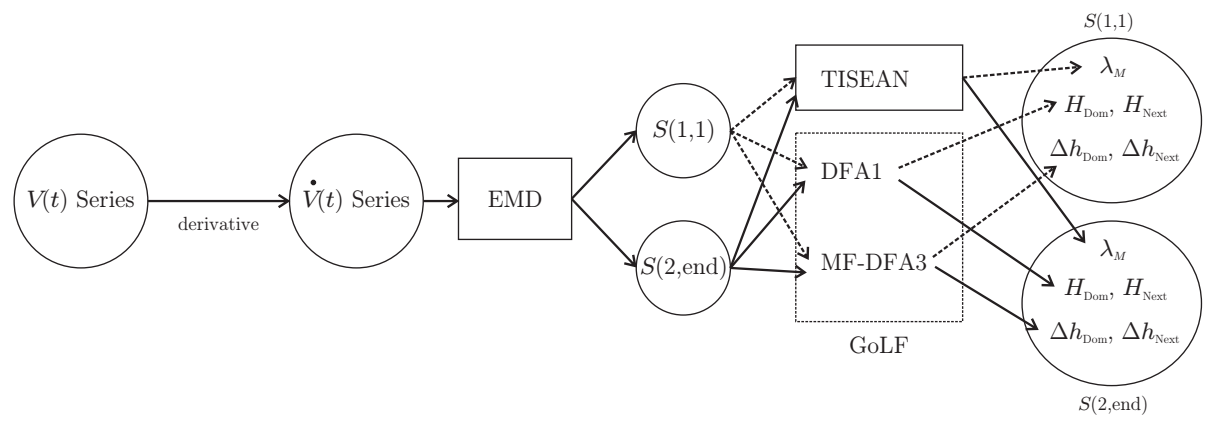

Figura 7.2: Estrategia de análisis de datos.

Decidimos entonces trabajar con la derivada de esta señal $\dot{V}(t)$; este proceso reduce a $h(q)$ aproximadamente en una unidad (haciendo que $H$ quede bien definido). La estrategia general para el procesamiento de datos está detallada en la Figura 7.2 Asimismo determinamos el máximo exponente de Lyapunov de acuerdo a lo descrito en el Apéndice (conservamos los valores arrojados por el paquete TISEAN, pero los confirmamos con las rutinas propias).

Después de un estudio cuidadoso de los resultados de DFA filtrados previemente con EMD tanto para la serie original como sus derivadas, determinamos que las componente de alta frecuencia (así como las propiedades monofractales) existen predominantemente en $S(1,1)$ (principalmente ruido electrónico), y que las componentes de menor frecuencia (caos y turbulencia) existen en la suma de todas la IMF excepto la primera (llamaremos a esta suma $S(2$, end), puesto que la cantidad de descomposiciones puede variar: la media usual es 12).

Siguiendo a Kantz et al. [166] estimamos el máximo exponente de Lyapunov $\left(\lambda_{M}\right)$ para $S(1,1)$ y $S(2$, end $)$ en cada intensidad de turbulencia. Un valor positivo es hallado luego del procesamiento, confirmando que las series son caóticas.

Usamos DFA1 para hallar $H$ para $S(1,1)$ y $S(2$, end). Usamos MF-DFA3 con $q \in[-20,20]$ para hallar los espectros multifractales $h(q)$ para $S(1,1)$ y $S(2$, end) y calculamos el rango multifractal MFR $(\Delta h)$. Los rangos de ajuste hallados para DFA1 y MF-DFA3 son de la clase 'Dominant' y 'Next' , y fueron obtenidos con el criterio de calidad de ajuste lineal $\operatorname{con} \delta=25$.

Una señal típica se presenta en la Fig 7.3 El diagrama de fase de $\dot{V}(t)$ versus $V(t)$ (Figura 7.4 muestra un aumento en la dispersión a medida que $\Delta T\left(\equiv C_{n}^{2}\right)$ aumenta.

Tanto $V(t)$ como $\dot{V}(t)$, así como sus descomposiciones parciales $S(1,1)$ y $S$ (2, end) han mostrado un $\lambda_{M}$ positivo y pueden ser consideradas como caóticas. Un ejemplo de la descomposición EMD se muestra en la Figura 2.19: un

\footnotetext{
${ }^{1}$ Para hallar rápidamente el valor máximo $\lambda_{\max }$, estudiamos directamente la derivada de $S$ respecto de la iteración $\Delta n$; como por ejemplo sería estudiar las diferencias sucesivas de $S$ respecto de $\Delta n$ en la Figura D.5 en la página 151
} 

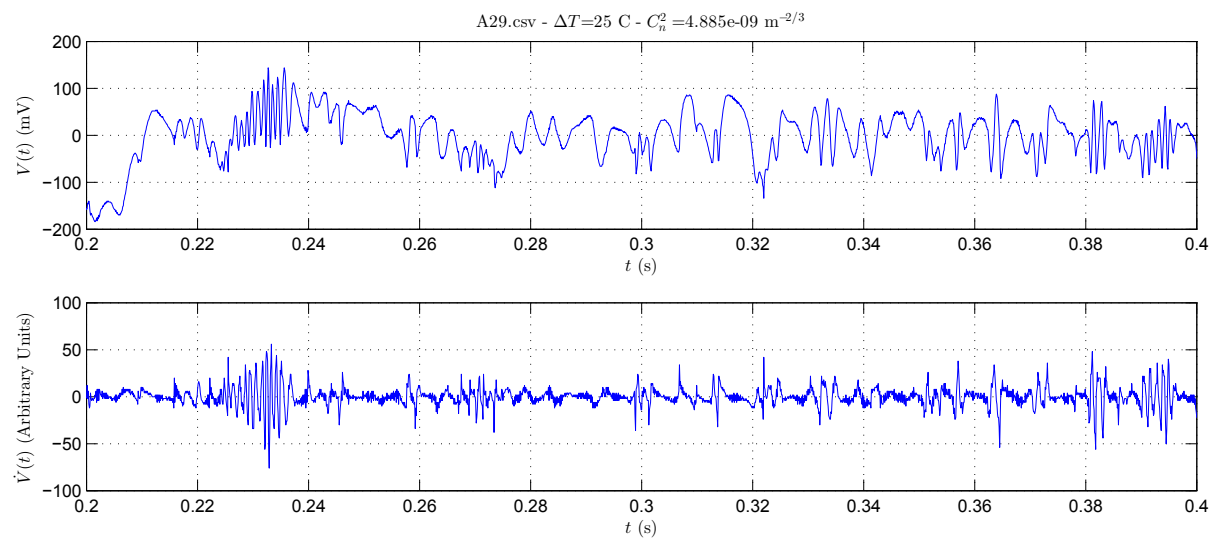

Figura 7.3: Señal típica a la salida y su derivada $\left(\Delta T=25 C, C_{n}^{2}=4,885\right.$. $\left.10^{-9} \mathrm{~m}^{-2 / 3}\right)$.

ejemplo de la salida del análisis de $\dot{V}(t)(S(1,1)$ and $S$ (2, end)) se muestra en la figura.7.6 En general se encuentran regiones de tipo 'Dominant'para pequeños valores de $s$ (pequeñas escalas), mientras que las regiones 'Next' generalmente han aparecido para valores grandes de $s$. Tal es el caso para las funciones de fluctuación para MF-DFA3 en la Figura 7.6 donde la región 'Dominant' es casi toda la gama de escala y/o no hay regiones 'Next' identificadas; hemos asumido ambas regiones iguales para los propósitos de la figura. 7.7 ('Next/Dominant').

$\dot{V}(t), S(1,1)$ : El valor medio de $H$ para la región 'Dominant' es $0,432 \pm$ 0,13 , mientras que en la región 'Next/Dominant' es $0,395 \pm 0,219$. Combinando ambos conjuntos de datos obtenemos un valor esperado $\langle H\rangle=0,413 \pm 0,179$ (Figura 7.7 a)). El rango multifractal para la región 'Dominant' es 0,358 $\pm 0,199$ (la gran dispersión en la región 'Next/Dominant' arroja 2,74 $\pm 3,76$ ) (Figura7.7 c)). Estos resultados combinados sugieren que $S(1,1)$ (la componente de altas frecuencias de la derivada de la señal) es un monofractal descorrelacionado por debajo de un movimiento browniano que está probablemente vinculado al ruido electrónico.

$\dot{V}(t), S\left(2\right.$, end): existe una notable correlación entre $C_{n}^{2}$ y el exponente de Hurst $H$ tanto para los ajustes hechos en la región 'Dominant' y la 'Next/Dominant' (Figura 7.7 b)). Los ajustes lineales 2 se detallan en la Figura 7.8 Los rangos multifractales (MFR) muestran a grandes resgos un decaimiento exponencial respecto de $C_{n}^{2}$ con mejor acuerdo para las regiones 'Next/Dominant' (correlaciones de grandes escalas) (Figura 7.9. Esto sugiere que la turbulencia actúa como un factor de ruido en el sistema multifractal caóticd 3 llevando a

\footnotetext{
${ }^{2}$ Los puntos de la menor $C_{n}^{2}$ tienen una desviación que puede ser corregida tomando promedios de grandes conjuntos de mediciones posteriores (Figura 7.7b) y Figura 7.8. Esto también mejoraría la intepretación de la Figura 7.9

${ }^{3}$ Considerando el caos inducido por la retroalimentación y posiblemente el ruido de naturaleza
} 

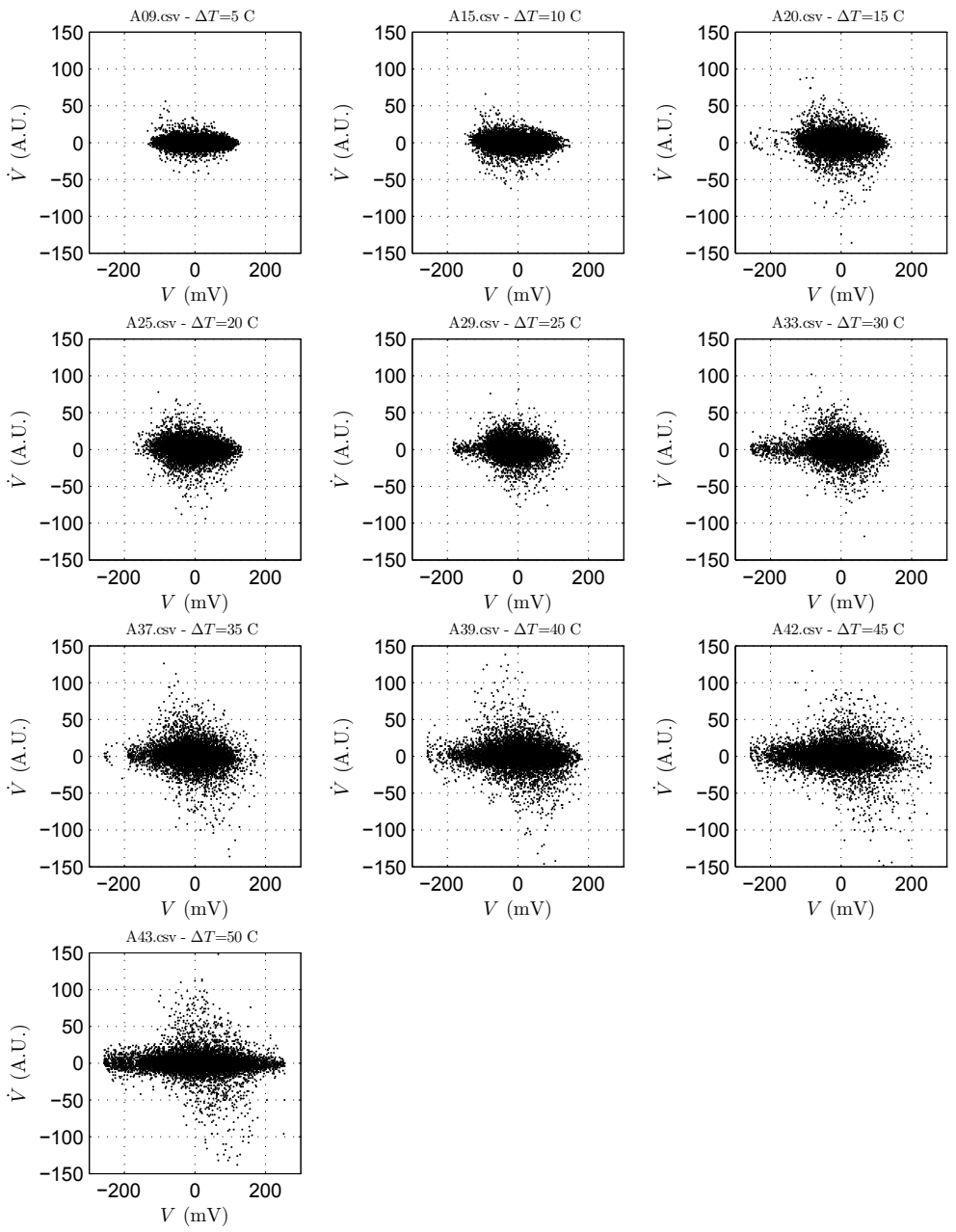

Figura 7.4: Diagrama de fase de $\dot{V}(t)$ versus $V(t)$ (donde $V$ es la tensión registrada por el detector, que es proporcional a la intensidad lumínica); 'A.U.' significa 'Unidades Arbitrarias' . 
éste hacia un monofractal caótico con correlaciones en aumento, tal como fue reportado por Gulich y Zunino para series artificiales [54].

\subsection{Conclusiones}

Hemos generado con éxito un régimen de caos en un láser de gas con retroalimentación simple, mientras introdujimos un parámetro de turbulencia controlada. Hemos sido capaces de separar la componente de ruido de alta frecuencia en la señal del caos afectado por la turbulencia después de la diferenciación y la el filtrado por EMD de las series temporales. Hemos encontrado que la intensidad de la turbulencia del aire $\left(C_{n}^{2}\right)$ tiene una muy buena correlación con el exponente de Hurst $H$ tanto para escalas de tiempo pequeñas como grandes. La turbulencia actúa como un factor de ruido en el sistema multifractal caótico conduciéndolo hacia un monofractal caótico mientras que aumenta las correlaciones.

Teniendo en cuenta el reciente interés en el cifrado de mensajes con este tipo de configuraciones, el estudio de los efectos de la turbulencia atmosférica juega un papel clave en el campo de la comunicación por láser segura a través de la atmósfera. Creemos que estos resultados pueden ser de utilidad para la optimización del rendimiento de los sistemas de comunicación por láser en el espacio libre mediante regímenes caóticos. Una discusión sobre este tema se encuentra también en [168].

mecánica en inherente al turbulador. 

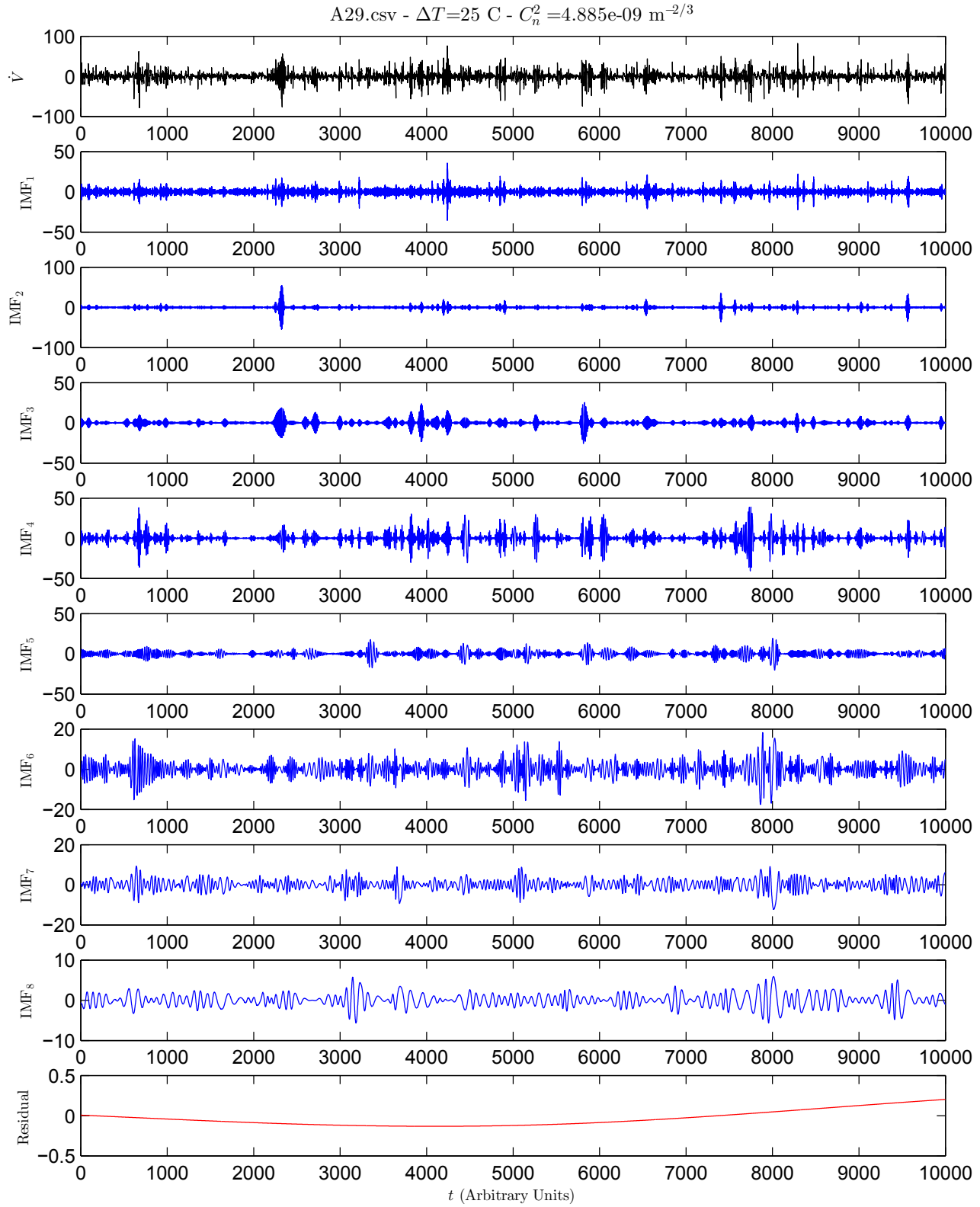

Figura 7.5: Descomposición EMD de las series derivadas $\left(\Delta T=25 \mathrm{C}, C_{n}^{2}=4,885\right.$. $10^{-9} \mathrm{~m}^{-2 / 3}$ ). En este caso en particular los niveles de descomposición fueron 15; sólo se muestran $\mathrm{IMF}_{1}-\mathrm{IMF}_{8}$ (azul) y el residug (rojo). 

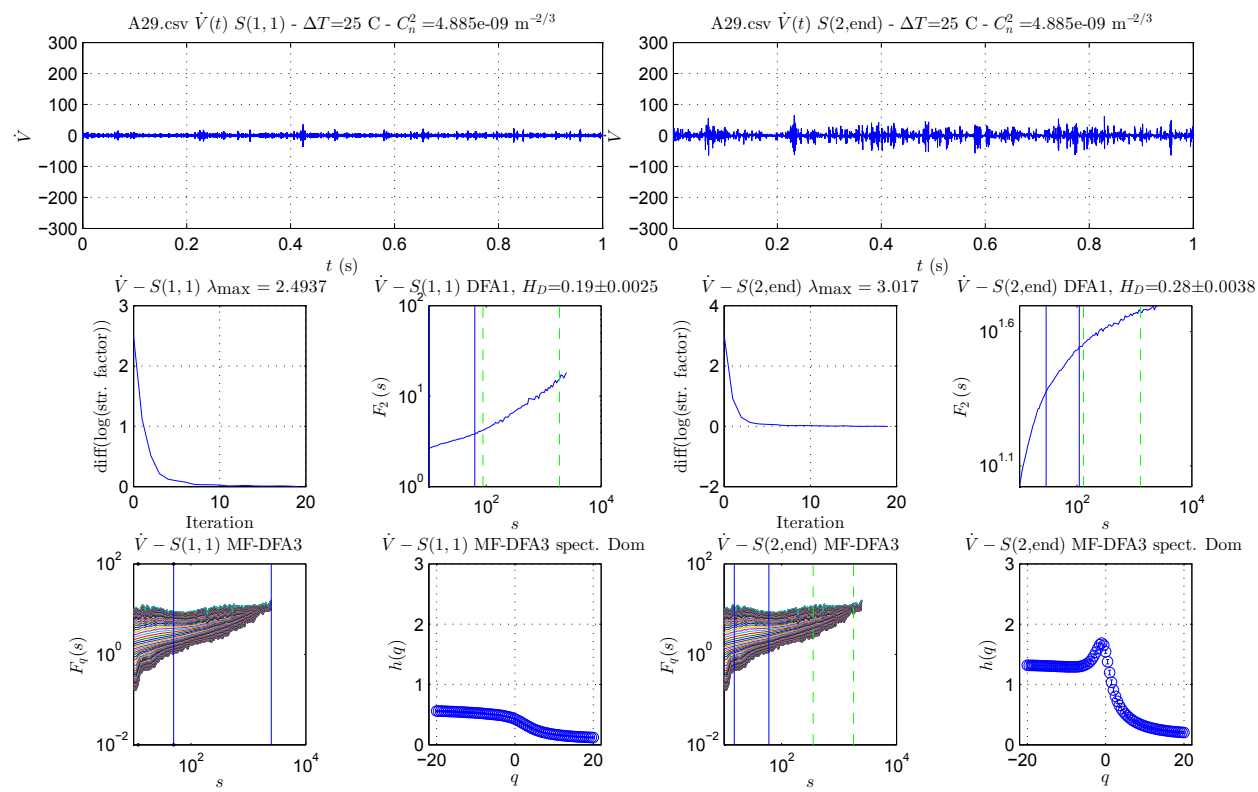

Figura 7.6: Ejemplo del análisis de la serie derivada $\left(\Delta T=25 \mathrm{C}, C_{n}^{2}=4,885\right.$. $10^{-9} \mathrm{~m}^{-2 / 3}$ ). En azul están indicadas las regiones de ajuste 'Dominant' y las de tipo 'Next' en verde. 

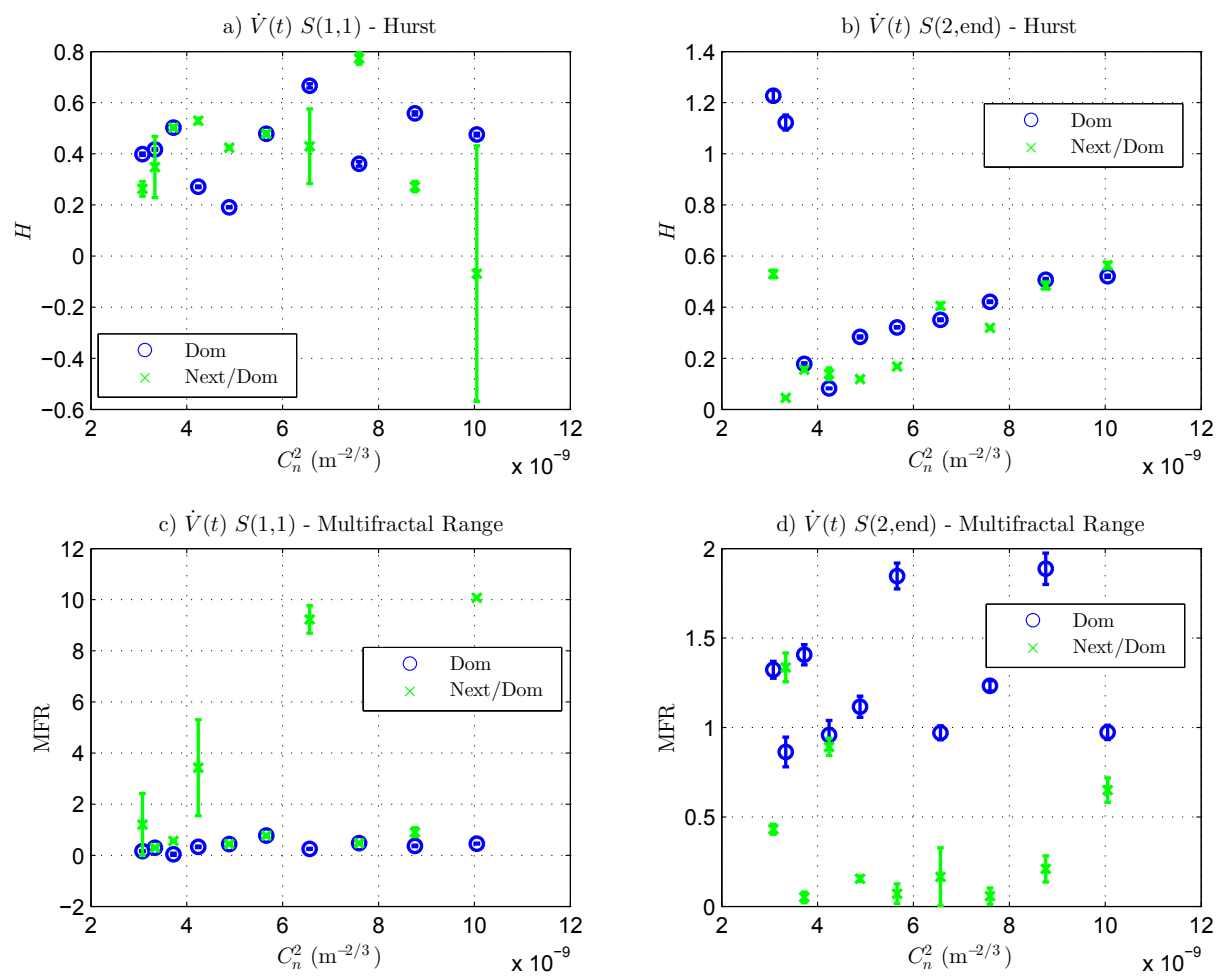

Figura 7.7: Análisis fractal y multifractal para $\dot{V}(t)(S(1,1)$ y $S(2$, end $))$. a) y b) Los exponentes de Hurst para los ajustes en las regiones 'Dominant' $\mathrm{y}$ 'Next/Dominant' . c) y d) Rango multifractal para las regiones 'Dominant' y 'Next/Dominant'. 

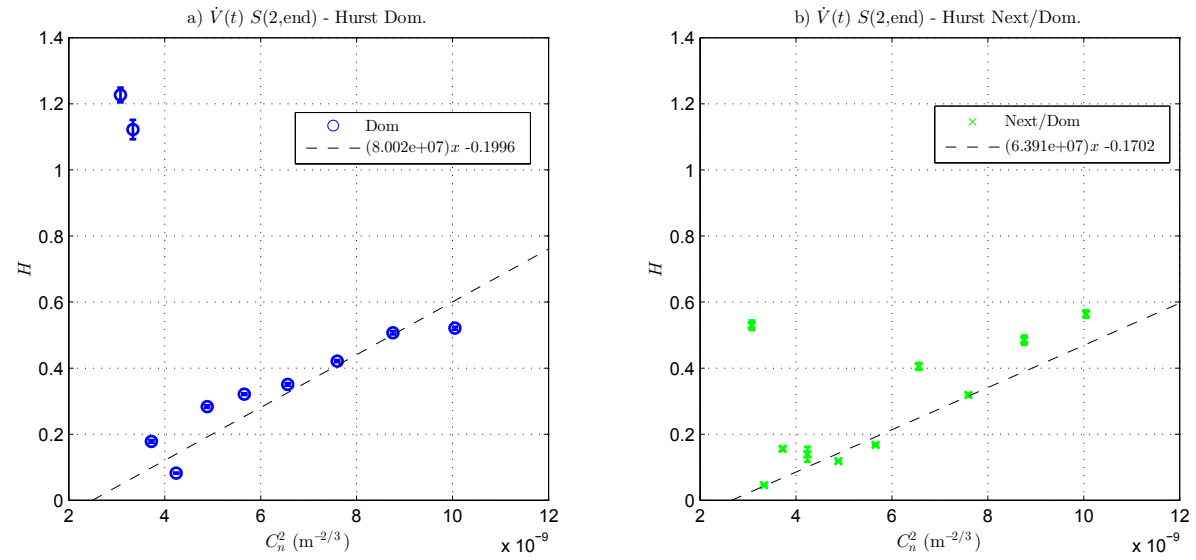

Figura 7.8: Ajustes lineales de los exponentes de Hurst de $\dot{V}(t) S(2$, end). a) Excluyendo los dos primeros puntos, la regresión lineal tiene una calidad $R^{2}=0,8461$ (región 'Dominant'). b) Excluyendo el primer punto la calidad de la regresión lineal es $R^{2}=0,878$ (región 'Next/Dominant').
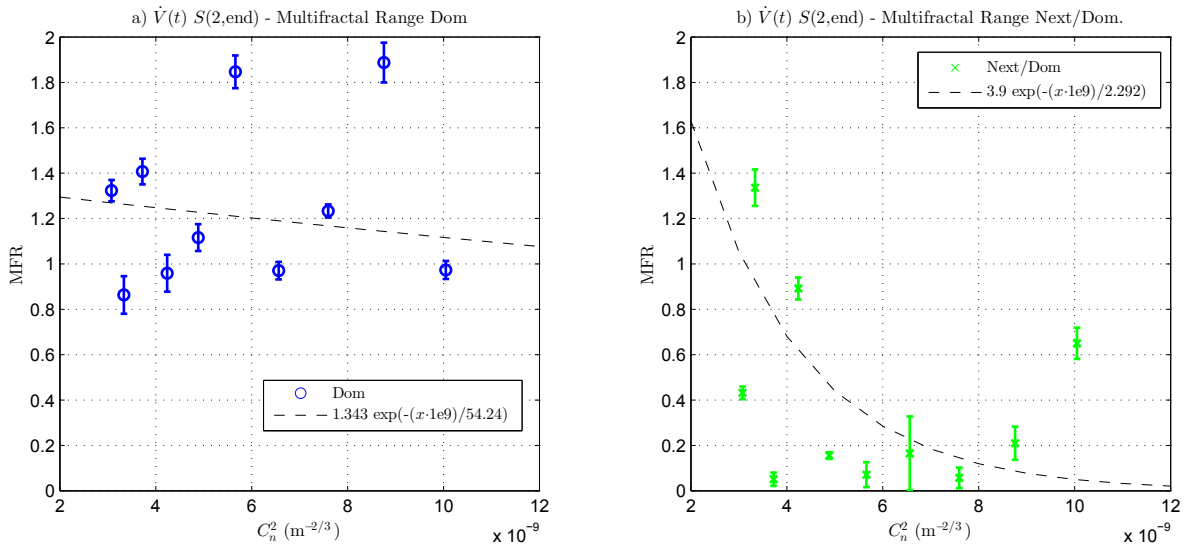

Figura 7.9: Ajustes de decaimiento exponential para $\dot{V}(t) S$ (2, end) MFR. a) Región ‘Dominant'. b) Región 'Next/Dominant'. 


\section{Capítulo 8}

\section{Conclusiones}

\subsection{Técnicas de análisis}

En el estudio del efecto de los ruidos sobre los espectros multifractales (Capítulo 2, hemos encontrado que el efecto espurio de ruidos aditivos correlacionados debe tenerse debidamente en cuenta al analizar el carácter multifractal de datos experimentales (Sección 2.3. . Los espectros multifractales estimados mediante la técnica MF-DFA pueden estar sesgados debido a la presencia de tales artefactos. Por un lado, $\operatorname{los} h(q)$ con $q<2$ son notablemente subestimados para una pequeña cantidad de ruido aditivo correlacionado y no correlacionado. Por otro lado, las adiciones moderadas de ruidos coloreados también afec$\tan h(q)$ con $q \geq 2$. Más precisamente, los exponentes de Hurst generalizados en este rango de $q$ están sobreestimados y el sesgo es más significativo cuando la correlación del ruido aumenta. Está claro que las correlaciones de largo alcance presentes en los ruidos tienen una influencia en los comportamientos de escala asociados a grandes fluctuaciones y por lo tanto, los momentos positivos resultan afectados. Teniendo en cuenta que los ruidos correlacionados están inherentemente presentes en los datos experimentales, los resultados obtenidos pueden ser útiles para revelar características multifractales en situaciones prácticas.

En la Sección 2.4.2 hemos propuesto y empleado un criterio conceptualmente simple para determinar sistemáticamente las regiones óptimas de ajuste para las funciones de fluctuación en DFA; y lo hemos generalizado para MFDFA. Este método proporciona una clasificación para estas regiones de escalamiento óptimo ('Previous', 'Dominant', 'Next') sobre la base de la calidad del ajuste lineal de las funciones de fluctuación en un gráfico log-log. Cuando se utiliza en DFA, esta técnica ayuda a identificar las escalas de crossover entre los diferentes regímenes de ley de potencia. Cuando se utiliza en MF-DFA, estima el rango de ajuste del espectro multifractal que tiene las barras de error más pequeñas.

Las regiones de ajuste son un punto crítico en DFA y MF-DFA y su identi- 
ficación óptima es una tarea fundamental para una verdadera determinación del fenómeno de escala subyacente. Tanto el caso mono como el multifractal a menudo son dependientes del tamaño de escala; el criterio propuesto en este trabajo ayuda a identificar comportamientos de escala y de multi-escala de una manera más precisa, confiable y objetiva. Por otra parte, las escalas de crossover que separan dos o más regímenes pueden estimarse fácilmente.

Este criterio puede ser automatizado para el análisis de grandes conjuntos de series temporales, ya que no requiere ningún conocimiento previo sobre los datos en bruto. Por otra parte, las variantes en tiempo real de DFA introducidas para el seguimiento y previsión de las señales que cambian dinámicamente (médicas, meteorológicas, de mercado, acciones, etc.) 93 así como los análisis locales de DFA y MF-DFA ideados para seguir la evolución en el tiempo de propiedades fractales y multifractales en los datos [94] pueden beneficiarse especialmente de su implementación. A pesar de tratarse de un algoritmo de fuerza bruta, la cantidad de cálculos implicados hace que sea computacionalmente práctico.

\subsection{Experiencias}

\subsubsection{Memoria en frentes de onda estelares}

En el Capítulo 4 hemos confirmado la presencia de correlaciones de largo alcance en las fluctuaciones de AA de frentes de onda estelares que se propagan a través de la turbulencia atmosférica. El exponente de Hurst estimado siempre está cerca, pero por debajo del valor $5 / 6$ esperado teóricamente para una turbulencia de Kolmogorov. De hecho, este exponente de Hurst estimado por debajo de lo esperado originalmente se puede entender en términos de un modelo de turbulencia no-Kolmogorov. Vale la pena destacar que estos resultados permiten sugerir que la fase del frente de onda degradado por la turbulencia puede ser modelado como un $\mathrm{fBm}$ con $H \approx 0,8$. La predictibilidad inherente asociada con este proceso estocástico persistente podría ser útil para mejorar el rendimiento de técnicas de alta resolución angular.

\subsubsection{Persistencia en el wandering láser inducida por la turbu- lencia}

En las experiencias para estudiar la persistencia en el wandering de un haz láser (Capítulo 5) encontramos que el exponente de Hurst muestra un comportamiento creciente, tanto para las coordenadas horizontales y verticales, saturando a un valor cercano a $5 / 6$ para los mayores valores de $C_{n}^{2}$. Los resultados obtenidos permiten confirmar que la turbulencia introduce efectos de memoria en las series temporales de wandering, puesto que una dinámica altamente persistente se observa para las mayores intensidades de turbulencia. Además, la similitud entre los exponentes de Hurst estimados horizontales y verticales 
confirma la isotropía de la turbulencia dentro de la cámara de laboratorio. Vale la pena mencionar aquí que $H=5 / 6$ se ha propuesto originalmente como un resultado teórico dentro del modelo de Kolmogorov [119, y muy recientemente estudiado experimentalmente [130], por las fluctuaciones del ángulo de arribo de frentes de onda estelares propagándose a través de la turbulencia atmosférica.

Resumiendo, se concluye la existencia de un comportamiento fractal estocástico claramente persistente del análisis por DFA del wandering de un haz láser pasando por una turbulencia generada en laboratorio. Los exponentes de Hurst estimados para las dos coordenadas convergen (de a poco) a un valor cercano a 5/6 - el valor teórico asociado a la turbulencia de Kolmogorov para las condiciones de turbulencia más intensa.

\subsubsection{Centelleo de imágenes y correlaciones temporales}

El modelo propuesto en el Capítulo6 6 para el estudio del centelleo de luz incoherente a través de la turbulencia brinda la posibilidad de emplear un arreglo experimental sencillo para lograr una estimación razonable de $C_{n}^{2}$ tomando ventaja de la propagación de luz proveniente de una imagen de alto contraste. Propusimos un factor de estructura por centelleo de píxeles $\left(G_{0}\right)$ y estimamos su valor a partir de datos experimentales. Mediante consideraciones adecuadas sobre las características de los píxeles, nos fue posible estimar constantes de estructura dentro de un rango lineal empírico.

Hemos encontrado que, al capturar imágenes sucesivas de objetivos de alto contraste a través de turbulencia atmosférica, aumentan las correlaciones con la intensidad de la turbulencia para los píxeles con un índice de centelleo relativamente alto. Este comportamiento puede ser clave para refinar el aspecto temporal tanto en las técnicas de simulación como en los modelos teóricos. Las técnicas de simulación deben tener en cuenta las restricciones que los comportamientos encontrados imponen sobre las series temporales de los píxeles individuales que producen. De hecho, en nuestro rango experimental hemos encontrado una relación lineal sencilla entre las variables descriptas por dichas ecuaciones y $C_{n}^{2}$.

El estudio general de $H_{i, j}$ que hemos hecho también puede ser de utilidad en el campo de reconstrucción de imágenes deformadas por condiciones de turbulencia: para los píxeles con $H_{i, j}<1 / 2$ (anti-persistentes) los incrementos sucesivos en la serie temporal tienen signos opuestos, de manera que tomar el promedio temporal se hace de alguna manera estadísticamente representativo del valor verdadero en el objetivo. Sin embargo, los píxeles que muestran valores mayores de $H_{i, j}$ deben ser necesariamente tratados con otras técnicas de reconstrucción. 


\subsubsection{La multifractalidad y el efecto de la turbulencia en la di- námica caótica de un láser de $\mathrm{HeNe}$}

En el Capítulo7hemos generado con éxito un régimen de caos en un láser de gas con retroalimentación simple, mientras introdujimos un parámetro de turbulencia controlada. Hemos sido capaces de separar el componente de ruido de alta frecuencia en la señal del caos afectado por la turbulencia después de la diferenciación y el filtrado por EMD de las series temporales. Hemos encontrado que la intensidad de la turbulencia del aire $\left(C_{n}^{2}\right)$ tiene una muy buena correlación con el exponente de Hurst $H$ tanto para escalas de tiempo pequeñas como grandes. La turbulencia actúa como un factor de ruido en el sistema multifractal caótico conduciéndolo hacia un monofractal caótico mientras que aumenta las correlaciones.

Teniendo en cuenta el reciente interés en el cifrado de mensajes con este tipo de configuraciones, el estudio de los efectos de la turbulencia atmosférica juega un papel clave en el campo de la comunicación por láser segura a través de la atmósfera. Creemos que estos resultados pueden ser de utilidad para la optimización del rendimiento de los sistemas de comunicación por láser en el espacio libre aprovechando un régimen caótico.

\subsection{Temas de frontera}

\subsubsection{Centelleo de imágenes y correlaciones temporales}

La degradación por seeing causada por la turbulencia atmosférica en imágenes astronómicas puede evitarse mediante el uso de telescopios en órbita, como lo es por ejemplo el telescopio espacial Hubble. Los aparatos de detección no están afectados por la atmósfera. Las soluciones espaciales siguen siendo difíciles de implementar, mantener y mejorar con el tiempo en comparación con los sistemas de imágenes astronómicas basadas en tierra. La búsqueda de la resolución comparable de los telescopios basados Tierra ha dado lugar a una línea de investigación muy activa; siendo la técnica de lucky imaging una de las más exitosas [169 170]. El estudio fino de centelleo y correlaciones temporales en situaciones de imágenes de objetos estacionarios detallado en el Capítulo 6 puede ayudar a distinguir las diversas técnicas de reconstrucción que puedan ser necesarias en diversas partes de una misma imagen.

\subsubsection{Comunicaciones ópticas por un canal caótico}

Las comunicaciones ópticas a través de la atmósfera constituyen un tema de gran interés reciente debido a la movilidad de los equipos y el gran ancho de banda disponible [165]. Se justifica entonces un estudio detallado de la influencia de la turbulencia atmosférica en este tipo de canal de comunicación tal. Una de las técnicas más novedosas en comunicaciones a través de la atmósfera consiste en propagar señales caóticas [163]. En el pasado se ha estudiado 
la caoticidad en sistemas de láser gaseoso al introducir un factor de realimentación. Dicho factor actúa como parámetro bifurcante en la dinámica generada 157 158. Cabe destacar que aunque la dinámica caótica en láseres es una línea de investigación muy activa [160 161 que principalmente se encuentra enfocada en láseres de tipo semiconductor (en [165] se han presentado enlaces de comunicación de hasta $5 \mathrm{~km}$ de largo), la dinámica caótica en láseres de tipo gaseoso ha sido menos explorada.

Como es de esperar, las comunicaciones ópticas a través de la atmósfera se ven afectadas por la turbulencia [162]. Muy recientemente se ha concluido teóricamente que en comunicaciones inalámbricas caóticas el espectro de exponentes de Lyapunov de las series temporales propagadas no se degrada al pasar por la atmósfera, mientras que diversas otras propiedades de la serie sí se deterioran 163. De allí se desprende que una comunicación en condiciones de caoticidad permitiría la transmisión de información de manera eficiente y segura 164.

En el Capítulo 7 hemos esbozado un primer abordaje experimental a esta problemática. Queda por ejemplo corroborar fuera de la teoría [163] si el espectro de Lyapunov de una serie caótica se ve afectado o no por la turbulencia atmosférica. Para esto basta con:

1. En un láser, modular en el tiempo una señal de algún objeto caótico de espectro de Lyapunov conocido.

2. Estimar el espectro de Lyapunov de la serie de tiempo de la intensidad del láser al salir del turbulador.

3. Comparar los espectros de entrada/salida en diversas intensidades de turbulencia.

La máxima dificultad en esta experiencia no es en sí hacerla, sino lograr que coincidan en un mismo lugar y a un mismo tiempo un turbulador totalmente caracterizado con un sistema de modulación arbitraria de láser. Los altos valores de $C_{n}^{2}$ logrados en el turbulador son en realidad una ventaja para este experimento: corroborar que los espectros en esa situación no cambian es casi una garantía de que en casos atmosféricos tampoco lo harán. La experiencia en campo (con una intensidad de turbulencia incontrolable por el experimentador) sería entonces un apéndice de lo estudiado en laboratorio.

\subsubsection{Simulaciones}

Es posible formular un planteo de propagación de luz (imágenes) a través de un medio turbulento siguiendo el modelo de sistemas de agentes autopropulsados propuesto por T. Vicsek et al. [171]172]. El modelo de Vicsek se basa en la suposición de que cada individuo o agente autopropulsado tiende a adoptar la dirección de movimiento de sus vecinos, perturbados por un cierto ruido intrínseco que afecta sus interacciones. Una de las características más interesantes del modelo de Vicsek es que muestra una transición de fase, similar a la 
observada en otros sistemas físicos, entre un estado de movimiento colectivo ordenado (régimen de ruido bajo) y un estado desordenado que se asemeja a un gas (régimen de ruido alto).

Una experiencia de propagación de imágenes como la que describimos en el Capítulo 6 puede ser interpretable en términos de muchos haces paralelos como los que estudiamos en la experiencia del Capítulo 5 Si consideramos que cada haz se comporta como un agente autopropulsado con una posición inicial fija y con velocidad cero, puede considerarse que el wandering estudiado es sólo el ruido que afecta a una versión degenerada del modelo de Vicsek. Las fluctuaciones de intensidad en un determinado píxel en el detector se deberán entonces a la suma de las contribuciones de vecinos haciendo wandering. La información sobre la desviación estándar de las posiciones del centroide, así como el comportamiento de $H$ en función de $C_{n}^{2}$ (Capítulo 5) son de vital importancia para este estudio. 
Apéndices 



\section{Apéndice A}

\section{MFDFA: Toolbox de MATLAB para Multifractal Detrended Fluctuation Analysis}

Archivos: F2_MFDFA.m, MFDFAQ.m, PLOTMFDFA.m, LOGPLOTMFDFA.m, MFDFAFIT.m Ambiente nativo: MATLAB R2010a.

\section{A.1. Esquema de uso}

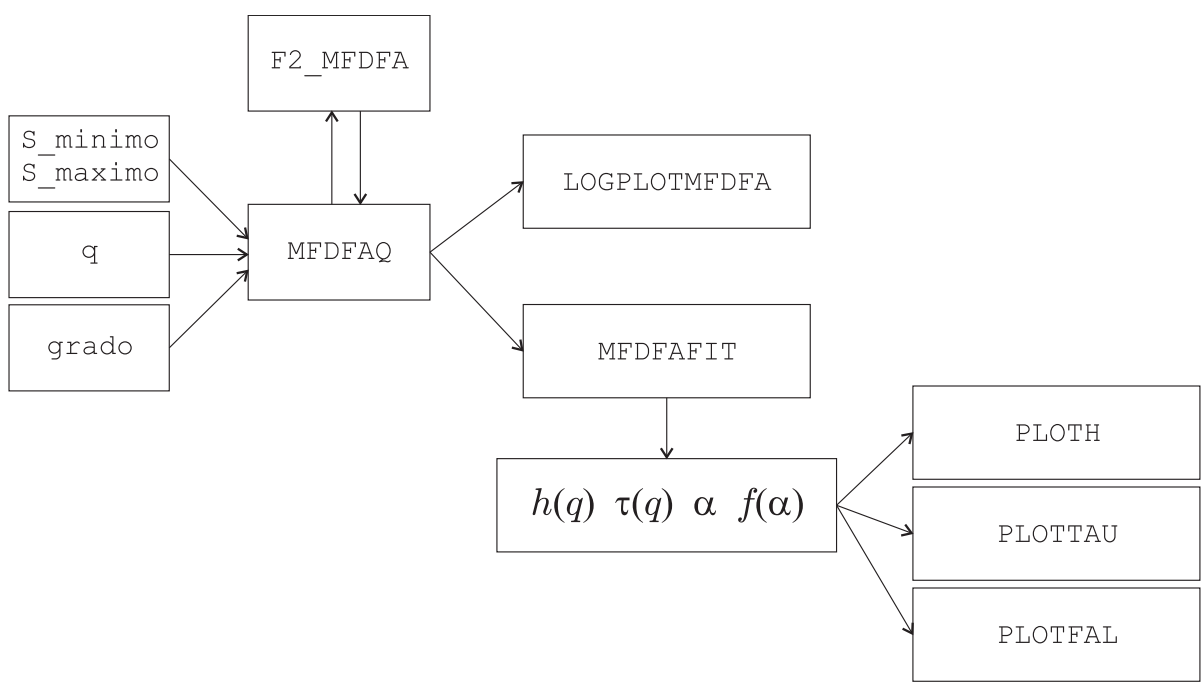

Figura A.1: Esquema de uso del toolbox. 


\section{A.2. F2_MFDFA.m}

\section{A.2.1. Sintaxis}

$$
\text { F2_MFDFA( serie, s, grado) }
$$

Donde

- serie es un vector fila con ls datos a analizar

- s es el ancho de ventana

- grado es el grado del polinomio que se utiliza para remover las tendencias en la ventana

Esta parte sólo calcula las desviaciones cuadráticas de la serie dada la escala s de la ventana. El grado indica el grado del polinomio de aproximación (generalmente se usa 2).

\section{A.2.2. Salida}

La salida es un vector columna de $2 N_{s}$ elementos (ver A.2.3.

\section{A.2.3. Funcionamiento interno}

Determinar el rango de la serie $(N)$ y su promedio total $\langle x\rangle$

Determinar el perfil $Y$ (nuevo vector columna de $N$ datos) según

$$
Y(i)=\sum_{k=0}^{i}\left[x_{k}-\langle x\rangle\right], i=1, \ldots, N
$$

Dividir la cadena de los $Y$ en $N_{s}$ partes de $s$ datos donde

$$
N_{s}=\left\lfloor\frac{N}{s}\right\rfloor
$$

Aproximar por un polinomio de grado = grado en cada uno de los segmentos y promediar las desviaciones cuadráticas medias respecto de los $Y(i)$, generando asi un nuevo vector columna de $2 N_{s}$ datos F2_MFDFA.

- Si $N$ es exactamente divisible por $N_{s}$, los valores de F2_MFDFA están repetidos dos veces.

- Si $N$ es no exactamente divisible por $N_{s}$, se hacen dos pasadas a la serie considerando el offset del resto. 


\section{A.3. MFDFAQ.m}

\section{A.3.1. Sintaxis}

$\operatorname{MFDFAQ}($ serie, S_min, S_max, S_cantidad, grado, q )

Funciones requeridas: F2_MFDFA, S_vec.m

Donde

- serie es la serie a analizar

- s es el parámetro de ventana,

- grado es el grado polinómico (usualmente 2)

- q es el vector FILA de las potencias de promediado

S_vec genera una serie de S_cantidad valores entre S_min y S_max que están distribuidos uniformemente cuando se los logaritma.

$q$ debe estar definido previamente. Una forma usual de hacerlo es, por ejemplo: $q=-20: 1: 20$.

\section{A.3.2. Salida}

La salida es una matriz ordenada según la tabla A.1

\begin{tabular}{|c|c|c|c|}
\hline$s$ & $q_{\text {inicial }}$ & $\cdots$ & $q_{\text {final }}$ \\
\hline \hline$s_{\text {min }}=$ S_min & $F_{q_{\text {inicial }}}\left(s_{\text {min }}\right)$ & $\cdots$ & $F_{q_{\text {final }}}\left(s_{\text {min }}\right)$ \\
\hline$\vdots$ & $\vdots$ & $\vdots$ & $\vdots$ \\
\hline$s_{\text {max }}=$ S_max & $F_{q_{\text {inicial }}}\left(s_{\text {max }}\right)$ & $\cdots$ & $F_{q_{\text {final }}}\left(s_{\text {max }}\right)$ \\
\hline
\end{tabular}

Tabla A.1: Organización de salida de MFDFAQ.

Cada valor de $F_{q}(s)$ está calculado según

$$
\begin{aligned}
& F_{q}(s)=\left\{\frac{1}{2 N_{s}} \sum_{v=1}^{2 N_{s}}\left[F^{2}(v, s)\right]^{q / 2}\right\}^{1 / q}, \quad q \neq 0 \\
& F_{q}(s)=\exp \left\{\frac{1}{4 N_{s}} \sum_{v=1}^{2 N_{s}} \ln \left[F^{2}(v, s)\right]\right\}, \quad q=0
\end{aligned}
$$




\section{A.3.3. Tiempo de cómputo}

\section{Sistema de prueba}

- Sistema operativo Microsoft Windows 7 Ultimate

- Versión 6.1.7601 Service Pack 1 Compilación 7601

- Descripción adicional del sistema operativo No disponible

- Fabricante del sistema operativo Microsoft Corporation

- Nombre del sistema DAMIAN-PC

- Fabricante del sistema NVIDIA

- Modelo del sistema AWRDACPI

- Tipo de sistema PC basado en x64

- Procesador AMD Athlon(tm) 64 X2 Dual Core Processor 4200+, 2200 Mhz, 2 procesadores principales, 2 procesadores lógicos

- Versión y fecha de BIOS Phoenix Technologies, LTD 6.00 PG, 16-May-06

- Versión de SMBIOS 2.2

- Directorio de Windows C: $\backslash$ Windows

- Directorio del sistema C: $\backslash$ Windows $\backslash$ system32

- Dispositivo de arranque \Device \HarddiskVolume1

- Configuración regional United States

- Capa de abstracción de hardware Versión = "6.1.7601.17514"

- Nombre de usuario Damian-PC \Damian

- Zona horaria Hora estándar de Argentina

- Memoria física instalada (RAM) 3.00 GB

- Memoria física total 3.00 GB

- Memoria física disponible 1.21 GB

- Memoria virtual total 6.00 GB

- Memoria virtual disponible 3.88 GB

- Espacio de archivo de paginación 3.00 GB

- Archivo de paginación C: \pagefile.sys 


\section{Series estudiadas}

Se estudiaron 11 series de ruidos gaussianos fraccionarios con cantidades de datos (longitudes) $N=2^{k}, k=10, \ldots, 20$. Se midió el tiempo en correr MFDFAQ en cada una de ellas con 73 anchos de ventana desde 10 hasta $N / 4$ según $\mathrm{q}=-20: 1: 20 \mathrm{y}$

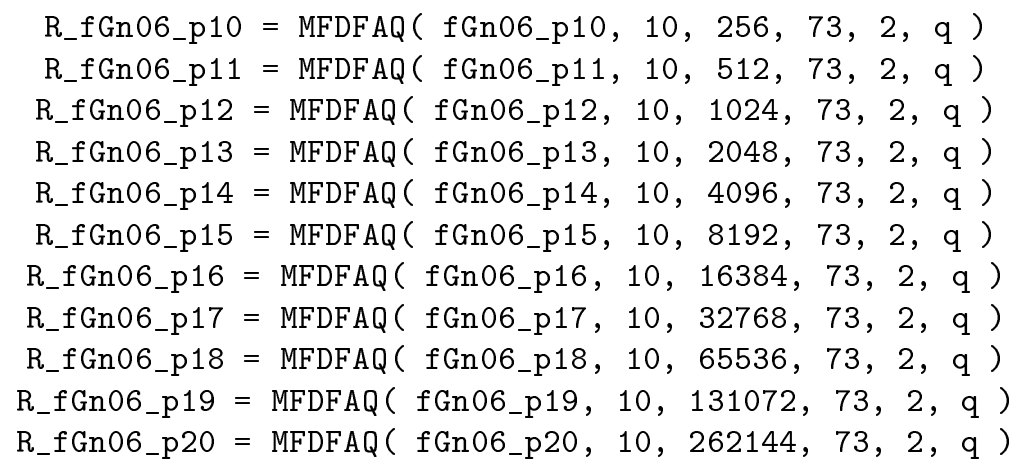

Tabla A.2: Comandos empleados.

\section{Resultados}

Los tiempos de cómputo en el sistema de prueba pueden verse en la tabla A.3 y la figura A.2 en la página siguiente También se muestra el resultado de las curvas de $F_{q}(s)$ para $R_{-} f \mathrm{Gn} 06 \_\mathrm{p} 20$ en la figura A.3 en la página 135

\begin{tabular}{|c|c|c|}
\hline Archivo & Longitud & $\begin{array}{c}\text { Tiempo de cómputo } \\
\text { [s] }\end{array}$ \\
\hline \hline fGn06_p10 & 1024 & 7,063 \\
\hline fGn06_p11 & 2048 & 9,6 \\
\hline fGn06_p12 & 4096 & 19,252 \\
\hline fGn06_p13 & 8192 & 34,547 \\
\hline fGn06_p14 & 16384 & 60,954 \\
\hline fGn06_p15 & 32768 & 121,353 \\
\hline fGn06_p16 & 65536 & 261,964 \\
\hline fGn06_p17 & 131072 & 488,932 \\
\hline fGn06_p18 & 262144 & 1065,837 \\
\hline fGn06_p19 & 524288 & 2376,918 \\
\hline fGn06_p20 & 1048576 & 7359,166 \\
\hline
\end{tabular}

Tabla A.3: Tiempos de cómputo.

En el sistema de prueba, los tiempos de cómputo en segundos se pueden aproximar según

$$
t(c)=2^{-7,65308} c^{0,99141}[\mathrm{~s}]
$$




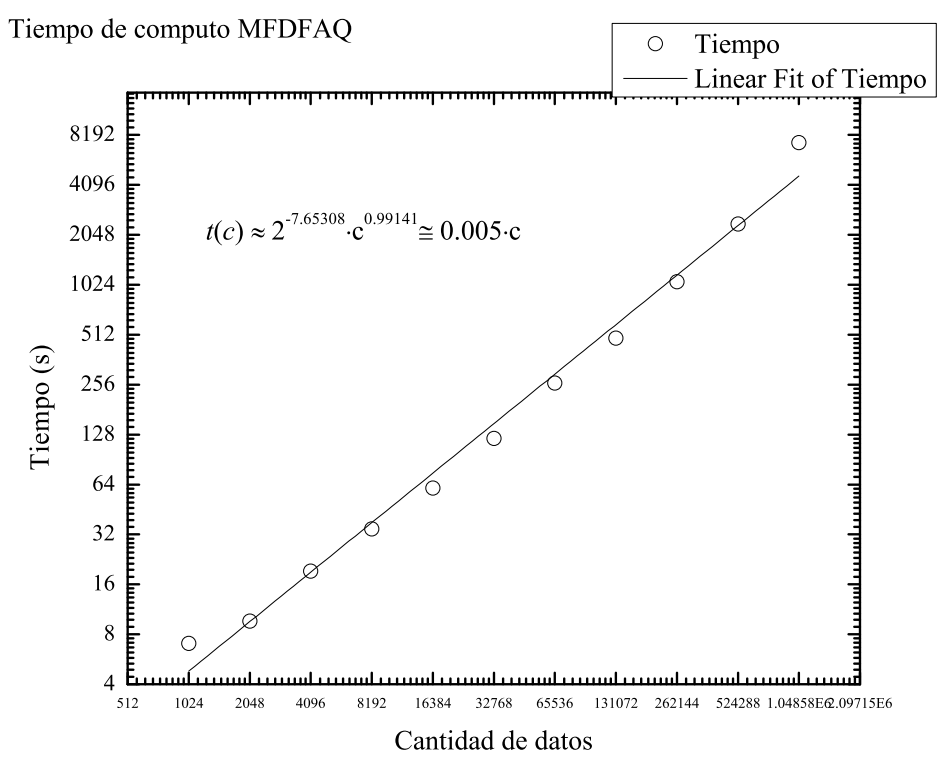

Figura A.2: Tiempos de cómputo $\left(\log _{2}-\log _{2}\right)$.

donde $c$ es la cantidad de datos de la serie $(N)$. El tiempo esperable de cómputo en otro procesador puede ser estimado en principio usando la Ley de Moore.

\section{A.4. LOGPLOTMFDFA.m}

\section{A.4.1. Sintaxis}

$$
\text { LOGPLOTMFDFA ( mfdfaq_mat, q ) }
$$

Donde

- mfdfaq_mat es una matriz de resultados de MFDFAQ.

- q es el vector de valores con que se armó MFDFAQ.

\section{A.4.2. Salida}

La salida es un gráfico log-log donde el eje $x$ son los anchos de ventana $s$ y el eje $y$ muestra cada una de las $F_{q}(s)$. Ver figura A.3 en la página siguiente 


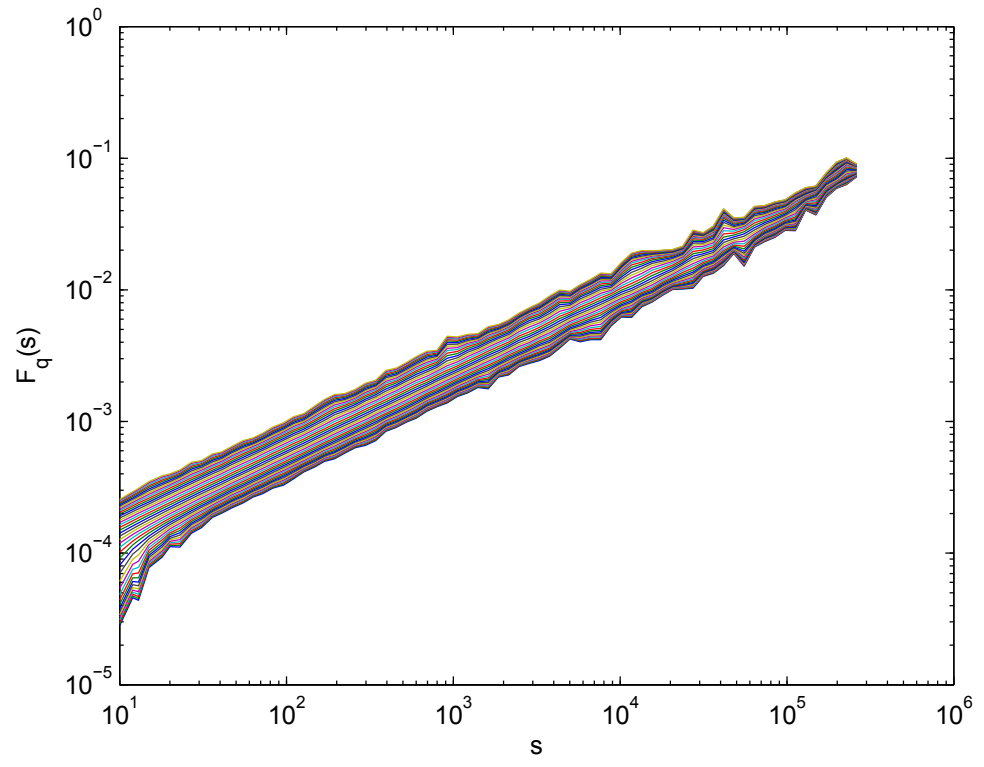

Figura A.3: Curvas de $F_{q}(s)$ para fGn06_p20 (R_fGn06_p20 = MFDFAQ ( fGn06_p20, 10, 262144, 73, 2, q )) generadas con LOGPLOTMFDFA (R_fGn06_p20,q). 

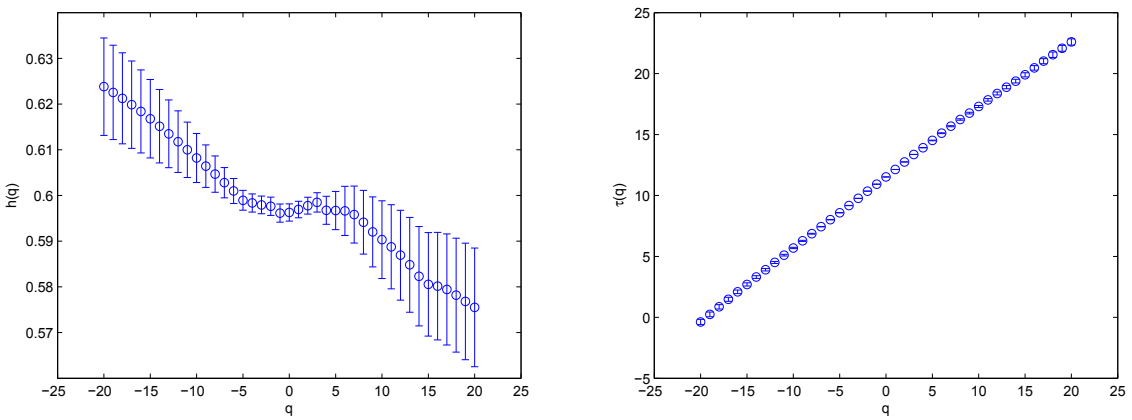

Figura A.4: Espectros de $h(q)$ y $\tau(q)$ para la serie $\mathrm{fGn} 06$ _p20 generadas con MFDFAFIT $\left(R_{-} f \mathrm{Gn} 06 \_p 20, q, 1000,40000\right)$ y ploteadas con las funciones PLOTH y PLOTTAU.

\section{A.5. MFDFAFIT.m}

\section{A.5.1. Sintaxis}

$\operatorname{MFDFAFIT}\left(R_{-}\right.$matriz, q, S_i, S_f )

Donde

- R_matriz es una matriz de resultados de MFDFAQ.

- q es el vector de valores con que se armó MFDFAQ

- S_i es la escala mínima para hacer el ajuste

- S_f es la escala máxima para hacer el ajuste

Esta función hace un ajuste lineal del gráfico $\log _{10}-\log _{10}$ de una matriz de resultados de MFDFAQ en el rango $S_{-} i \rightarrow S_{-} f$.

\section{A.5.2. Salida}

La salida es una matriz de tantos elementos como tenga q y de 9 columnas según la tabla A.4

\begin{tabular}{|c||c|c||c|c||c|c||c|c|}
\hline$q$ & $h(q)$ & $\Delta h(q)$ & $\tau(q)$ & $\Delta \tau(q)$ & $\alpha$ & $\Delta \alpha$ & $f(\alpha)$ & $\Delta f(\alpha)$ \\
\hline \hline$\vdots$ & $\vdots$ & $\vdots$ & $\vdots$ & $\vdots$ & $\vdots$ & $\vdots$ & $\vdots$ & $\vdots$ \\
\hline & & & & & 0 & 0 & 0 & 0 \\
\hline
\end{tabular}

Tabla A.4: Organización de salida de MFDFAFIT. 


\section{A.6. Funciones de ploteo de resultados}

A.6.1. PLOTH.m

Plotea $h(q)$ versus $q$.

Sintaxis

PLOTH( matriz_resultados )

Donde

- matriz_resultados es una matriz de resultados del toolbox de la rutina MFDFAFIT (Sección A.5.

A.6.2. PLOTTAU.M

Plotea $\tau(q)$ versus $q$

Sintaxis

PLOTTAU( matriz_resultados )

Donde

- matriz_resultados es una matriz de resultados del toolbox de la rutina MFDFAFIT (Sección A.5.

A.6.3. PLOTFAL .m

Plotea $f(\alpha)$ versus $\alpha$

Sintaxis

PLOTFAL( matriz_resultados )

Donde

- matriz_resultados es una matriz de resultados del toolbox de la rutina MFDFAFIT (Sección A.5. 


\section{Apéndice B}

\section{Performance del criterio basado en la calidad de ajuste lineal}

Hemos probado el rendimiento de la aplicación del algoritmo utilizado en este trabajo mediante el análisis MF-DFA3 de una serie multifractal binomial como se describe en la subsección 2.4.3 (elegimos MF-DFA para estudiar la versión computacionalmente más intensa del análisis). Generamos una serie de $2^{16}$ valores con $a=0,75$ empleando una estación de trabajo $\mathrm{PC} 1$ Luego calculamos las funciones de fluctuación $(q=-20,-19,5, \ldots, 20)$ con $M=8,16,32, \ldots, 1024$ escalas y corrimos la implementación en MATLAB usando $\delta=M / 4$ en cada caso.

Encontramos que para esta implementación el tiempo de cómputo (medido en segundos) corriendo en el sistema detallado (véase la Fig. B.1 puede ser aproximado por

$$
t(M, \# C) \simeq 0,0316 \mathrm{~s} \frac{M^{2}}{\# C^{\prime}},
$$

donde \#C es la cantidad de núcleos activos. La proporcionalidad inversa es debida al hecho de que los elementos en la matriz $\langle r\rangle$ son independientes entre sí, por lo cual es posible dividir la carga de procesamiento.

\footnotetext{
${ }^{1}$ Processor AMD FX(tm)-8350 Eight-Core Processor, 4013 Mhz, 4 Cores, 8 Logical Processors; Total Physical Memory 15,9 GB; Available Physical Memory 11,7 GB; Total Virtual Memory 31,8 GB; Available Virtual Memory 27,0 GB. Sólo un núcleo de ocho estuvo ocupado durante la prueba.
} 


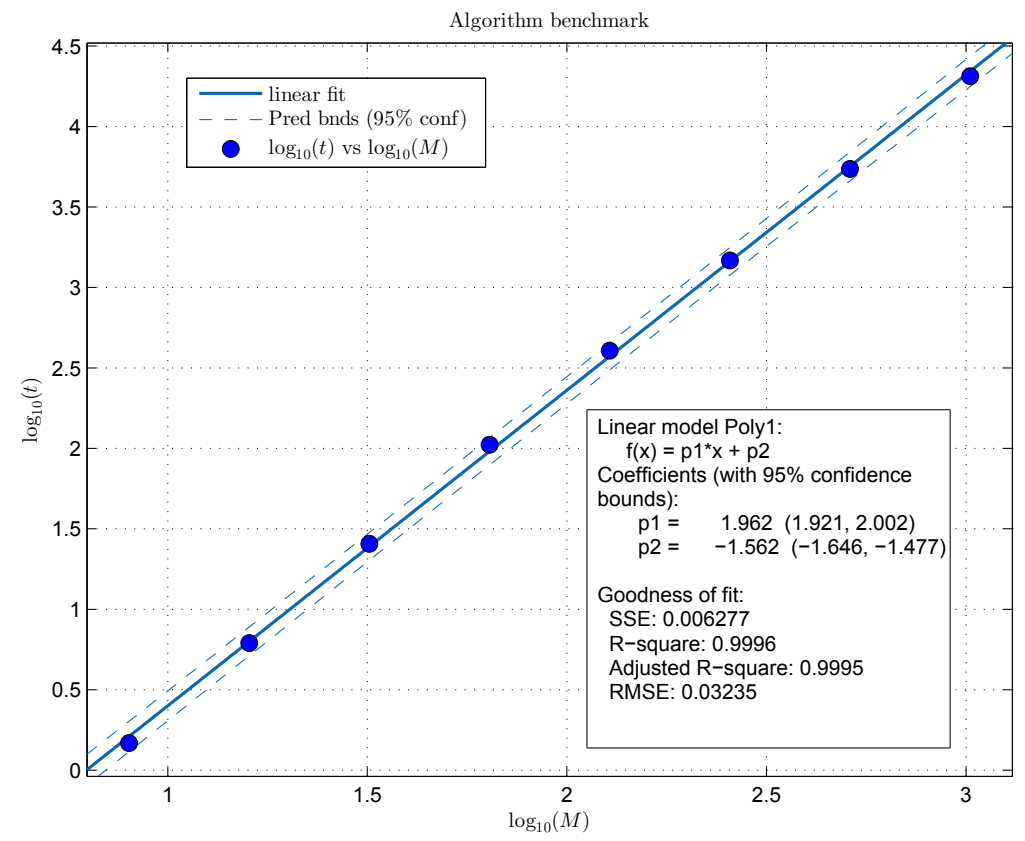

Figura B.1: Performance de la implementación del algoritmo en MATLAB. 


\section{Apéndice C}

\section{Estimación del máximo exponente de Lyapunov $\left(\lambda_{M}\right)$ de una serie temporal}

THE DOCTOR: The dawn of time, the beginning of all beginnings. Two forces, only good and evil. Then chaos. Time is born, matter, space. The universe cries out like a newborn. The forces shatter as the universe explodes outwards.

Only echoes remain, yet somehow, somehow the evil force survives... an intelligence of pure evil.

- Doctor Who, 'The Curse of Fenric'

\section{C.1. Introducción}

\section{C.1.1. Reconstrucción desfasada (delay reconstruction)}

Supongamos que nuestra serie es una sucesión de medidas escalares de cierta cantidad que depende del estado actual del sistema, tomado a múltiplos de un tiempo de muestreo dado:

$$
s_{n}=s(\mathbf{x}(n \Delta t))+\eta_{n}
$$

donde $\eta_{n}$ representa el nivel de ruido de la serie, que a efectos prácticos supondremos como cero.

Una reconstrucción desfasada ('delay reconstruction') en $m$ dimensiones está formada por los vectores $\mathbf{s}_{n}$ formados según

$$
\mathbf{s}_{n}=\left(s_{n-(m-1) \tau}, s_{n-(m-2) \tau}, \ldots, s_{n-\tau}, s_{n}\right)
$$

El tiempo de retardo o desfasaje ('delay' o 'lag') es la cantidad de muestras $\tau$ entre componentes adyacentes de los vectores $\mathbf{s}_{n}$. 


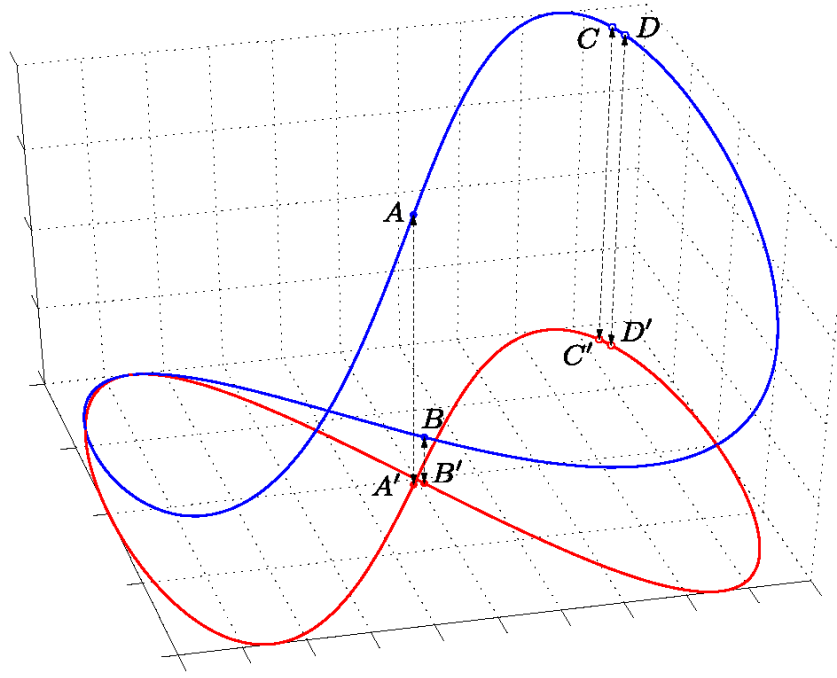

Figura C.1: Falsos vecinos. La idea básica de FNN se ilustra por una curva tridimensional (azul) y su proyección en dos dimensiones (curva roja) 175]. Los puntos que son falsos vecinos más cercanos en la proyección $\left(A^{\prime}\right.$ y $\left.B^{\prime}\right)$ se separarán en dimensiones superiores $(A$ y $B)$, mientras que los verdaderos vecinos $\left(C^{\prime}\right.$ y $\left.D^{\prime}\right)$ se quedarán cerca $(C$ y $D)$.

\section{C.1.2. Falsos vecinos más cercanos (FNN)}

La idea detrás de los falsos vecinos más cercanos ('false nearest neighbors' FNN) 173 174, 175 se basa en la propiedad de unicidad de la trayectoria de un sistema dinámico en el espacio de fases. El vecino más cercano a un punto en un embedding $m$-dimensional se etiqueta como falso si los puntos están cerca sólo si esto se debe a ser la proyección de un espacio de fases de mayor dimensión (por ejemplo, $(m+1)$-dimensional). Así, por FNN se separarán dos puntos si éstos vienen de un embedding de un espacio $(m+1)$-dimensional, mientras los verdaderos vecinos cercanos permanecerán juntos (ver la Figura C.1 para la ilustración gráfica de este concepto). Si uno es capaz de detectar todos los FNNs, entonces la dimensión mínima de embedding suficiente puede ser identificada como la dimensión mínima necesaria para alcanzar la fracción cero de los FNNs.

Dicho de otra manera, la idea básica es encontrar puntos en el conjunto de datos que son vecinos en el espacio de embedding, pero que no deberían serlo porque su futura evolución temporal es muy diferente. Si la dimensión de embedding correcta para un conjunto de datos es $m_{0}$, estudiamos los datos en una dimensión de embedding $m<m_{0}$. La transición de $m_{0}$ a $m$ es una proyección eliminando ciertos ejes del sistema de coordenadas. Los puntos cuyas coordenadas eliminadas por la proyección difieran mucho, pueden convertirse en «falsos vecinos» en el espacio $m$-dimensional. La estadística a estudiar es en- 
tonces la siguiente: para cada punto de la serie se toma su vecino más cercano en $m$ dimensiones, y se calcula el cociente de la distancia entre esos puntos en $m+1$ dimensiones. Si este cociente es mayor a cierto valor $r$, el vecino era falso. El valor de $r$ debe ser lo suficientemente grande para permitir la divergencia exponencial debida al caos determinístico. Si $\sigma$ es la desviación estándar de los datos, la estadística a computar es:

$$
\begin{aligned}
X_{F N N}(r)= & {\left[\sum_{n=1}^{N-m-1} H\left(\frac{\left|\mathbf{s}_{n}^{(m+1)}-\mathbf{s}_{k(n)}^{(m+1)}\right|}{\left|\mathbf{s}_{n}^{(m)}-\mathbf{s}_{k(n)}^{(m)}\right|}-r\right) \times\right.} \\
& \left.H\left(\frac{\sigma}{r}-\left|\mathbf{s}_{n}^{(m)}-\mathbf{s}_{k(n)}^{(m)}\right|\right)\right] \times \\
& \times\left[\sum_{n=1}^{N-m-1} H\left(\frac{\sigma}{r}-\left|\mathbf{s}_{n}^{(m)}-\mathbf{s}_{k(n)}^{(m)}\right|\right)\right]^{-1}
\end{aligned}
$$

donde $\mathbf{s}_{k(n)}^{(m)}$ es el vecino más cercano a $\mathbf{s}_{n}$ en $m$ dimensiones; es decir que $k(n)$ es el índice del elemento en la serie temporal tal que $k \neq n$ para el cual $\left|\mathbf{s}_{n}^{(m)}-\mathbf{s}_{k(n)}^{(m)}\right|=\min$. La primera función de Heaviside sólo considera los cocientes mayores que $r$, mientras que la segunda se asegura de que además las distancias en $m$ dimensiones sean mayores que $\sigma / r$ (a su vez, este es el criterio de normalización). Un análisis más detallado implica proponer varias combinaciones de $\tau$ y $m$ y estudiar las curvas de $X_{F N N}(r)$ para esos valores.

\section{C.1.3. Máximo exponente de Lyapunov $\left(\lambda_{M}\right)$}

Como un máximo exponente de Lyapunov $\left(\lambda_{M}\right)$ positivo es una fuerte firma del caos, es de interés determinar su valor para una serie temporal dada. Aquí queremos describir el algoritmo introducido por Kantz (1994) 174]173. Este algoritmo prueba directamente la divergencia exponencial de las trayectorias cercanas y por lo tanto nos permite decidir si realmente tiene sentido calcular un exponente de Lyapunov para el conjunto de datos.

Sea $\mathbf{s}_{n_{0}}$ un punto de la serie en el espacio de embedding, y busque en ese espacio todos sus vecinos a una distancia menor que $\varepsilon$ de él. Calcule la media de las distancias de todos los vecinos al punto de referencia de la trayectoria en función del tiempo relativo $\Delta n$. El logaritmo de la distancia promedio al tiempo $\Delta n$ es de cierta manera una efectiva tasa de expansión sobre el corrimiento del índice temporal $\Delta n$ (más el logaritmo de la distancia inicial) que contiene todos las fluctuaciones deterministas debidas a la proyección y la dinámica. Repitiendo este proceso para muchos valores de $n_{0}$, las fluctuaciones de las tasas de expansión eficaces se promediarán. Por lo tanto, uno debe calcular:

$$
S(\Delta n)=\frac{1}{N} \sum_{n_{0}=1}^{N} \ln \left(\frac{1}{\left|\mathscr{U}\left(\mathbf{s}_{n_{0}}\right)\right|} \times \sum_{\mathbf{s}_{n} \in \mathscr{U}\left(\mathbf{s}_{n_{0}}\right)}\left|s_{n_{0}+\Delta n}-s_{n+\Delta n}\right|\right)
$$


Los vectores de referencia $\mathbf{s}_{n_{0}}$ son vectores de embedding; $\mathscr{U}\left(\mathbf{s}_{n_{0}}\right)$ es el entorno punteado con centro en $\mathbf{s}_{n_{0}}$ y radio $\varepsilon$ y $\left|\mathscr{U}\left(\mathbf{s}_{n_{0}}\right)\right|$ es la cantidad de vecinos encontrados en $\mathscr{U}\left(\mathbf{s}_{n_{0}}\right)$.

Como a priori generalmente uno no conoce la dimensión mínima de embedding $m$, ni la distancia óptima $\varepsilon$, uno debe estudiar $S(\Delta n)$ para varios juegos de esos valores. El radio de la vecindad debe ser lo más pequeño posible, pero aún así debe permitir que en él entren algunos vecinos. Si es demasiado pequeño, pueden omitirse sistemáticamente ciertas partes del atractor y por lo tanto llegar a una conclusión errónea.

En el Apéndice D detallamos las rutinas desarrolladas para la estimación del máximo exponente de Lyapunov, así como varios ejemplos. 


\section{Apéndice D}

\section{Rutinas para la estimación del máximo exponente de Lyapunov}

\section{D.0.1. Funciones principales}

LYAPMUTINFO.m estima el $\tau$ óptimo para hacer embedding (en cantidad de datos) con el criterio del primer mínimo de la información mutua promedio de la serie [176]. Gráfico opcional.

LYAPXCORR.m Estima el $\tau$ óptimo para hacer embedding (en cantidad de datos) con el criterio del primer mínimo de la autocorrelación de la serie [177 178.

LYAPPHASE.m Genera el vector delayed de la serie (en cantidad de datos $\tau$ ) y opcionalmente el correspondiente gráfico en el espacio de fases.

EMBEDING.m Embedding de una serie temporal con dimensión $m$ y delay de tiempo $\tau$.

LYAPFALSENEIGHBOURS.m Calcula la fracción de falsos vecinos según la ecuación (3.8) de [173.

LYAPMAX.m Da las funciones de fluctuación para estimar el máximo exponente de Lyapunov según el algoritmo de Kantz [174,173.

\section{D.0.2. Funciones auxiliares}

ENTORNO.m Devuelve la matriz de vectores fila de una matriz a distancia menor a $\varepsilon$ de una fila dada.

MINFILA.m Dada una matriz y una fila, busca la distancia mínima euclideana a otra fila distinta de la matriz. 
HEAVISIDE.m Función escalón de Heaviside.

LATEXLABELS.m Escribe los nombres de los ejes de coordenadas en estilo LATEX.

LATEXTITLE.m Escribe los títulos de las figuras en estilo $\mathrm{HT}_{\mathrm{E}} \mathrm{X}$.

lorenz.m Function generates the Lorenz attractor of the prescribed values of

parameters $\rho, \sigma, \beta$ http://www . mathworks . com/matlabcentral/fileexchange/ 30066-lorenz-attaractor-plot/content/lorenz.m.

mai.m Calculates the mutual average information of a time series $\mathrm{x}$ for some time lag.http://www . mathworks . com/matlabcentral/fileexchange/ 880-mutual-average-information

\section{D.1. Ejemplos de uso}

\section{D.1.1. Atractor de Lorenz}

\section{Generación}

Genero un Lorenz clásico [179]:

$$
\begin{aligned}
\dot{x} & =\sigma(y-x) \\
\dot{y} & =-x z+\rho x-y \\
\dot{z} & =x y-\beta z
\end{aligned}
$$

$\operatorname{con} \rho=28, \sigma=10, \beta=8 / 3$. Ver Figura D.1

[LORX LORY LORZ] = lorenz $(28, \ldots$ $10,8 / 3)$;

serie = LORX;

Hago mi reconstrucción del atractor con la serie del eje $x$.

\section{Estimación de $\tau$}

Estimo $\tau$ con el criterio del primer mínimo de la autocorrelación de la serie (Figura D.2)

tau = LYAPMUTINFO ( serie, 1);

Este criterio indica un valor de $\tau=37$.

Miro si el $\tau$ es apropiado comparando el atractor original con la reconstrucción con $m=3$ (ver Figura D.3.

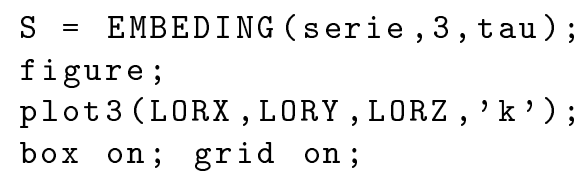




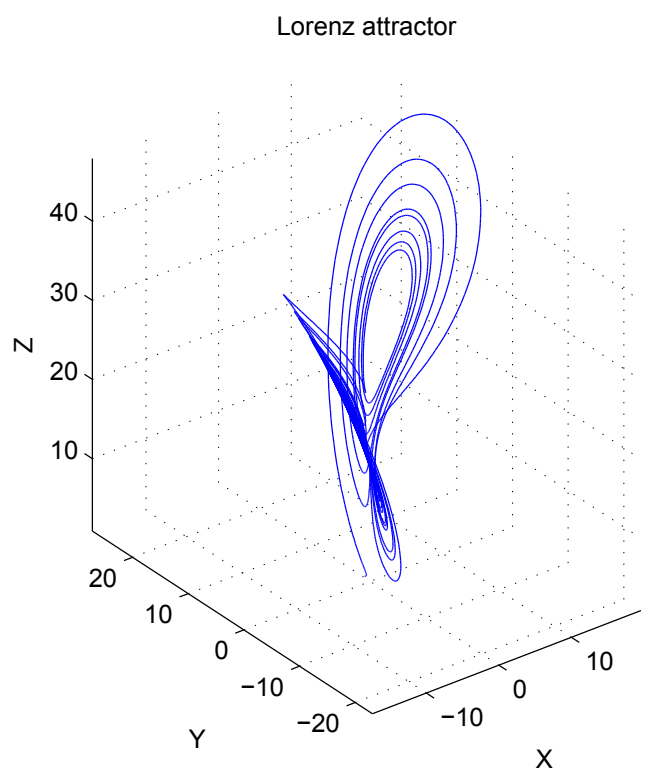

Figura D.1: Atractor de Lorenz, $\rho=28, \sigma=10, \beta=8 / 3$.

hold all;

$\mathrm{plot} 3\left(\mathrm{~S}(:, 1), \mathrm{S}(:, 2), \mathrm{S}(:, 3), \mathrm{r}^{\prime}\right)$;

\section{Estimación de la dimensión de embedding $m$}

Con este nuevo valor de $\tau$ ahora calculo el porcentaje de falsos vecinos para hallar dimensión de embedding $m$ (se espera que sea 3; ver Figura D.4. Proponemos $r=5$ (Los valores recomendados por [173] van de 5 a 10).

XFNN = LYAPFALSENEIGHBOURS ( serie,...

tau , 5);

De este gráfico se concluye que $m=3$ es buen candidato para dimensión de embedding.

Estimación de $\lambda_{M}$

Proponemos $\epsilon=1$ [173 y calculamos las fluctuaciones $S(\Delta n)$ :

DELTAN $=0: 1: 20$;

$\mathrm{S}=\operatorname{LYAPMAX}(\operatorname{serie}, 3$, tau, 1, DELTAN );

El ajuste de la Figura D.5 arroja un $\lambda_{M}=0,01924 \pm 0,00035>0$ de donde se concluye que la dinámica es caótica. 


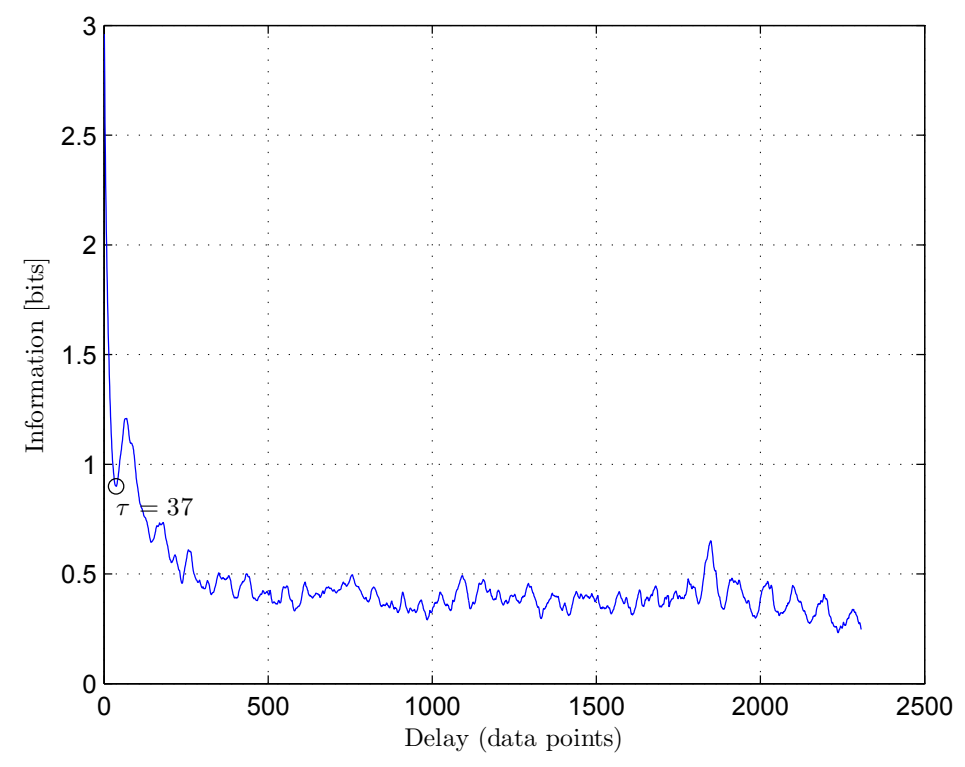

Figura D.2: Estimación de $\tau$ para el atractor de Lorenz (eje $x$ ).

\section{D.1.2. Mapa de Hénon}

Siguiendo el ejemplo propuesto en [180], genero un mapa de Hénon [179]:

$$
\begin{aligned}
X_{n+1} & =1+Y_{n}-a X_{n}^{2} \\
Y_{n+1} & =b X_{n}
\end{aligned}
$$

Con $a=1,4 ; b=0,3$;

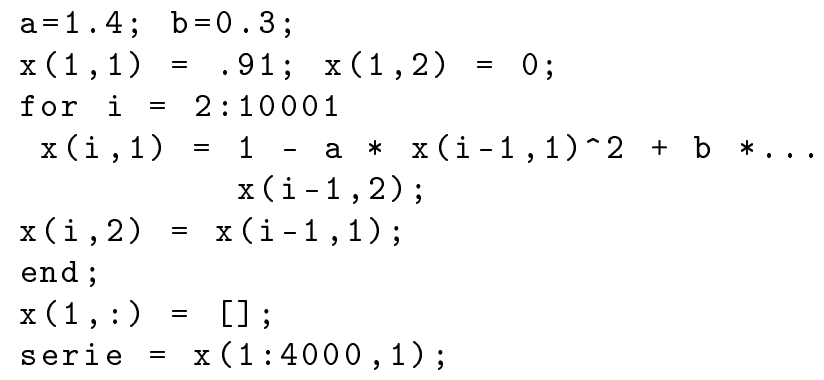

(me quedo sólo con los primeros 4000 datos como ejemplo).

Encuentro los parámetros óptimos:

tau 0 LYAPMUTINFO ( serie, 1 ); 
El valor de $\tau$ hallado es 17 . Sin embargo esta curva es muy ruidosa y no tiene un verdadero mínimo local, sino que decrece monótonamente ${ }^{1}$ Para un mapa simple el tiempo de delay natural es 1 , y es ese el valor de $\tau$ que se usará (ver Figura D.6.

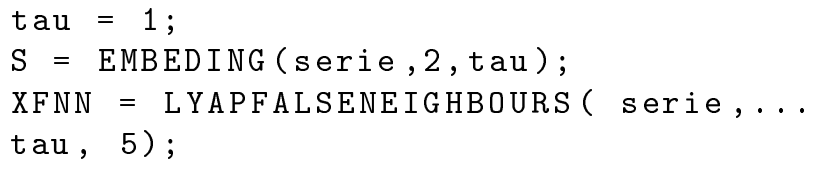

En la Figura D.7puede verse la confirmación de que la dimensión de embedding $m$ es 2 .

Así estimo las fluctuaciones para calcular $\lambda_{M}$

$\mathrm{m}=2$;

DELTAN $=0: 1: 20$;

$\mathrm{S}=\operatorname{LYAPMAX}($ serie, $\mathrm{m}$, tau, 0.1 , DELTAN );

Ajusto la zona lineal y obtengo (ver Figura D.8.

$\lambda_{M}=0,4683$ (entre 0,4201 y 0,5165$)$ con un $95 \%$ de certeza $\left(R^{2}=0,9989\right)$.

Según la [179] $\lambda_{M}=0,41922$ (mismos valores: $a=1,4, b=0,3$ ).

http://www.physics .emory.edu/faculty/weeks//research/tseries3.html\#expt1 


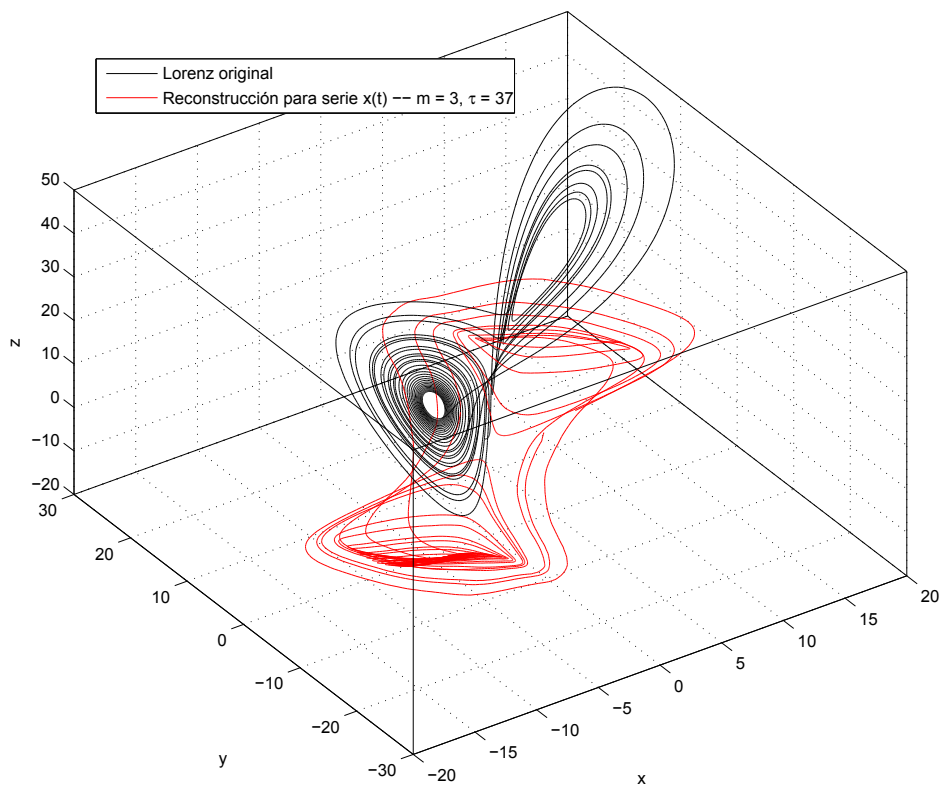

Figura D.3: Reconstrucción del atractor $\tau=37$. 


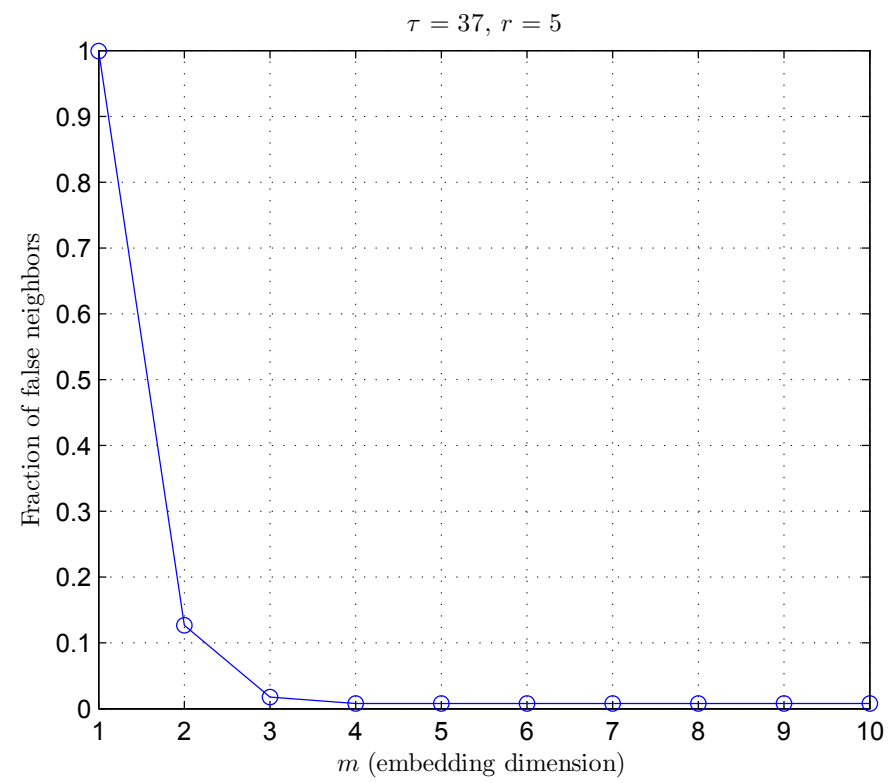

Figura D.4: Porcentaje de falsos vecinos más cercanos (FNN) para $\tau=37, r=$ 5 .

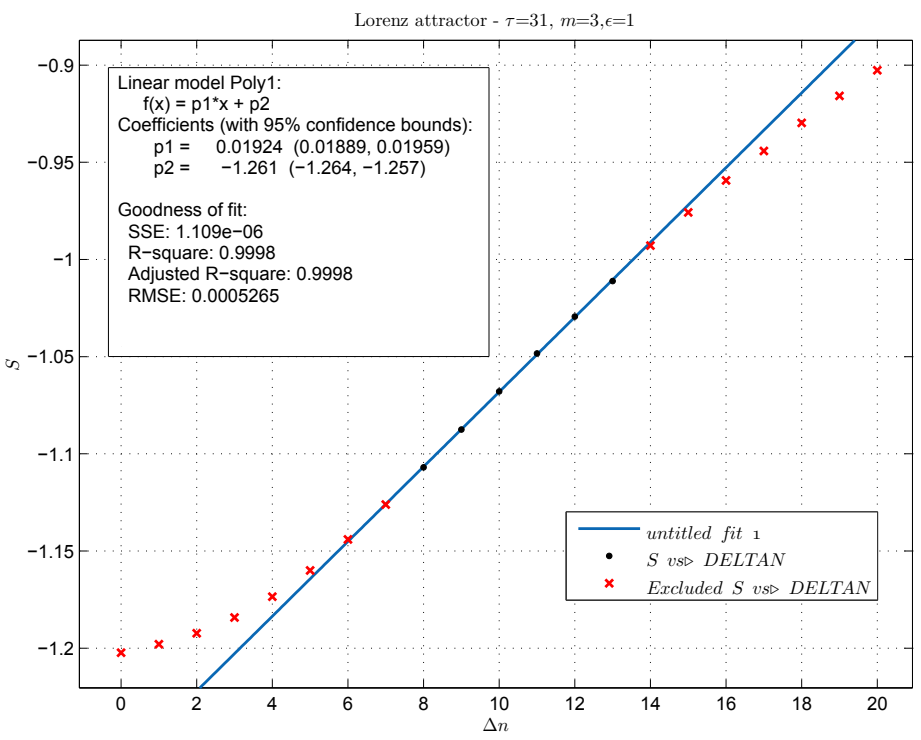

Figura D.5: Ajuste de $\lambda_{M}$ para $\tau=37, r=5$. $\left(^{*}\right)$ Errata: en el título de la Figura debe decir $« \tau=37 »$. 

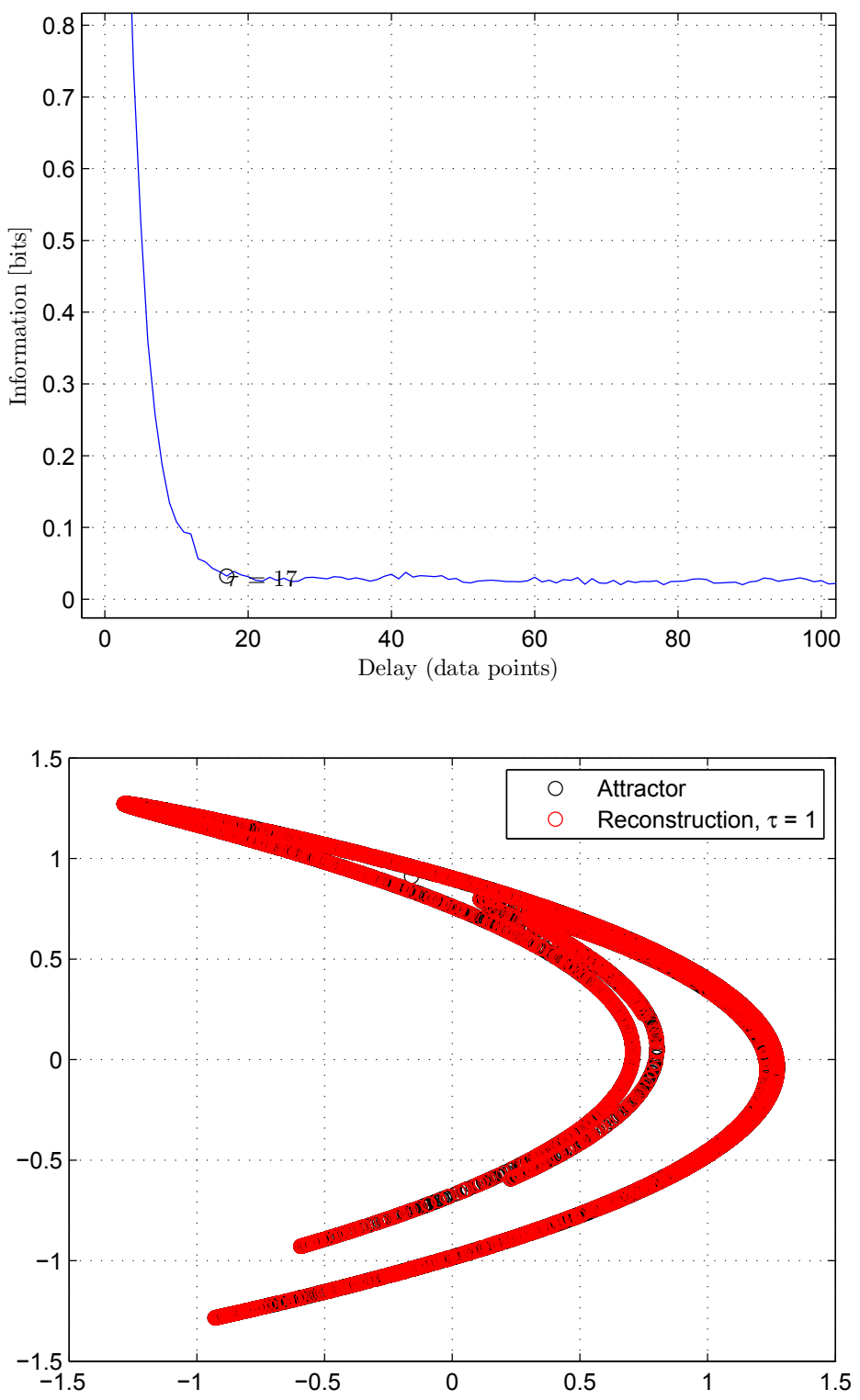

Figura D.6: Mapa de Hénon. Arriba: Información mutua. Abajo: reconstrucción $\operatorname{con} \tau=1$.

152 


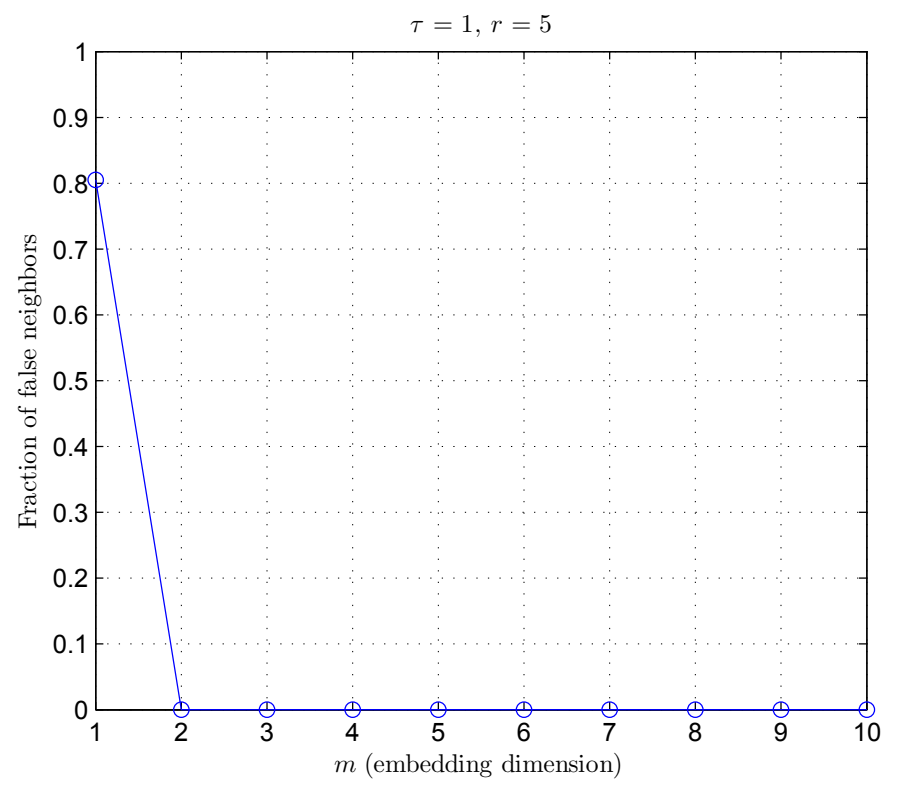

Figura D.7: Mapa de Hénon. Dimensión de embedding.

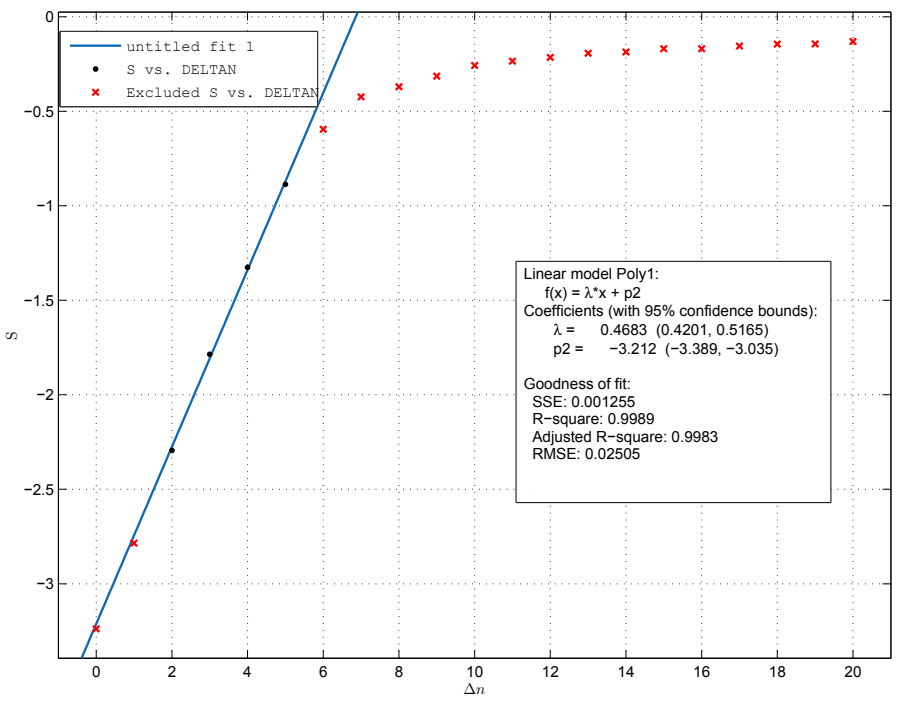

Figura D.8: Ajuste de $\lambda_{M}$ para el mapa de Hénon $(a=1,4, b=0,3), \tau=1$, $r=5, \epsilon=0,1$. 


\section{Apéndice E}

\section{Caracterización del turbulador}

THE Doctor: There's a Cyberman out there on the fuselage. But on the plus side, it's not turbulence. .

- Doctor Who, ' Death in Heaven'

\section{E.1. Introducción}

Un turbulador es un generador de turbulencias estadísticamente repetible ${ }^{1}$ basado en la mezcla de dos flujos de aire a diferentes temperaturas [145 182 $183,181,184,138$.

Para generar una turbulencia óptica real (por ejemplo, en el índice de refracción) es necesario crear una turbulencia dinámica (velocidad del aire, por ejemplo) y una fluctuación de temperatura en el flujo. Esto se logra mezclando dos flujos de aire de diferentes temperaturas en un espacio confinado: la cámara de turbulencia. El aire de una de las entradas es calentado (toma caliente), mientras que el del otro permanece a temperatura ambiente (toma fría). Ambos ventiladores funcionan a velocidades fijas idénticas. Los parámetros sintonizables son la velocidad de los ventiladores y $\Delta T$ (en este trabajo sólo se toma como parámetro ajustable $\Delta T$ por una limitación técnica en los ventiladores empleados).

El modelo implementado es según el diseño de Keskin, Jolissaint y Bradley 145184.

\footnotetext{
${ }^{1}$ Un interesante análisis de varios métodos para generar turbulencias en laboratorio puede encontrarse en 181 .
} 


\section{E.2. Caracterización de tiempos operativos de esta- bilización de temperatura}

Esta experiencia tiene como objeto determinar el tiempo de respuesta del turbulador modificado. Las modificaciones en esta versión del dispositivo son

- nuevo juego de resistencias para el foco caliente

- la incorporación de una estructura de iguales dimensiones y sección transversal que el juego de resistencias para el foco frío

\section{E.2.1. Modelo teórico}

En la caracterización anterior hubo evidencias de que el comportamiento de $\Delta T$ en función de $t$ para una corriente dada tiende exponencialmente al valor límite final.

Proponemos para este caso un comportamiento tipo ley de calentamiento de Newton (análogo a la carga/descarga de un capacitor). Así, $\Delta T$ a tiempo $t$ es

$$
\Delta T(t)=A-B e^{-\left(t-t_{0}\right) / \tau}
$$

donde $A>0, B>0$ y $\tau>0$. Queda claro que a $t=0 \Delta T(0)=A-B$ y el $\lim _{t \rightarrow \infty}(\Delta T)=A$.

Una de las preguntas de orden práctico que se desea responder es ¿cuánto tiempo hay que esperar para que el $\Delta T$ deseado se considere práctiacmente estable? En otras palabras, dado un cambio de corriente, ¿cuál es el $t^{\prime}$ tal que $d(\Delta T) / d t \leq \varepsilon=(\sqrt{2} / 10){ }^{\circ} \mathrm{C} / \mathrm{min} \simeq 0,14{ }^{\circ} \mathrm{C} / \mathrm{min}$ (el error en la medida de $\Delta T) ?$

En efecto, se busca $t^{\prime}$ tal que

$$
\left.\frac{d(\Delta T)}{d t}\right|_{t=t^{\prime}}=\frac{B}{\tau} e^{-\left(t^{\prime}-t_{0}\right) / \tau} \leq \varepsilon
$$

Después de logaritmar y despejar, se halla que

$$
\Delta t=t^{\prime}-t_{0} \geq \tau \ln \left(\frac{B}{\tau \varepsilon}\right)
$$

Hemos visto que el comportamiento de las temperaturas finales $(A)$ de la ecuación E.1 siguen un comportamiento cuadrático. En esta ocasión consideramos una pequeña diferencia de temperatura aun cuando no pasa corriente por las resistencias. Este efecto se debe a la temperatura inducida en el flujo caliente por la resistencia del ventilador de ese foco (recordemos que por esa rama el aire recircula y no se renueva constantemente como en el caso del foco frío). Así, proponemos

$$
A(I)=A_{0}+A_{1} I^{2}
$$




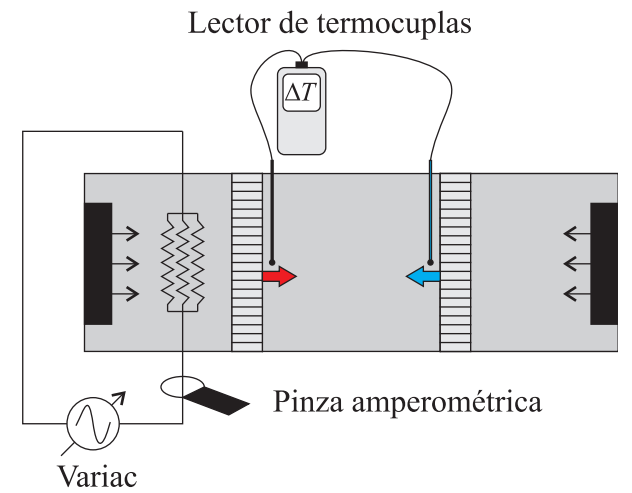

Figura E.1: Arreglo experimental.

donde el segundo término está vinculado con la potencia eléctrica suministrada al sistema. Esta relación se invierte sencillamente como

$$
I(A)=\sqrt{\frac{A-A_{0}}{A_{1}}}
$$

En una serie de pasos secuenciales, también se cumple la relación

$$
B_{n}=A_{n}-A_{n-1}
$$

\section{E.2.2. Desarrollo experimental}

Se montó la experiencia tal como se muestra en el esquema de la figuraE.1.

\section{Materiales}

- 266 clamp meter Protomax

- Digital Thermometer 6802 II Type K

- Termómetro de mercurio

- Variac Variosat

\section{E.2.3. Resultados y análisis}

Los resultados de las tomasde datos y ajustes se muestran en las figuras E.2 y E.3 en la página 159 así como en la tabla E.1

\section{E.2.4. Cálculo práctico}

Con los parámetros obtenidos podemos calcular los tiempos de espera según la ecuación E.2 para realizar la experiencia de caracterización de la constante de estructura. Los resultados se resumen en la tablaE.2 

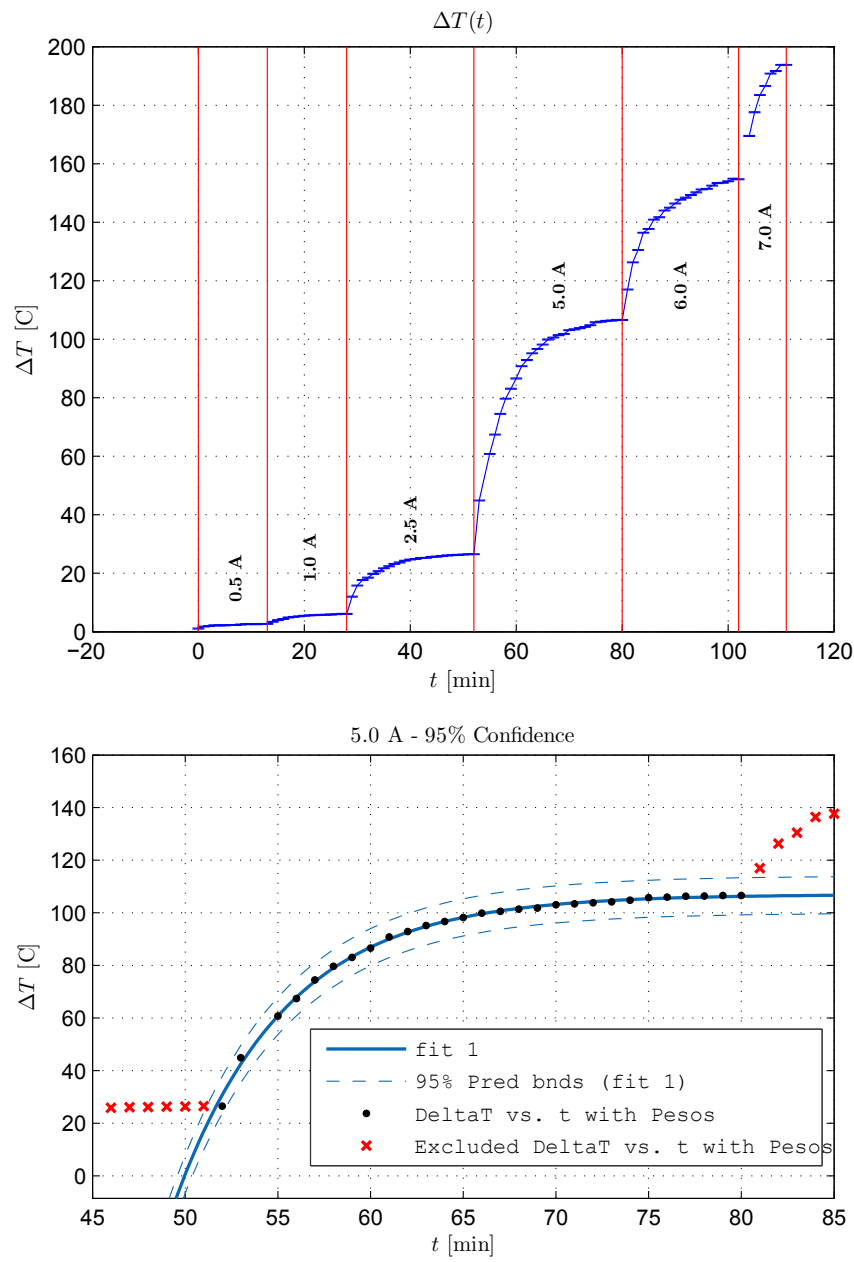

Figura E.2: (Arriba) Comportamiento de $\Delta T$ en función del tiempo. (Abajo) Ajuste según el modelo para una corriente de $5 \mathrm{~A}$ a modo de ejemplo. 


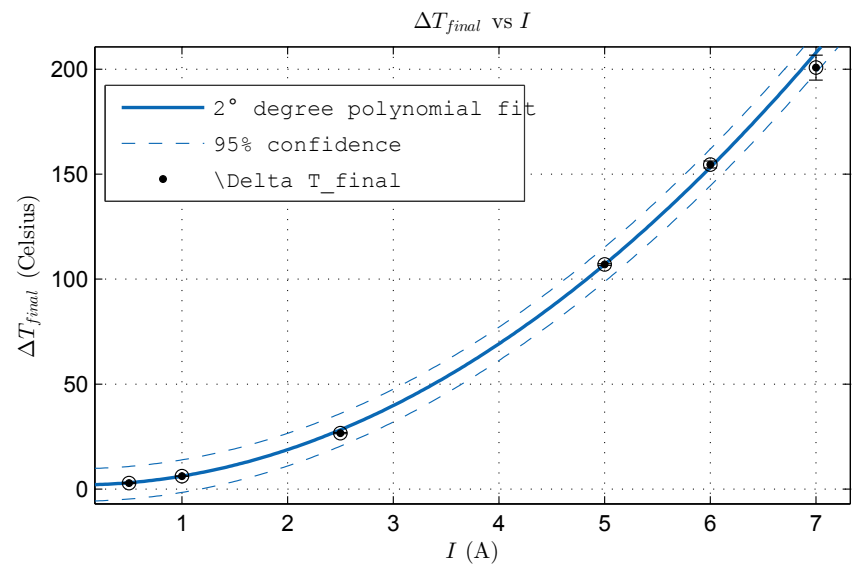

Figura E.3: $\Delta T_{\text {final }}=A$ por el ajuste en función de la corriente E.3.

\begin{tabular}{|c||c|c|c|}
\hline $\begin{array}{c}I \\
{[\mathrm{~A}]}\end{array}$ & $\begin{array}{c}A \\
{\left[{ }^{\circ} \mathrm{C}\right]}\end{array}$ & $\begin{array}{c}B \\
{\left[{ }^{\circ} \mathrm{C}\right]}\end{array}$ & $\begin{array}{c}\tau \\
{[\mathrm{min}]}\end{array}$ \\
\hline \hline 0,5 & $2,86 \pm 0,29$ & $1,24 \pm 0,26$ & $6,32 \pm 3,56$ \\
\hline 1,0 & $6,17 \pm 0,08$ & $3,47 \pm 0,098$ & $4,33 \pm 0,34$ \\
\hline 2,5 & $26,67 \pm 0,29$ & $17,57 \pm 0,50$ & $5,54 \pm 0,39$ \\
\hline 5,0 & $107,0 \pm 0,4$ & $76,20 \pm 0,76$ & $5,99 \pm 0,13$ \\
\hline 6,0 & $154,6 \pm 1,7$ & $45,03 \pm 2,46$ & $5,52 \pm 0,78$ \\
\hline 7,0 & $200,8 \pm 5,9$ & $46,12 \pm 5,72$ & $4,25 \pm 1,30$ \\
\hline \hline & $A(I) \equiv 1,966^{\circ} \mathrm{C}+4,201 \frac{{ }^{\circ} \mathrm{C}}{\mathrm{A}^{2}} I^{2}$ & - & $\langle\tau\rangle=5,33 \pm 0,65$ \\
\hline
\end{tabular}

Tabla E.1: Resultados de los ajustes. 


\begin{tabular}{|c|c|c|}
\hline $\begin{array}{c}\text { Para un } \Delta T=A \text { de } \\
{\left[{ }^{\circ} \mathrm{C}\right]}\end{array}$ & $\begin{array}{c}\text { se debe usar una } I \simeq \\
{[\mathrm{A}]}\end{array}$ & $\begin{array}{c}\text { y se debe esperar } \simeq \\
{[\mathrm{min}]}\end{array}$ \\
\hline \hline 1,966 & 0 & 0 \\
\hline 5 & 0,85 & 7,4 \\
\hline 10 & 1,38 & 10,1 \\
\hline 15 & 1,76 & 10,1 \\
\hline 20 & 2,07 & 10,1 \\
\hline 30 & 2,58 & 13,8 \\
\hline 40 & 3,01 & 13,8 \\
\hline 50 & 3,38 & 13,8 \\
\hline 70 & 4,02 & 17,5 \\
\hline 90 & 4,58 & 17,5 \\
\hline 110 & 5,07 & 17,5 \\
\hline 130 & 5,52 & 17,5 \\
\hline 150 & 5,94 & 17,5 \\
\hline
\end{tabular}

Tabla E.2: Cálculo práctico para la caracterización del turbulador.

\section{E.3. Determinación de $l_{0}, L_{0} \mathbf{y} C_{n}^{2}$,}

Dentro de la teoria de la cascada de energía de Kolmogorov donde el flujo de energía de los remolinos grandes a los pequeños es constante, vemos que para una turbulencia homogénea e isótropa, la función de estructura del índice de refracción es según:

$$
D_{n}(R)=\left\langle\left(n\left(\mathbf{R}_{1}\right)-n\left(\mathbf{R}_{2}\right)\right)^{2}\right\rangle=\left\{\begin{array}{ccc}
C_{n}^{2} R^{2 / 3} & \text { si } & l_{0} \ll R \ll L_{0} \\
C_{n}^{2} l_{0}^{-4 / 3} R^{2} & \text { si } & R \ll l_{0}
\end{array}\right.
$$

Para el caso de la temperatura

$$
D_{T}(\mathbf{R})=D_{T}(R)=C_{T}^{2} R^{2 / 3}
$$

Para la mezcla de masas de aire de diferentes densidades las fluctuaciones del índice de refracción son directamente proporcionales a la densidad del aire según la ley de Dale-Gladstone:

$$
n-1=\alpha_{n} \frac{P}{T}
$$

donde $\alpha_{n}=80 \cdot 10^{-8} \mathrm{~K} / \mathrm{Pa}, P$ es la presión y $T$ es la temperatura.

La relación entre las constantes de estructura es sencillamente

$$
C_{n}^{2}=\left(\alpha_{n} \frac{P}{T}\right)^{2} C_{T}^{2}
$$

Como $C_{T}^{2} \sim(\delta T)^{2}$

$$
C_{n}^{2} \sim\left(\alpha_{n} \frac{P}{T}\right)^{2}(\delta T)^{2}
$$


Asi, el turbulador es sintonizable mediante la diferencia de temperaturas entre ambos chorros de aire.

Por otro lado, el turbulador provee una capa de constante de estructura de grosor $\Delta h$, de manera que el parámetro de Fried es simplemente

$$
r_{0}^{-5 / 3}=0.4234\left(\frac{2 \pi}{\lambda}\right)^{2} C_{n}^{2} \Delta h
$$

\section{E.3.1. Método del ángulo de arribo}

El ángulo de arribo (AoA $)^{2}$ viene de la pendiente promedio que el frente de onda turbulento $W(x, y)$ tiene en una pupila $P(x, y)$ de un telescopio, o la pupila de salida del turbulador en este experimento (ver figura E.4 según

$$
\alpha_{p}=\frac{x_{c}}{f}=\frac{\iint P(x, y) \partial_{x} W(x, y) d x d y}{\iint P(x, y) d x d y}
$$

donde $f$ es la distancia focal y $x_{c}$ es la coordenada $x$ del centroide en el detector. La relación para la coordenada $y$ es exactamente igual, pero derivando respecto de $y$.

Partiendo de un espetro de Von Kármán [138] que tiene en cuenta los efectos de la escala interna $l_{0}$ y la escala externa $L_{0}$

$$
\Phi_{N}(K)=0,033 C_{n}^{2}\left(K^{2}+K_{0}^{2}\right)^{-11 / 6} \exp \left\{-\frac{K^{2}}{K_{m}^{2}}\right\}
$$

donde $K$ es el número de onda espacial en tres dimensiones, $K_{0}=2 \pi / L_{0}$ y $K_{m}^{2}=2 \pi / l_{0}$, es posible encontrar, para el caso general de un flujo limitado, la varianza del ángulo de arribo $\left(\sigma_{A o A}^{2}\right)$. La misma está dada para una capa turbulenta de espesor $\Delta h$ según $138,145{ }^{3}$

$$
\begin{aligned}
\sigma_{A o A}^{2}(x, y)= & (2 \pi)^{4 / 3} 0,033 C_{n}^{2} \Delta h \times \ldots \\
& \ldots \iint F_{x, y}^{2}\left(F^{2}+L_{0}^{-2}\right)^{-11 / 6} e^{-l_{0}^{2} F^{2}}\left[\frac{2 J_{1}(\pi D F)}{\pi D F}\right]^{2} d F_{x} d F_{y}
\end{aligned}
$$

En coordenadas polares la varianza puede expresarse [138 como

$$
\sigma^{2}=1,19 C_{n}^{2} \Delta h \int_{0}^{\infty} f^{3}\left(f^{2}+\frac{1}{L_{0}^{2}}\right)^{-11 / 6} \exp \left\{-l_{0}^{2} f^{2}\right\} d f
$$

\footnotetext{
${ }^{2}$ Del inglés "Angle of arrival".

${ }^{3}$ Nota: ecuación E.7 sólo tiene solución analítica en el régimen de escala infinita $\left(L_{0}=\infty \mathrm{y}\right.$ $\left.l_{0}=0\right)$ :

$$
\begin{aligned}
\sigma_{A o A}^{2}(x, y) & =2,8375 C_{n}^{2} \Delta h D^{-1 / 3} \\
& =0,1698 \lambda^{2} r_{0}^{-5 / 3} D^{-1 / 3}
\end{aligned}
$$
}


Para considerar el efecto de filtrado de una pupila, se multiplica el integrando de la ecuación E.8 por una función de Airy salida de elevar al cuadrado el módulo de la transformada de Fourier de la pupila circular, que lleva a

$$
\sigma_{A o A}^{2}=1,19 C_{n}^{2} \Delta h \int_{0}^{\infty} f^{3}\left(f^{2}+\frac{1}{L_{0}^{2}}\right)^{-11 / 6} \exp \left\{-l_{0}^{2} f^{2}\right\} \times\left[\frac{2 J_{1}(2 \pi D f)}{2 \pi D f}\right]^{2} d f
$$

Esta ecuación es una función de $L_{0}, l_{0}$, el diámetro del haz $D$ y $C_{n}^{2} \Delta h$.

La relación de $C_{n}^{2}$ con $\Delta T$ es, según [185 proporcional a $(\Delta T)^{2}$. Sin embargo, la evidencia experimental sugiere que también debe considerarse una proporcionalidad a $\Delta T$ [145].

La experiencia consiste en capturar a un cierto $\Delta T$ las posiciones de centroide de un haz $\left(x_{c}, y_{c}\right)$ luego de ser filtrado a la salida del turbulador por pupilas de diversos tamaños y enfocado en el detector. Luego se calcula la varianza del ángulo de arribo según [182]:

$$
\begin{aligned}
\sigma_{A o A}^{2} & \approx \sigma_{x}^{2} / f^{2} \\
& \approx \sigma_{y}^{2} / f^{2}
\end{aligned}
$$

donde $f$ es la distancia focal de la lente empleada $a^{4}$ Nótese que las varianzas tendrán un error de la propagación del error de $f$.

\section{E.4. Procedimiento experimental}

La experiencia fue montada en el Laboratorio de Procesamiento Láser del CIOp, y se muestra en las figura E.4 en la página siguiente. La velocidad de los ventiladores se deja fija. El equipo empleado fue el siguiente:

- Turbulador Mark 2: trabajando con valores $\Delta T=0$ (referencia, ventiladores apagados); 1,2583 (referencia, ventiladores encendidos); 6,0167; 9,$7833 ; 14,475 ; 18,875 ; 30,667 ; 43,367 ; 52,0833 ; 70,7333 ; 96,7417$ y 131,8000 ${ }^{\circ} \mathrm{C}$ (la última a aprovximadamente una corriente de $6 \mathrm{~A}$ ).

- Láser Melles Griot ${ }^{5}$ 05-LHP-991, $\lambda=633$ nm; se empleó también un espejo para esa longitud de onda por cuestiones de espacio.

${ }^{4}$ En 182 se toma por ejemplo para la coordenada $x$ después de $k$ observaciones:

$$
\sigma^{2}\left(\alpha_{P}\right) \approx \frac{1}{k f^{2}} \sum_{i=1}^{k}\left(x_{i}-\mu_{x}\right)^{2}
$$

donde $\mu_{x}$ es el promedio. El factor de división empleado por el software usado para hallar las varianzas fue en realidad $k-1$. Como la cantidad de datos es grande (360000 por cálculo), la corrección es en la sexta cifra significativa, diferencia que carece de importancia después de propagar errores. En efecto, $359999 / 360000=0,999997222$.

${ }^{5}$ Gentileza de la Doctora Myriam Tebaldi. 


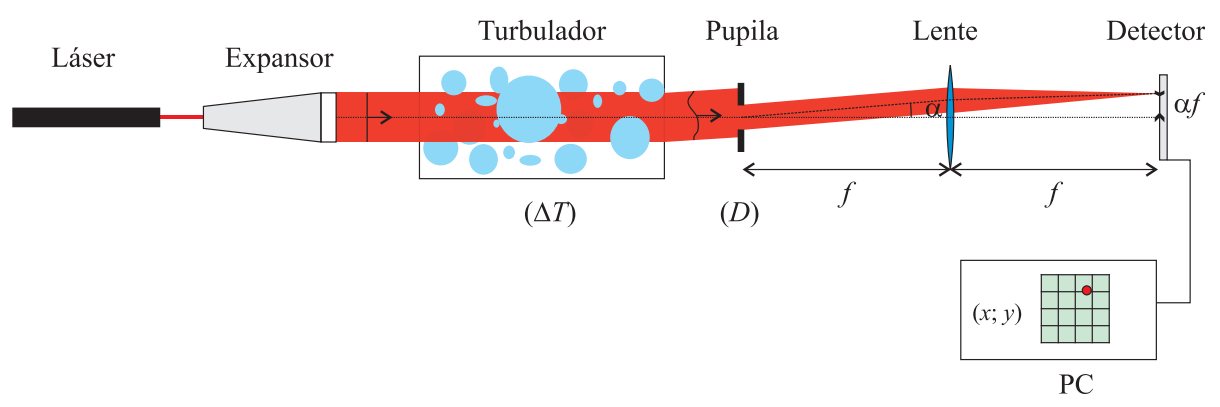

Figura E.4: Esquema experimental.

- Pupilas de diámetros $D=2,52 ; 3,3 ; 4,4 ; 5,08 ; 6 ; 7,1 ; 8,24 ; 9,12 ; 9,68 ; 10,22$; 11,$3 ; 14,70 ; 17,72$ y $24,7 \mathrm{~mm}$, montadas sobre vidrio flotado de $2 \mathrm{~mm}$ de grosor.

- Lente Thorlabs de $f=(20,0 \pm 0,05) \mathrm{cm}$.

- Expansor de alta energía Spectra Physics con pinhole de $15 \mu \mathrm{m}$.

- Sistema opto-electrónico para la determinación de posiciones configurado para registrar 6000 posiciones de centroide por segundo. Las capturas para cada pupila fueron de 1 minuto ( 360000 posiciones de centroide).

La longitud de propagación dentro del turbulador es $\Delta h=(35 \pm 0,5) \mathrm{cm}$.

\section{E.5. Método de ajuste numérico de los datos}

El método es el seguido por 138, 182 145]. La determinación de los 3 parámetros de la turbulencia $L_{0}, l_{0}$ y $C_{n}^{2}$ requiere ajustar el modelo teórico de la varianza del ángulo de arribo (E.9) a partir de las medidas de la varianza del ángulo de arribo para todos los diámetros $D$ de pupila (para cada eje).

Primero se elije particionar los 360000 datos de posiciones en 12 tramos de 30000 datos cada uno, a cada uno de los cuales se le calcula la varianza. Luego éstas se promedian y se saca su desviación estándar. Se divide por $f$ y se propaga el error. Así se consiguen las curvas empíricas de $\sigma_{A o A}^{2}(D)$ para cada eje e intensidad de turbulencia.

La constante de estructura aparece como un factor en la expresión de la varianza $\sigma_{A o A}^{2}$ (Ecuación E.9) ), y por lo tanto es posible «normalizar» las varianzas medidas con uno de los valores de diámetro de pupila dados (el más pequeño) y separar así la determinación de las escalas. Para eliminar la dependencia de $C_{n}^{2} \Delta h$, el primer paso es normalizar la varianza del ángulo de arribo por el valor obtenido para el menor diámetro hecho en el experimento $D_{\min }$ :

$$
\sigma_{\text {norm, emp. }}^{2}\left(l_{0}, L_{0}, D\right)=\frac{\sigma_{A o A}^{2}\left(l_{0}, L_{0}, D\right)}{\sigma_{A o A}^{2}\left(l_{0}, L_{0}, D_{\min }\right)}
$$


Así, las series obtenidas comienzan en 1 y decrecen con $D$. Desde el punto de vista teórico, esta normalización es equivalente en la Ecuación (E.9) a

$$
\sigma_{\text {norm, teór. }}^{2}\left(l_{0}, L_{0}, D\right)=\frac{\int_{0}^{\infty} f^{3}\left(f^{2}+\frac{1}{L_{0}^{2}}\right)^{-11 / 6} \exp \left\{-l_{0}^{2} f^{2}\right\} \times\left[\frac{2 J_{1}(2 \pi D f)}{2 \pi D f}\right]^{2} d f}{\int_{0}^{\infty} f^{3}\left(f^{2}+\frac{1}{L_{0}^{2}}\right)^{-11 / 6} \exp \left\{-l_{0}^{2} f^{2}\right\} \times\left[\frac{2 J_{1}\left(2 \pi D \min ^{f}\right)}{2 \pi D_{\text {min }} f}\right]^{2} d f}
$$

Entonces, dada una intensidad de turbulencia y la serie normalizada de varianzas para el ángulo de arribo en función de $D$ (para cada eje), el ajuste se lleva a cabo de la siguiente manera:

1. Teniendo en cuenta valores previos de referencia [145] y las dimensiones de la cámara de turbulencia, se proponen 150 valores equiespaciados para $l_{0}$ desde 0,1 hasta $11 \mathrm{~mm}$, y 150 valores equiespaciados para $L_{0}$ desde 10 hasta $25 \mathrm{~cm}$.

2. Para los diámetros de pupila empleados se evalúa numéricamente $\sigma_{\text {norm, teór. }}^{2}\left(l_{0}, L_{0}, D\right)$ con la Ecuación E.12 para las $150 \times 150=22500$ combinaciones de $l_{0}$ y $L_{0}$ propuestas en el paso anterior.

3. Para cada una de las combinaciones de $l_{0}$ y $L_{0}$ se calcula la diferencia cuadrática entre los datos normalizados y la curva teórica según

$$
\delta^{2}\left(l_{0}, L_{0}\right)=\sum_{i}\left[\sigma_{\text {norm, emp. }}^{2}\left(l_{0}, L_{0}, D_{i}\right)-\sigma_{\text {norm, teór. }}^{2}\left(l_{0}, L_{0}, D_{i}\right)\right]^{2}
$$

4. Se busca la combinación de valores $l_{0}^{*}$ y $L_{0}^{*}$ que dan el valor mínimo de $\delta^{2}\left(l_{0}, L_{0}\right)$.

5. El valor de $C_{n}^{2}$ para cada curva se halla luego como

$$
C_{n}^{2}=\frac{\sigma_{A o A}^{2}\left(l_{0}, L_{0}, D_{\min }\right)}{1,19 \Delta h \int_{0}^{\infty} f^{3}\left(f^{2}+\frac{1}{L_{0}^{2}}\right)^{-11 / 6} \exp \left\{-l_{0}^{2} f^{2}\right\} \times\left[\frac{2 J_{1}\left(2 \pi D_{\min } f\right)}{2 \pi D_{\min } f}\right]^{2} d f}
$$

Los ajustes de las varianzas de ángulo de arribo paa cara eje se muestran en las Figuras E.5 y E.6. Se emplean promedios y desviaciones estándard para reportar los valores de las escalas:

$l_{0}<4 \mathrm{~mm}$, con un valor más probable de $1 \mathrm{~mm}$

$$
L_{0}=(16 \pm 7) \mathrm{cm}
$$


Finalmente, se calcularon los promedios de $C_{n}^{2}$ para cada eje como función de $\Delta T$ y se ensayaron varios modelos de ajuste, de los cuales se encontró que el tipo logístico es el más justado para caracterizar la unidad (ver Figura E.7):

$$
C_{n}^{2}(\Delta T)=\frac{4,035}{1+\exp \left\{-0,04232\left(\Delta T-43,19^{\circ} \mathrm{C}\right) /{ }^{\circ} \mathrm{C}\right\}} \cdot 10^{-8} \mathrm{~m}^{-2 / 3}
$$



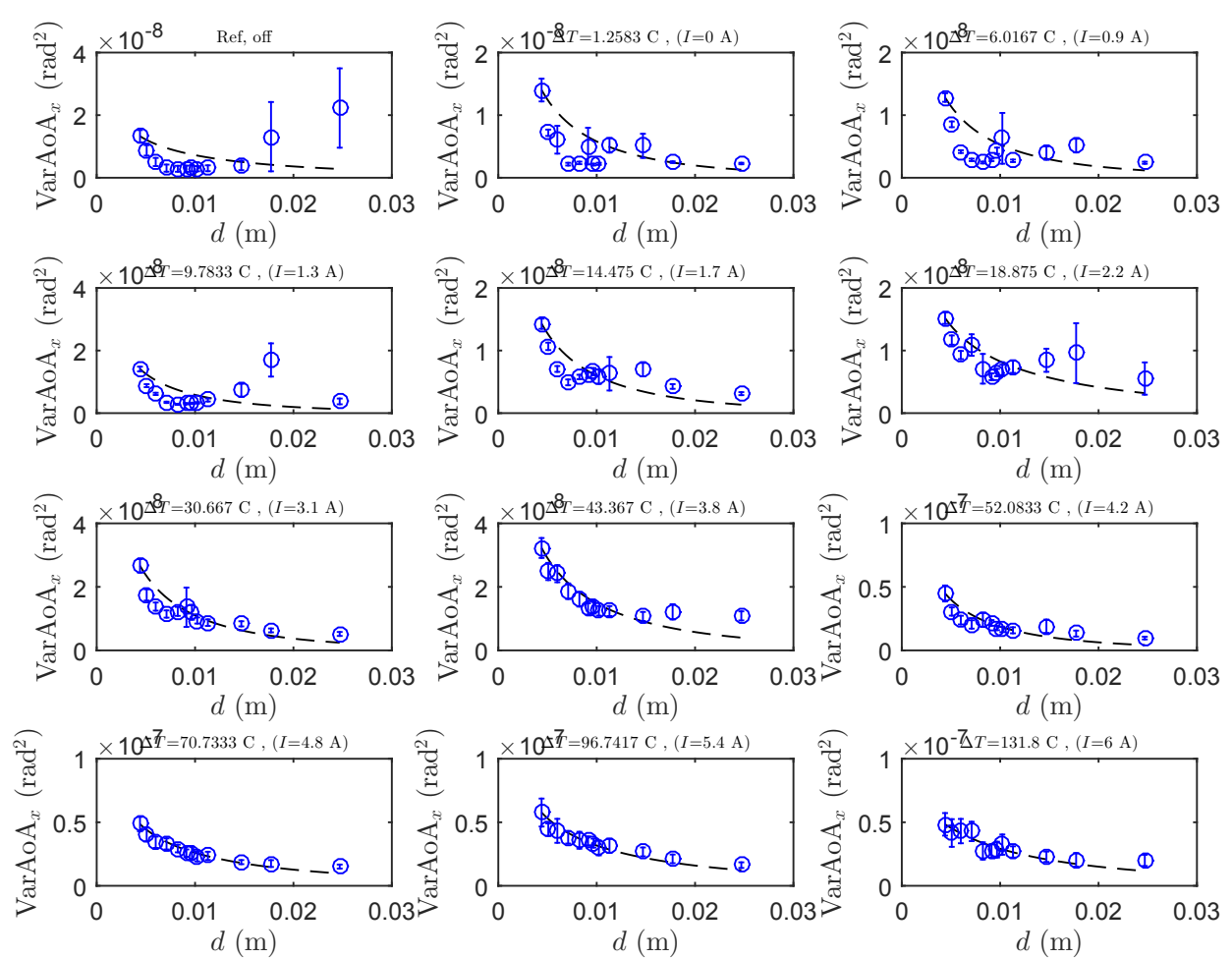

166

Figura E.5: Ajuste de varianzas para el ángulo de arribo, eje $x$. 

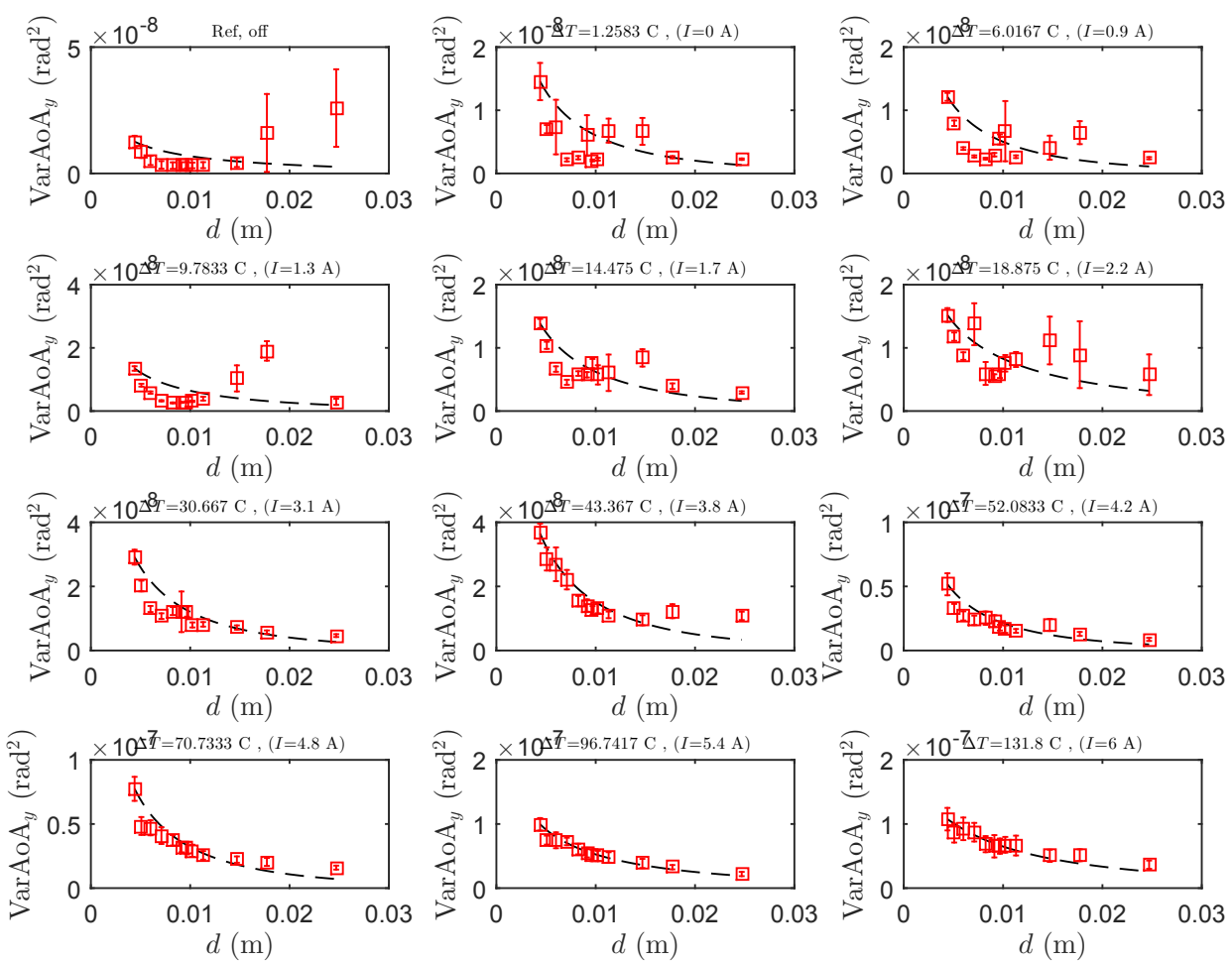

Figura E.6: Ajuste de varianzas para el ángulo de arribo, eje $y$. 


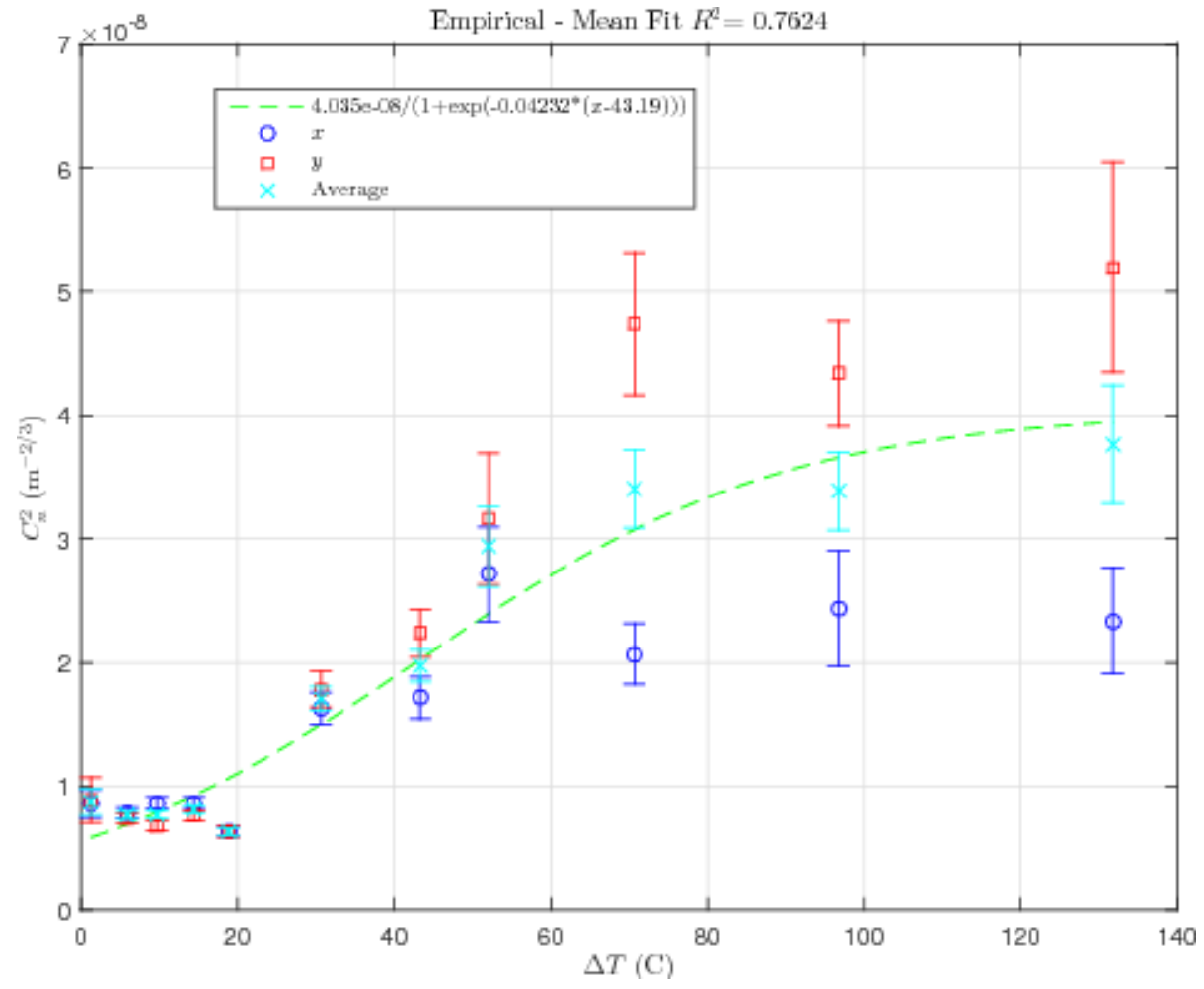

Figura E.7: Ajuste del comportamiento promedio . 


\section{Clara: Doctor! \\ THE DOCTOR: Hello.}

CLARA: You're young again. You're okay... You didn't even change your face. THE DOCTOR: Ha! It's started, I can't stop it now. This is just the reset: a whole new regeneration cycle, ooh! Taking a bit longer, just breaking it in. It all just disappears, doesn't it? Everything you are, gone in a moment; like breath on a mirror. Any moment now, he's a coming.

CLARA: Who's coming?

THE DOCTOR: The Doctor.

CLARA: You, you are The Doctor.

THE Doctor: Yup, and I always will be. But times change, and so must I...

Amelia.

CLARA: Who is Amelia?

THE Doctor: The first face this face saw. We all change, when you think about it, we're all different people; all through our lives, and that's okay, that's good, you've got to keep moving, so long as you remember all the people that you used to be. I will not forget one line of this, not one day, I swear. I will always remember when The Doctor was me. 


\section{Bibliografía}

[1] Larry C. Andrews and Ronald L. Phillips. Laser Beam Propagation through Random Media, Second Edition (SPIE Press Monograph Vol. PM152). SPIE Publications, 2005.

[2] Larry C. Andrews, Ronald L. Phillips, and Cynthia Y. Hopen. Laser Beam Scintillation with Applications (SPIE Press Monograph Vol. PM99). SPIE Publications, 2001.

[3] Jason D. Schmidt. Numerical Simulation of Optical Wave Propagation With Examples in MATLAB (SPIE Press Monograph Vol. PM199). SPIE Press, 2010.

[4] Richard J. Sasiela. Electromagnetic Wave Propagation in Turbulence: Evaluation and Application of Mellin Transforms. SPIE Press, 2nd edition, 2007.

[5] Andrew Loomis. El dibujo de la figura en tdo su valor. Lancelot, 2010.

[6] A. N. Kolmogorov. 'the local structure of turbulence in an incompressible viscous fluid for very large Reynolds numbers. C. R. (Doki) Acad. Sci. U.S.S.R., 30:301-305, 1941.

[7] Gustavo Funes, Damián Gulich, Luciano Zunino, Darío G. Pérez, and Mario Garavaglia. Behavior of the laser beam wandering variance with the turbulent path length. Optics Communications, 272(2):476-479, Apr 2007.

[8] Damián Gulich, Gustavo Funes, Luciano Zunino, Darío G. Pérez, and Mario Garavaglia. Angle-of-arrival varianceś dependence on the aperture size for indoor convective turbulence. Optics Communications, 277(2):241-246, Sep 2007.

[9] Byron M. Welsh. Fourier-series-based atmospheric phase screen generator for simulating anisoplanatic geometries and temporal evolution. Propagation and Imaging through the Atmosphere, Sep 1997.

[10] L. Zunino, D. G. Pérez, and M. Garavaglia. Ten years of research on light propagation through a turbulent atmosphere. In Niklaus Ursus Wetter 
and Jaime Frejlich, editors, RIAO/OPTILAS 2007: 6th Ibero-American Conference on Optics (RIAO); 9th Latin-American Meeting on Optics, Lasers and Applications (OPTILAS), volume 992, pages 15-20. AIP, 2008.

[11] D. G. Pérez and M. Garavaglia. Fractional Brownian motion property of the atmospheric refraction index. In Vera L. Brudny, Silvia A. Ledesma, and Mario C. Marconi, editors, 4th Iberoamerican Meeting on Optics and 7th Latin American Meeting on Optics, Lasers, and Their Applications, volume 4419, pages 503-505. SPIE, SPIE, 2001.

[12] L. Zunino, D.G. Pérez, M. Garavaglia, and Osvaldo A. Rosso. Characterization of laser propagation through turbulent media by quantifiers based on the wavelet transform: Dynamic study. Physica A: Statistical Mechanics and its Applications, 364:79-86, May 2006.

[13] L. Zunino, D.G. Pérez, A. Kowalski, M.T. Martín, M. Garavaglia, A. Plastino, and O.A. Rosso. Fractional brownian motion, fractional Gaussian noise, and tsallis permutation entropy. Physica A: Statistical Mechanics and its Applications, 387(24):6057-6068, Oct 2008.

[14] Luciano Zunino, Miguel C. Soriano, Alejandra Figliola, Darío G. Pérez, Mario Garavaglia, Claudio R. Mirasso, and Osvaldo A. Rosso. Performance of encryption schemes in chaotic optical communication: A multifractal approach. Optics Communications, 282(23):4587-4594, Dec 2009.

[15] G. R. Cattáneo, P. Meilán, D. Gulich, M. Fernández, and M. Garavaglia. Arqueología de Fuego-Patagonia. Levantando piedras, desenterrando huesos...y develando arcanos, chapter Microscopía láser confocal de barrido (CLSM) aplicada al estudio de microhuellas de utilización en instrumentos líticos experimentales: una perspectiva cuantitativa, pages 327-342. Ediciones CEQUA, 2007.

[16] A. A. Semenov and W. Vogel. Entanglement transfer through the turbulent atmosphere. Physical Review A, 81(2), Feb 2010.

[17] Kevin Murphy, Daniel Burke, Nicholas Devaney, and Chris Dainty. Experimental detection of optical vortices with a Shack-Hartmann wavefront sensor. Optics Express, 18(15):15448, Jul 2010.

[18] Li-Gang Wang and Wei-Wei Zheng. The effect of atmospheric turbulence on the propagation properties of optical vortices formed by using coherent laser beam arrays. J. Opt. A: Pure Appl. Opt., 11(6):065703, Mar 2009.

[19] L. Zunino, B. M. Tabak, D. G. Pérez, M. Garavaglia, and O. A. Rosso. Inefficiency in Latin-American market indices. Eur. Phys. J. B, 60(1):111121, Nov 2007.

[20] Luciano Zunino, Alejandra Figliola, Benjamin M. Tabak, Darío G. Pérez, Mario Garavaglia, and Osvaldo A. Rosso. Multifractal structure in LatinAmerican market indices. Chaos, Solitons E Fractals, 41:2331-2340, 2009. 
[21] L. Zunino, B.M. Tabak, A. Figliola, D.G. Pérez, M. Garavaglia, and O.A. Rosso. A multifractal approach for stock market inefficiency. Physica A, 387(26):6558 - 6566, 2008.

[22] C.-K. Peng, S. V. Buldyrev, S. Havlin, M. Simons, H. E. Stanley, and A. L. Goldberger. Mosaic organization of DNA nucleotides. Phys. Rev. E, 49:1685-1689, Feb 1994.

[23] Jan W. Kantelhardt, Stephan A. Zschiegner, Eva Koscielny-Bunde, Shlomo Havlin, Armin Bunde, and H.Eugene Stanley. Multifractal detrended fluctuation analysis of nonstationary time series. Physica A: Statistical Mechanics and its Applications, 316(1-4):87-114, Dec 2002.

[24] Petre Caraiani. Evidence of multifractality from emerging European stock markets. PLoS ONE, 7(7):e40693, Jul 2012.

[25] Luciano Telesca, Vincenzo Lapenna, and Maria Macchiato. Mono- and multi-fractal investigation of scaling properties in temporal patterns of seismic sequences. Chaos, Solitons \& Fractals, 19(1):1 - 15, 2004.

[26] C.-K. Peng, Shlomo Havlin, H. Eugene Stanley, and Ary L. Goldberger. Quantification of scaling exponents and crossover phenomena in nonstationary heartbeat time series. Chaos, 5(1):82-87, 1995.

[27] Nandan Das, Subhasri Chatterjee, Jalpa Soni, Jaidip Jagtap, Asima Pradhan, Tapas K. Sengupta, Prasanta K. Panigrahi, I. Alex Vitkin, and Nirmalya Ghosh. Probing multifractality in tissue refractive index: prospects for precancer detection. Opt. Lett., 38(2):211-213, Jan 2013.

[28] M. Sadegh Movahed, F. Ghasemi, Sohrab Rahvar, and M. Reza Rahimi Tabar. Long-range correlation in cosmic microwave background radiation. Phys. Rev. E, 84:021103, Aug 2011.

[29] G. Z. dos Santos Lima, M. A. Corrêa, R. L. Sommer, and F. Bohn. Multifractality in domain wall dynamics of a ferromagnetic film. Phys. Rev. E, 86:066117, Dec 2012.

[30] Leonardo Dagdug, Jose Alvarez-Ramirez, Carlos Lopez, Rodolfo Moreno, and Enrique Hernandez-Lemus. Correlations in a Mozart's music score (k-73x) with palindromic and upside-down structure. Physica $A$, 383:570-584, 2007.

[31] G. R. Jafari, P. Pedram, and L. Hedayatifar. Long-range correlation and multifractality in Bach's Inventions pitches. J. Stat. Mech., page P04012, 2007.

[32] Luciano Telesca and Michele Lovallo. Revealing competitive behaviours in music by means of the multifractal detrended fluctuation analysis: application to Bach's Sinfonias. Proc. R. Soc. A, 467:3022-3032, 2011. 
[33] Holger Hennig, Ragnar Fleischmann, Anneke Fredebohm, York Hagmayer, Jan Nagler, Annette Witt, Fabian J. Theis, and Theo Geisel. The nature and perception of fluctuations in human musical rhythms. PLOS ONE, 6(10):e26457, 2011.

[34] Luciano Telesca and Michele Lovallo. Analysis of temporal fluctuations in Bach's sinfonias. Physica A, 391:3247-3256, 2012.

[35] Jan W. Kantelhardt. Fractal and multifractal time series. In Robert A. Meyers, editor, Encyclopedia of Complexity and Systems Science. Springer, 2009.

[36] Antonio Turiel, Conrad J. Pérez-Vicente, and Jacopo Grazzini. Numerical methods for the estimation of multifractal singularity spectra on sampled data: A comparative study. Journal of Computational Physics, 216:362-390, 2006.

[37] S. Drożdż, J. Kwapień, P. Oświęcimka, and R. Rak. Quantitative features of multifractal subtleties in time series. Europhys. Lett., 88:60003, 2009.

[38] Dariusz Grech and Grzegorz Pamuła. Multifractal background noise of monofractal signals. Acta Phys. Pol. A, 121:B34-B39, 2012.

[39] J. W. Kantelhardt, S. A. Zschiegner, E. Koscielny-Bunde, S. Havlin, A. Bunde, and H. E. Stanley. Multifractal detrended fluctuation analysis of nonstationary time series. Physica A, 316:87-114, 2002.

[40] J. F. Muzy, E. Bacry, and A. Arneodo. Wavelets and multifractal formalism for singular signals: Application to turbulence data. Phys. Rev. Lett., 67:3515-3518, 1991.

[41] Albert-László Barabási, Péter Szépfalusy, and Tamás Vicsek. Multifractal spectra of multi-affine functions. Physica A, 178:17-28, 1991.

[42] Eduardo Serrano and Alejandra Figliola. Wavelet Leaders: A new method to estimate the multifractal singularity spectra. Physica A, 388:27932805, 2009.

[43] P. Oświęcimka, J. Kwapień, and S. Drożdż. Wavelet versus detrended fluctuation analysis of multifractal structures. Phys. Rev. E, 74:016103, 2006.

[44] Gao-Feng Gu and Wei-Xing Zhou. Detrended fluctuation analysis for fractals and multifractals in higher dimensions. Phys. Rev. E, 74:061104, 2006.

[45] Wei-Xing Zhou. Multifractal detrended cross-correlation analysis for two nonstationary signals. Phys. Rev. E, 77:066211, 2008. 
[46] Boris Podobnik and H. Eugene Stanley. Detrended cross-correlation analysis: A new method for analyzing two nonstationary time series. Phys. Rev. Lett., 100:084102, Feb 2008.

[47] Boris Podobnik, Davor Horvatic, Alexander M. Petersen, and H. Eugene Stanley. Cross-correlations between volume change and price change. PNAS, 106:22079-22084, 2009.

[48] Mikhail I. Bogachev and Armin Bunde. On the predictability of extreme events in records with linear and nonlinear long-range memory: Efficiency and noise robustness. Physica A, 390:2240-2250, 2011.

[49] Josef Ludescher, Mikhail I. Bogachev, Jan W. Kantelhardt, Aicko Y. Schumann, and Armin Bunde. On spurious and corrupted multifractality: The effects of additive noise, short-term memory and periodic trends. Physica A, 390:2480-2490, 2011.

[50] J. Feder. Fractals. Plenum Press, New York, 1988.

[51] C. Meneveau and K. R. Sreenivasan. Simple multifractal cascade model for fully developed turbulence. Phys. Rev. Lett., 59:1424-1427, 1987.

[52] Aicko Y. Schumann and Jan W. Kantelhardt. Multifractal moving average analysis and test of multifractal model with tuned correlations. Physica A, 390(14):2637 - 2654, 2011.

[53] Hernán A. Makse, Shlomo Havlin, Moshe Schwartz, and H. Eugene Stanley. Method for generating long-range correlations for large systems. Phys. Rev. E, 53:5445-5449, 1996.

[54] Damián Gulich and Luciano Zunino. The effects of observational correlated noises on multifractal detrended fluctuation analysis. Physica $A$, 391:4100-4110, 2012.

[55] Ying-Hui Shao, Gao-Feng Gu, Zhi-Qiang Jiang, Wei-Xing Zhou, and Didier Sornette. Comparing the performance of FA, DFA and DMA using different synthetic long-range correlated time series. Sci. Rep., 2:835, 2012.

[56] Erjia Ge and Yee Leung. Detection of crossover time scales in multifractal detrended fluctuation analysis. J. Geogr. Syst., 15(2):115-147, 2013.

[57] R.B. Govindan, J.D. Wilson, H. Preißl, H. Eswaran, J.Q. Campbell, and C.L. Lowery. Detrended fluctuation analysis of short datasets: An application to fetal cardiac data. Physica D, 226:23-31, 2007.

[58] Amir Bashan, Ronny Bartsch, Jan W. Kantelhardt, and Shlomo Havlin. Comparison of detrending methods for fluctuation analysis. Physica A, 387(21):5080-5090, 2008. 
[59] Juan Luis López and Jesús Guillermo Contreras. Performance of multifractal detrended fluctuation analysis on short time series. Phys. Rev. E, 87:022918, 2013.

[60] Sebastian Michalski. Blocks adjustment - reduction of bias and variance of detrended fluctuation analysis using Monte Carlo simulation. Physica A, 387(1):217-242, 2008.

[61] Dariusz Grech and Grzegorz Pamuła. On the multifractal effects generated by monofractal signals. Physica A: Statistical Mechanics and its Applications, 392(23):5845-5864, Dec 2013.

[62] Dariusz Grech and Zygmunt Mazur. On the scaling ranges of detrended fluctuation analysis for long-term memory correlated short series of data. Physica A, 392(10):2384-2397, 2013.

[63] E. Alessio, A. Carbone, G. Castelli, and V. Frappietro. Second-order moving average and scaling of stochastic time series. Eur. Phys. J. B, 27(2):197-200, 2002.

[64] Jose Alvarez-Ramirez, Eduardo Rodriguez, and Juan Carlos Echeverría. Detrending fluctuation analysis based on moving average filtering. Physica A, 354:199-219, 2005.

[65] Ken Kiyono, Zbigniew R. Struzik, Naoko Aoyagi, Fumiharu Togo, and Yoshiharu Yamamoto. Phase transition in a healthy human heart rate. Phys. Rev. Lett., 95(5):058101, 2005.

[66] M. Staudacher, S. Telser, A. Amann, H. Hinterhuber, and M. RitschMarte. A new method for change-point detection developed for online analysis of the heart beat variability during sleep. Physica A, 349(34):582-596, 2005.

[67] Wei-Xing Zhou. Multifractal detrended cross-correlation analysis for two nonstationary signals. Phys. Rev. E, 77(6), Jun 2008.

[68] Gao-Feng Gu and Wei-Xing Zhou. Detrending moving average algorithm for multifractals. Phys. Rev. E, 82(1), Jul 2010.

[69] Zhi-Qiang Jiang and Wei-Xing Zhou. Multifractal detrending movingaverage cross-correlation analysis. Phys. Rev. E, 84(1), Jul 2011.

[70] D. Horvatic, H. E. Stanley, and B. Podobnik. Detrended cross-correlation analysis for non-stationary time series with periodic trends. EPL ( $E u-$ rophysics Letters), 94(1):18007, Apr 2011.

[71] Xi-Yuan Qian, Gao-Feng Gu, and Wei-Xing Zhou. Modified detrended fluctuation analysis based on empirical mode decomposition for the characterization of anti-persistent processes. Physica A, 390(23-24):43884395, 2011. 
[72] Jan W Kantelhardt, Eva Koscielny-Bunde, Henio H.A Rego, Shlomo Havlin, and Armin Bunde. Detecting long-range correlations with detrended fluctuation analysis. Physica A: Statistical Mechanics and its Applications, 295(3-4):441-454, Jun 2001.

[73] V. Livina, Z. Kizner, P. Braun, T. Molnar, A. Bunde, and S. Havlin. Temporal scaling comparison of real hydrological data and model runoff records. J. Hydrol., 336:186-198, 2007.

[74] Pengjian Shang, Yongbo Lu, and Santi Kamae. Detecting long-range correlations of traffic time series with multifractal detrended fluctuation analysis. Chaos, Solitons \& Fractals, 36(1):82-90, 2008.

[75] Patrice Abry and Fabrice Sellan. The wavelet-based synthesis for fractional brownian motion proposed by f. sellan and y. meyer: Remarks and fast implementation. Applied and Computational Harmonic Analysis, 3(4):377-383, Oct 1996.

[76] Galileo Galilei and Christoph Scheiner. On Sunspots. University Of Chicago Press, 2010.

[77] K.K.C. Yau and F.R. Stephenson. A revised catalogue of Far Eastern observations of sunspots (165 BC to AD 1918). Quarterly Journal of the Royal Astronomical Society, 29:175-197, Jun 1988.

[78] X. Moussas, J.M. Polygiannakis, P. Preka-Papadema, and G. Exarhos. Solar cycles: A tutorial. Advances in Space Research, 35(5):725 - 738, 2005.

[79] Samuli Helama and Jari Holopainen. Spring temperature variability relative to the North Atlantic oscillation and sunspots - a correlation analysis with a Monte Carlo implementation. Palaeogeography, Palaeoclimatology, Palaeoecology, 326-328:128 - 134, 2012.

[80] Jianjun Xu and Alfred M. Powell Jr. What happened to surface temperature with sunspot activity in the past 130 years? Theoretical and Applied Climatology, 111:609-622, 2013.

[81] Pablo J. D. Mauas, Eduardo Flamenco, and Andrea P. Buccino. Solar forcing of the stream flow of a continental scale South American river. Phys. Rev. Lett., 101:168501, Oct 2008.

[82] Pablo J.D. Mauas, Andrea P. Buccino, and Eduardo Flamenco. Long-term solar activity influences on South American rivers. Journal of Atmospheric and Solar-Terrestrial Physics, 73(2-3):377 - 382, 2011.

[83] Stanisław Zieba and Zenon Nieckarz. Sunspot time series - relations inferred from the location of the longest spotless segments. Solar Physics, 278(2):457-469, 2012. 
[84] Jing Hu, Jianbo Gao, and Xingsong Wang. Multifractal analysis of sunspot time series: the effects of the 11-year cycle and Fourier truncation. $J$. Stat. Mech., 2009(2):P02066, 2009.

[85] Yu Zhou and Yee Leung. Empirical mode decomposition and long-range correlation analysis of sunspot time series. J. Stat. Mech., 2010(12):P12006, 2010.

[86] M Sadegh Movahed, G R Jafari, F Ghasemi, Sohrab Rahvar, and M Reza Rahimi Tabar. Multifractal detrended fluctuation analysis of sunspot time series. J. Stat. Mech., 2006(2):P02003, 2006.

[87] Kun Hu, Plamen Ch. Ivanov, Zhi Chen, Pedro Carpena, and H. Eugene Stanley. Effect of trends on detrended fluctuation analysis. Phys. Rev. E, 64(1):011114 (19 pages), 2001.

[88] Eva Koscielny-Bunde, Jan W. Kantelhardt, Peter Braun, Armin Bunde, and Shlomo Havlin. Long-term persistence and multifractality of river runoff records: Detrended fluctuation studies. J. Hydrol., 322:120-137, 2006.

[89] R. Nagarajan and R. G. Kavasseri. Minimizing the effect of sinusoidal trends in detrended fluctuation analysis. Int. J. Bifurcation Chaos, 15(5):1767-1773, 2005.

[90] Norden E. Huang, Zheng Shen, Steven R. Long, Manli C. Wu, Hsing H. Shih, Quanan Zheng, Nai-Chyuan Yen, Chi Chao Tung, and Henry H. Liu. The empirical mode decomposition and the Hilbert spectrum for nonlinear and non-stationary time series analysis. Proc. R. Soc. A, 454(1971):903-995, 1998.

[91] Zhaohua Wu, Norden E. Huang, Steven R. Long, and Chung-Kang Peng. On the trend, detrending, and variability of nonlinear and nonstationary time series. Proc. Natl. Acad. Sci. USA, 104(38):14889-14894, 2007.

[92] G. Rilling, P. Flandrin, and P. Gonçalves. On Empirical Mode Decomposition and its algorithms. In IEEE-EURASIP Workshop on Nonlinear Signal and Image Processing NSIP-03, 2003.

[93] András Hartmann, Péter Mukli, Zoltán Nagy, László Kocsis, Péter Hermán, and András Eke. Real-time fractal signal processing in the time domain. Physica A, 392:89-102, 2013.

[94] Luciano Telesca, Vincenzo Lapenna, and Maria Macchiato. Multifractal fluctuations in earthquake-related geoelectrical signals. New J. Phys., $7: 214,2005$.

[95] Damián Gulich and Luciano Zunino. A criterion for the determination of optimal scaling ranges in DFA and MF-DFA. Physica A: Statistical Mechanics and its Applications, 397:17-30, Mar 2014. 
[96] Samuel V. Mantravadi, Troy A. Rhoadarmer, and Robert S. Glas. Simple laboratory system for generating well-controlled atmospheric-like turbulence. Advanced Wavefront Control: Methods, Devices, and Applications II, Oct 2004.

[97] Troy A. Rhoadarmer and J. Roger P. Angel. Low-cost, broadband static phase plate for generating atmosphericlike turbulence. Applied Optics, 40(18):2946-2955, 2001.

[98] Wm. A. Coles, J. P. Filice, R. G. Frehlich, and M. Yadlowsky. Simulation of wave propagation in three-dimensional random media. Applied Optics, 34(12):2089-2101, 1995.

[99] J. M. Martin and Stanley M. Flatté. Intensity images and statistics from numerical simulation of wave propagation in 3-D random media. Applied Optics, 27(11):2111-2126, 1988.

[100] J. M. Martin and Stanley M. Flatté. Simulation of point-source scintillation through three-dimensional random media. Journal of the Optical Society of America A, 7(5):838-847, 1990.

[101] A. M. Obukov. Structure of the temperature field un turbulent flow. Izv. Acad. Nauk. SSSR, Ser. Georgr. I Geofiz., 13:58-69, 1949.

[102] Stanley Corrsin. On the spectrum of isotropic temperature fluctuations in an isotropic turbulence. Journal of Applied Physics, 22(4):469-473, 1951.

[103] Akira Ishimaru. Wave Propagation and Scattering in Random Media. WileyIEEE Press, 1999.

[104] Albert D. Wheelon. Electromagnetic Scintillation: Volume 2, Weak Scattering. Cambridge University Press, 2006.

[105] S. F. Clifford. Laser Beam Propagation in the Atmosphere (Topics in Applied Physics), chapter The classical theory of wave propagation in a turbulent medium, pages 9-43. Springer, 1978.

[106] D. L. Fried. Statistics of a Geometric Representation of Wavefront Distortion. Journal of the Optical Society of America, 55(11):1427-1431, 1965.

[107] L.C. Andrews, S. Vester, and C.E. Richardson. Analytic expressions for the wave structure function based on a bump spectral model for refractive index fluctuations. Journal of Modern Optics, 40(5):931-938, May 1993.

[108] Michael C. Roggemann, Byron M. Welsh, and Bobby R. Hunt. Imaging Through Turbulence (Laser \& Optical Science \& Technology). CRC Press, 1996. 
[109] Michael C. Roggemann, Byron M. Welsh, Dennis Montera, and Troy A. Rhoadarmer. Method for simulating atmospheric turbulence phase effects for multiple time slices and anisoplanatic conditions. Applied Optics, 34(20):4037-4051, 1995.

[110] Chunyu Zhao and James H. Burge. Orthonormal vector polynomials in a unit circle, Part I: basis set derived from gradients of Zernike polynomials. Optics Express, 15(26):18014-18024, 2007.

[111] Benjamin L. McGlamery. Restoration of turbulence-degraded images. Journal of the Optical Society of America, 57(3):293-296, 1967.

[112] R G Lane, A Glindemann, and J C Dainty. Simulation of a Kolmogorov phase screen. Waves in Random Media, 2(3):209-224, Jul 1992.

[113] Rod Frehlich. Simulation of laser propagation in a turbulent atmosphere. Appl. Opt., 39(3):393-397, 2000.

[114] Suman Kumar Maji, Hussein M. Yahia, and Thierry Fusco. A multifractal-based wavefront phase estimation technique for groundbased astronomical observations. IEEE Transactions on Geoscience and Remote Sensing, pages 1-11, 2015.

[115] Hans Jakobsson. Simulations of time series of atmospherically distorted wave fronts. Applied Optics, 35(9):1561, Mar 1996.

[116] Thomas Goldring and Lawrence Carlson. Analysis and implementation of non-Kolmogorov phase screens appropriate to structured environments $</$ title $>$. Nonlinear Optical Beam Manipulation and High Energy Beam Propagation Through the Atmosphere, Aug 1989.

[117] Mark B. Jorgenson and George J. M. Aitken. Prediction of atmospherically induced wave-front degradations. Optics Letters, 17(7):466, 1992.

[118] J. W Goodman. Statistical Optics. Wiley-Interscience, New York, 1985.

[119] C. Schwartz, G. Baum, and E. N. Ribak. Turbulence-degraded wave fronts as fractal surfaces. Journal of the Optical Society of America A, 11(1):444, Jan 1994.

[120] Benoit B. Mandelbrot and John W. Van Ness. Fractional brownian motions, fractional noises and applications. SIAM Review, 10(4):422-437, Oct 1968.

[121] J. Feder. Fractals. Plenun Press, New York, 1988.

[122] M. B. Jorgenson, G. J. M. Aitken, and E. K. Hege. Evidence of a chaotic attractor in star-wander data. Optics Letters, 16(2):64, 1991. 
[123] Donald R. McGaughey and George J. M. Aitken. Temporal analysis of stellar wave-front-tilt data. Journal of the Optical Society of America A, 14(8):1967, 1997.

[124] Aziz Ziad, Rodolphe Conan, Andrei Tokovinin, FranÃß̧ois Martin, and Julien Borgnino. From the grating scale monitor to the generalized seeing monitor. Appl. Opt., 39(30):5415, 2000.

[125] A Ziad, J Borgnino, W Dali Ali, A Berdja, J Maire, and F Martin. Temporal characterization of atmospheric turbulence with the generalized seeing monitor instrument. J. Opt., 14(4):045705, Mar 2012.

[126] Jean-Marc Conan, Gérard Rousset, and Pierre-Yves Madec. Wave-front temporal spectra in high-resolution imaging through turbulence. Journal of the Optical Society of America A, 12(7):1559, 1995.

[127] David Dayton, Bob Pierson, Brian Spielbusch, and John Gonglewski. Atmospheric structure function measurements with a shack-hartmann wave-front sensor. Optics Letters, 17(24):1737, 1992.

[128] T. W. Nicholls, G. D. Boreman, and J. C. Dainty. Use of a shack-hartmann wave-front sensor to measure deviations from a kolmogorov phase spectrum. Optics Letters, 20(24):2460, 1995.

[129] Wenhe Du, Liying Tan, Jing Ma, and Yijun Jiang. Temporal-frequency spectra for optical wave propagating through non-kolmogorov turbulence. Optics Express, 18(6):5763, 2010.

[130] Luciano Zunino, Damián Gulich, Gustavo Funes, and Aziz Ziad. Experimental confirmation of long-memory correlations in star-wander data. Optics Letters, 39(13):3718, 2014.

[131] James H. Churnside and Richard J. Lataitis. Wander of an optical beam in the turbulent atmosphere. Appl. Opt., 29(7):926, 1990.

[132] D.G. Pérez, L. Zunino, and M. Garavaglia. A fractional brownian motion model for the turbulent refractive index in lightwave propagation. Optics Communications, 242(1-3):57-63, Nov 2004.

[133] Darío G. Pérez, Luciano Zunino, and Mario Garavaglia. Modeling turbulent wave-front phase as a fractional brownian motion: a new approach. Journal of the Optical Society of America A, 21(10):1962, 2004.

[134] Gustavo Funes, Eduardo Figueroa, Damián Gulich, Luciano Zunino, and Darío G. Pérez. Characterizing inertial and convective optical turbulence by detrended fluctuation analysis. Remote Sensing of Clouds and the Atmosphere XVIII; and Optics in Atmospheric Propagation and Adaptive Systems XVI, Oct 2013. 
[135] Hemani Kaushal, Vivek Kumar, Agnibesh Dutta, Harika Aennam, V. K. Jain, Subrat Kar, and Joby Joseph. Experimental study on beam wander under varying atmospheric turbulence conditions. IEEE Photon. Technol. Lett., 23(22):1691-1693, Nov 2011.

[136] A. Arockia Bazil Raj, J. Arputha Vijaya Selvi, D. Kumar, and N. Sivakumaran. Mitigation of beam fluctuation due to atmospheric turbulence and prediction of control quality using intelligent decision-making tools. Appl. Opt., 53(17):3796, 2014.

[137] Mircea Hulea, Zabih Ghassemlooy, Sujan Rajbhandari, and Xuan Tang. Compensating for optical beam scattering and wandering in fso communications. Journal of Lightwave Technology, 32(7):1323-1328, Apr 2014.

[138] E. Masciadri and J. Vernin. Optical technique for inner-scale measurement: possible astronomical applications. Applied Optics, 36(6):1320, 1997.

[139] Bart-Jan Pors, C. H. Monken, Eric R. Eliel, and J. P. Woerdman. Transport of orbital-angular-momentum entanglement through a turbulent atmosphere. Optics Express, 19(7):6671, 2011.

[140] M. V. da Cunha Pereira, L. A. P. Filpi, and C. H. Monken. Cancellation of atmospheric turbulence effects in entangled two-photon beams. Phys. Rev. A, 88(5), Nov 2013.

[141] Stanislav Zvanovec, Joaquin Perez, Zabih Ghassemlooy, Sujan Rajbhandari, and Jiri Libich. Route diversity analyses for free-space optical wireless links within turbulent scenarios. Optics Express, 21(6):7641, 2013.

[142] S. Avramov-Zamurovic, C. Nelson, R. Malek-Madani, and O. Korotkova. Polarization-induced reduction in scintillation of optical beams propagating in simulated turbulent atmospheric channels. Waves in Random and Complex Media, 24(4):452-462, May 2014.

[143] Osvaldo Jiménez Farías, Vincenzo DÁmbrosio, Caterina Taballione, Fabrizio Bisesto, Sergei Slussarenko, Leandro Aolita, Lorenzo Marrucci, Stephen P. Walborn, and Fabio Sciarrino. Resilience of hybrid optical angular momentum qubits to turbulence. Sci. Rep., 5:8424, Feb 2015.

[144] A. Fuchs, J. Vernin, and M. Tallon. Laboratory simulation of a turbulent layer: optical and in situ characterization. Applied Optics, 35(10):1751, 1996.

[145] Onur Keskin, Laurent Jolissaint, and Colin Bradley. Hot-air optical turbulence generator for the testing of adaptive optics systems: principles and characterization. Applied Optics, 45(20):4888, 2006. 
[146] Luciano Zunino, Damián Gulich, Gustavo Funes, and Darío G. Pérez. Turbulence-induced persistence in laser beam wandering. Opt. Lett., 40(13):3145, Jun 2015.

[147] Galileo Galilei. Sidereus Nuncius, or The Sidereal Messenger. University Of Chicago Press, 1989.

[148] Rita Mahon, Christopher I. Moore, Mike S. Ferraro, William S. Rabinovich, and Michele R. Suite. Optical scintillation measurements in a desert environment iii: high-speed imaging of scintillation patterns and their application to aperture averaging. Free-Space and Atmospheric Laser Communications XI, Sep 2011.

[149] Colin N. Reinhardt, D. Wayne, K. McBryde, and G. Cauble. Extracting atmospheric turbulence and aerosol characteristics from passive imagery. Laser Communication and Propagation through the Atmosphere and Oceans II, Sep 2013.

[150] Kevin McBryde and Kris Gibson. Simulating video through turbulence. Laser Communication and Propagation through the Atmosphere and Oceans II, Sep 2013.

[151] Kristofor B. Gibson and Stephen M. Hammel. Turbulence estimation and mitigation in horizontal path imaging. Laser Communication and Propagation through the Atmosphere and Oceans III, Oct 2014.

[152] Mikhail Charnotskii. Energy conservation: a third constraint on the turbulent point spread function. Opt. Eng, 52(4):046001, Apr 2013.

[153] J.R. Parker. Algorithms for Image Processing and Computer Vision, Second Edition. Wiley Publishing, 2011.

[154] Mikhail I. Charnotskii. Turbulence effects on the imaging of an object with a sharp edge: asymptotic technique and aperture-plane statistics. J. Opt. Soc. Am. A, 13(5):1094, 1996.

[155] Gustavo Funes, Matías Vial, and Jaime A. Anguita. Orbital-angularmomentum crosstalk and temporal fading in a terrestrial laser link using single-mode fiber coupling. Optics Express, 23(18):23133, 2015.

[156] Damián Gulich, Gustavo Funes, Darío Pérez, and Luciano Zunino. Estimation of $c_{n}^{2}$ based on scintillation of fixed targets imaged through atmospheric turbulence. Opt. Lett., 40(23):5642, Nov 2015.

[157] Fumiyoshi Kuwashima, Takesi Ichikawa, Iwao Kitazima, and Hiroshi Iwasawa. Chaotic Oscillation in a Single-Mode Class A He-Ne laser (6328 A) II. Japanese Journal of Applied Physics, 38(Part 1, No. 11):6321-6326, Nov 1999. 
[158] Fumiyoshi Kuwashima, Iwao Kitazima, and Hiroshi Iwasawa. The Chaotic Oscillation of the Single-Mode He-Ne (6328 A) Class A Laser. Japanese Journal of Applied Physics, 37(Part 2, No. 3B):L325-L328, Mar 1998.

[159] H. F. Ranea-Sandoval and M. Gallardo. Measuring flatness of large tables: new methods. Applied Optics, 25(9):1370, May 1986.

[160] Lucas Illing, Daniel J. Gauthier, and Rajarshi Roy. Controlling Optical Chaos, Spatio-Temporal Dynamics, and Patterns. Elsevier, 2006.

[161] Jia-Gui Wu, Guang-Qiong Xia, Xi Tang, Xiao-Dong Lin, Tao Deng, Li Fan, and Zheng-Mao Wu. Time delay signature concealment of optical feedback induced chaos in an external cavity semiconductor laser. Optics Express, 18(7):6661, Mar 2010.

[162] Xiaoming Zhu and J.M. Kahn. Free-space optical communication through atmospheric turbulence channels. IEEE Transactions on Communications, 50(8):1293-1300, Aug 2002.

[163] Hai-Peng Ren, Murilo S. Baptista, and Celso Grebogi. Wireless communication with chaos. Physical Review Letters, 110(18), Apr 2013.

[164] Valerio Annovazzi-Lodi, Giuseppe Aromataris, Mauro Benedetti, and Sabina Merlo. Secure chaotic transmission on a free-space optics data link. IEEE Journal of Quantum Electronics, 44(11):1089-1095, Nov 2008.

[165] N. Rulkov, M. Vorontsov, and L. Illing. Chaotic free-space laser communication over a turbulent channel. Physical Review Letters, 89(27), Dec 2002.

[166] Holger Kantz and Thomas Schreiber. Nonlinear Time Series Analysis (Cambridge Nonlinear Science Series). Cambridge University Press, 1997.

[167] M. Damián Gulich. Construcción y caracterización de un generador de turbulencias isotrópicas en aire caliente. Trabajo de Diploma, Departamento de Física, Facultad de Ciencias Exactas, Universidad Nacional de La Plata, 2011.

[168] Damián Gulich, Luciano Zunino, Darío Pérez, and Mario Garavaglia. Multifractality and the effect of turbulence on the chaotic dynamics of a hene laser. Laser Communication and Propagation through the Atmosphere and Oceans II, Sep 2013.

[169] N. M. Law, C. D. Mackay, and J. E. Baldwin. Lucky imaging: high angular resolution imaging in the visible from the ground. AEA, 446(2):739-745, Feb 2006.

[170] N. M. Law, C. D. Mackay, R. G. Dekany, M. Ireland, J. P. Lloyd, A. M. Moore, J. G. Robertson, P. Tuthill, and H. C. Woodruff. Getting lucky with Adaptive Optics: fast adaptive optics image selection in the visible with a large telescope. The Astrophysical Journal, 692(1):924-930, Feb 2009. 
[171] Tamás Vicsek, András Czirók, Eshel Ben-Jacob, Inon Cohen, and Ofer Shochet. Novel type of Phase Transition in a System of Self-driven particles. Physical Review Letters, 75(6):1226-1229, Aug 1995.

[172] Tamás Vicsek and Anna Zafeiris. Collective motion. Physics Reports, 517(3-4):71â140, Aug 2012.

[173] Holger Kantz and Thomas Schreiber. Nonlinear Time Series Analysis. Cambridge University Press, second edition, 2004.

[174] Rainer Hegger, Holger Kantz, and Thomas Schreiber. Practical implementation of nonlinear time series methods: The tisean package. Chaos: An Interdisciplinary Journal of Nonlinear Science, 9(2):413-435, 1999.

[175] David Chelidze. Notes on false nearest neighbors, Dec. 2013.

[176] Andrew Fraser and Harry Swinney. Independent coordinates for strange attractors from mutual information. Physical Review A, 33(2):1134-1140, Feb 1986.

[177] Sean Whalen. Chaotic attractor reconstruction.

[178] Ray Huffaker. Phase space reconstruction from time series data: Where history meets theory. In 2010 Internatonal European Forum, February 812, 2010, Innsbruck-Igls, Austria, number 100455. International European Forum on Innovation and System Dynamics in Food Networks, 2010.

[179] J. C. Sprott. Chaos and Time-Series Analysis. Oxford University Press, 2001.

[180] Norbert Marwan. Lyapunov exponents.

[181] Laurent Jolissaint. Optical turbulence generators for testing astronomical adaptive optics systems: A review and designer guide. Publications of the Astronomical Society of the Pacific, 118(847):1205-1224, 2006.

[182] Laurent Jolissaint. Optique adaptative au foyer d'un télescope de la classe 1mètre. PhD thesis, Faculté des sciences de l'Université de Genève, 2001.

[183] Laurent Jolissaint, Onur Keskin, Colin Bradley, Brian Wallace, and Aaron Hilton. Multiple-layer optical turbulence generator principle and slodar characterization: preliminary results. volume 5572, pages 256-261. SPIE, 2004.

[184] Onur Keskin, Laurent Jolissaint, Colin Bradley, Sadik Dost, and Inna Sharf. Hot-air turbulence generator for multiconjugate adaptive optics. volume 5162, pages 49-57. SPIE, 2003.

[185] V. I. Tatarskii. Wave Propagation in a Turbulent Medium. Dover, 1960. 